University of Louisville

ThinkIR: The University of Louisville's Institutional Repository

Electronic Theses and Dissertations

$12-2004$

\title{
The characterization and model optimization of an analog integrated circuit standard cell library.
}

Mallika Gopinath 1977-

University of Louisville

Follow this and additional works at: https://ir.library.louisville.edu/etd

\section{Recommended Citation}

Gopinath, Mallika 1977-, "The characterization and model optimization of an analog integrated circuit standard cell library." (2004). Electronic Theses and Dissertations. Paper 518.

https://doi.org/10.18297/etd/518

This Master's Thesis is brought to you for free and open access by ThinkIR: The University of Louisville's Institutional Repository. It has been accepted for inclusion in Electronic Theses and Dissertations by an authorized administrator of ThinkIR: The University of Louisville's Institutional Repository. This title appears here courtesy of the author, who has retained all other copyrights. For more information, please contact thinkir@louisville.edu. 
THE CHARACTERIZATION AND MODEL OPTIMIZATION OF AN ANALOG INTEGRATED CIRCUIT STANDARD CELL LIBRARY

\author{
By \\ Mallika Gopinath \\ B.E., Manipal Institute of Technology, 1999
}

\begin{abstract}
A Thesis
Submitted to the Faculty of the

Graduate School of the University of Louisville

In Partial Fulfillment of the Requirements
\end{abstract}

For the Degree of

Master of Science

Department of Electrical and Computer Engineering

University of Louisville

Louisville, Kentucky

December 2004 


\author{
By \\ Mallika Gopinath \\ B.E., Manipal Institute of Technology, India, 1999
}

A Thesis Approved on

December 16, 2004

By the following Thesis Committee:

Dr. John F. Naber, Thesis Director

Dr. Kevin M. Walsh

Dr. Robert S. Keynton 


\section{ACKNOWLEDGEMENTS}

I would like to take this opportunity to thank my thesis advisor, Dr. John. F. Naber, for his guidance and patience. I am also thankful to the other committee members Dr. Kevin M. Walsh and Dr. Robert S. Keynton for their comments and critiques. I would also like to thank Mr. Doug Jackson for all his technical assistance and support in making this thesis a success. Thanks are also due to Mr. Larry Cassady for his HPVee programs, which helped in the testing of the circuits. I am grateful to Mr. Tom Carroll for providing the lab equipment and for the lab facility.

I extend my gratitude to my parents, Dr. K. Gopinath and Mrs. Padmini Gopinath for believing in my endeavors and encouraging me. Finally, I extend my utmost thanks to my husband, Dr. K Arun Kumar for being supportive, understanding and encouraging me through the hard and trying times of this thesis. 


\section{ABSTRACT \\ THE CHARACTERIZATION AND MODEL OPTIMIZATION OF AN ANALOG INTEGRATED \\ CIRCUIT STANDARD CELL LIBRARY \\ Mallika Gopinath \\ December 16, 2004}

Since the beginning of the VLSI era, various technologies have been adopted for developing the design and characterization of analog circuits. For robust design, the influences of the process parameter variations have been considered over the circuit simulation. Previous studies in this field concentrated more on the physical dimensions such as the width, length, area and perimeter as well as the threshold voltage of the device.

The focus of this thesis was to characterize the performance of an analog IC standard cell library as well as optimize the simulation models. The circuits include NMOS FETs ( $\mathrm{n}$-channel metal-oxide semiconductor field-effect transistor), PMOS FETs ( $p$-channel metal-oxide semiconductor field-effect transistor), poly resistors, current mirrors, comparators, bias generators, voltage references, op-amps, and voltage regulators. The spice model used for simulation was the BSIM3 (Berkeley Simulator version 3) model.

Tanner Research designed the majority of the standard cells evaluated. These cells were fabricated in the AMI 1.5-um CMOS process using the MOSIS service. The ICs (Integrated Circuits) have been developed using software from Tanner Research namely, the schematic editor, S-Edit; layout editor, L-Edit and simulated using T-Spice (Tanner version of Spice). The simulations carried out on the circuits using the optimized model exhibited an overall performance improvement over the unoptimized model. Based on these simulations, numerous plots and tables are presented and the data was discussed in terms of the output characteristics. There was a noticeable improvement in the accuracy of $60.44 \%$ for the PMOS FET and $17.25 \%$ for the 
NMOS FET with the optimized model. The DC (direct current) fit using the optimized model over the unoptimized model showed an improvement of $2.17 \%$ (Voltage reference), $1-24 \%$ (Bias Generator), 2\% (N-Current mirror), 5\% (P-Current mirror), 11-30\% (Analog Buffer) and 1.74\% (Op-Amp). 


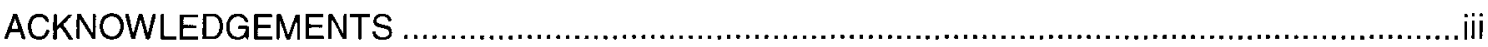

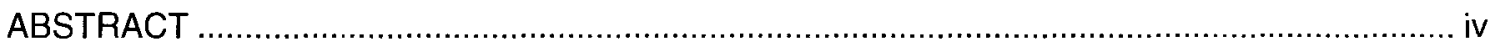

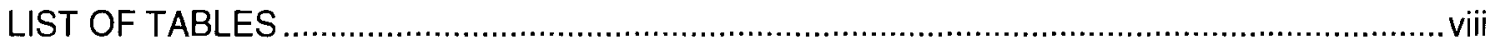

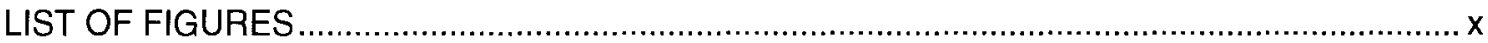

\section{CHAPTER}

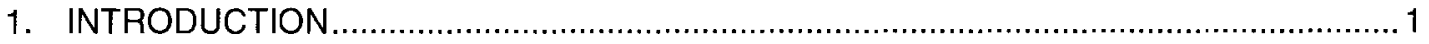

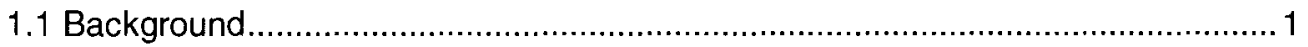

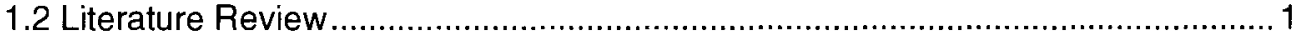

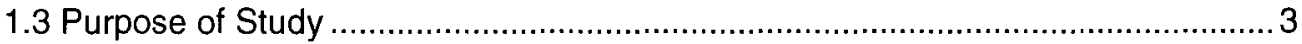

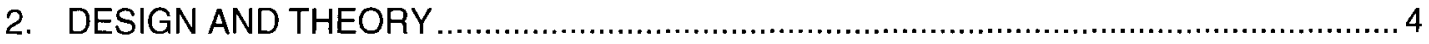

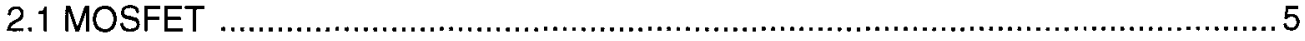

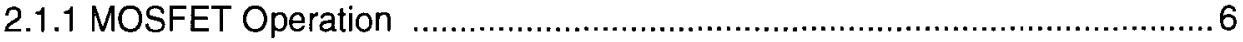

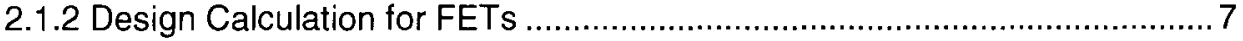

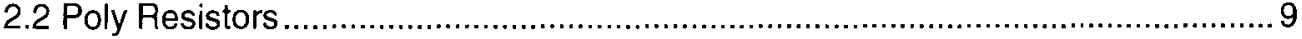

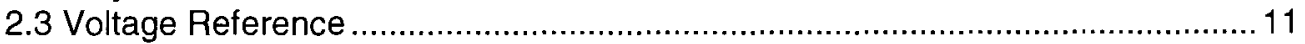

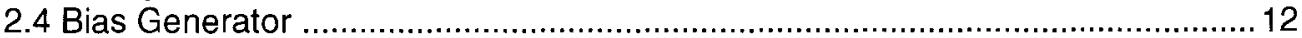

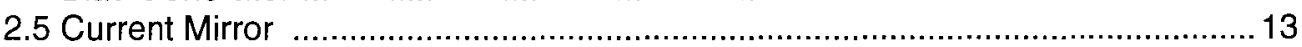

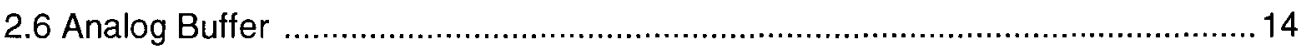

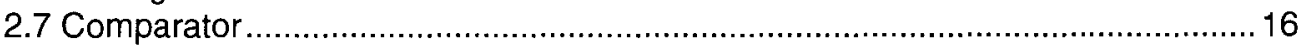

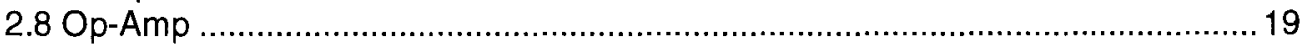

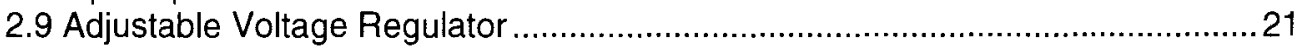

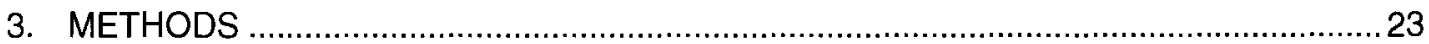

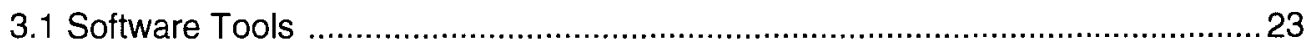

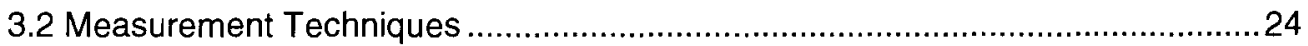

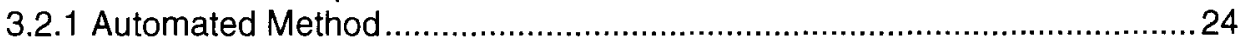

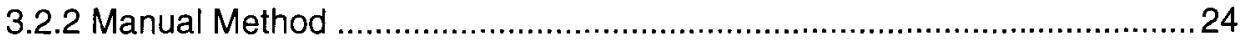

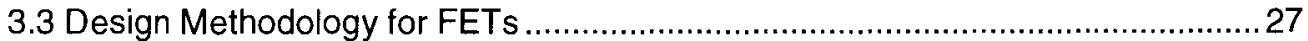

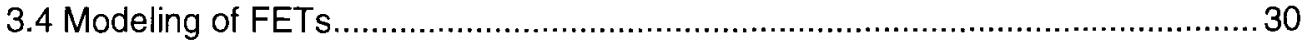

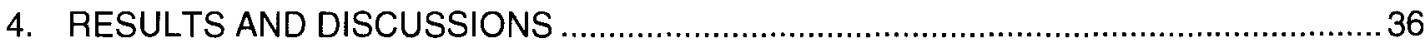

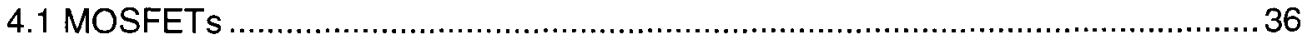

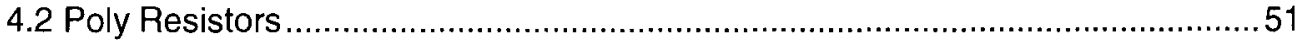

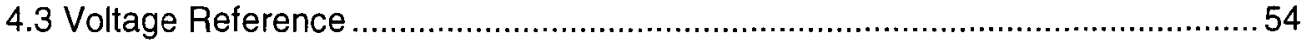

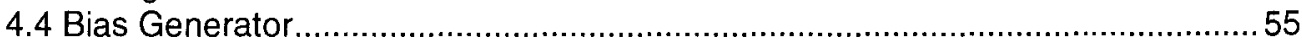

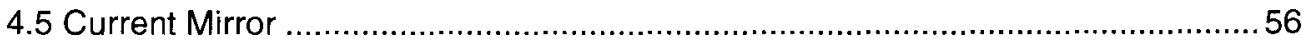

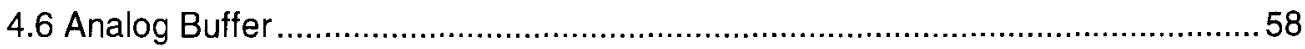

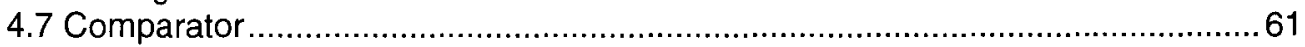

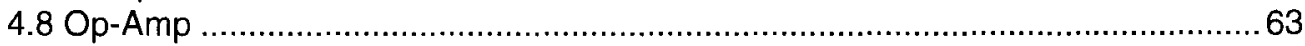

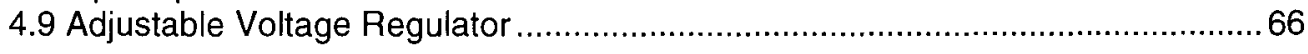

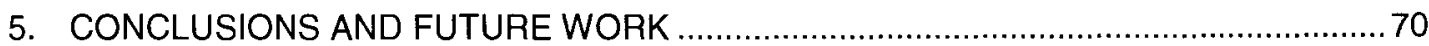


APPENDICES

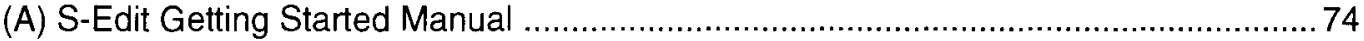

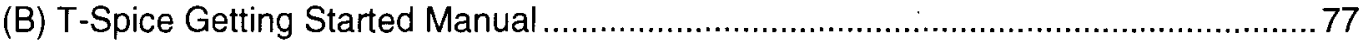

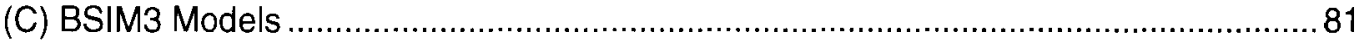

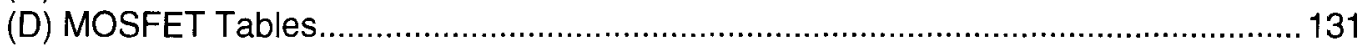

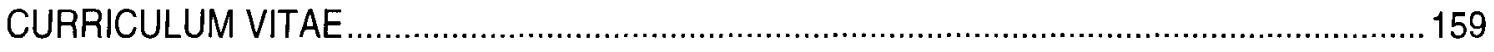




\section{LIST OF TABLES}

\section{TABLE}

PAGE

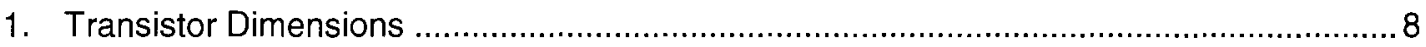

2. Unoptimized and Optimized data using Percentage Error Method for $24 \times 02 u m$ NMOS FETs

3. Unoptimized and Optimized data using Average Error Current Method for 24x02um NMOS FETs

4. Unoptimized and Optimized data using Percentage Error Method for 24x02um PMOS FETS

5. Unoptimized and Optimized data using average error current method for 24x02um PMOS FET.

6. Scalability data for NMOS FETs

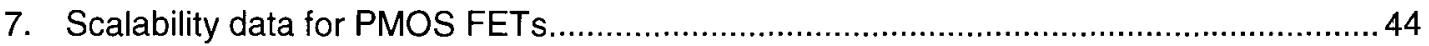

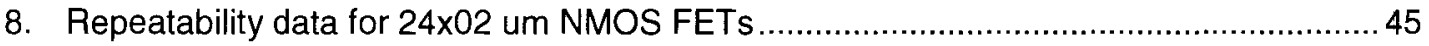

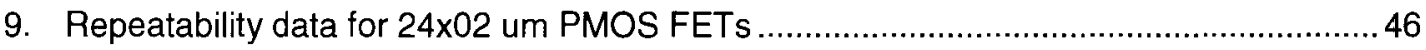

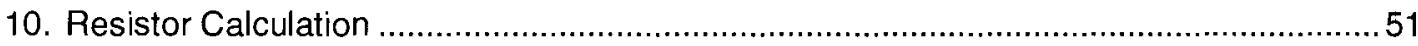

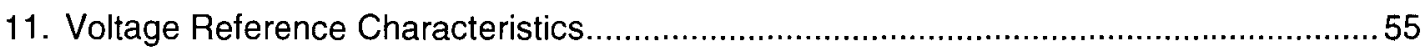

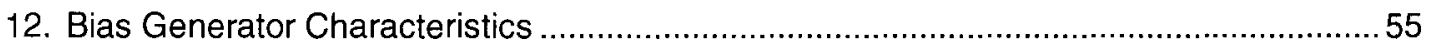

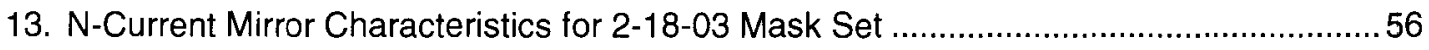

14. N-Current Mirror Characteristics for 9-15-03 Mask Set ...............................................57

15. P-Current Mirror Characteristics for 2-18-03 Mask Set..................................................57

16. P-Current Mirror Characteristics for 9-15-03 Mask Set.................................................58

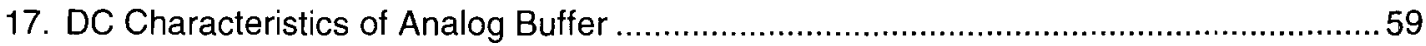

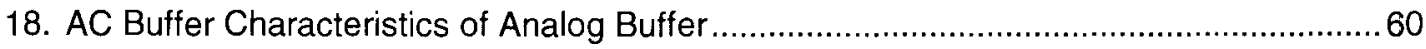




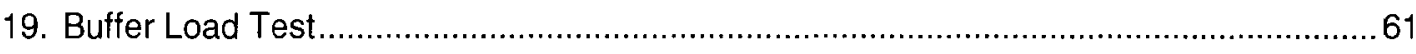

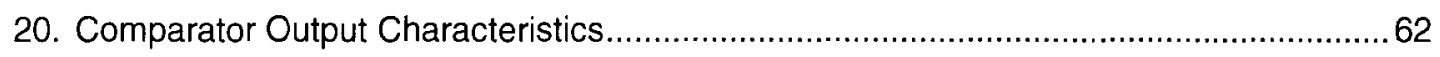

21. Comparator Output Characteristics with Different Supply Voltages .............................62

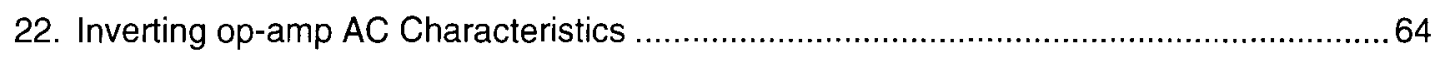

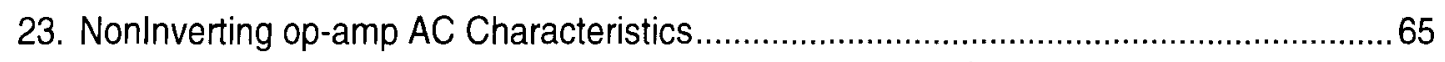

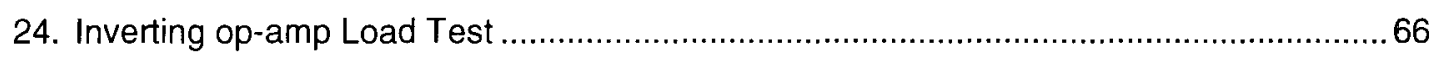

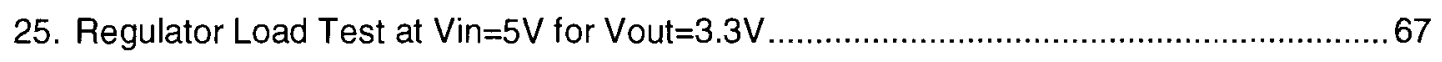

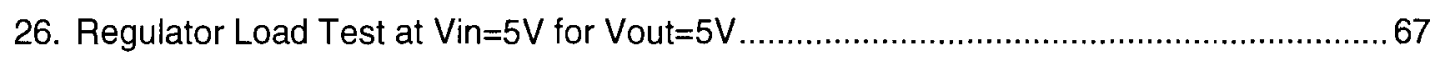

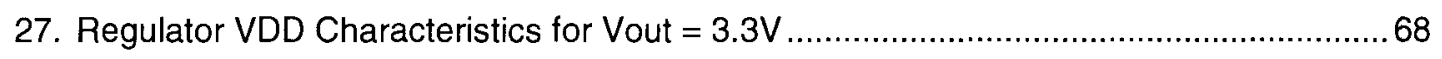

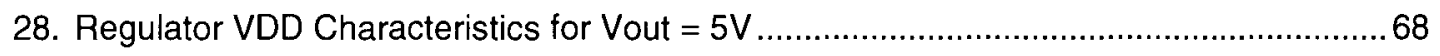




\section{LIST OF FIGURES}

\section{FIGURE}

\section{PAGE}

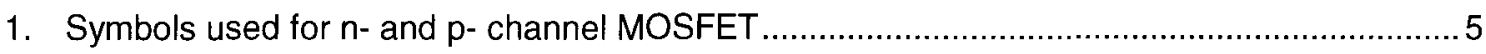

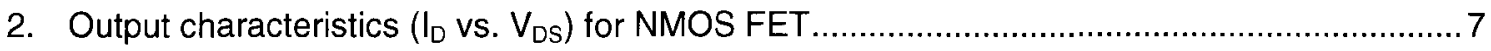

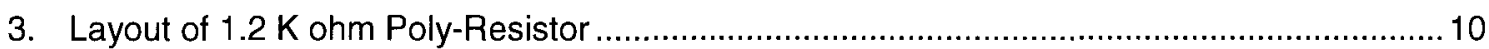

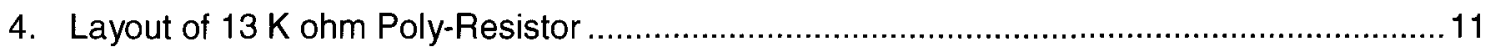

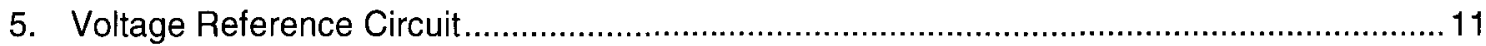

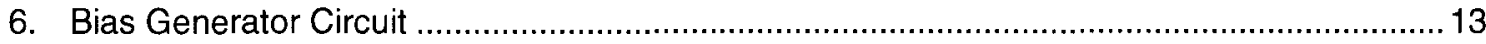

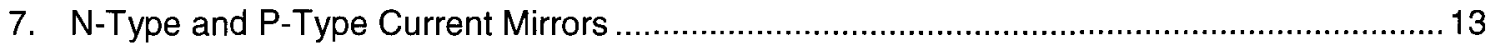

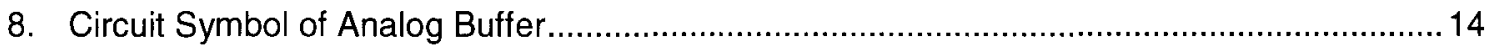

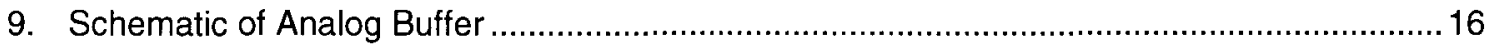

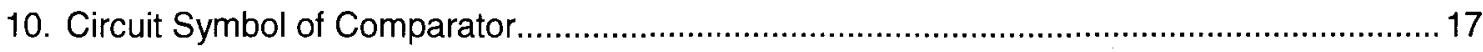

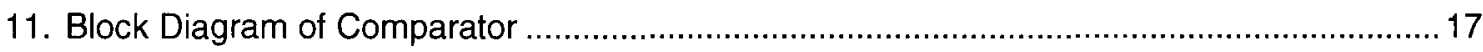

12. Preamplification Stage for the Comparator ........................................................... 17

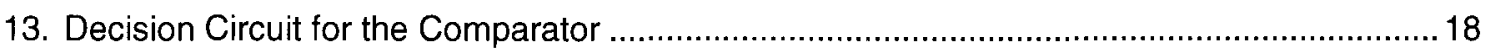

14. Self Biasing Differential Amplifier used as the Comparator's Output Buffer .........................19

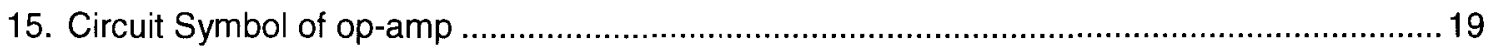

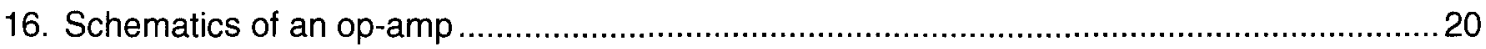

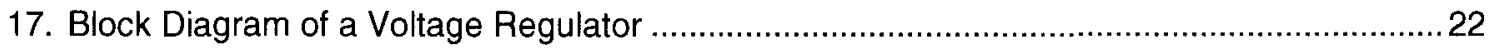

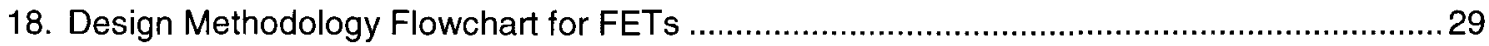

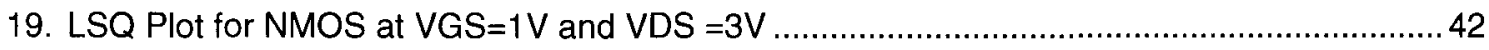

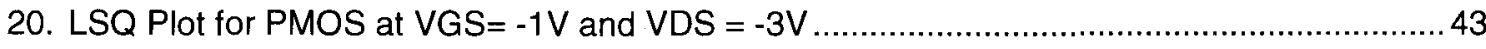

21. Unoptimized and Optimized Curves for NMOS FETs ................................................... 48

22. Unoptimized and Optimized Curves for PMOS FETs ................................................. 49

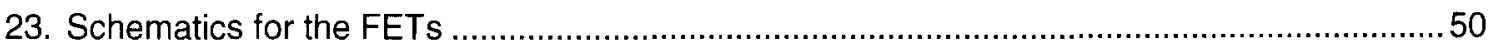


24. Layout for the FETs

50

25. Relationship between the Measured and Calculated Polysilicon Resistors ........................... 52

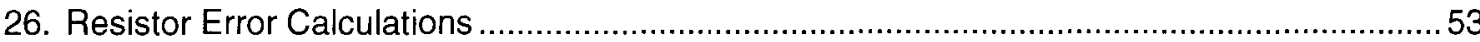

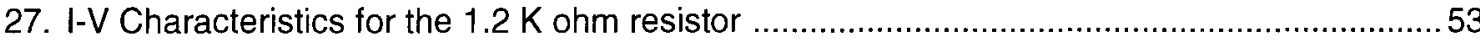

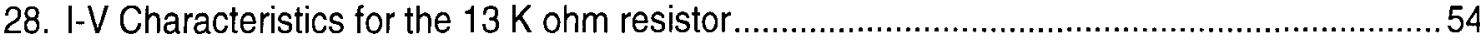




\section{CHAPTER 1}

\section{INTRODUCTION}

\subsection{Background}

The improvement in the design and the fabrication of the devices (analog and digital circuits) were studied by characterizing the device. In order to design a device, technology with a set of rules for the layout of the device is needed. Many different technologies can be adopted. Some of the different process technologies available through Metal Oxide Semiconductor Implementation System (MOSIS) [program sponsored by United States Defense Advanced Research Projects Agency] are the Automotive, Medical and Industrial Semiconductors (AMIS), International Business Machines corporation (IBM), Taiwan Semiconductor Manufacturing Company limited (TSMC), and Agilent/ Hewlett-Packard (HP) etc. Each of these technologies developed a standard set of modeling parameters based on different feature sizes as well. There have been different Simulation Program for Integrated Circuit Emphasis (SPICE) models used for the Metal-Oxide. Semiconductor Field-Effect Transistors (MOSFETs). Some of them in chronological order are Level 1(Shichman-Hodges model), Level 2, Level 3, Berkeley ShortChannel IGFET Model (BSIM), High-performance Simulation Program for Integrated Circuit Emphasis by Synopsys, Inc (HSPICE) Level 28, BSIM2, BSIM3, Model 9, Enz- Krummenacher and Vittoz (EKV) Model and BSIM4. [MOSFET Models for SPICE Simulation including BSIMv3 and BSIMv4, William Liu, pgs 5-7].

From the simulation aspect, the model that gives the best output performance has to be adopted. Hence, one model needs to be optimized based on the desired characterization. There have been many design parameters that have been optimized and characterized, which will be discussed in the literature review section. 


\subsection{Literature Review}

Some of the design constraints that were experimented with are discussed as follows. Design constraints such as threshold voltage variation, off state leakage current and draininduced barrier lowering effects have been examined to improve the device performance. Engineers at the semiconductor technology center, MIMOS Berhad, Toh Hong Ting et.al [1] examined these constraints using the 0.8um Complementary Metal-Oxide Semiconductor (CMOS) technology. They employed the constant voltage scaling method to characterize the Field-Effect Transistors (FETs). The results observed were that the output current increased by scaling down the threshold voltage and gate oxide thickness. This experiment was conducted to exhibit the long channel behavior for the 0.8um transistors.

Byung -Jong Moon et.al. [2] proposed a new model for sub micrometer n-channel MOSFETs, which was suitable for circuit simulation and rapid process characterization. They developed a model based on velocity-field relationship in the linear region and finite drain conductance due to channel length modulation effect in the saturation region. Their model was accurate enough for the circuit simulation of submicrometer devices, but their study was based on considering the effect of quite a few process parameters.

Amitava Chatterjee et.al [3] presented a model based on the channel length modulation effects. The study was carried out to observe the effect of the $g_{d}$ (transconductance of the transistor) with the gate, drain and substrate bias on the Current-Voltage (I-V) characteristics. Using the model with a derivation of set of equations for the channel length modulation, and characterizing with other CMOS device, they noticed that their model improved the prediction of the circuit parameters.

Rafael M. Coitinho et.al [4] extracted the model parameters from the BSIMv3 model for the 0.8um CMOS technology. Their study was conducted mainly to present a simplified methodology for the extraction of the parameters rather than the accuracy of the model. They were successful in presenting good results in their experiment.

T. Yamaguchi et.al [5] performed the characterization of small geometry n-channel as well as p-channel MOSFETs. In their experiments, the model of the FETS included the narrow - 
channel, short-channel, and carrier-velocity saturation effects. Using this model, they characterized other analog circuits namely, op-amp and inverter. Their study was conducted on transistors over wide range of channel lengths from 1 to 9 um and channel widths from 2 to 14um. Their theoretical results showed good agreement with the experimental results.

There have been extensive studies conducted by varying the fabrication techniques as well as refining the design modeling parameters for their simplicity and accuracy. Most of these studies were carried out on the BSIM3 SPICE model, as this was one of the standardized models used in the industry for the MOSFET fabrication. This model contains over 100 parameters for the FET modeling. In this thesis, some of the modeling parameters in the BSIM3 model were studied. This research evaluates the accuracy of the SPICE parameters in the BSIM3 SPICE model for a variety of analog Integrated Circuit (IC) cells to be used in a standard cell library.

\subsection{Purpose of Study}

In this thesis, the focus was on optimizing the BSIMv3 model and characterizing various analog circuits based on this model. The first step in this process was to fully characterize an analog IC standard cell by measuring the $A C$ and DC performance. The next step was to determine the accuracy of the default Spice model by comparing the measured results against the simulated results. Finally, significant time was spent attempting to improve the accuracy of the simulation by optimizing various model parameters of the BSimv3 SPICE model. The FETs were modeled by evaluating the effects of the various SPICE parameters. Previous studies also draw attention to the drain-induced barrier lowering (DIBL) effects on the I-V curves in the sub threshold region. The Tanner version of SPICE, T-Spice, uses a parameter namely the multiplicity factor, $M$ (which is the number of FETS that can be placed in parallel with each other. Theoretically, this parameter acts as a scaling parameter. By default, this value was set to $M=1$ ), in the simulation of the circuits. Since until now, the effects of this parameter and some of the other parameters that are influenced by the DIBL effects have not been studied in depth with respect to the FET modeling, these parameters are considered. 


\section{CHAPTER 2}

\section{DESIGN AND THEORY}

Tanner Research Inc designed most of the circuits. Some of these circuits were later modified for this thesis to obtain completely new cells as well as cells with no external bias supplies. The circuits designed by Tanner Research were:

- MOSFETs: The 03×02 um and 24x02um FET sizes.

- Poly silicon Resistor: 1.2K Ohm.

- Current Mirrors

The circuits that were designed by Tanner Research and modified at the University of Louisville (UofL) are as shown below along with the changes made.

- Bias generator: eliminate external bias.

- Voltage Reference: one of the output ports was removed.

- Analog Buffer: eliminate external bias.

- Comparator: eliminate external bias.

- Op-Amp: eliminate external bias.

The circuits designed at UofL were:

- 48x02um, 72x02 um and 96x02 um were designed by connecting the 24x02um FET in parallel.

- $13 \mathrm{~K}$ Ohm resistor was laid out using the tanner version layout Editor, L-Edit.

- Adjustable voltage regulator.

An explanation of the theory and design of these circuits follows. 


\subsection{MOSFET}

MOSFETs are the primarily used type of transistors for most integrated circuits today. The MOSFET is a three-terminal device in which the drain current is controlled through the gate of the field effect. In this chapter, the MOSFET and its I-V characteristics are discussed.

In MOSFETs, a thin dielectric barrier was used to isolate the gate and the channel. The control voltage applied to the gate terminal induces an electric field across the dielectric barrier and modulates the free-carrier concentration in the channel region. In the literature, these devices are also referred as MOS transistors. [Handbook for transistors- John Lenk]

MOS transistors were classified as p-channel and n-channel devices, depending on the conductivity type of the channel region. In addition, these devices were also classified according to their mode of operation as enhancement or depletion type devices. The notation used for a pchannel MOSFET and an n-channel MOSFET is shown in Figure (1).

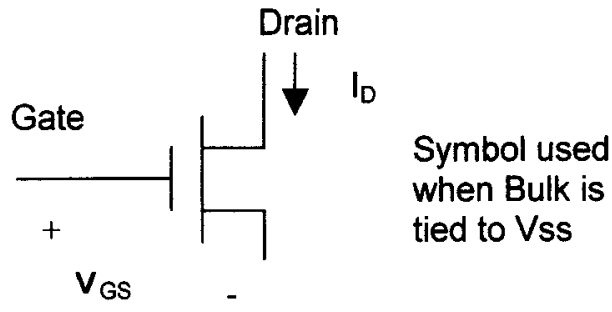

Source

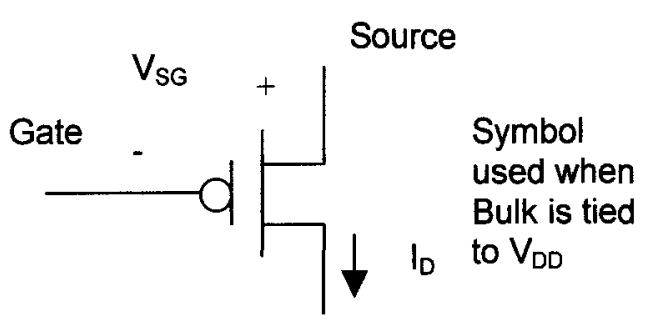

Drain

Figure (1) Symbols used for $n$ - and p-channel MOSFETs.

The depletion MOSFET has a behavior similar to that of the JFET; at zero gate voltage and a fixed drain voltage, the current was maximum and then decreased with applied gate potential. The enhancement MOSFET exhibits no current at zero gate voltage and the magnitude of the output current increased with an increase in the magnitude of the gate potential. 


\subsubsection{MOSFET Operation}

The MOSFET operates in three regions, namely, cut-off, ohmic and saturation regions. [Microelectronics -Jacob Millman] The operations hold good for both the NMOS and PMOS devices.

\section{Cut-Off Region}

For $V_{G S}<V_{T}$, there are no mobile carriers at the drain end of the channel and $I_{D}=0$. Thus, $V_{T}$ is analogous to the pinch-off voltage in a JFET. This condition signifies that the MOSFET was cut-off and corresponds to an open switch.

\section{Ohmic Region}

For $V_{G S}>V_{T}$, the channel conductivity was controlled by $V_{D S}$ in the ohmic (also called the nonsaturation or triode) region. The ohmic region is defined by $V_{G S}-V_{T}>V_{D S}$. Analysis of the ohmic region results in the drain characteristic as given in equation (1):

$$
I_{D}=k(W / L)\left[2\left(V_{G S}-V_{T}\right) V_{D S}-V_{D S}^{2}\right]
$$

where, $L$ is the channel length, $W$ the channel width (perpendicular to $L$ ), and $k$ the process parameter in microamperes per square volt. The process parameter $k=\mu_{n} C_{0} / 2$, where $\mu_{n}$ is the electron mobility and $C_{o}$ is the gate capacitance per unit area (and equals $\mu / T_{o x}$, the ratio of the permittivity and thickness of the oxide layer). $V_{T}$ also depends on the $C_{0}$ as well as the doping densities of the n-type drain and source and $p$ substrate.

\section{Saturation Region}

$I_{D}$ is constant and independent of $V_{D S}$ in the saturation region for which $V_{G S}-V_{T}<V_{D S}$ (but greater than zero). The value of $I_{D}$ depends only on the effective control voltage $V_{G S}-V_{T}$ as given in equation (2):

$$
I_{D}=k(W / L)\left(V_{G S}-V_{T}\right)^{2} \equiv I_{D S}
$$


where, the subscript $S$ added to $I_{D}$ denotes that the drain current in the saturation region is under consideration. The dividing line between the ohmic and saturation regions is given by $V_{G S}-V_{T}=V_{D S}$. By substituting this value in equation (1), equation (2) is obtained.

The output characteristic of an n-channel MOSFET is shown in Figure (2). The line in Figure (2), which acts as a boundary between the ohmic and saturation regions, is given by equation (3):

$$
\mathrm{I}_{\mathrm{D}}=k(\mathrm{~W} / \mathrm{L}) \mathrm{V}_{\mathrm{DS}}^{2}
$$

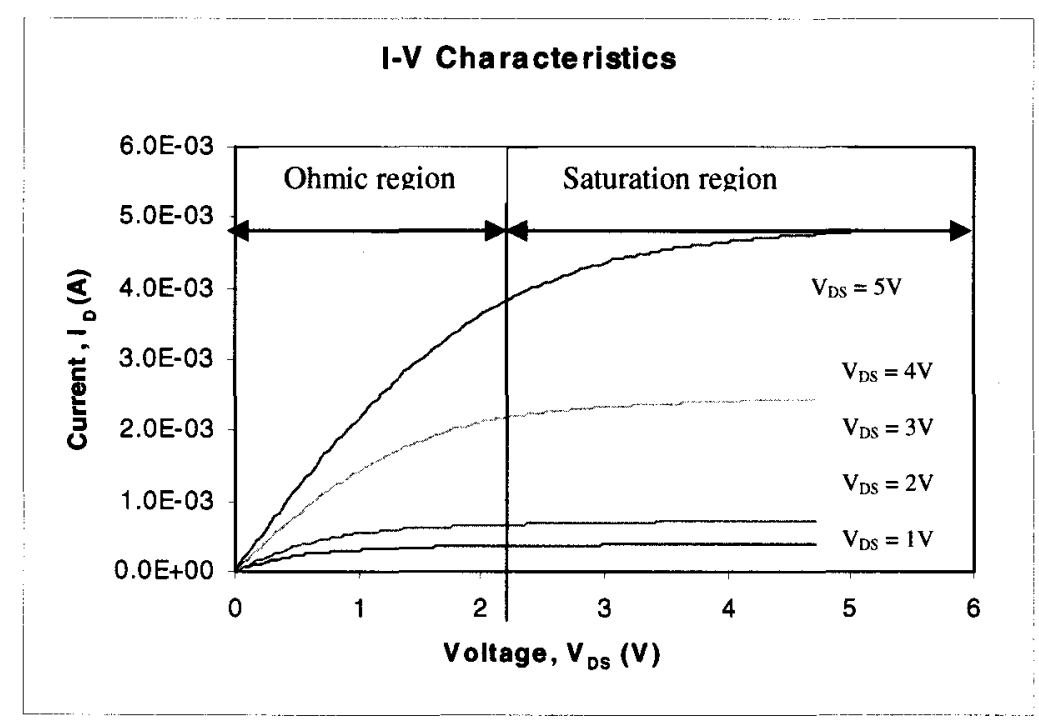

Figure (2) Output characteristics ( $I_{D}$ vs. $\left.V_{D S}\right)$ for a NMOS FET

\subsubsection{Design Calculations for FETs}

The n-type and p-type transistors of various sizes are used for the measurements and simulations in the course of the thesis. As discussed in the beginning of this chapter, some of these transistors were already available from the Tanner Cell Library. The transistor dimensions are shown in Table 1. 
Table 1 Transistor Dimensions

\begin{tabular}{|c|c|}
\hline Channel Width (um) & Channel Length (um) \\
\hline 2.4 & 1.6 \\
\hline 19.2 & 1.6 \\
\hline 38.4 & 1.6 \\
\hline 57.6 & 1.6 \\
\hline 76.9 & 1.6 \\
\hline
\end{tabular}

The $2.4 \times 1.6,2.4 \times 12.8$ and $19.2 \times 1.6$ um size transistors were developed from the AMI semiconductor's linear CMOS library of the Tanner tools using L-Edit. The source and drain area and perimeter are computed by the acm model parameter (area calculation method selector, default value for $\mathrm{acm}=0$ ) is given as below in equations (4) and (5):

Area $\left(a_{s} / a_{d}\right)=W \times L$ with moscap $=1$, defas and defad otherwise

Perimeter $\left(p_{s} / p_{d}\right)=2 \times(L+W)$ with moscap $=1$

where, $a_{s}$ is the source area, $a_{d}$ is the drain area, $W$ is the channel width, $L$ is the channel length, $p_{s}$ is the perimeter of the source, and $P_{d}$ is the perimeter of the drain. moscap is the parameter, which enables the automatic source/drain area/perimeter estimation for MOSFET (default is set to 0$)$. defas is the default source area and defad is the default drain area.

The $38.4 \times 1.6,57.6 \times 1.6$ and $76.9 \times 1.6$ transistor sizes were constructed by two methods. One was by placing 2, 3 and $419.2 \times 1.6$ transistors in parallel respectively. In the second method, changing the channel width, area and perimeter of the $19.2 \times 1.6$ transistor resulted in these sizes. Simulations performed on transistors from these methods resulted in similar output results.

The drain current calculation for the MOSFET was computed as in equation (6): [TSPICE Help manual].

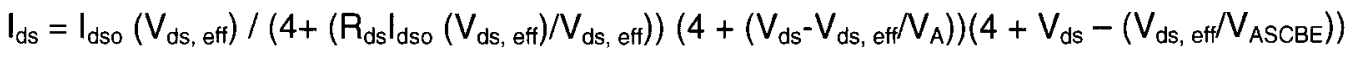

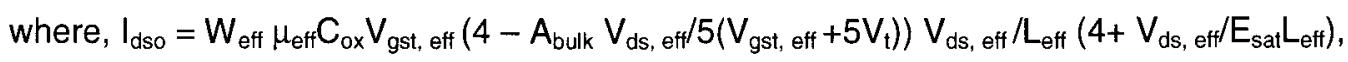

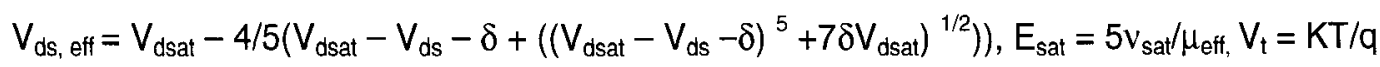

$$
\begin{aligned}
& W_{\text {eff }}=W_{\text {drawn }}-2 . W_{\text {int }} L_{\text {eff }}=L_{\text {drawn }}-2 . L_{\text {int }}
\end{aligned}
$$




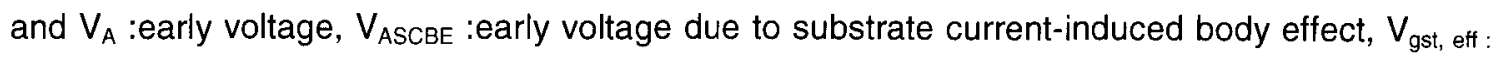
effective $V_{g s}-V_{t h}\left(V_{\text {th }}\right.$ : effective threshold voltage $), \mu_{\text {eff }}$ : effective mobility, $A_{\text {bulk }}$ : bulk charge effect factor, $V_{d s a t}$ : the drain saturation voltage, $v_{\text {sat }}$ : saturation velocity $\left(8 \times 10^{4} \mathrm{~m} / \mathrm{s}\right), \delta$ : effective $V_{d s}$ parameter $(0.01), q$ : the charge of the electron, $W_{\text {eff }}$ : the effective width, $L_{\text {eff }}:$ the effective length, $L_{\text {int }}$ and $W_{\text {int }}$ : channel-length and channel-width offset for DC I-V characteristics and $L_{\text {drawn }}$ and $\mathrm{W}_{\text {drawn }}$ : the drawn lengths and widths of the transistors. $\mathrm{C}_{\mathrm{ox}}$ : the oxide capacitance (here no oxide capacitance was created), $\mathrm{k}$ : the Boltzmann constant and $\mathrm{T}$ : the Temperature in degree Kelvin $\left(273^{\circ} \mathrm{K}\right)$. The FETs used in this thesis were the short-channel FETs (gate lengths lesser than $2 \mathrm{um}$ ) and the parameters that were considered in the modeling are discussed in the next chapter.

\subsection{Poly Resistors}

In standard MOS processes, the most ideal resistors are merely strips of Polysilicon. Major tradeoffs must be made between linearity, area, biasing complexity and temperature characteristics in these types of resistors. These resistors are laid out in a serpentine pattern to improve packaging density. The major limitations of these resistors are the low resistance densities (which limit the total resistance to quite small values), the high deviations in resistance (seen due to process variations) and large temperature coefficients. [VLSI Design Techniques for Analog and Digital Circuits - Geiger, Allen and Strader, pg-213]. The characterizing equation is:

$$
V=I R_{s h} \Delta(L N)
$$

where, V-Voltage, I- Current, $R_{s h^{-}}$sheet resistance and L, W are the lengths and widths of the resistor layout respectively.

Most of the resistors are laid out in the serpentine pattern, which usually employ the rectangular turns. This is not only easy to layout but also it allows the spacing between the turns of the resistor to be easily adjusted. The current does not flow uniformly around the bends in a serpentine resistor. Each square corner adds approximately 0.56 squares. Neglecting the process biases, end effects and the contact resistance, the value of the resistor as shown in Figure (4) is given by: 


$$
R=\operatorname{Rsh}\left((4 A+3 B / W)+6^{*} 0.56 s q\right)
$$

The resistor in Figure (4) is so narrow that the contacts cannot reside inside it without violating the design rules. Hence, to overcome this problem, the ends are enlarged to form heads around the contacts. The resulting structure is called a dogbone or dumbbell resistor because of its characteristic shape. [The Art of Analog Layout - Alan Hastings, pgs 160-161]. The approximate value of the resistor then can be computed considering this also in the equation. Figures (3) and (4) show the resistors that were tested. These resistors were from the 2-18-03-mask set.

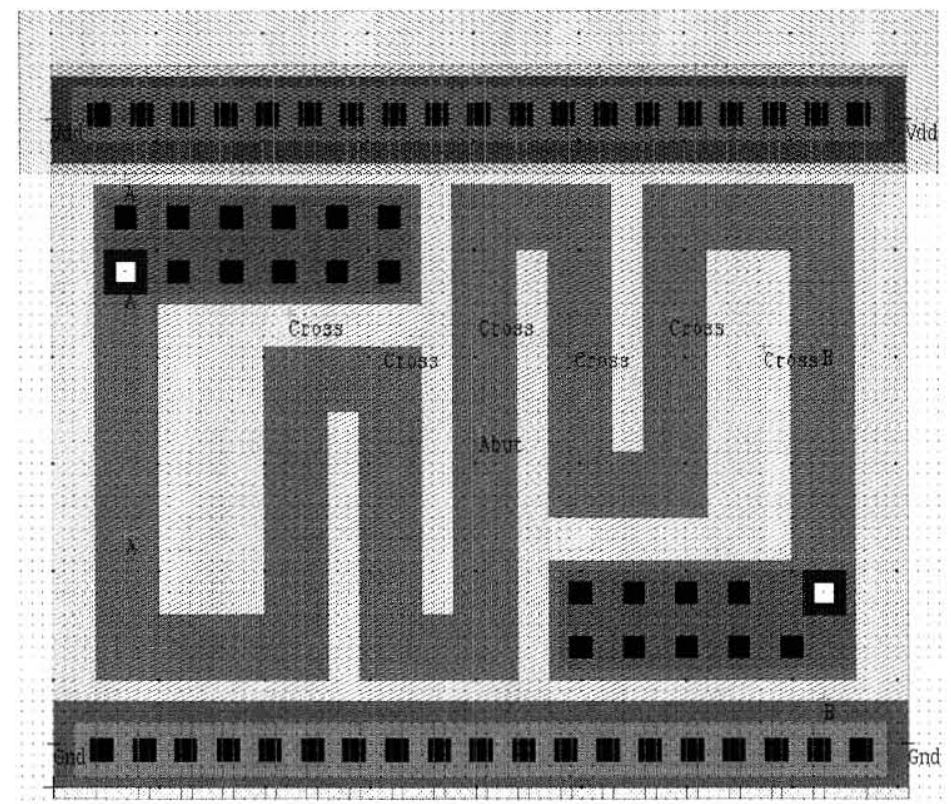

Figure (3) $1.2 \mathrm{~K}$ Ohm Poly resistors 


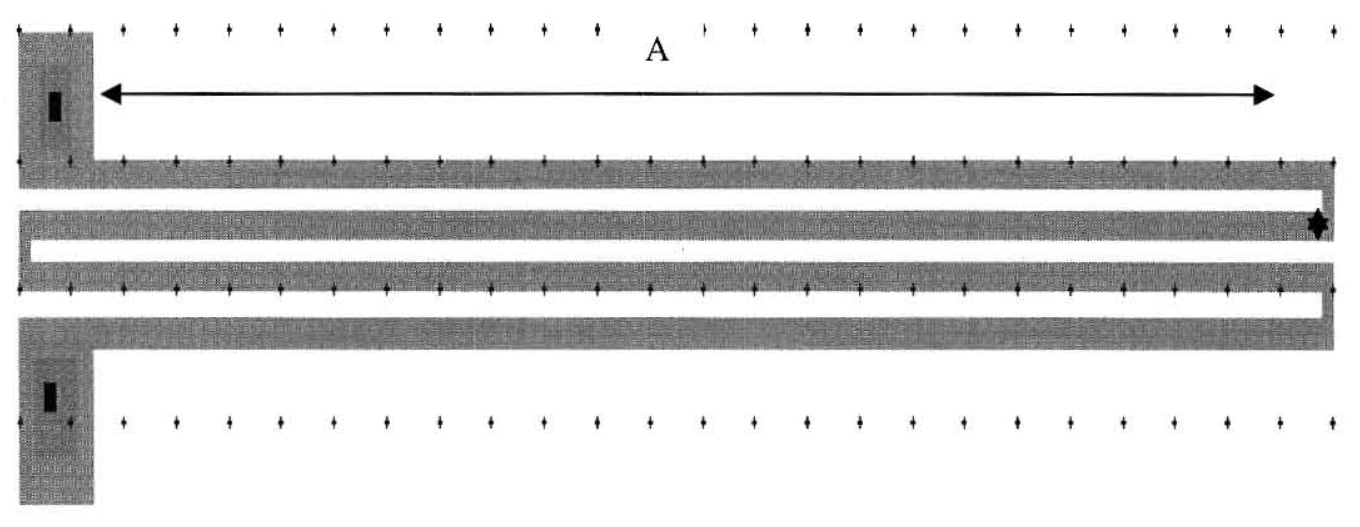

Figure (4) 13 K Ohm Poly Resistor

\subsection{Voltage Reference}

A voltage reference circuit uses the supply voltage to generate a reference voltage at the output. This circuit is also known as the Beta Multiplier referenced Self-Biasing circuit. Figure (5) shows the reference circuit. The PMOS FETs force the same current to flow through the NMOS FETs.

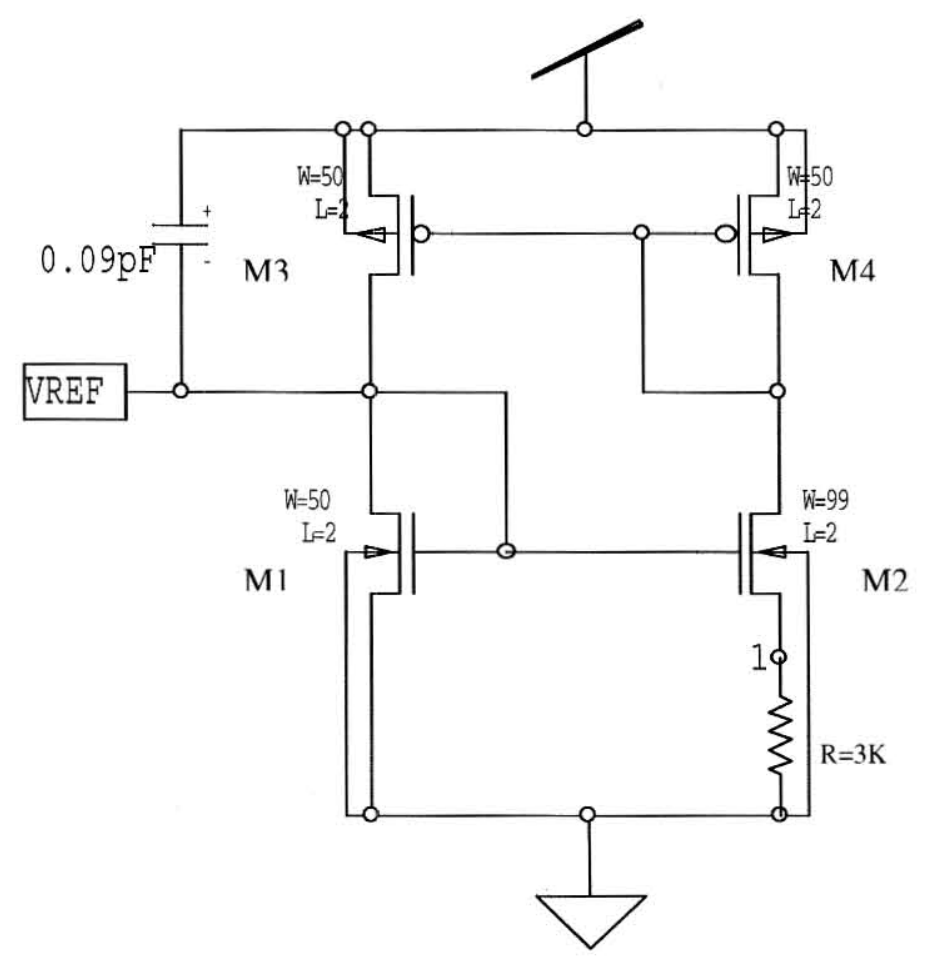

Figure (5) Voltage Reference Circuit 
The width of $\mathrm{M} 2$ was made $\mathrm{K}$ times larger than the width of $\mathrm{M} 1$, so that

$$
\mathrm{B} 2=\mathrm{K} . \mathrm{B} 1 \text {, }
$$

Knowing that $L 1=L 2$, the relationship holds when $W 2=K . W 1$ and hence,

$$
\text { VGS } 1=\text { VGS2 }+\mathrm{IR}
$$

In terms of current,

$$
\text { VGS1 }=\text { VTHN }+(2 \mid / B 1)^{1 / 2}
$$

Neglecting the body effect,

$$
\text { VGS2 }=\text { VTHN }+(21 / B 1)^{1 / 2}
$$

If $\mathrm{B}$. is large, solving the above equations, the current is given by

$$
\mathrm{I}=\mathrm{VTHN} / \mathrm{R}
$$

In practice, the $2^{\text {nd }}$ term in equation (1) is not negligible, and the current is given by

$$
\mathrm{I}=\text { VGS1/R }
$$

Practical values of VGS1 are 1.0 to1.2V. The equations above indicate that the current calculation does not depend on the power supply voltage. Cascoding M3 and M4 help to make the bias circuit behave more ideal. The accuracy of the current is limited by the threshold voltage accuracy. The capacitance is introduced in the circuit to cut out the noise introduced from the supply. [CMOS Circuit Design, Layout, and Simulation - Baker, Li, and Boyce, pg-480]

\subsection{Bias Generator}

This circuit is used to produce a known bias voltage output and it uses the supply voltage in order to do this. The transistors used in this circuit were all long channel devices that had large width dimensions. The main bias output was the OUT2 and depending on this output, the other biases were set. An explanation of the functioning of the circuit follows.

In the circuit, as shown in Figure (6), transistor M3 turns on M2. When M3 is turned on hard, M2 is pulled to ground and M1 is pulled towards VDD. The OUT2 is used to turn ON M4 and this in turn operates the transistors M5 and M6. M6 moreover, acts like a diode and M5 acts like a level 
shifter about VTHN + 0.7V (drop across the diode). The Bias Generator can be used to bias the required voltage needed for other circuitry instead of using an external voltage source.

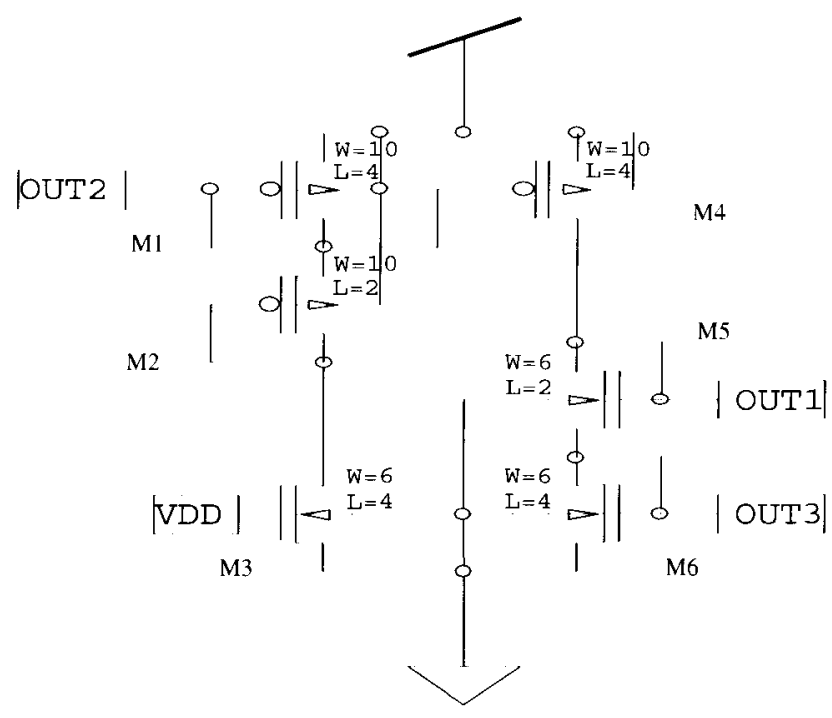

Figure (6) Bias Generator Circuit

\subsection{Current Mirror}

Current mirrors are matched devices that act as current sources. They can be used for biasing the circuits. Since, they use the matching principle, the name current mirror is applied. There are p-type as well as n-type current mirrors. Figure (7) below shows the schematic symbols for the p-type as well as n-type current mirrors.
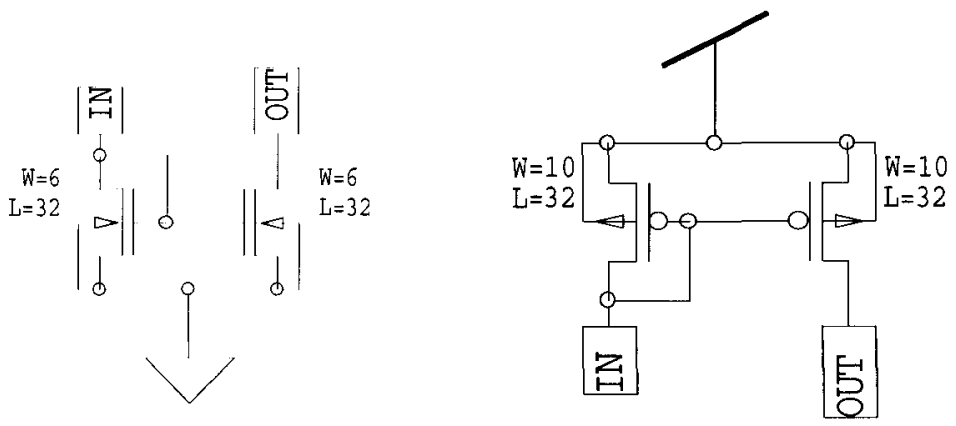

Figure (7) N-Type and P-Type Current Mirrors 
The two transistors in the circuit should be scaled equally in order to provide the matching. The current applied at the input, should be reflected at the output due to the matching principle. For the N-Current Mirror, a voltage had to be applied at the output, which was lesser than the VDD voltage, for the matching to occur. While for the P-Current mirror, the current could be directly measured. [Design of Analog CMOS Integrated Circuits - Behzad Razavi, pgs 135139].

\subsection{Analog Buffer}

An analog buffer is also called a voltage follower with a gain of 1 or less with the output voltage following the input voltage. An analog buffer uses a single supply voltage to drive up a load. This circuit is also referred to as an Unity-Gain amplifier since the gain equals 1 . Figure (8) shows the circuit symbol of analog buffer. The buffer can be configured using an Op-Amp as shown in the Figure below.

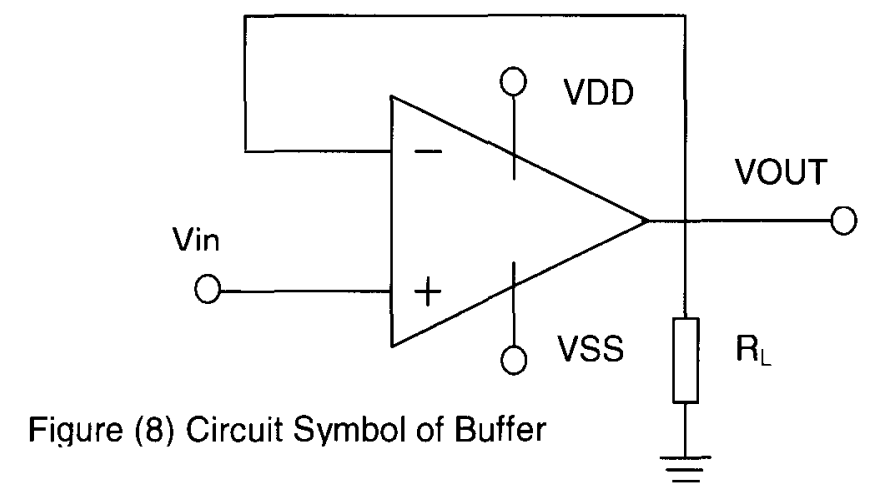

The feedback resistance equals 0 ; therefore, according to the stage gain for a Noninverting amplifier (since, the input voltage is fed to the Noninverting input:

$$
A=R_{F} / R_{\text {in }}+1=0 / R_{\text {in }}+1=1
$$

where, $R_{F}$ is the feedback resistance, $R_{\text {in }}$ - input resistance and $A$ is the gain. 
In other words, with $100 \%$ feedback, the output voltage followed the input voltage. The inverting input would always be at the same potential as the noninverting input. Thus, the voltage difference between the two inputs would always be approximately zero. The advantage of this circuit was an extremely high input impedance and low output impedance, which was ideal for buffering or isolation between circuits.

The Analog buffer could also be configured in the inverting mode for a phase inversion, but the limitation of this circuit would be greatly reduced input impedance. [Op-Amp Handbook -Hughes, pgs 42-43, and Bipolar and MOS Analog Integrated Circuit DesignGrebene, pg386]. The buffer circuit used for testing is as shown in Figure (9) below. The bias voltage was applied to the first stage of the circuit and this voltage was applied from the PBias Output of the bias generator. This voltage, in turn, sources the current through the differential pair of the second stage. The input voltage was applied to the differential pair. The transistors attached to the output nodes 6 and 7 of the differential pair, act as the level shifters, since there will be some crossover distortion in the differential pair when the output switches between the two pairs and hence, to reduce the distortion to an acceptable level, the level shifters were used. If the nodes 3 and 7 and the nodes 4 and 6 of the differential pair are well matched, then the output will track the input. 


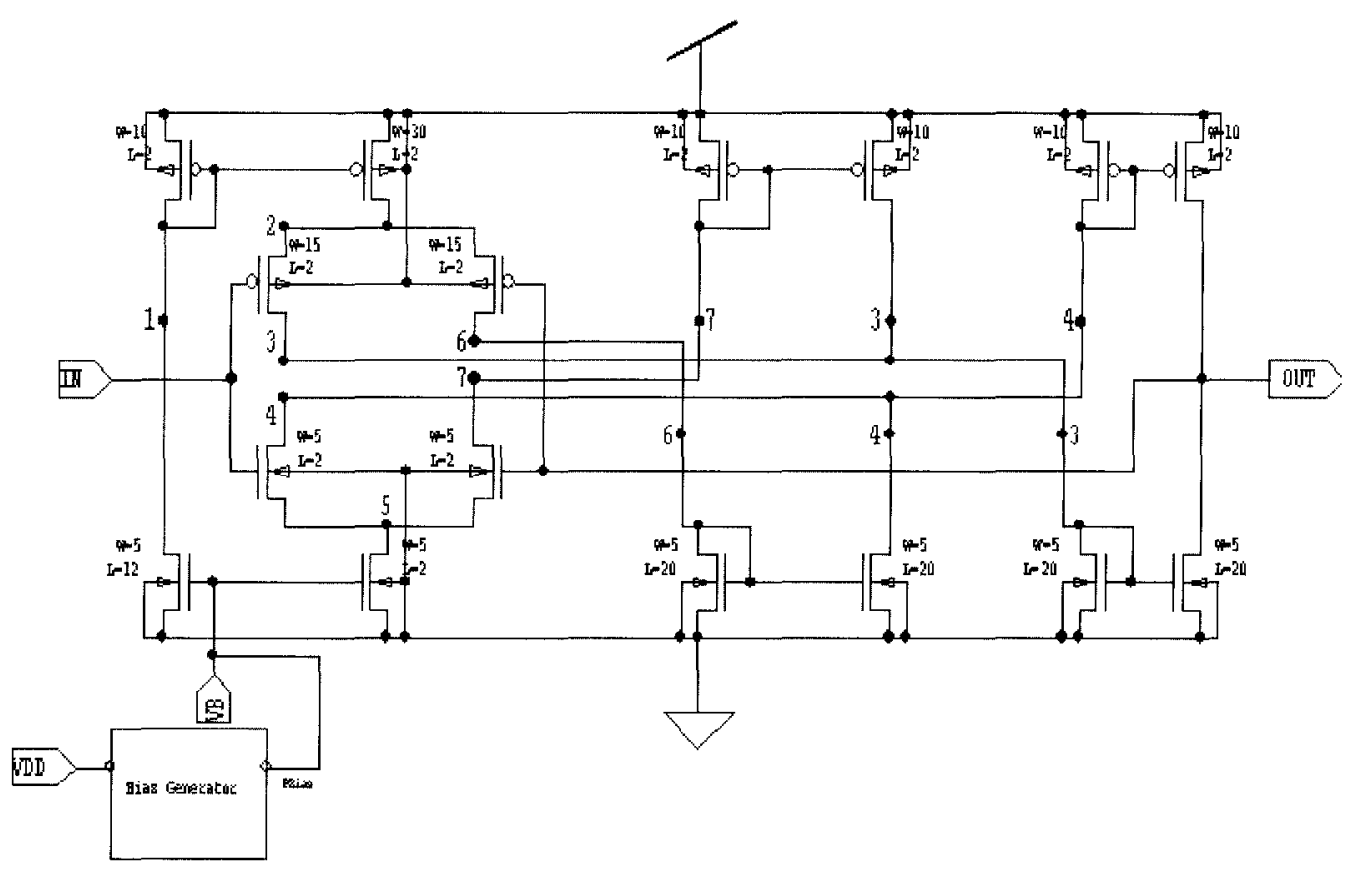

Figure (9) Schematic of Analog Buffer

\subsection{Comparator}

The basic circuit symbol of the comparator is as shown in Figure (10). This symbol is similar to that of an Op-Amp, because a comparator has many of the same characteristics as a high-gain amplifier. A positive voltage applied at the $V_{P}$ input will cause the comparator output to go positive, whereas a positive voltage applied at the $V_{N}$ input will cause the comparator output to go negative. If the voltage applied to the $V_{P}$ terminal was at a greater potential than that applied to the $V_{N}$ terminal, the output of the comparator goes to a logic1 or it goes to logic 0 . [CMOS Circuit Design, Layout, and Simulation - R Jacob Baker]. The block diagram of a highperformance comparator is as shown in Figure (11). The comparator consists of three stages; the input preamplifier, a positive feedback or decision stage, and an output buffer. This is discussed in detail with the role played by each of the stages, in the functioning of the comparator in the later sections. 

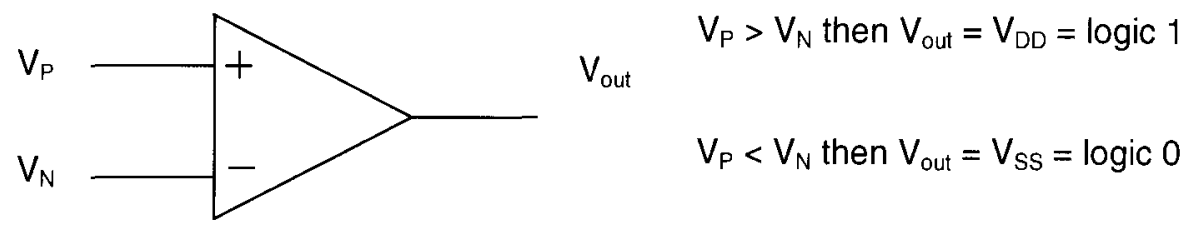

Figure (10) Circuit Symbol of a Comparator

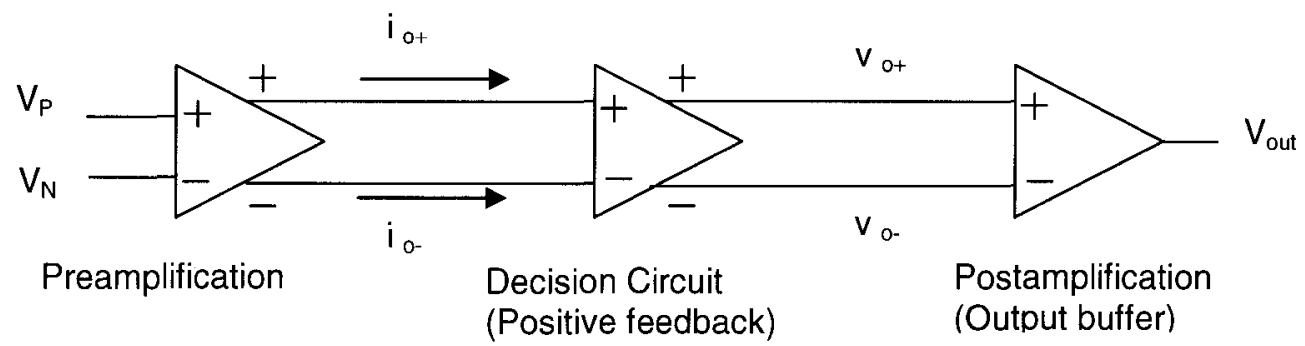

Figure (11) Block Diagram of a Comparator.

\section{Preamplification}

The preamplification stage circuit is a differential amplifier with active loads. Considering the diff-amp transconductance and the input capacitance sets the sizes of the transistors, M1 and M2. In this circuit, the sizes of $M 1$ and $M 2$ is $12 \times 1.6$, where $L=1.6$ um and $W=12$ um. Figure (12) shows the circuit of the preamplification stage.

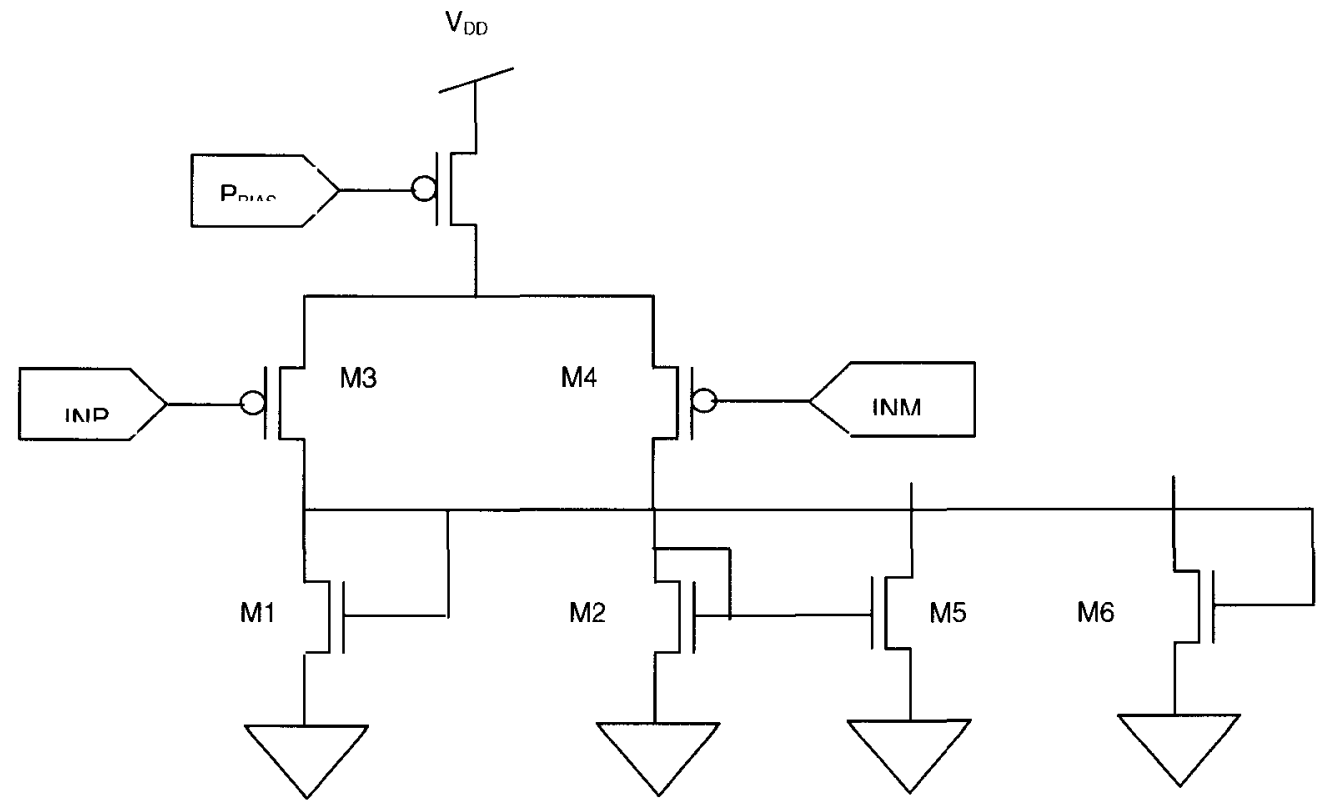

Figure (12) - Preamplification Stage 


\section{Decision Circuit}

The decision circuit is the heart of the comparator and should be capable of discriminating $\mathrm{mV}$ level signals. The circuit used in the comparator under test is shown in Figure (13). The circuit used positive feedback from the cross-gate connection of M8 and M9 to increase the gain of the decision element. If $\mathrm{i}_{0}$. was increased and $\mathrm{i}_{0_{+}}$was decreased, switching took place when the drain-source voltage of M9 was equal to $\mathrm{V}_{\mathrm{THN}}$ (threshold voltage) of M8. At this point, M8 started to take current away from M7. This decreased the drain-source voltage of M7 and thus M9 starts to turn off.

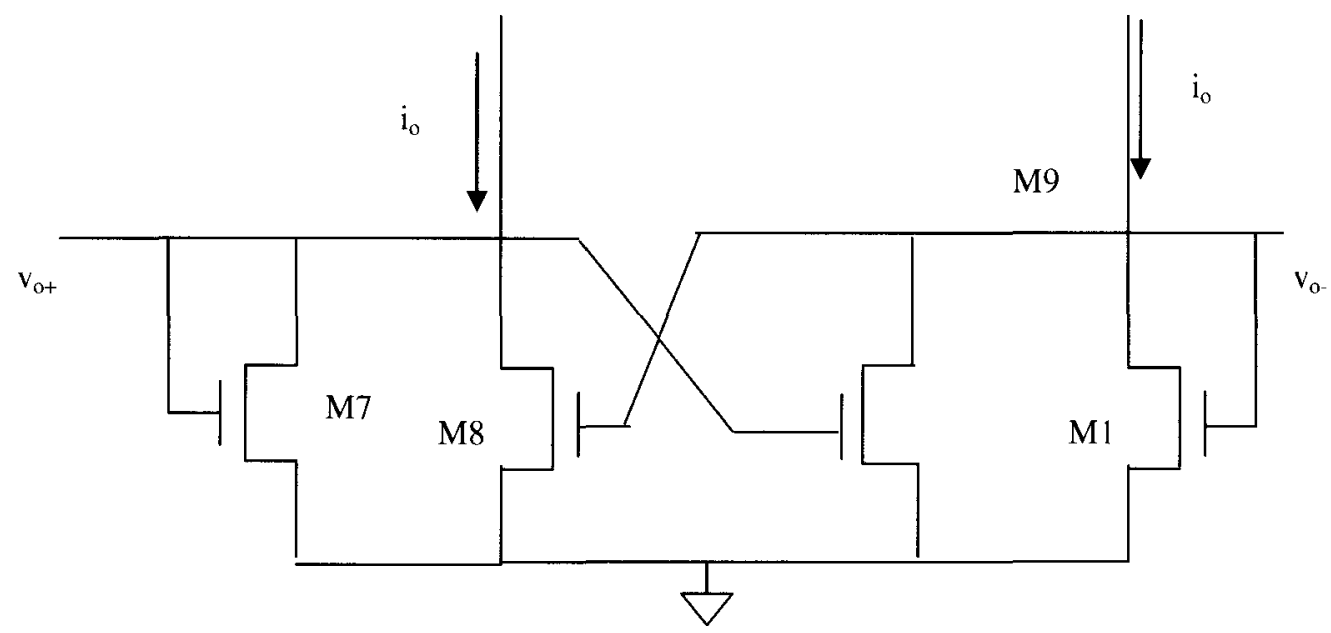

Figure (13) - Decision Circuit

\section{Output Buffer}

The final component in the comparator design is the output buffer or the Post amplifier. The main purpose of this circuit was to convert the output of the decision circuit into a logic signal. The output buffer should accept a differential input signal and not have slew-rate limitations. The output buffer stage is as shown in Figure (14). This is a self-biasing differential amplifier. An inverter was added on the output of the amplifier as an additional gain stage and to isolate any load capacitance from the self-biasing differential amplifier. 


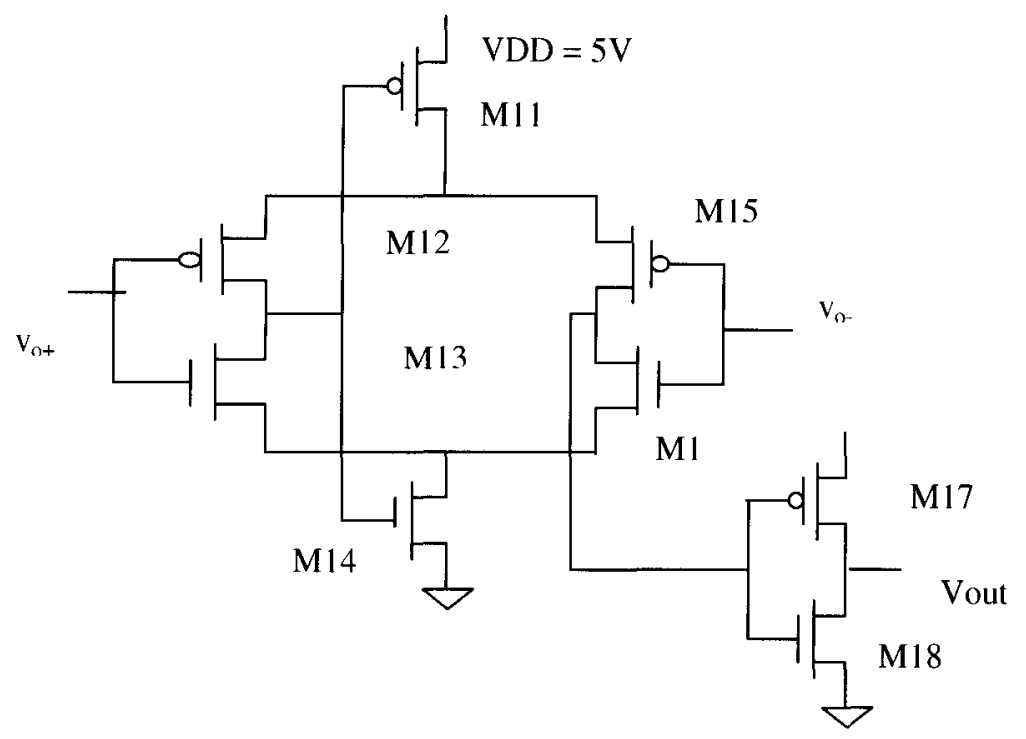

Figure (14) Self- biasing differential amplifier used as the comparator output buffer

\subsection{Op-Amp}

The term Op-Amp or Operational Amplifier refers to a high-gain dc amplifier that has a differential input and a single-ended output. The signal output voltage Vo was larger than the differential input signal across the two inputs by the gain factor of the amplifier. It was capable of sensing and amplifying DC and AC input signals. A typical Op-Amp consists of three basic circuits, a high-input impedance differential amplifier, a high-gain voltage amplifier, and a lowimpedance output amplifier (usually a push-pull amplifier). Figure (15) below shows the circuit symbol of an Op-Amp.

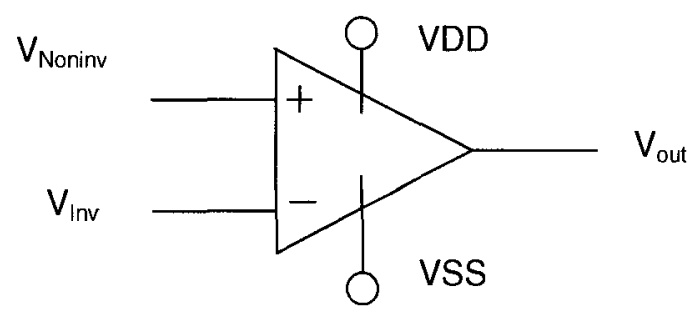

Figure (15) Circuit Symbol of an Op-Amp 
The most important characteristics of an op-amp are high input impedance, low output impedance, high open loop gain, etc. These are some of the characteristics studied in the tests. In addition to these, the closed loop gain and load tests were also studied. The Op-Amp can be configured in the inverting mode as well as the non-inverting mode and open loop or closed loop mode. Most of the tests were performed in the open-loop mode. Figure (16) shows the schematic of an Op-Amp.

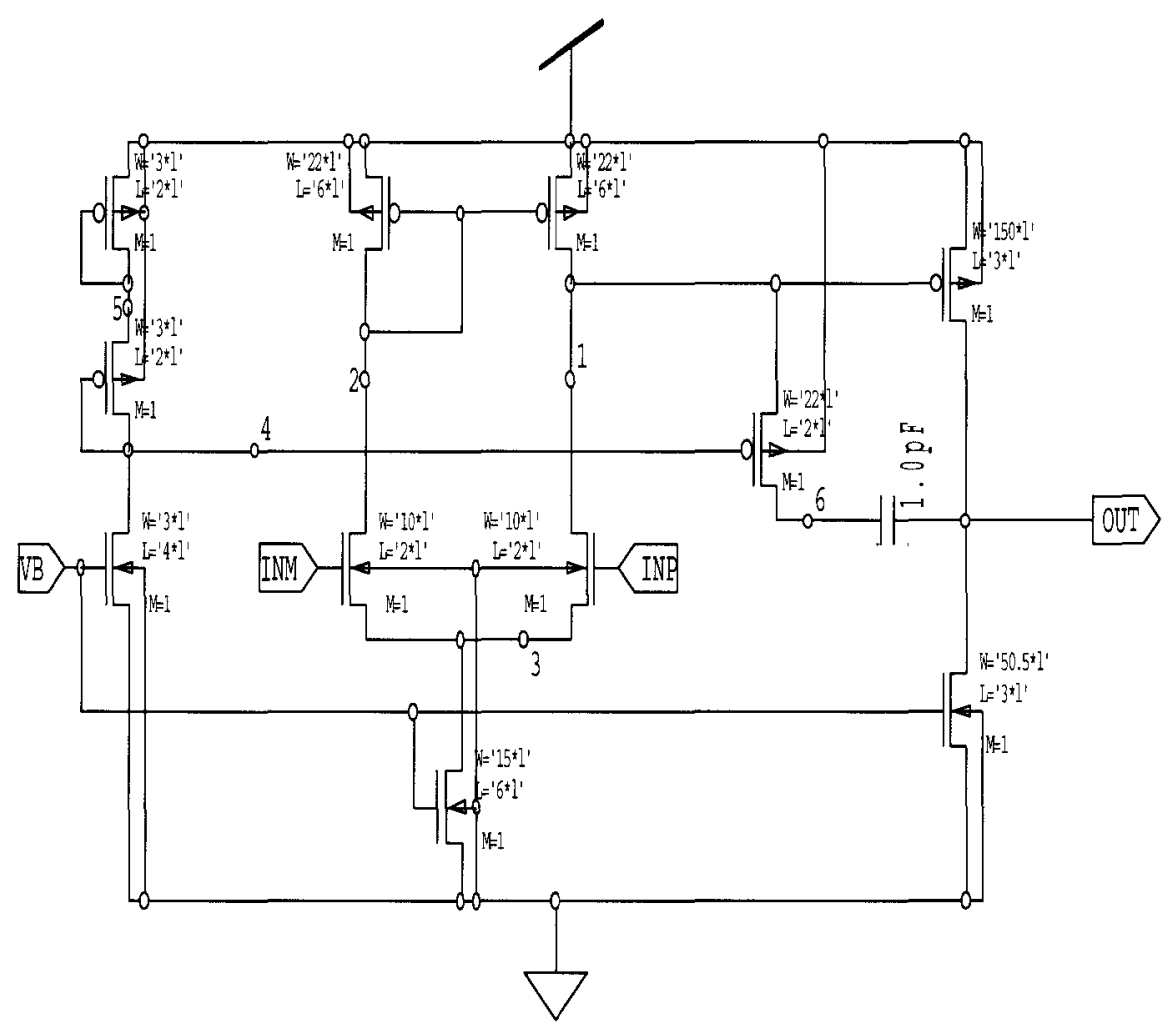

Figure (16) Schematic of an op-amp

The biasing for the Op-Amp was applied from the PBias output of the Bias Generator. The INM is the inverting input and INP is the non-inverting input of the Op-Amp. The compensation capacitor was used to stop the output oscillations. The output was tracked by the INM input of the Op-Amp. The transistor connected to the Capacitor acts as a level shifter 
(permitting the output to swing positive and negative). The output short-circuit protection was provided by the current-limiting transistor connected to the differential stage. In the Open Loop mode, there is no feedback from the output to the inputs and the voltage gain (Av) is maximum. In the closed loop mode, the input and the feedback resistors control the gain. [Op-Amp Handbook - Hughes and Handbook of Integrated Circuit Operational Amplifiers - Rutkowski] For an inverting Op-Amp, the closed loop gain is:

$$
A v=-R_{F} / R_{\text {in }}=\text { Vout } / \text { Vin }
$$

For a non-inverting Op-Amp, the gain is:

$$
\mathrm{Av}=1+\mathrm{R}_{\mathrm{F}} / \mathrm{R}_{\text {in }}=\text { Vout } / \text { Vin }
$$

\subsection{Adjustable Voltage Regulator}

The Voltage Regulator was constructed using a combination of Operational Amplifier and voltage reference. The name adjustable applies because the output voltage was adjustable to any output required using the adjustable feedback resistance. This was constructed in the noninverting mode. The voltage regulator has an in-built input resistance of $25 \mathrm{Kohms}$. The circuit constructed was a positive voltage regulator with the $25 \mathrm{~K}$ resistor and the $R_{A D J}$ (Feedback Resistance) determining the gain. The voltage reference provides the reference voltage as well as the bias for the Op-Amp Circuit. The built-in resistor was a poly resistor laid using the L-Edit software with the dimensions of $L=1759 \lambda$ and $W=2 \lambda$, where $1 \lambda=0.6 \mathrm{um}$. The block diagram of the voltage regulator is as shown in Figure (17). 


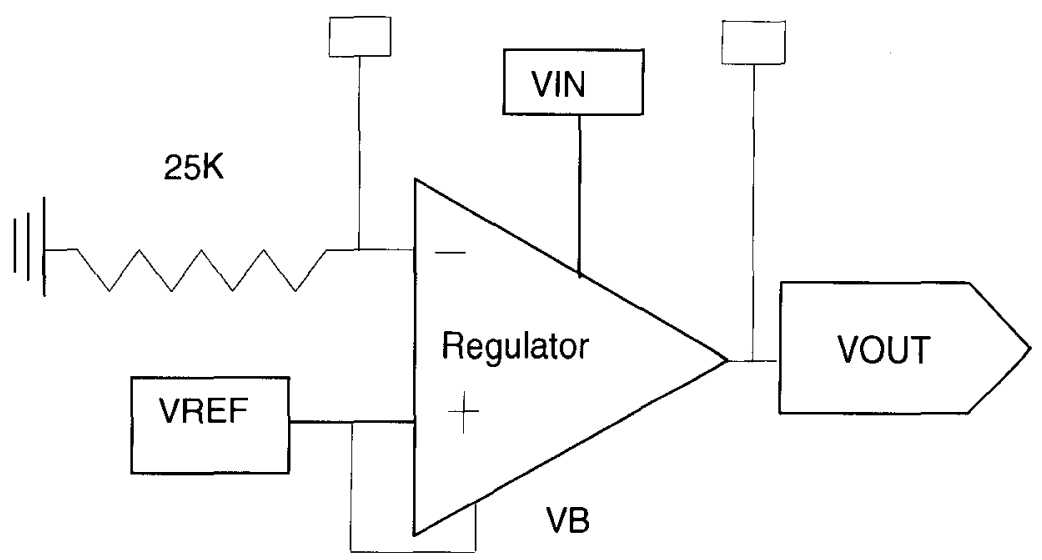

Figure (17) Block Diagram of the Voltage Regulator

The Output Voltage is then given by:

$$
\begin{aligned}
& \text { VOUT }=V_{A D J}(R 2 / 25 K+1) \\
& \text { Where } V_{A D J}=\text { VOUT when } R 2=0
\end{aligned}
$$

For more information on the specifications, refer to the Adjustable Voltage regulator section in [Appendix C]. 


\section{CHAPTER 3}

\section{METHODS}

\subsection{Software Tools}

The simulation software used in this thesis was T-Spice 8.0 (Tanner Version of SPICE), which is a part of the Tanner Tools EDA toolkit used for the design and simulation of the various integrated circuits [Appendix B]. T-Spice was used to solve a wide variety of circuit problems. The simulation model used was BSIMv3, level 49 and the model files for the circuits are obtained from the MOSIS site for the AMI 1.5um process. The model parameters are extracted from T38f.md and T39t.md model files for the transistors. For other integrated circuits, the model parameters are extracted from the T32q.md. These model files contained the process parameters for the various transistors and it was to be included in the Spice file as the process library.

The circuit designs were developed using the S-Edit (Tanner version schematic editor). The highest level of the S-Edit hierarchy is the design file. Files contain modules, which in turn contain the primitives and references to other modules. The symbol mode consists of the shapes, ports and the properties of the circuit where as the schematic mode defines the connectivity of the primitives and lower-level modules within the higher-level modules. [Appendix A]

The standard cells simulated and tested in this thesis were obtained from Tanner's Linear CMOS library for the AMI 1.5-um process. The parameters such as the length, width, area and perimeter are left as default for the standard cells. The scaling factor was set for the length of the circuit as $\mathrm{I}=0.8 \mathrm{um}$ for the simulation to match that of the fabricated cells. L-Edit was the layout tool that uses elements drawn on layers to represent the masks that are used to fabricate the integrated circuit. 


\subsection{Measurement Techniques}

Prior to the measurements, care was taken not to cause Electrostatic discharge (ESD) damage to these transistors as the circuits lack ESD protection. Hence, a wrist strap, connecting to the ground, was used to prevent the damage to these circuits. Measurements for the circuits are taken manually or in some cases, via a computer controlled program-using HP-Vee.

\subsubsection{Automated Method}

The FETs were tested using the parametric Analyzer and the program used was written in HP-Vee. The FETs were mounted on the Test Equipment fixture. The drain/source (source in the case of PMOS) voltage, $V_{D S}$, was varied from 0 to $5 \mathrm{~V}$ for NMOS in steps of $50 \mathrm{mV}$ and -5 to OV for PMOS in steps of $10 \mathrm{mV}$. The source of the NMOS and drain of the PMOS were connected to ground. The gate voltage, $V_{G S}$, for both the NMOS and PMOS were stepped from 0 to $5 \mathrm{~V}$ in $1 \mathrm{~V}$ steps. The output drain current along with the respective gate and drain voltages were stored in a text file. The design methodology adopted for the FET measurements is explained in section 3.3. Similarly, the I-V measurements for the poly-resistors were done using the Parametric Analyzer, with the resistor in the fixture, the HP-Vee program was written to sweep the voltage in steps of $1 \mathrm{~V}$ and the current values were noted down. The results were stored in a text format.

\subsubsection{Manual Method}

For the DC measurements, the inputs were set using the Agilent E3630A triple output DC power supply and the outputs were measured from the HP 3457A Multimeter. For the AC measurements, apart from the power supply, the input signals were fed to the circuit using a $20 \mathrm{MHz}$ function generator and the outputs were measured using the Oscilloscope. The average error for the DC conditions was calculated by the following equation:

$$
\text { Error Percent }=\text { abs }\left(V_{\text {meas }}-V_{\text {sim }}\right) / a b s\left(V_{\text {sim }}\right)
$$

For some circuits, the measurements varied as follows:

- Voltage Reference - The output resistor value was initially set to $2.5 \mathrm{~K}$ (since the circuit was scaled to $80 \%$ of its original dimensions) for the simulation and the data was logged. It was 
noticed that, there was an erratic behavior seen at Vdd-2V, which may be due to some oscillations, and hence, this was discarded and the original value of $3 \mathrm{~K}$ used on the output. The measurements for this circuit were taken using the multimeter to measure the output voltage and the power supply was varied in steps of $1 \mathrm{~V}$ from $0-5 \mathrm{~V}$. The regulation was calculated as follows:

$$
\Delta V_{0} / \Delta V d d=V_{(5 V)}-V_{(2 V)} / 3
$$

- Bias Generator - The input was set using the DC power supply and varied in steps of $1 \mathrm{~V}$ from $0-5 \mathrm{~V}$. The output was measured with the multimeter.

- Current Mirror - The tests for the N-Current Mirror and P-Current Mirror were performed on the 2-18-03- mask as well as the 9-15-03 mask set. The input was set through a $1 \mathrm{~K}$ resistor connected in series with a voltage supply and applying a voltage across this, so as to vary the current from $0-400 \mathrm{uA}$ in steps of 50uA. The output was also connected to another terminal of the supply and a voltage of $3.5 \mathrm{~V}$ was applied across this and the output current was measured using the multimeter. The currents were measured with no output load and output loads of $100 \mathrm{Ohms}, 1 \mathrm{Kohm}$ and $10 \mathrm{Kohm}$ respectively. Similar test was carried out with the P-Current Mirror without the output voltage supply connected across the output terminal.

- Analog Buffer- The input signal fed was a sine wave with $1 \mathrm{Vp}-\mathrm{p}$ and a $1.5 \mathrm{~V}$ offset and the input was swept in powers of $10^{x} \mathrm{~Hz}$ starting $1 \mathrm{~Hz}$ to $20 \mathrm{MHz}$ and output voltage noted down. For the load test, the bias voltage was set to Vbias $=1 \mathrm{~V}$ and input voltage was varied in steps of $0.5 \mathrm{~V}$ upto the Vdd voltage value. The error calculation for the $A C$ and load tests used was:

$$
\text { Error Percent }=\text { abs }\left(V_{\text {meas }}-V_{\text {sim }}\right) / a b s\left(V_{\text {meas }}\right)
$$

- Comparator- the measurements were obtained using three different equipment sets, HP multimeter 3457A, Keithley 175 auto ranging multimeter and fluke $867 \mathrm{~B}$ graphical multimeter. After obtaining the measured results from each of these instruments, a comparison was drawn. The resistance measurements of each of these meters were also taken and the instrument with the best sensitivity was chosen and measurements taken with this instrument were used for the comparison with the simulated results. The tests revealed that the HP multimeter and the Fluke meter showed good sensitivity and hence, values were measured 
using both these meters. Since, the chip contained many other circuits apart from the comparator; the current measurements were not taken. The measurements were taken using a load of $510 \mathrm{~K}$ on the output. Setting different bias voltages from $0-1 / 2 \mathrm{Vdd}$ and choosing the bias voltage where the comparator switched, and setting this voltage, in this case, bias-0V, the outputs were measured. The input voltage was swept in steps of $500 \mathrm{mV}$. The tests were performed for 2 different supply voltages, $V d d=3 V$ and $V d d=5 V$. For $V d d=3 V$, reference voltage, Vref was set to $1 / 2 \mathrm{Vdd}=1.5 \mathrm{~V}$ and for $\mathrm{Vdd}=5 \mathrm{~V}$, Vref was set to $2.5 \mathrm{~V}$.

- Op-Amp - The AC characteristics were performed by feeding a sine wave signal of Vinv=100mV from the $20 \mathrm{MHz}$ Agilent function generator for the Inv input. The Noninv input was set to1.35V and $\mathrm{Vdd}=5 \mathrm{~V}$. The Bias was set by connecting the Bias pin of the Op-Amp to the PBias output pin of the Bias Generator. $R 1=10 \mathrm{~K}$ and $\mathrm{R} 2=100 \mathrm{~K}$. In the non-inverting mode, the $A C$ tests were performed by feeding a sine wave signal of $1.35 \mathrm{~V}$ offset and $V_{\text {Noninv }}=100 \mathrm{mV}$ from the $20 \mathrm{MHz}$ Agilent function generator for the Noninv input. $V d d=5 V$. The Bias was set by connecting the Bias pin of the Op-Amp to the PBias output pin of the Bias Generator. $\mathrm{R} 1=10 \mathrm{~K}$ and $\mathrm{R} 2=100 \mathrm{~K}$. Similar to the buffer tests, the input signal was swept in powers of $10^{x} \mathrm{~Hz}$ starting $1 \mathrm{~Hz}$ to $20 \mathrm{MHz}$ and output noted down.

- Adjustable Voltage Regulator - For the load test, two standard outputs were considered, 3.3V and $5 \mathrm{~V}$ outputs. For the $5 \mathrm{~V}$ output, the Op-Amp used in the circuit, was configured in the closed loop with $\mathrm{R} 1=25.96 \mathrm{~K}$ and $\mathrm{R} 2$ (Feedback resistance) with $34.6 \mathrm{~K}$. The feedback resistance value was set to this value after experimenting with different resistor values to result in the $5 \mathrm{~V}$ output. The output was measured, by varying the output loads from $100-$ 50K Ohm, using the Fluke Meter. The Inverting input was connected through the closed-loop resistors to the ground and output terminals. The bias and non-inverting input are set from the VREF pin of the voltage reference. The supply voltage was set at $5 \mathrm{~V}$. Measurements were obtained from only one die, as this configuration did not work for the other dies. The outputs on the other dies were of the orders of $\mathrm{mV}$. The Output without any load was $4.996 \mathrm{~V}$. Hence, to maintain the output value at around $5 \mathrm{~V}$, the $34.6 \mathrm{~K}$ resistor for the feedback was used. With the other lower resistors this output value was not achieved. This was the closest 
resistor value that gave the output value around $5 \mathrm{~V}$, for a VDD $=5 \mathrm{~V}$. Similarly for a $3.3 \mathrm{~V}$ output, the Op-Amp was configured in the closed loop with R1=25.96K and R2 (Feedback resistance) with $12.98 \mathrm{~K}$ and the other measurements remain same as before.

For the Output Characteristics test, with the same resistor configuration for the closed-loop, the supply voltage was varied in steps of $1 \mathrm{~V}$ from $0-10 \mathrm{~V}$ and output was noted using the multimeter.

\subsection{Design Methodology for the FETs}

The FETs are initially tested for the repeatability and scalability for the measured data. The scalability for the FETs was also compared with the simulated data. The methodology used explains the different steps carried out while testing for the I-V Characteristics for the FETs. The methodology used for the optimization is as shown in the section below. For the scaling tests, the 19.2x1.6 um transistor was used as the primary transistor and the other transistor sizes were scaled with respect to this. The current, $\mathrm{I}_{\mathrm{DS}}$ was compared at $\mathrm{V}_{\mathrm{GS}}=1,3$ and $5 \mathrm{~V}$ and $\mathrm{V}_{\mathrm{DS}}=1,3$ and $5 \mathrm{~V}$, respectively, and the error measurement was performed by using the following equation:

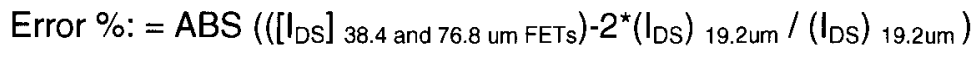

The average scaling error calculated between the other FETS and the measured 19.2 um FET was calculated using the above equation. Since there was limited availability of the fabricated FETs in terms of the sizes, the comparison was done between the 19.2um, 38.4um, 57.6um and 76.8um FET sizes and from the results it was noticed that there was good agreement in the scalability between these sizes.

The repeatability tests were done over two days and for each FET size, two tests were performed on each of these days. The average error was obtained by comparing the measured current values at the 18 different bias points namely, $V_{G S}=1,3$ and $5 \mathrm{~V}$ and $V_{D S}=1,3$ and $5 \mathrm{~V}$.

For optimization, the average current error method was used where the error was calculated by taking the absolute difference between the measured and simulated data at the 18 different bias points at the optimized and default $M$ values. $M$ is the multiplicity factor. 
The average errors between the simulated and measured data were calculated in two ways. The First method was by using the percentage error method and the second method was by calculating the average error in terms of actual currents. In the percentage error calculation method, all the I-V curves were equally weighted. However, the fit around $V_{t}$ can typically be orders of magnitude different between measured and simulated results, which would skew the comparison significantly. Hence, to solve this problem, the data around $V_{t}$ was not included or use the second method of error calculation of just comparing actual currents.

In addition to optimizing the multiplicity factor, $\mathrm{M}$, other modeling parameters were also considered for the FET optimization. The threshold values for the FETs were changed to get a better fit in the larger $V_{\mathrm{gs}}$ regions of the I-V curve. This optimization indicated that by optimizing the $V_{t}$ value, better fit at the higher $V_{g s}$ regions was obtained at the cost of reducing the fit in the lower $V_{g s}$ regions. Hence, the simulations were performed for the default threshold voltage value for the NMOS and PMOS FET. The error calculation using the percentage error method was done using the following equation:

$$
\text { Error } \left.\%=\text { Average [(Measured } I_{d s} \text { value/Simulated } I_{d s} \text { value }\right) \text { vGS, vDS=0-5v] }
$$

The equation used for the error calculation using the average current error method was:

Actual Error $=$ Average $\left[\left(\text { Measured } I_{d s} \text { value }- \text { Simulated } I_{d s} \text { value }\right)_{\text {VGS, vDS }=0-5 \mathrm{v}}\right]$ 


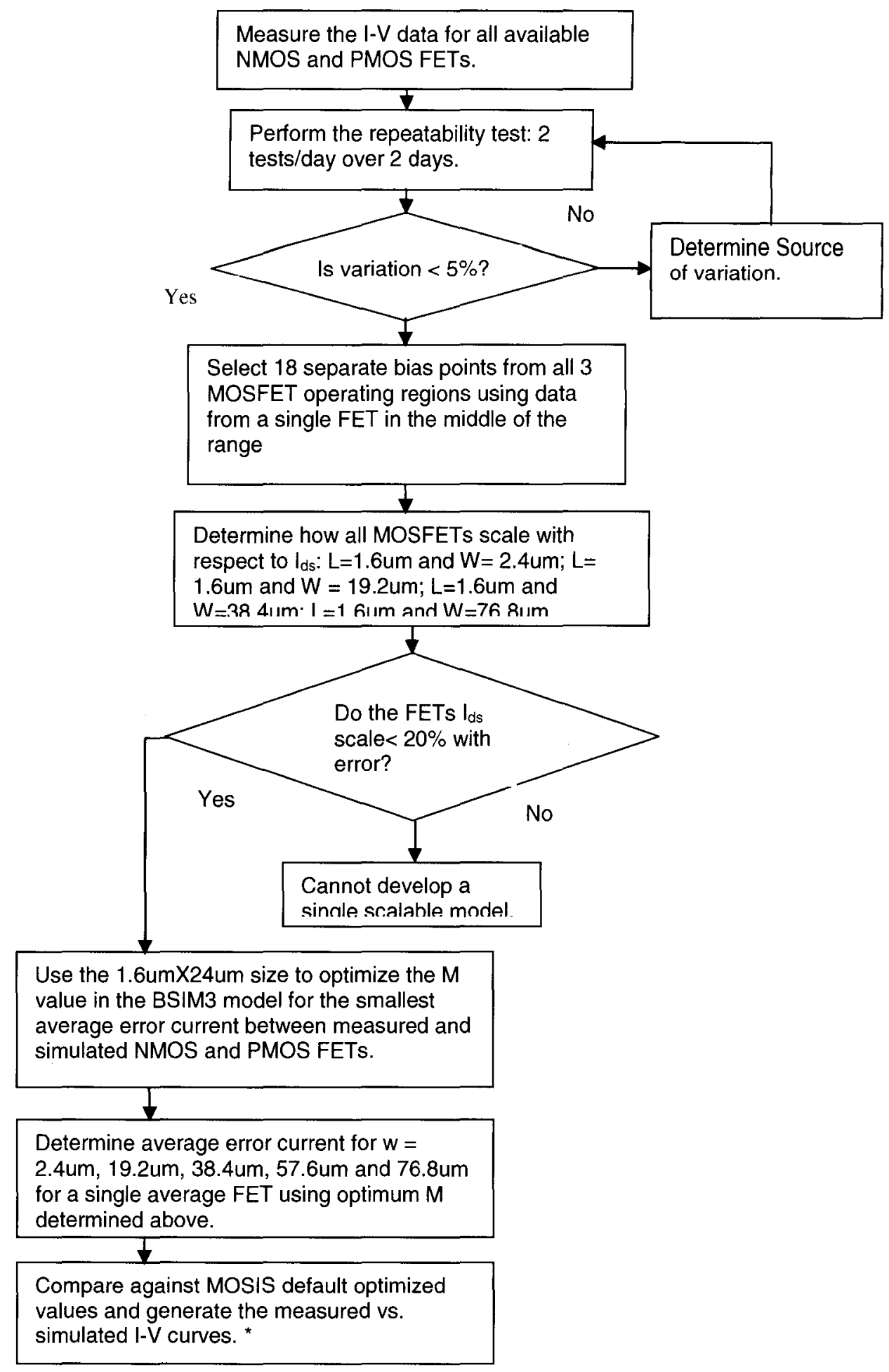

Figure (18) Design Methodology Flowchart

${ }^{*}$ For the future modeling, the tests will be performed for the 2.4um, 4.8um, 9.6um, 19.2um, 38.4um and 76.8um FETs. 
For the 2-18-03 Mask Set, the tests were performed only on the 19.2x1.6 um die and all data collected and scaled with respect to this die size which falls in the middle of all the die sizes. The NMOS FETs did not require any optimization since the measured and simulated data were in close agreement with each other, changing the Dsub value after reviewing some other modeling parameters optimized the PMOS FET. This is explained in the following section.

\subsection{Modeling of the FETs}

For the modeling of the PMOS FETs, some other parameters that affect the I-V and C-V calculations were evaluated. The parameters were: u0, Dsub, Drout, Beta0, Alpha0, Is, Nfactor, PSCBE1, PSCBE2, Delta and PCLM. These parameters are discussed in detail below. Some of these parameters affect only the I-V curves while the others affect the $C-V$ curves as well. [MOSFET Models for SPICE Simulation -William Liu]

The parameters that affected the I-V calculations (DC) only were Delta, u0, PCLM, Drout, Nfactor, PSCBE1 and PSCBE2. The parameters that affected the I-V as well as C-V calculation were $V_{t}$ and Dsub. Also, some parameters that are devoted to the substrate current due to impact ionization were dealt with. They are Beta0 and Alpha0.The output average error between the simulated values and the measured value was calculated as follows:

Error $=$ Average $[($ abs $($ measured data - simulated data $) /$ simulated data $)$ vGS, vDS 0-5V $]$

(1) Alpha0 - It is the first parameter of the substrate current due to impact ionization.

When $V_{d s}$ was high, a large voltage drop across the depletion region near the drain was observed. The resultant high field accelerated the electrical carriers as they flow through the channel. If these accelerated carriers acquire enough energy, they generate electron-hole pairs upon impacting the lattice. The generated holes move in the direction of the field toward the substrate. The portion of the bulk terminal current $\left(I_{B}\right)$ due to these holes from impact ionization is denoted as $I_{\text {sub }}$ in BSIM3. In BSIM3, $I_{\text {sub }}$ is modeled as: 


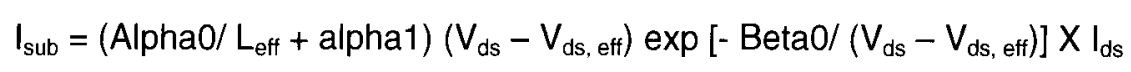

where, $V_{d s, \text { eff }}$ is the smoothing function defined in BSIM3 to smooth out the transition between the linear and saturation region. It is identical to Vds when the externally applied Vds was small, and

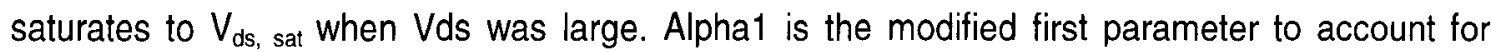
length variation in the calculation of $\mathrm{I}_{\text {sub }}$.Alpha0 was set to the default and the units are $\mathrm{m} / \mathrm{V}$ where $\mathrm{m}$ - meter and V-volts. NMOS has a higher substrate current than PMOS for a given bias and hence Alpha0 is expected to be larger for NMOS than the PMOS. In this research, this parameter was not included in the model file, so the parameter AO was replaced with this parameter and observed the impact it had on the I-V calculation was observed. The default values of $A 0$, for NMOS $=0.552232$ and for PMOS as 0.1 and the error between the simulated values with $\mathrm{AO}$ and Alpha0 computed. These values were tested for the buffer circuit.

(2) Beta0 - It is the second parameter of the substrate current due to impact ionization. The relationship between the Beta0 and Isub was as given in the equation (26). BSIM3's impact ionization model was accurate only when the impact ionization current was small. When Beta was less than zero, BSIM3 equates the substrate current due to impact ionization to zero. It is set to a default value of 0 for BSIM3 and the unit is $V^{-1}$ where $V$ is volts. The model file that was used for the simulations did not include this parameter and this value was set to 30 as well as 300 .

3) Delta - It is the effective $V_{d s}$ smoothing parameter. Delta is the parameter used to control the

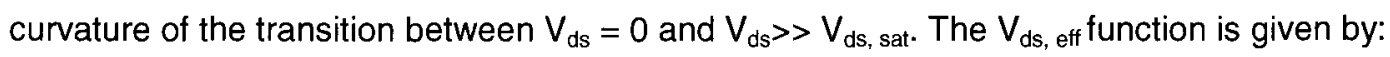

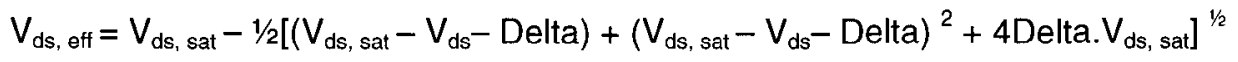

where, $V_{d s \text {, eff }}$ is the smoothing function used to smooth the transition between the linear and saturation regions, is equal $V_{d s}$ when $V_{d s}$ approaches 0 but asymptotically tends to $V_{d s \text {, sat }}$ when

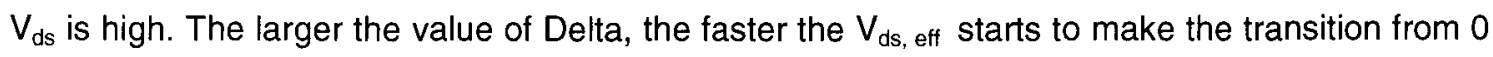

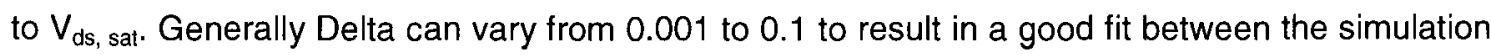
and measured data. In the model file, this was set to 0.01 and was changed to 0.001 , since the 
$\mathrm{I}-\mathrm{V}$ curves at the higher $\mathrm{V}_{\mathrm{gs}}$ value needed to be pulled down.

(4) Drout - (default-0.56, unit less)

It is the $L_{\text {eff }}$ dependence exponent in the drain-induced barrier-lowering's (DIBL) correction on the early voltage. This is explained in detail in the PCLM modeling parameter section. The default value for the Drout (PMOS) in the model files is set to 9.96E-04. This value was changed from $0-1$ in steps of 0.5 and output evaluated.

(5) Dsub $-L_{\text {eff }}$ - dependence exponent of the drain- induced barrier lowering (DIBL) effects on the threshold voltage. The default of Dsub was set to the value of Drout specified in the SPICE parameter set. If Drout was not specified, then Dsub is defaulted to 0.56. Dsub is the parameter used to control the amount of $\Delta \mathrm{V}_{\mathrm{t}, \text { DIBL }}$ as a function of Leff, where $\Delta \mathrm{V}_{\mathrm{t}, \text { DIBL }}$ is the drain-induced barrier lowering around the threshold voltage value. The threshold voltage in BSIM3 is expressed as

$V_{t}=V$ tho $+\delta_{N P}\left(\Delta V_{t, \text { body_effect }}-\Delta V_{t, \text { charge-sharing }}-\Delta V_{t, \text { DIBL }}+\Delta V_{t, \text { reverse_short_channel }}+\right.$

$\left.\Delta \mathrm{V}_{\mathrm{t}, \text { narrow-width }}+\Delta \mathrm{V}_{\mathrm{t}, \text { small-size }}\right)$

where, $\delta_{\mathrm{NP}}$ is +1 for NMOS and -1 for PMOS. The DIBL component is given by,

$\Delta V_{t, D I B L}=\left[\exp \left(-D s u b L_{e f f} / 2 L_{t 0}\right)+2 \exp \left(-D S U B L_{e f f} / L_{t 0}\right)\right]\left(E T A O+E T A B . V_{B S}\right) \times V_{D S}$,

where, $L_{t 0}=\left(\varepsilon_{s} X_{\text {dep }, 0} / C^{\prime}{ }_{o x}\right)^{1 / 2}, X_{\text {dep, } 0}$, the depletion thickness in the substrate at zero bulk bias., $\Delta \mathrm{V}_{\mathrm{t} \text {, body_effect }}$ - The voltage observed when there is a large reverse bulk-source bias $\left(\mathrm{V}_{\mathrm{BS}}\right) ., \Delta \mathrm{V}_{\mathrm{t}}$, charge-sharing - The voltage observed due to short-channel transistors, $\Delta \mathrm{V}_{\mathrm{t}}$, reverse_short_channel - Voltage in short-channel transistors with large NLX., $\Delta V_{t, \text { narrow-width }}-$ Voltage seen in narrow-width devices, $\Delta \mathrm{V}_{\mathrm{t}}$, small-size - Voltage seen due to narrow-width and short-channel transistors., $\varepsilon_{\mathrm{s}}-$ Dielectric constant, ETAO - (default - 0.008) - DIBL coefficient for threshold voltage calculation, ETAB (default $=-0.07$, unit $=\mathrm{V}^{-1}$ ) - bulk-bias coefficient of the DIBL effects, and $C^{\prime}{ }_{\text {ox }}-$ Oxide capacitance per unit area.

DIBL was a short-channel effect. In short-channel devices, as $V_{d s}$ changes, there was noticeable change seen in the surface potential. When $V_{d s}$ increases, the barrier blocking the 
carriers in the drain from entering the channel diminishes, and the device turns on sooner. $V_{d s}$ induce this barrier lowering. Hence, it was referred to as drain induced barrier-lowering effect. Dsub is a parameter used to control the amount of $\Delta V_{t, D I B L}$ as a function of $L_{\text {eff. Negative Dsub }}$ can cause the exponential function in equation (25) to approach infinity. Dsub should always be positive.

(6) NFACTOR - It is the sub threshold turn-on swing factor. The drain current increases exponentially with $V_{G S}$ in the sub threshold region. $\mathrm{n}$ is referred to as the ideality factor adapting to the terminology used for describing the diode current. The ideality factor in MOS was always larger than 1 and was bias-dependant.

$$
\mathrm{n}=1+\mathrm{C}_{\mathrm{dep}}^{\prime}+\mathrm{CIT} / \mathrm{C}_{\mathrm{ox}}^{\prime}
$$

where, $C_{\text {dep }}^{\prime}$ is the depletion capacitance per unit area in the bulk, CIT is the interface capacitance per unit area and $C^{\prime}{ }_{\text {ox }}$ is the oxide capacitance per unit area. In BSIM3, the ideality factor equation was modified as below:

$$
n=1+\text { NFACTOR. } C_{d e p}^{\prime} / C_{o x}^{\prime}+C I T / C_{o x}^{\prime}+\left(C D S C+C D S D . V_{D S}+\text { CDSCB. } V_{B S} / C_{o x}^{\prime}\right) X
$$$$
\left[\exp \left(-D V T 1 L_{e f f} / 2 L_{t}\right)+2 \exp \left(-D V T 1 L_{e f f} / L_{t}\right)\right]
$$

The last term in the above equation was meant for the charge sharing correction in short channel devices. It was used to model the effects from the coupling capacitances between the drain or source to the channel. CDSC, CDSDC and CDSCD should be positive numbers, whereas CDSCB should be negative (since $V_{B S}$ in normal operation was negative). The default values CDSC, CDSDC, and CDSCB are $2.4 \times 10^{-4}\left(\mathrm{~F} / \mathrm{m}^{2}\right), 0$ and 0 , respectively. Generally, when the absolute values of any of the three parameters exceed 0.1 , some kinks in simulated drain current may develop under certain bias condition. NFACTOR is the main BSIM3 parameter that modifies the sub threshold ideality factor. Apart from this, VOFF was used to fit the transistors' off current. NFACTOR can then be optimized independently. The NFACTOR can be used to fit the 
sub threshold slope. The VOFF and NFACTOR are interrelated and the change in one of these parameters affects the other. The NFACTOR was set to a default value of 1 and it is unit less.

The Nfactor value was decreased from the default of NMOS $=0.5740385$ and PMOS $=$ 0.2508342 to NMOS $=0.0385776$ and PMOS $=0.1597389$ (typical slow-fast model values)

(7) PCLM - It is the channel-length modulation parameter in the calculation of the drain current. The default value is 1.3 and this parameter too is unit less. In long-channel MOSFETs, the current remains constant with $V_{D S}$ once $V_{D S}$ exceeds VDS, Sat. In short-channel devices, there was some finite of slope to the current due to a combination of the channel-length modulation and DIBL (drain-induced barrier-lowering) effects. In short channel devices, $V_{A}, C M L-D I B L$, gives the early voltage where the dependence of the early voltage on the channel-length modulation and draininduced barrier-lowering effects are seen. This was calculated as shown below:

$V_{A, C M L-D I B L}=1+$ PVAG. $\left(V_{\text {GS }}-V_{t}\right) \cdot u_{\text {eff }} /\left(2\right.$ VSAT. $\left.L_{\text {eff }}\right) /\left(\right.$ PCLM. $11+\Theta_{\text {rout }}\left(1+\right.$ PDIBLCB. $\left.V_{B S}\right) \cdot f 2$, (32) where, $\Theta_{\text {rout }}=$ PDIBLC1 $X\left[\exp \left(-\right.\right.$ DROUT $\left.L_{\text {eff }} / 2 L_{t 0}\right)+2 \exp \left(-\right.$ DROUT $\left.\left.L_{\text {eff }} / L_{10}\right)\right]+$ PDIBLC2, and f1 and $\mathrm{f} 2$ are functions of $\mathrm{A}_{\text {bulk. }}$. The parameters PVAG, PCLM, DROUT, PDIBLC1, PDIBLC2, and PDIBLCB, affect only short-channel devices. PVAG was set to 0 and is the gate-bias dependence of the early voltage. PDIBLCB is the body-effect coefficient to the DIBL's correction on the early voltage. PDIBLC1 and PDIBLC2 are the first and second coefficients of DIBL's correction on the early voltage. In the model file, the values were set as $1 \mathrm{e}-9,1 \mathrm{e}-10$ (default in the model) and $1 \mathrm{e}-$ 11.

(8) PSCBE1- It is the first high-voltage drain-conduction modification factor. It is set to a default value of $4.24 \times 10^{8}$ with the units $\mathrm{V} / \mathrm{m}$. It is meant to model the drain current increase at high $\mathrm{V}_{\mathrm{DS}}$, due to the increased current caused from impact ionization. The drain terminal current in BSIM3 models are given by:

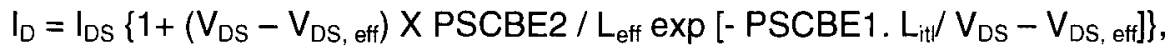

where, the variable $L_{i t 1}$ is: $L_{i t 1}=\left(\varepsilon_{s} / \varepsilon_{0 x} \text { Tox. } X J\right)^{1 / 2}$ 
BSIM3 calculates the effects of the impact ionization on the drain terminal current, but not the bulk terminal current. Hence, PSCBE1 and PSCBE2 were considered as the fitting parameters.

(9) PSCBE2 is the second high-voltage drain-conduction modification factor. This is set to a default value of $1 \times 10^{-5}$ with a unit of $\mathrm{m} N$. It is related to the drain terminal current as given in the equation (28). The PSCBE1 and PSCBE2 were set to $1 \mathrm{E} 30$ and 0 (BSIM3 values) respectively from the default values in the model, 2.179583E9 and 5E-10 for NMOS and 3.522972E9 and 5.285524E-10 for PMOS respectively

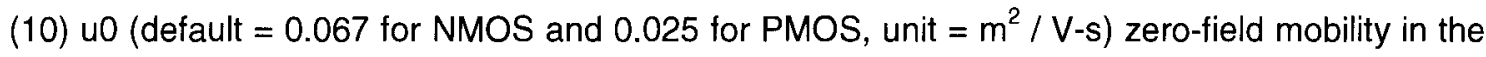
universal mobility formulation, when the device operating temperature is equal to TNOM (the temperature at which the model parameters are extracted). BSIM3 offers three mobility models, all of which are slight variations of the universal mobility model. When the device temperature in a circuit simulation is not equal to TNOM, BSIM3 adjusts the u0 parameter by a factor:

$\mathrm{u} 0\left(\mathrm{~T}_{\text {device }}\right)=\mathrm{u} 0(\mathrm{TNOM}) \times\left(\mathrm{T}_{\text {device }}+273.15 / \mathrm{TNOM}+273.15\right)^{\mathrm{UTE}}$,

where, $u 0(T N O M)$ is the $u 0$ specified in the parameter set, whereas $u 0\left(T_{\text {device }}\right)$ : the mobility value actually used for the I-V and C-V calculations. The parameter UTE specifies the amount of temperature dependence of the mobility variation. This value was varied from 620 (default) 10,000 in the following order $620,1000,5000$ and 10000 for NMOS while it was changed from 236(default) to $50,100,236$ and 500 .Apart from the above parameters, the saturation current was modified from the default in the model of 0 to $1 \mathrm{E}-14$ [obtained from SPICE help manual]. The results of the modeling parameters are shown in [Appendix D] 


\section{CHAPTER 4}

\section{RESULTS AND DISCUSSION}

\subsection{MOSFETS}

The results obtained for the 1.6 um FETs are shown in the tables that follow with the scalability and repeatability test data. The results obtained for the other FET sizes are tabulated in [Appendix D]. Tables 2-3 and 4-5 show the NMOS FET and PMOS FET results, respectively, obtained using the two error methods. For the percentage error method, the absolute average error calculated using the default model values between measured and simulated results for the 19.2um, 38.4um, 57.6um and 76.8um NMOS FETs was $7.74 \%$ and the absolute average error calculated using the optimized model values between measured and simulated data for the 19.2um, 38.4um, 57.6um and 76.8um NMOS FETs was $5.28 \%$. Using the average error current method, the absolute average error current calculated using the optimized model values, between measured and simulated results for the 19.2um, 38.4um, and 76.8um NMOS FETs was 137.40 uA. The absolute average error current calculated using the default model values between measured and simulated results for the 19.2um, 38.4um, and 76.8um NMOS FETs was 154.83 uA. The Student's paired t-Test was performed on the error data from Table 3 using Minitab software. It indicated that there was a significant change. With the $95 \%$ confidence interval, the mean difference between the two sets, optimized and default values, was $(-0.000068,-0.000016)$, and with the $99 \%$ confidence interval it was $(-0.000078,-0.000007)$. In this case, there was a greater than $99 \%$ probability that the error was reduced. The "p" value for this test was found out to be 0.002 . Statistically, the base hypothesis, which states that the error is the same in both cases, optimized and default, could be rejected in favor of the alternate hypothesis, which is that the optimized model has lower error. 
Table 2 - UnOptimized and Optimized data using Percentage Error method for 19.2x1.6 um

NMOS FET.

\begin{tabular}{|c|c|c|c|c|c|c|c|}
\hline \multicolumn{2}{|c|}{$\begin{array}{l}W=19.2 u m \\
\& L=1.6 \text { um }\end{array}$} & \multicolumn{3}{|c|}{$\begin{array}{c}\text { Using the optimized values of } \\
V t=0.48 \mathrm{~V} \text { and } M=1.05\end{array}$} & \multicolumn{3}{|c|}{$\begin{array}{c}\text { Using the default values of } \mathrm{Vt}= \\
0.48 \mathrm{~V} \text { and } M=1\end{array}$} \\
\hline \multirow[t]{3}{*}{$\begin{array}{l}\text { Vgs } \\
\text { (V) }\end{array}$} & $\begin{array}{l}\text { Vds } \\
\text { (V) }\end{array}$ & $\begin{array}{c}\text { Ids } \\
\text { Measured } \\
\text { with dual } \\
\text { SMUs }\end{array}$ & $\begin{array}{c}\text { Ids } \\
\text { Simulated } \\
w / \\
V t=0.48 \mathrm{~V} \\
\text { and } \\
M=1.05\end{array}$ & $\begin{array}{l}\text { Error } \\
\text { Factor } \\
\text { Meas. } \\
\text { Vs } \\
\text { Sim. } \\
\text { (SMU/ } \\
\text { Sim) }\end{array}$ & $\begin{array}{l}\text { Ids } \\
\text { Measured } \\
\text { with dual } \\
\text { SMUs }\end{array}$ & $\begin{array}{c}\text { Ids } \\
\text { Simulated } \\
w / \\
V t=0.48 V \\
\text { and } M=1\end{array}$ & $\begin{array}{c}\text { Error } \\
\text { Factor } \\
\text { Meas. } \\
\text { Vs } \\
\text { Sim. } \\
\text { (SMU/ } \\
\text { Sim) }\end{array}$ \\
\hline & & Die \#3 & & & \multicolumn{3}{|l|}{ Die \#3 } \\
\hline & & (A) & (A) & & (A) & (A) & \\
\hline 0 & 1.0 & $1.21 \mathrm{E}-11$ & $1.966 \mathrm{E}-11$ & 0.615 & $1.21 \mathrm{E}-11$ & $1.88 \mathrm{E}-11$ & 0.644 \\
\hline 0 & 3.0 & $2.79 \mathrm{E}-11$ & $2.902 \mathrm{E}-11$ & 0.960 & $2.79 \mathrm{E}-11$ & $2.78 \mathrm{E}-11$ & 1.003 \\
\hline 0 & 5.0 & $4.08 \mathrm{E}-11$ & $3.837 \mathrm{E}-11$ & 1.062 & $4.08 \mathrm{E}-11$ & $3.68 \mathrm{E}-11$ & 1.108 \\
\hline 1.0 & 1.0 & $1.34 \mathrm{E}-04$ & $1.418 \mathrm{E}-04$ & 0.947 & $1.34 \mathrm{E}-04$ & $1.35 E-04$ & 0.995 \\
\hline 1.0 & 3.0 & 1.56E-04 & $1.601 \mathrm{E}-04$ & 0.977 & 1.56E-04 & 1.52E-04 & 1.025 \\
\hline 1.0 & 5.0 & $1.74 \mathrm{E}-04$ & 1.746E-04 & 0.995 & 1.74E-04 & $1.66 \mathrm{E}-04$ & 1.044 \\
\hline 2.0 & 1.0 & $7.57 \mathrm{E}-04$ & $7.188 \mathrm{E}-04$ & 1.053 & $7.57 \mathrm{E}-04$ & $6.85 E-04$ & 1.105 \\
\hline 2.0 & 3.0 & $8.72 \mathrm{E}-04$ & $8.316 \mathrm{E}-04$ & 1.049 & 8.72E-04 & 7.92E-04 & 1.102 \\
\hline \multirow[t]{2}{*}{2.0} & 5.0 & $9.26 \mathrm{E}-04$ & $8.698 \mathrm{E}-04$ & 1.064 & \multirow[t]{2}{*}{$9.26 \mathrm{E}-04$} & 8.28E-04 & 1.117 \\
\hline & & & & 4 & & & 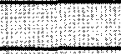 \\
\hline 3.0 & 1.0 & 1.37E-03 & $1.287 \mathrm{E}-03$ & 1.062 & 1.37E-03 & $1.23 \mathrm{E}-03$ & 1.115 \\
\hline 3.0 & 3.0 & 1.79E-03 & $1.752 \mathrm{E}-03$ & 1.024 & $1.79 \mathrm{E}-03$ & 1.67E-03 & 1.075 \\
\hline \multirow[t]{2}{*}{3.0} & 5.0 & 1.87E-03 & $1.816 \mathrm{E}-03$ & 1.032 & \multirow[t]{2}{*}{ 1.87E-03 } & 1.73E-03 & 1.083 \\
\hline & & & & & & & \\
\hline 4.0 & 1.0 & 1.86E-03 & 1.757E-03 & 1.057 & $1.86 \mathrm{E}-03$ & 1.67E-03 & 1.109 \\
\hline 4.0 & 3.0 & $2.79 \mathrm{E}-03$ & $2.789 \mathrm{E}-03$ & 1.000 & $2.79 \mathrm{E}-03$ & $2.66 \mathrm{E}-03$ & 1.050 \\
\hline \multirow[t]{2}{*}{4.0} & 5.0 & $2.89 \mathrm{E}-03$ & $2.890 \mathrm{E}-03$ & 1.001 & $2.89 \mathrm{E}-03$ & $2.75 \mathrm{E}-03$ & 1.051 \\
\hline & & & & & & & 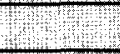 \\
\hline 5.0 & 1.0 & $2.26 \mathrm{E}-03$ & $2.141 \mathrm{E}-03$ & 1.057 & $2.26 \mathrm{E}-03$ & 2.04E-03 & 1.109 \\
\hline 5.0 & 3.0 & $3.80 \mathrm{E}-03$ & $3.885 \mathrm{E}-03$ & 0.977 & $3.80 \mathrm{E}-03$ & $3.70 \mathrm{E}-03$ & 1.026 \\
\hline \multirow[t]{4}{*}{5.0} & 5.0 & $3.95 \mathrm{E}-03$ & $4.066 \mathrm{E}-03$ & 0.970 & $3.95 \mathrm{E}-03$ & $3.87 \mathrm{E}-03$ & 1.019 \\
\hline & & & & & & & 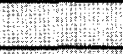 \\
\hline & & & AVG Error & $0.55 \%$ & & $\begin{array}{l}\text { AVG } \\
\text { Error }\end{array}$ & $4.35 \%$ \\
\hline & & & SD Error & 0.10 & & SD Error & 0.11 \\
\hline
\end{tabular}


Table 3 - UnOptimized and Optimized data using Average Error Current method for 19.2×1.6 um NMOS FET.

\begin{tabular}{|c|c|c|c|c|c|c|c|}
\hline \multicolumn{2}{|c|}{$\begin{array}{l}W=19.2 u m \\
\& L=1.6 u m\end{array}$} & \multicolumn{3}{|c|}{$\begin{array}{l}\text { Using the optimized values of Vt } \\
=0.48 \mathrm{~V} \text { and } \mathrm{M}=1.05\end{array}$} & \multicolumn{3}{|c|}{$\begin{array}{c}\text { Using the default values of } \mathrm{Vt}= \\
0.48 \mathrm{~V} \text { and } M=1\end{array}$} \\
\hline \multirow[t]{3}{*}{$\begin{array}{l}\text { Vgs } \\
\text { (V) }\end{array}$} & \multirow[t]{3}{*}{$\begin{array}{l}\text { Vds } \\
\text { (V) }\end{array}$} & \multirow{2}{*}{$\begin{array}{c}\text { Ids } \\
\text { Measured } \\
\text { with dual } \\
\text { SMUs } \\
\text { Die \#3 } \\
\end{array}$} & \multirow[t]{2}{*}{$\begin{array}{c}\text { Ids } \\
\text { Simulated } \\
w / \\
V t=0.48 \mathrm{~V} \\
\text { and } \\
M=1.05 \\
\end{array}$} & $\begin{array}{c}\text { Error } \\
\text { Factor } \\
\text { Meas. } \\
\text { Vs Sim. } \\
\text { (SMU- } \\
\text { Sim) }\end{array}$ & $\begin{array}{l}\text { Ids } \\
\text { Measured } \\
\text { with dual } \\
\text { SMUs }\end{array}$ & $\begin{array}{l}\text { Ids } \\
\text { Simulated } \\
w / \\
V t=0.48 \mathrm{~V} \\
\text { and } M= \\
1.0\end{array}$ & $\begin{array}{l}\text { Error } \\
\text { Factor } \\
\text { Meas. Vs } \\
\text { Sim. } \\
\text { (SMU- } \\
\text { Sim) }\end{array}$ \\
\hline & & & & & Die \#3 & & \\
\hline & & (A) & (A) & & (A) & (A) & \\
\hline 0 & 1.0 & $1.21 \mathrm{E}-11$ & $1.966 \mathrm{E}-11$ & $7.58 \mathrm{E}-12$ & $1.21 \mathrm{E}-11$ & $1.88 \mathrm{E}-11$ & $6.69 \mathrm{E}-12$ \\
\hline 0 & 3.0 & $2.79 E-11$ & $2.902 \mathrm{E}-11$ & $1.16 E-12$ & $2.79 \mathrm{E}-11$ & $2.78 E-11$ & $790 E-14$ \\
\hline 0 & 5.0 & $4.08 \mathrm{E}-11$ & $3.837 \mathrm{E}-11$ & $2.40 \mathrm{E}-12$ & $4.08 \mathrm{E}-11$ & $3.68 E-11$ & $3.98 E-12$ \\
\hline 10 & 10 & 13 & $1418 F_{-}$ & 6 & & 13 & $00 \mathrm{~F}-07$ \\
\hline 1.0 & 3.0 & $1.56 \mathrm{E}-04$ & $1.601 \mathrm{E}-04$ & 3.76E-06 & $1.56 \mathrm{E}-04$ & 1.52E-04 & 3.87E-06 \\
\hline 1.0 & 5.0 & $1.74 \mathrm{E}-04$ & $1.746 \mathrm{E}-04$ & $9.40 \mathrm{E}-07$ & $1.74 \mathrm{E}-04$ & 1.66E-04 & $7.37 E-06$ \\
\hline & & & & & & & \\
\hline 2.0 & 1.0 & $7.57 \mathrm{E}-04$ & $7.188 \mathrm{E}-04$ & $3.79 E-05$ & $7.57 \mathrm{E}-04$ & $6.85 \mathrm{E}-04$ & 7.22E 05 \\
\hline 2.0 & 3.0 & $8.72 \mathrm{E}-04$ & $8.316 \mathrm{E}-04$ & $4.08 E-05$ & $8.72 E-04$ & 7.92E-04 & 8.04E-05 \\
\hline 2.0 & 5.0 & $9.26 \mathrm{E}-04$ & $8.698 \mathrm{E}-04$ & $5.58 E-05$ & $9.26 \mathrm{E}-04$ & 8.28E-04 & $9.72 E-05$ \\
\hline & & & & & & & \\
\hline 3.0 & 1.0 & 1.37E-03 & 1.287E-03 & 7.99E-05 & 1.37E-03 & 1.23E-03 & $1,41 \mathrm{E}-04$ \\
\hline 3.0 & 3.0 & $1.79 E-03$ & $1.752 \mathrm{E}-03$ & $4.16 E-05$ & $1.79 \mathrm{E}-03$ & 1.67E-03 & $1.25 \mathrm{E}-04$ \\
\hline 3.0 & 5.0 & $1.87 \mathrm{E}-03$ & $1.816 \mathrm{E}-03$ & $5.78 E-05$ & 1.87E-03 & $1.73 \mathrm{E}-03$ & $1,44 \mathrm{E}-04$ \\
\hline & & & & & & & \\
\hline 4.0 & 1.0 & $1.86 \mathrm{E}-03$ & $1.757 \mathrm{E}-03$ & 9.94E-05 & $1.86 \mathrm{E}-03$ & $1.67 \mathrm{E}-03$ & $1.83 E-04$ \\
\hline 4.0 & 3.0 & $2.79 E-03$ & $2.789 \mathrm{E}-03$ & 7.00E-07 & 2.79E-03 & $2.66 \mathrm{E}-03$ & $1.32 E-04$ \\
\hline 4.0 & 5.0 & $2.89 \mathrm{E}-03$ & $2.890 \mathrm{E}-03$ & 3.60E-06 & $2.89 \mathrm{E}-03$ & $2.75 \mathrm{E}-03$ & $1.41 \mathrm{E}-04$ \\
\hline & & & & & & & \\
\hline 5.0 & 1.0 & $2.26 \mathrm{E}-03$ & $2.141 \mathrm{E}-03$ & $121 \mathrm{E}-04$ & $2.26 \mathrm{E}-03$ & $2.04 \mathrm{E}-03$ & 2.23E-04 \\
\hline 5.0 & 3.0 & $3.80 E-03$ & $3.885 \mathrm{E}-03$ & $8.80 E-05$ & $3.80 \mathrm{E}-03$ & 3.70E-03 & 9.71E-05 \\
\hline 5.0 & 5.0 & $3.95 \mathrm{E}-03$ & $4.066 \mathrm{E}-03$ & $1,21 \mathrm{E} 04$ & $3.95 \mathrm{E}-03$ & 3.87E-03 & 7.29E-05 \\
\hline & & & & & & & \\
\hline & & & AVG Error & $422=05$ & & AVG Error & $8.45 E-05$ \\
\hline & & & SD Error & $4.38 E-05$ & & SD Error & 7.04E 05 \\
\hline
\end{tabular}


Table 4 - UnOptimized and Optimized data using Percentage Error method for 19.2x1.6 um

PMOS FET.

\begin{tabular}{|c|c|c|c|c|c|c|c|}
\hline \multicolumn{2}{|c|}{$\begin{array}{l}W= \\
19.2 \text { um \& } L= \\
1.6 \text { um }\end{array}$} & \multicolumn{3}{|c|}{$\begin{array}{l}\text { Using the optimized values of } \mathrm{Vt} \\
\quad=-0.84 \mathrm{~V} \text { and } \mathrm{M}=0.9\end{array}$} & \multicolumn{3}{|c|}{$\begin{array}{l}\text { Using the default values of } \mathrm{Vt} \\
\quad=-0.84 \mathrm{~V} \text { and } \mathrm{M}=1\end{array}$} \\
\hline $\begin{array}{l}\text { Vgs } \\
\text { (V) }\end{array}$ & $\begin{array}{l}\text { Vds } \\
\text { (V) }\end{array}$ & $\begin{array}{c}\text { Ids } \\
\text { Measured } \\
\text { with dual } \\
\text { SMUs } \\
\text { Die \#3 }\end{array}$ & $\begin{array}{c}\text { Ids } \\
\text { Simulated } \\
w / V t=- \\
0.84 V \text { and } \\
M=0.9\end{array}$ & $\begin{array}{l}\text { Error } \\
\text { Factor } \\
\text { Meas. } \\
\text { Vs } \\
\text { Sim. } \\
\text { (SMU/ } \\
\text { Sim) }\end{array}$ & $\begin{array}{c}\text { Ids } \\
\text { Measured } \\
\text { with dual } \\
\text { SMUs } \\
\text { Die \#3 }\end{array}$ & $\begin{array}{c}\text { Ids } \\
\text { Simulated } \\
w / V t=- \\
0.84 V \text { and } \\
M=1\end{array}$ & $\begin{array}{c}\text { Error } \\
\text { Factor } \\
\text { Meas. } \\
\text { Vs } \\
\text { Sim. } \\
\text { (SMU/ } \\
\text { Sim) }\end{array}$ \\
\hline & & (A) & (A) & & (A) & (A) & \\
\hline 0.0 & -1.0 & $-1.452 \mathrm{E}-11$ & $-1.53 E-12$ & 9.521 & $-1.452 \mathrm{E}-11$ & $-1.625 \mathrm{E}-12$ & 8.935 \\
\hline 0.0 & -3.0 & $-2.584 \mathrm{E}-11$ & $-4.53 E-12$ & & $-2.584 \mathrm{E}-11$ & -4.63 & 5.582 \\
\hline 0.0 & -5.0 & $-4.036 \mathrm{E}-11$ & $-8.02 E-12$ & 5.032 & $-4.036 \mathrm{E}-11$ & $-8.119 \mathrm{E}-12$ & 4.971 \\
\hline-1.0 & -1.0 & $-1.827 E-07$ & $-5.25 E-06$ & 0.035 & $-1.827 \mathrm{E}-07$ & -6.36 & 0.029 \\
\hline-1.0 & -3.0 & $-3.419 \mathrm{E}-07$ & $-2.46 \mathrm{E}-05$ & 0.014 & $-3.419 \mathrm{E}-07$ & $-2.830 \mathrm{E}-05$ & 0.012 \\
\hline-1.0 & -5.0 & $-5.529 E-07$ & $-5.36 E-05$ & 0.010 & $-5.529 \mathrm{E}-07$ & $-5.954 \mathrm{E}-05$ & 0.009 \\
\hline & & & & & & & \\
\hline-2.0 & -1.0 & $2 E-04$ & $-1.21 E-04$ & 0.92 & $-1.112 \mathrm{E}-04$ & $-1.366 \mathrm{E}-04$ & 0.81 \\
\hline-2.0 & -3.0 & $-1.406 \mathrm{E}-04$ & $-1.89 E-04$ & 0.75 & $-1.406 \mathrm{E}-04$ & $5 E-04$ & 0.66 \\
\hline-2.0 & -5.0 & $-1.600 \mathrm{E}-04$ & $-2.60 E-04$ & 0.62 & $-1.600 \mathrm{E}-04$ & $-2.884 \mathrm{E}-04$ & 0.55 \\
\hline-3.0 & -1.0 & E-04 & $-2.82 E-04$ & 1.07 & $=-04$ & $E-04$ & 0.96 \\
\hline-3.0 & -3.0 & $-4.403 E-04$ & $-4.59 \mathrm{E}-04$ & 0.96 & $-4.403 E-04$ & $-5.119 \mathrm{E}-04$ & 0.86 \\
\hline-3.0 & -5.0 & $-4.909 E-04$ & $-5.64 E-04$ & 0.87 & $-4.909 \mathrm{E}-04$ & $-6.268 E-04$ & 0.78 \\
\hline-4.0 & -1.0 & E-04 & 04 & & $-4.610 \mathrm{E}-04$ & E-04 & 1.00 \\
\hline-4.0 & -3.0 & $-7.696 \mathrm{E}-04$ & & & $-7.696 \mathrm{E}-04$ & $-8.933 \mathrm{E}-04$ & 0.86 \\
\hline-4.0 & -5.0 & $-9.000 E-04$ & $-9.38 E-04$ & 0.96 & $-9.000 \mathrm{E}-04$ & $-1.042 \mathrm{E}-03$ & 0.86 \\
\hline-5.0 & -1.0 & E-04 & $-5.24 \mathrm{E}-04$ & 1.13 & $-5.926 \mathrm{E}-04$ & $-5.823 E-04$ & 1.02 \\
\hline-5.0 & -3.0 & $-1.190 \mathrm{E}-03$ & $-1.17 \mathrm{E}-03$ & 1.02 & $-1.190 \mathrm{E}-03$ & $-1.298 \mathrm{E}-03$ & 0.92 \\
\hline-5.0 & -5.0 & $-1.353 \mathrm{E}-03$ & $-1.37 \mathrm{E}-03$ & 0.99 & $-1.353 \mathrm{E}-03$ & $-1.517 \mathrm{E}-03$ & 0.89 \\
\hline & & & AVG Error & $23.95 \%$ & & AVG Erron & $31.75 \%$ \\
\hline & & & SD Error & 0.41 & & SD Error & 0.66 \\
\hline
\end{tabular}


Table 5 - UnOptimized and Optimized data using Average Error Current method for 19.2×1.6 um PMOS FET.

\begin{tabular}{|c|c|c|c|c|c|c|c|}
\hline \multicolumn{2}{|c|}{$\begin{array}{l}W=19.2 u m \\
\& L=1.6 u m\end{array}$} & \multicolumn{3}{|c|}{$\begin{array}{c}\text { Using the optimized values of } \mathrm{Vt} \\
=-0.84 \mathrm{~V} \text { and } \mathrm{M}=0.9\end{array}$} & \multicolumn{3}{|c|}{$\begin{array}{l}\text { Using the default values of } \mathrm{Vt} \\
\quad=-0.84 \mathrm{~V} \text { and } M=1\end{array}$} \\
\hline \multirow[t]{3}{*}{$\begin{array}{l}\text { Vgs } \\
\text { (V) }\end{array}$} & \multirow[t]{3}{*}{$\begin{array}{c}\text { Vd } \\
\text { s } \\
\text { (V) }\end{array}$} & \multirow{2}{*}{$\begin{array}{c}\text { Ids } \\
\text { Measured } \\
\text { with dual } \\
\text { SMUs } \\
\text { Die \#3 }\end{array}$} & \multirow[t]{2}{*}{$\begin{array}{c}\text { Ids } \\
\text { Simulated } \\
w / V t=- \\
0.84 V \text { and } \\
M=0.9\end{array}$} & \begin{tabular}{|c|} 
Error \\
Factor \\
Meas. \\
Vs Sim. \\
(SMU- \\
Sim) \\
\end{tabular} & \multirow{2}{*}{$\begin{array}{c}\text { Ids } \\
\text { Measured } \\
\text { with dual } \\
\text { SMUs } \\
\text { Die \#3 }\end{array}$} & \multirow[t]{2}{*}{$\begin{array}{c}\text { Ids } \\
\text { Simulated } \\
w / V t=- \\
0.84 V \text { and } \\
M=1\end{array}$} & $\begin{array}{c}\text { Error } \\
\text { Factor } \\
\text { Meas. Vs } \\
\text { Sim. } \\
\text { (SMU. } \\
\text { Sim) }\end{array}$ \\
\hline & & & & & & & \\
\hline & & (A) & (A) & & (A) & (A) & \\
\hline 0.0 & -1.0 & $-1.452 \mathrm{E}-11$ & $-1.53 \mathrm{E}-12$ & 1.30E-11 & $-1.452 \mathrm{E}-11$ & $-1.625 \mathrm{E}-12$ & 1.2 \\
\hline 0.0 & -3.0 & $-2.584 \mathrm{E}-11$ & $-4.53 \mathrm{E}-12$ & $2.13 \mathrm{E}-11$ & & -4.63 & -11 \\
\hline 0.0 & -5.0 & $-4.036 \mathrm{E}-11$ & $-8.02 E-12$ & 3.2 & $-4.036 \mathrm{E}-11$ & $-8.119 \mathrm{E}-12$ & $E-11$ \\
\hline-1.0 & -1.0 & $-1.827 \mathrm{E}-07$ & $-5.25 \mathrm{E}-06$ & 5.0 & 07 & -6 & -06 \\
\hline-1.0 & -3.0 & $-3.419 \mathrm{E}-07$ & $-2.46 \mathrm{E}-05$ & 2.4 & -07 & -2.8 & 0.05 \\
\hline-1.0 & -5.0 & $-5.529 \mathrm{E}-07$ & $-5.36 \mathrm{E}-05$ & $5,30 \mathrm{E}=05$ & $-5.529 E-07$ & -5.95 & 5.9 \\
\hline-2.0 & -1.0 & E-04 & $-1.21 \mathrm{E}$ & 1.0 & & & 2 \\
\hline-2.0 & -3.0 & $-1.406 \mathrm{E}-04$ & $-1.89 \mathrm{E}-04$ & 4.8 & $=-04$ & & $=05$ \\
\hline-2.0 & -5.0 & $-1.600 \mathrm{E}-04$ & $-2.60 \mathrm{E}-04$ & $9.96 E-05$ & $-1.600 \mathrm{E}-04$ & $-2.884 E-04$ & $=04$ \\
\hline & & & & & & & \\
\hline-3.0 & -1.0 & E-04 & $-2.82 E-04$ & & & & \\
\hline-3.0 & -3.0 & $-4.403 \mathrm{E}-04$ & $-4.59 \mathrm{E}-04$ & E-05 & 04 & & -05 \\
\hline-3.0 & -5.0 & 09E-04 & $-5.64 \mathrm{E}-04$ & E-05 & 04 & -6 & $=-04$ \\
\hline & & & & & & & \\
\hline-4.0 & -1.0 & $-4.610 \mathrm{E}-04$ & $-4.16 \mathrm{E}-04$ & -05 & $\mathrm{E}-04$ & -4.6 & $=06$ \\
\hline-4.0 & -3.0 & $-7.696 \mathrm{E}-04$ & $-8.03 E-04$ & $3.35 \mathrm{E}-05$ & $-7.696 \mathrm{E}-04$ & & E-04 \\
\hline-4.0 & -5.0 & $-9.000 \mathrm{E}-04$ & $-9.38 \mathrm{E}-04$ & 3.76E-0.5 & -9.000 E-04 & $-1.042 E-03$ & $1.42 E-04$ \\
\hline & & & & & & & \\
\hline-5.0 & -1.0 & $-5.926 \mathrm{E}-04$ & $-5.24 \mathrm{E}-04$ & $6.85 E-05$ & $-5.926 \mathrm{E}-04$ & $-5.823 E-04$ & $1.03 \mathrm{E}-05$ \\
\hline-5.0 & -3.0 & $-1.190 \mathrm{E}-03$ & $-1.17 E-03$ & $2.21 \mathrm{E}-05$ & $-1.190 \mathrm{E}-03$ & $-1.298 \mathrm{E}-03$ & $1,08 E-04$ \\
\hline-5.0 & -5.0 & $-1.353 \mathrm{E}-03$ & $-1.37 \mathrm{E}-03$ & $1.22 \mathrm{E}-05$ & $-1.353 \mathrm{E}-03$ & $-1.517 \mathrm{E}-03$ & $1,64 E 04$ \\
\hline & & & AVG Error & 3.81E-05 & & & \\
\hline & & & SD Error & $2.67 \mathrm{E}-05$ & & SD Error & $5.70 \mathrm{E}-0$ \\
\hline
\end{tabular}

For the PMOS FETs, the average error percentage calculated, using the percentage error method, for the optimized model between measured and simulated results for 19.2um, 38.4um, 57.6um and 76.8um PMOS FETs was $32.03 \%$. The absolute average error percentage for the default model between measured and simulated results for the 19.2um, 38.4um, 57.6um 
and 76.8um PMOS FETs was $39.02 \%$. Using the average current error method, the absolute average error current for the optimized model between measured and simulated results for the 19.2um, 38.4um, 57.6um and 76.8um PMOS FETs was 249.0 uA. The absolute average error current for the default model between measured and simulated results for the 19.2um, 38.4um, 57.6um and 76.8um PMOS FETs obtained was 393.1 uA. The Student's paired t-Test performed on the error data from Table 5 indicated that with the $95 \%$ confidence interval, the mean difference between the two sets, optimized and default values, was $(-0.000066,-0.000003)$. Hence, it depicts with greater than $95 \%$ confidence that the error was reduced with the optimized model (difference $<0$ means error is smaller). The $99 \%$ confidence interval on this difference was $(-0.000078,0.000009)$. The "p" value for the $t-T e s t$ was 0.017 , i.e., there was only a $1.7 \%$ probability that the error was the same in both cases. Typically, the base hypothesis is rejected if the $p$ values are smaller than 0.05

The scalability between the various sizes calculated for the NMOS and PMOS FETs are as shown in the Tables 6 and 7 . The least square fit error $\left(1-R^{2}\right) \%$ for all the gate voltages was less than 1\%. The data in Table 6 shows that the measured DC data from the NMOS FETs scale well linearly The data shows less than a $2 \%$ current scaling error from the $19.2 \mathrm{um}, 38.4 \mathrm{um}$, and 76.8um FETS at $\mathrm{Vgs}=3$ and $5 \mathrm{~V}$. Operating close to $V_{t}$ increased the average scaling error to about $6 \%$. 
Table 6 - Scalability data for NMOS FETs.

\begin{tabular}{|c|c|c|c|c|c|c|c|}
\hline $\begin{array}{l}\text { Transisto } \\
\text { r Width } \\
\text { (um) }\end{array}$ & Vds & $V g s=1 \mathrm{~V}$ & \begin{tabular}{|l|} 
Error \%: \\
Meas vs. \\
Ideal \\
Calc \\
from \\
19.2 um \\
FET \\
\end{tabular} & $V g s=3 V$ & $\begin{array}{l}\text { Error \%: } \\
\text { Meas } \\
\text { vs. Ideal } \\
\text { Calc } \\
\text { from 24 } \\
\text { um FET }\end{array}$ & $V g s=5 V$ & $\begin{array}{l}\text { Error \%: } \\
\text { Meas vs. } \\
\text { Ideal } \\
\text { Calc from } \\
19.2 \text { um } \\
\text { FET }\end{array}$ \\
\hline $\mathbf{w}$ & (V) & $I_{d s}(A)$ & & $I_{d s}(A)$ & & $I_{d s}(A)$ & \\
\hline 19.2 & 1 & 1.34E-04 & $\mathrm{n} / \mathrm{a}$ & 1.37E-03 & $\mathrm{n} / \mathrm{a}$ & $2.26 \mathrm{E}-03$ & $\mathrm{n} / \mathrm{a}$ \\
\hline 19.2 & 3 & $1.56 \mathrm{E}-04$ & $\mathrm{n} / \mathrm{a}$ & $1.79 \mathrm{E}-03$ & $\mathrm{n} / \mathrm{a}$ & 3.80E-03 & $\mathrm{n} / \mathrm{a}$ \\
\hline 19.2 & 5 & 1.74E-04 & $\mathrm{n} / \mathrm{a}$ & 1.87E-03 & $\mathrm{n} / \mathrm{a}$ & $3.95 \mathrm{E}-03$ & $\mathrm{n} / \mathrm{a}$ \\
\hline 38.4 & 1 & 2.82E-04 & $4.70 \%$ & $2.78 \mathrm{E}-03$ & $1.51 \%$ & 4.54E-03 & $0.35 \%$ \\
\hline 38.4 & 3 & 3.31E-04 & $5.46 \%$ & $3.65 \mathrm{E}-03$ & $1.79 \%$ & 7.67E-03 & $0.96 \%$ \\
\hline 38.4 & 5 & 3.69E-04 & $5.96 \%$ & 3.81E-03 & $1.72 \%$ & 7.96E-03 & $0.83 \%$ \\
\hline 76.8 & 1 & $5.69 \mathrm{E}-04$ & $5.53 \%$ & $5.44 \mathrm{E}-03$ & $0.56 \%$ & 8.76E-03 & $3.32 \%$ \\
\hline 76.8 & 3 & $6.66 \mathrm{E}-04$ & $6.17 \%$ & 7.22E-03 & $0.60 \%$ & 1.51E-02 & $0.65 \%$ \\
\hline 76.8 & 5 & 7.43E-04 & $6.55 \%$ & 7.52E-03 & $0.37 \%$ & 1.56E-02 & $1.00 \%$ \\
\hline \multicolumn{3}{|c|}{$\begin{array}{c}\text { Average scaling error } \\
\text { calculated from Meas. } 19.2 \\
\mu \mathrm{m} \text { FET }\end{array}$} & $5.73 \%$ & & $1.09 \%$ & & $1.19 \%$ \\
\hline
\end{tabular}

Transistor Width v/s Current (Ids) - (Vgs $=1 \mathrm{~V}, \mathrm{Vds}=1 \mathrm{~V})$

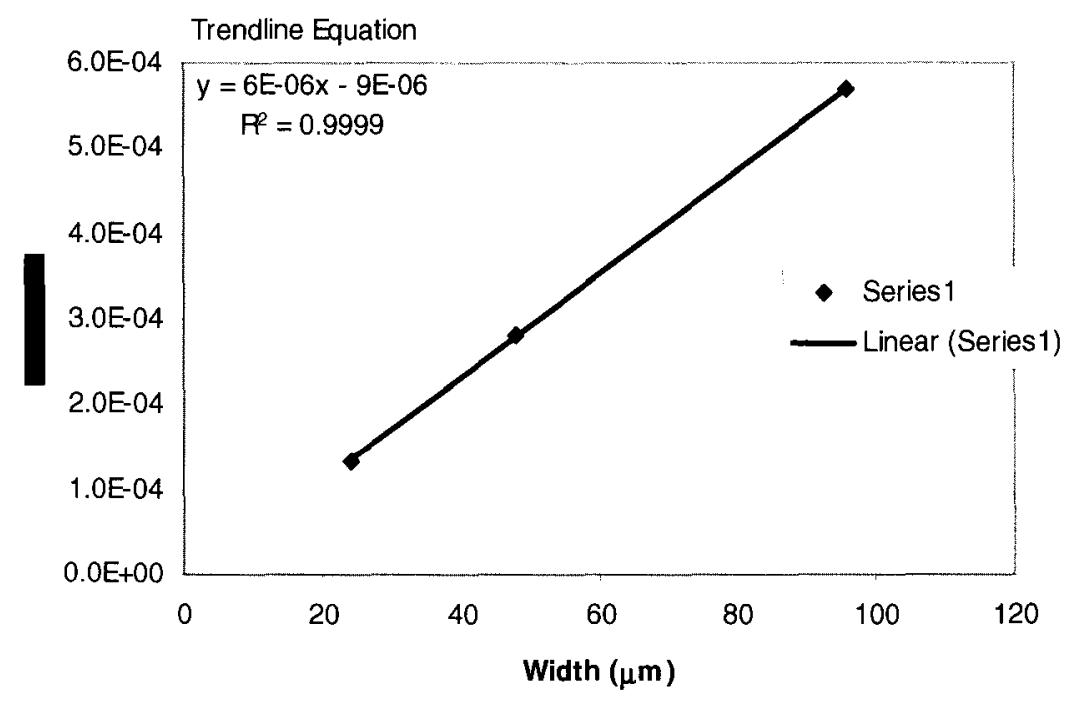

Figure (19) Least square (LSQ) plot for NMOS FETs at $V g s=1 \mathrm{~V}$ and $\mathrm{Vds}=3 \mathrm{~V}$ 
Table 7 - Scalability Data for PMOS FETs.

\begin{tabular}{|c|c|c|c|c|c|c|c|}
\hline $\begin{array}{l}\text { Transistor } \\
\text { Width (um) }\end{array}$ & Vds & Vgs $=-1 V$ & $\begin{array}{c}\text { Error \%: } \\
\text { Meas vs. } \\
\text { Ideal Calc } \\
\text { from } 19.2 \\
\text { um FET }\end{array}$ & $V g s=-3 V$ & $\begin{array}{c}\text { Error \%: } \\
\text { Meas vs. } \\
\text { Ideal Calc } \\
\text { from } 19.2 \\
\text { um FET }\end{array}$ & $V g s=-5 V$ & $\begin{array}{c}\text { Error \%: } \\
\text { Meas vs. } \\
\text { Ideal Calc } \\
\text { from } 24 \\
\text { um FET }\end{array}$ \\
\hline w & (V) & $I_{d s}(A)$ & & $I_{d s}(A)$ & & $\mathrm{I}_{\mathrm{ds}}(\mathrm{A})$ & \\
\hline & & & & & & & \\
\hline 19.2 & -1 & $-1.83 \mathrm{E}-07$ & $n / a$ & $-3.03 E-04$ & $n / a$ & $-5.93 E-04$ & n/a \\
\hline 19.2 & -3 & $-3.42 \mathrm{E}-07$ & $n / a$ & $-4.40 \mathrm{E}-04$ & $n / a$ & $-1.19 \mathrm{E}-03$ & $n / a$ \\
\hline 19.2 & -5 & $-5.53 \mathrm{E}-07$ & n/a & $-4.91 E-04$ & $n / a$ & $-1.35 \mathrm{E}-03$ & $n / a$ \\
\hline 38.4 & -1 & $-4.81 \mathrm{E}-07$ & $24.07 \%$ & $-5.84 \mathrm{E}-04$ & $3.85 \%$ & $-1.12 E-03$ & $5.62 \%$ \\
\hline 38.4 & -3 & $-9.24 \mathrm{E}-07$ & $26.03 \%$ & $-8.57 \mathrm{E}-04$ & $2.71 \%$ & $-2.28 \mathrm{E}-03$ & $4.30 \%$ \\
\hline 38.4 & -5 & $-1.50 \mathrm{E}-06$ & $26.25 \%$ & $-9.61 \mathrm{E}-04$ & $2.20 \%$ & $-2.62 E-03$ & $3.27 \%$ \\
\hline 76.8 & -1 & $-6.93 \mathrm{E}-07$ & $5.47 \%$ & $-1.15 \mathrm{E}-03$ & $5.67 \%$ & $-2.11 \mathrm{E}-03$ & $12.50 \%$ \\
\hline 76.8 & -3 & $-1.33 \mathrm{E}-06$ & $2.61 \%$ & $-1.69 \mathrm{E}-03$ & $4.39 \%$ & $-4.52 \mathrm{E}-03$ & $5.44 \%$ \\
\hline 76.8 & -5 & $-2.19 \mathrm{E}-06$ & $1.18 \%$ & $-1.89 \mathrm{E}-03$ & $4.15 \%$ & $-5.15 \mathrm{E}-03$ & $5.04 \%$ \\
\hline $\begin{array}{l}\text { Average s } \\
\text { calculated } \\
\text { Im FET }\end{array}$ & & - & $14.27 \%$ & & $3.83 \%$ & & $6.03 \%$ \\
\hline
\end{tabular}

Transistor Width v/s Current (Ids) - (Vgs $=-1 \mathrm{~V}, \mathrm{Vds}=-3 \mathrm{~V})$

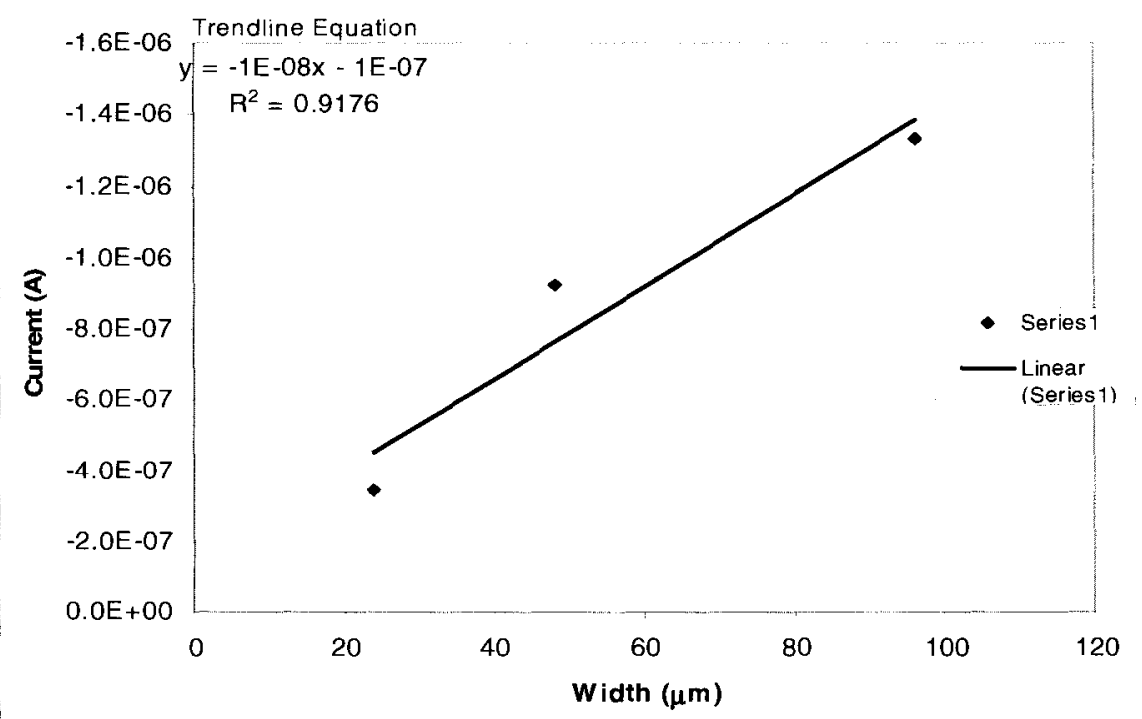

Figure (20) Least square (LSQ) plot for PMOS FETs at $V g s=-1 \mathrm{~V}$ and $\mathrm{Vds}=-3 \mathrm{~V}$ 
The cell highlighted in Table 7 is an outlier. The Least Square Fit Error (1-R^2) \% for Vgs $=-3$ and $-5 \mathrm{~V}$ is $<1 \%$ and that for $\mathrm{Vgs}=-1 \mathrm{~V}$ is $8 \%$. From this data it is observed that the measured DC data from the PMOS FETs scale well linearly. The data outputted less than a $5 \%$ current scaling error from the 19.2um, 38.4um, and 76.8um FETS at Vgs $=-3$ and $-5 \mathrm{~V}$. Operating close to Vt increased the average scaling error to about $15 \%$.

The repeatability tests were performed on 3 different FET sizes, namely, the 19.2um, 38.4um, and 76.8um of the FETs. Tables 8-9 show the repeatability test performed on the 19.2x1.6um NMOS and PMOS FETs, respectively. The average error calculations evaluated for NMOS FETs shows that the data for all the FETs were repeatable with an error $<0.5 \%$. Operating close to $V_{t}$, however, results in a large error and hence, the data obtained at $V g s=0 V$ was omitted. The above average error calculations evaluated for the PMOS FETs shows that the data for all the FETs were repeatable with an error $1 \%$. Operating close to $V_{t}$, however, resulted in a large error and hence, the data obtained at $\mathrm{Vgs}=-1 \mathrm{~V}$ was omitted. 
Table 8 - Repeatability Data for $19.2 \times 1.6$ um NMOS FET.

\begin{tabular}{|c|c|c|c|c|c|c|c|}
\hline \multicolumn{6}{|c|}{$W=19.2 u m \quad \& L=1.6 u m$} & \multirow{2}{*}{$\begin{array}{c}\text { Worst } \\
\text { case } \\
\text { Variation } \\
\text { (A) }\end{array}$} & \multirow{2}{*}{$\begin{array}{c}\% \text { Worst } \\
\text { case } \\
\begin{array}{c}\text { Variation I } \\
\text { Avg I }\end{array}\end{array}$} \\
\hline & & $6 / 17 / 2004$ & $6 / 17 / 2004$ & $6 / 18 / 2004$ & $6 / 18 / 2004$ & & \\
\hline & & Day 1 & Day 1 & Day 2 & Day 2 & & \\
\hline \multirow[t]{3}{*}{$\begin{array}{l}\text { Vgs } \\
\text { (V) }\end{array}$} & $\begin{array}{l}\text { Vds } \\
\text { (V) }\end{array}$ & Test 1 & Test 2 & Test 1 & Test 2 & & \\
\hline & & Die \#3 & Die \#3 & Die \#3 & Die \#3 & & \\
\hline & & (A) & (A) & (A) & (A) & & \\
\hline 0 & 10 & & & & & & \\
\hline 0 & 3.0 & $1.148 \mathrm{E}-04$ & $1.150 \mathrm{E}-04$ & $1.145 \mathrm{E}-04$ & $1.176 \mathrm{E}-04$ & 3.06E-06 & 2.650 \\
\hline 0 & 5.0 & $1.331 \mathrm{E}-04$ & $1.333 \mathrm{E}-04$ & $1.331 \mathrm{E}-04$ & $1.363 \mathrm{E}-04$ & $3.24 \mathrm{E}-06$ & 2.419 \\
\hline & & & & & & & \\
\hline 1.0 & 1.0 & $5.498 \mathrm{E}-04$ & $5.498 \mathrm{E}-04$ & -04 & 04 & $4.20 \mathrm{E}-06$ & 0.762 \\
\hline 1.0 & 3.0 & $6.884 \mathrm{E}-04$ & $6.879 \mathrm{E}-04$ & $6.902 \mathrm{E}-04$ & 04 & $5.34 \mathrm{E}-06$ & 0.774 \\
\hline 1.0 & 5.0 & $7.505 \mathrm{E}-04$ & $7.502 \mathrm{E}-04$ & $7.523 \mathrm{E}-04$ & $7.559 \mathrm{E}-04$ & $5.72 \mathrm{E}-06$ & 0.760 \\
\hline & & & & & & & \\
\hline 2.0 & 1.0 & $1.123 \mathrm{E}-03$ & $1.122 \mathrm{E}-03$ & $1.127 \mathrm{E}-03$ & $1.128 \mathrm{E}-03$ & $5.80 \mathrm{E}-06$ & $0.516 \%$ \\
\hline 2.0 & 3.0 & $1.557 \mathrm{E}-03$ & $=-03$ & -03 & & 7.60 & 487 \\
\hline 2.0 & 5.0 & $1.662 \mathrm{E}-03$ & $1.661 \mathrm{E}-03$ & $1.665 \mathrm{E}-03$ & -03 & $7.20 \mathrm{E}-06$ & 0.433 \\
\hline & & & & & & & \\
\hline 3.0 & 1.0 & $1.597 \mathrm{E}-03$ & 995E-03 & $1.601 \mathrm{E}-03$ & -03 & $6.20 \mathrm{E}-06$ & 0.388 \\
\hline 3.0 & 3.0 & $2.511 \mathrm{E}-03$ & $2.510 \mathrm{E}-03$ & $2.518 \mathrm{E}-03$ & $2.520 \mathrm{E}-03$ & $1.00 \mathrm{E}-05$ & 0.398 \\
\hline 3.0 & 5.0 & $2.656 \mathrm{E}-03$ & $2.656 \mathrm{E}-03$ & $2.664 \mathrm{E}-03$ & $2.665 \mathrm{E}-03$ & $9.20 \mathrm{E}-06$ & 0.346 \\
\hline & & & & & & & \\
\hline 4.0 & 1.0 & $1.994 \mathrm{E}-03$ & $4 \mathrm{E}-03$ & $E-03$ & -03 & $5.60 \mathrm{E}-06$ & 0.281 \\
\hline 4.0 & 3.0 & $3.474 \mathrm{E}-03$ & $3.473 \mathrm{E}-03$ & $3.483 \mathrm{E}-03$ & .03 & $1.02 \mathrm{E}-05$ & 0.293 \\
\hline 4.0 & 5.0 & $3.681 \mathrm{E}-03$ & $3.681 \mathrm{E}-03$ & $3.688 \mathrm{E}-03$ & $3.690 \mathrm{E}-03$ & $9.40 \mathrm{E}-06$ & 0.255 \\
\hline & & & & & & & \\
\hline 5.0 & 1.0 & 2.337E-03 & $2.335 \mathrm{E}-03$ & $2.342 E-03$ & $2.342 \mathrm{E}-03$ & 7.00E-06 & 0.299 \\
\hline 5.0 & 3.0 & 4.394E-03 & $4.394 \mathrm{E}-03$ & $=-03$ & & $1.12 \mathrm{E}-05$ & 0.25 \\
\hline 5.0 & 5.0 & $4.711 \mathrm{E}-03$ & $4.710 \mathrm{E}-03$ & $4.720 \mathrm{E}-03$ & $4.721 \mathrm{E}-03$ & $1.14 \mathrm{E}-05$ & 0.242 \\
\hline & & & & & & & \\
\hline & & & & & & Avg error & 0.43 \\
\hline
\end{tabular}


Table 9 - Repeatability Data for $19.2 \times 1.6$ um PMOS FET.

\begin{tabular}{|c|c|c|c|c|c|c|c|}
\hline \multicolumn{6}{|c|}{$W=19.2 u m \& L=1.6$ um } & \multirow{2}{*}{$\begin{array}{c}\begin{array}{c}\text { Worst } \\
\text { case }\end{array} \\
\begin{array}{c}\text { Variation } \\
\text { (A) }\end{array} \\
\end{array}$} & \multirow{2}{*}{\begin{tabular}{|c|}
$\begin{array}{c}\% \text { Worst } \\
\text { case }\end{array}$ \\
$\begin{array}{c}\text { Variation / } \\
\text { Avg I }\end{array}$ \\
\end{tabular}} \\
\hline & & $6 / 17 / 2004$ & $6 / 17 / 2004$ & $6 / 18 / 2004$ & $6 / 18 / 2004$ & & \\
\hline & & Day 1 & Day 1 & Day 2 & Day 2 & & \\
\hline $\operatorname{Vgs}(V)$ & Vds (V) & Test 1 & Test 2 & Test 1 & Test 2 & & \\
\hline & & Die \#3 & Die \#3 & Die \#3 & Die \#3 & & \\
\hline & & (A) & (A) & (A) & (A) & & \\
\hline & & & & & & & \\
\hline 0.0 & -1.0 & $-1.978 \mathrm{E}-11$ & $-4.814 \mathrm{E}-11$ & $-3.430 \mathrm{E}-11$ & $-2.814 \mathrm{E}-11$ & $2.836 \mathrm{E}-11$ & $-87.021 \%$ \\
\hline 0.0 & -3.0 & $5.780 \mathrm{E}-12$ & $-4.108 \mathrm{E}-11$ & $-4.034 \mathrm{E}-11$ & $-2.446 \mathrm{E}-11$ & 4.686E-11 & $-187.253 \%$ \\
\hline 0.0 & -5.0 & $-2.680 \mathrm{E}-11$ & $-4.912 \mathrm{E}-11$ & $-2.148 \mathrm{E}-11$ & $-3.856 \mathrm{E}-11$ & $2.764 \mathrm{E}-11$ & $-81.318 \%$ \\
\hline-1.0 & -1.0 & $-1.914 \mathrm{E}-07$ & $-1.911 \mathrm{E}-07$ & $-1.879 \mathrm{E}-07$ & $-1.880 \mathrm{E}-07$ & $3.44 \mathrm{E}-09$ & $-1.814 \%$ \\
\hline-1.0 & -3.0 & $-3.618 \mathrm{E}-07$ & $-3.605 \mathrm{E}-07$ & $-3.540 \mathrm{E}-07$ & $-3.555 \mathrm{E}-07$ & $7.86 \mathrm{E}-09$ & $2.196 \%$ \\
\hline-1.0 & -5.0 & \begin{tabular}{|l|}
$-5.932 E-07$ \\
\end{tabular} & $-5.924 \mathrm{E}-07$ & $-5.829 \mathrm{E}-07$ & $-5.843 \mathrm{E}-07$ & $1.032 \mathrm{E}-08$ & $-1.754 \%$ \\
\hline-2.0 & -1.0 & $\mid-1.113 \mathrm{E}-04$ & $-1.113 \mathrm{E}-04$ & $-1.114 \mathrm{E}-04$ & $-1.113 \mathrm{E}-04$ & $1.2 \mathrm{E}-07$ & $0.108 \%$ \\
\hline-2.0 & -3.0 & $-1.408 \mathrm{E}-04$ & $-1.408 \mathrm{E}-04$ & $-1.408 \mathrm{E}-04$ & $-1.408 \mathrm{E}-04$ & $6 \mathrm{E}-08$ & $0.043 \%$ \\
\hline-2.0 & -5.0 & $-1.604 \mathrm{E}-04$ & $-1.605 E-04$ & $-1.607 \mathrm{E}-04$ & $-1.605 \mathrm{E}-04$ & $3.2 \mathrm{E}-07$ & $0.199 \%$ \\
\hline-3.0 & -1.0 & $-3.031 E-04$ & $-3.031 \mathrm{E}-04$ & $-3.037 \mathrm{E}-04$ & $-3.038 E-04$ & $7.8 \mathrm{E}-07$ & $-0.257 \%$ \\
\hline-3.0 & -3.0 & $-4.411 \mathrm{E}-04$ & $-4.411 \mathrm{E}-04$ & $-4.416 \mathrm{E}-04$ & $-4.414 \mathrm{E}-04$ & $5.2 \mathrm{E}-07$ & $-0.118 \%$ \\
\hline-3.0 & -5.0 & $-4.922 E-04$ & $-4.922 \mathrm{E}-04$ & $-4.929 \mathrm{E}-04$ & $-4.928 \mathrm{E}-04$ & $7 \mathrm{E}-07$ & $0.142 \%$ \\
\hline & & & & & & & \\
\hline-4.0 & -1.0 & $-4.606 \mathrm{E}-04$ & $-4.610 \mathrm{E}-04$ & $-4.619 \mathrm{E}-04$ & $-4.617 \mathrm{E}-04$ & $1.24 \mathrm{E}-06$ & $-0.269 \%$ \\
\hline-4.0 & -3.0 & $-8.083 \mathrm{E}-04$ & $-8.079 \mathrm{E}-04$ & $-8.098 \mathrm{E}-04$ & $-8.094 \mathrm{E}-04$ & $1.9 \mathrm{E}-06$ & $0.235 \%$ \\
\hline-4.0 & -5.0 & $-9.017 \mathrm{E}-04$ & $-9.018 \mathrm{E}-04$ & $-9.036 \mathrm{E}-04$ & $-9.033 \mathrm{E}-04$ & $1.9 \mathrm{E}-06$ & $0.211 \%$ \\
\hline-5.0 & -1.0 & \begin{tabular}{|c|}
$-5.924 E-04$ \\
\end{tabular} & $-5.920 \mathrm{E}-04$ & $-5.932 \mathrm{E}-04$ & $-5.929 \mathrm{E}-04$ & $1.16 \mathrm{E}-06$ & $0.196 \%$ \\
\hline-5.0 & -3.0 & $-1.191 \mathrm{E}-03$ & $-1.191 \mathrm{E}-03$ & $-1.193 \mathrm{E}-03$ & $-1.193 \mathrm{E}-03$ & $2.6 \mathrm{E}-06$ & $0.218 \%$ \\
\hline-5.0 & -5.0 & $-1.355 \mathrm{E}-03$ & $-1.354 \mathrm{E}-03$ & $-1.357 \mathrm{E}-03$ & $\begin{array}{l}-1.355 \mathrm{E}-03 \\
\end{array}$ & $2.6 \mathrm{E}-06$ & $-0,192 \%$ \\
\hline & & & & & & Avg error & $-0.530 \%$ \\
\hline
\end{tabular}

The results of the modeling parameters, for the PMOS FETs on the 2-18-03-mask set, are tabulated in [Appendix D]. From the above tabular data, observations indicated that the transistors simulated with the default multiplicity factor resulted in very different results from that of the fabricated cells and by changing the multiplicity factor in the simulation and the DSUB parameter for the PMOS FET in the model file, results were closer to that of the measurements. It was also observed that the transistors of larger channel width resulted in better results compared 
to the smaller transistor size. The modified multiplicity factor for NMOS was $M=1.05$ and $M=0.9$ for PMOS for the 9-15-03-mask model. With these $M$ values, the average error in the voltages seen was the lowest and the best results were observed. It is also noticed that the change in the Dsub value, from the default of 0.2873 to 0.4373 , for the PMOS FET resulted in I-V curves giving a better fit at the lower Vgs values, i.e., from 0-3V. The Dsub for the NMOS FETs was set to 1. This value was not changed for the modeling because the accuracy didn't improve. However, the specific effect of the Dsub parameter could not be isolated because a change in Dsub changes a number of subsequent variables resulting in a "chain reaction."

The Current error calculation indicated that for the optimized model, the average current error between the 19.2um, 38.4um, 57.6um and 76.8um PMOS FET was 126.1 uA compared to the 327.6 uA obtained for the unoptimized model. For the NMOS FETs, the average current error between the 19.2um, 38.4um, and 57.6um was $137.4 \mathrm{uA}$ with the optimized model as compared to the $154.8 \mathrm{uA}$ with the unoptimized or default model. The $76.8 \mathrm{um}$ FET for the NMOS was not considered because the optimized model didn't improve the error over the unoptimized model

The I-V characteristic plots for the NMOS and PMOS FETs for the optimized and unoptimized values are shown in figures (21) and (22). As can be seen the NMOS and PMOS FETs optimized values more closely matches the values measured for all four FET sizes. Also, figures (23) and (24) show the entire standard cell library in the schematic and layout form respectively, used for the FET testing. The chained lines in the figures (21) and (22) indicate the simulated data and the solid line indicate the measured data. 

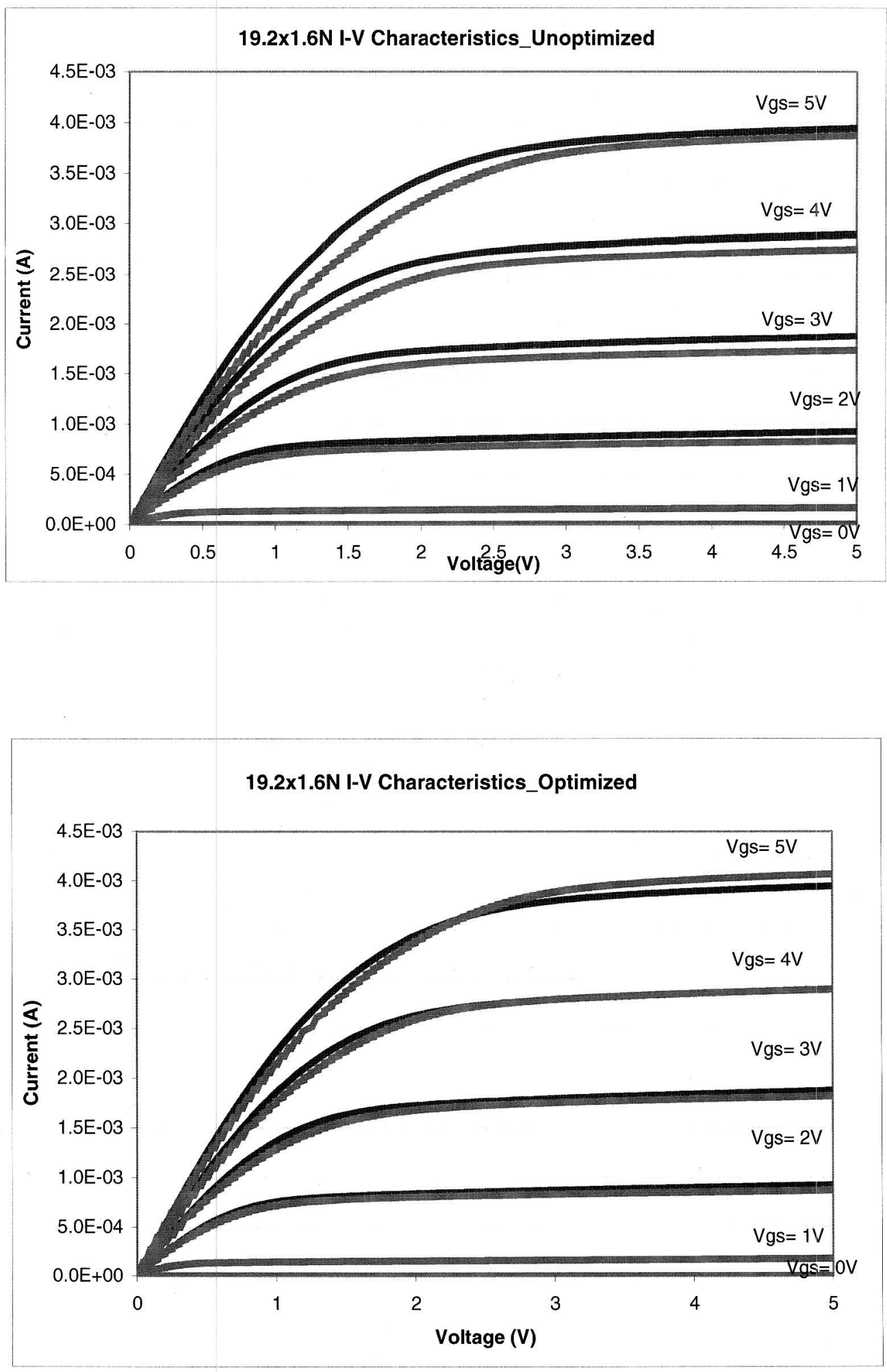

Figure (21) Measured v/s Unoptimized simulated plot and measured v/s optimized simulated plot of $19.2 \times 02$ um NMOS FET. 

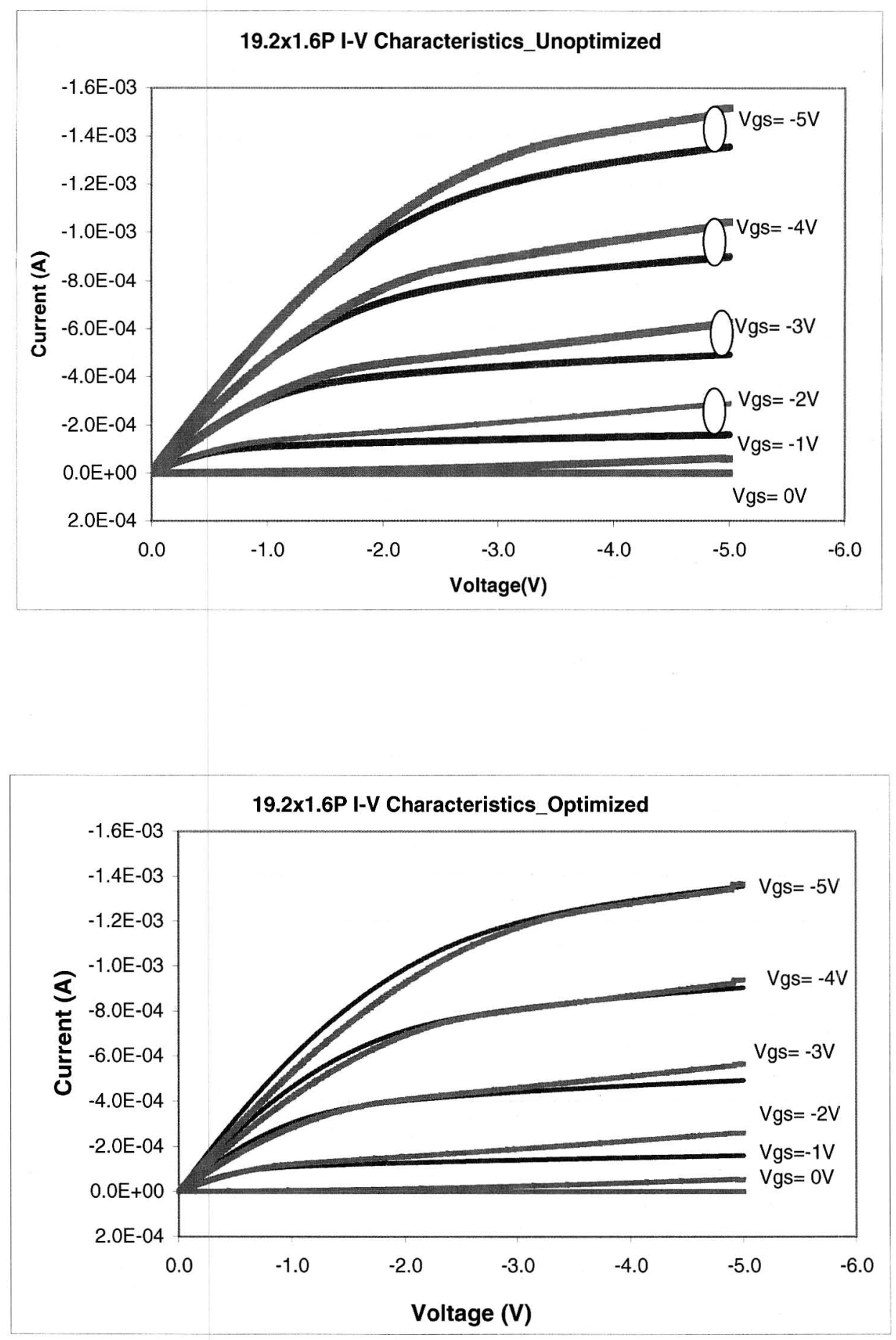

Figure (22) Measured v/s Unoptimized simulated plot and measured v/s optimized simulated plot of 19.2x1.6um PMOS FET. 


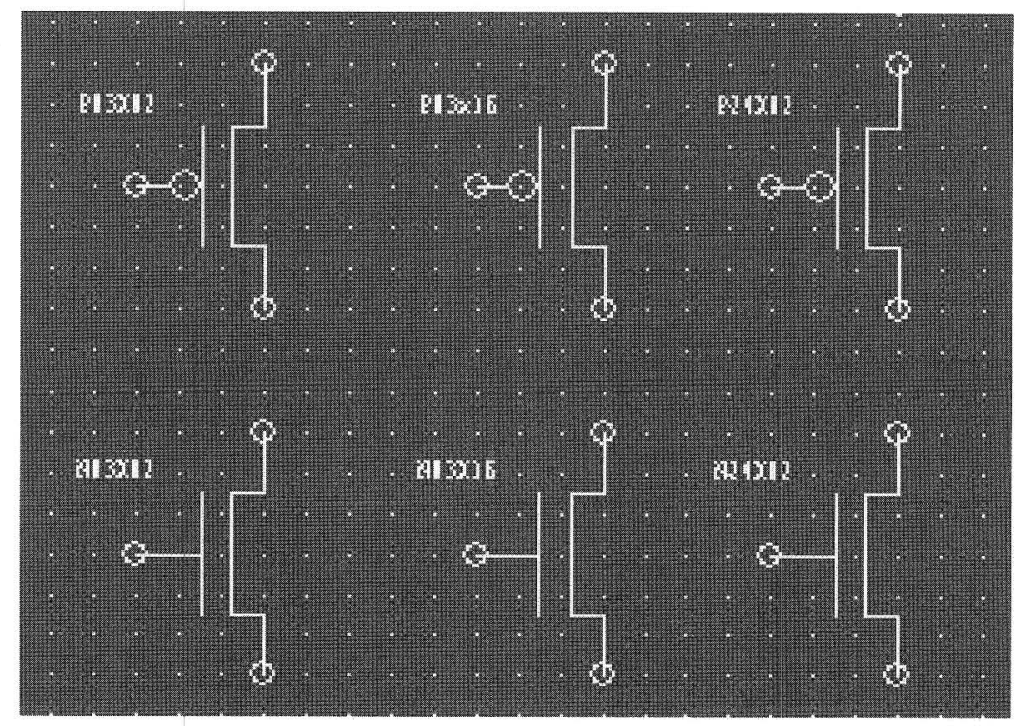

Figure (23) Schematics for the FETs
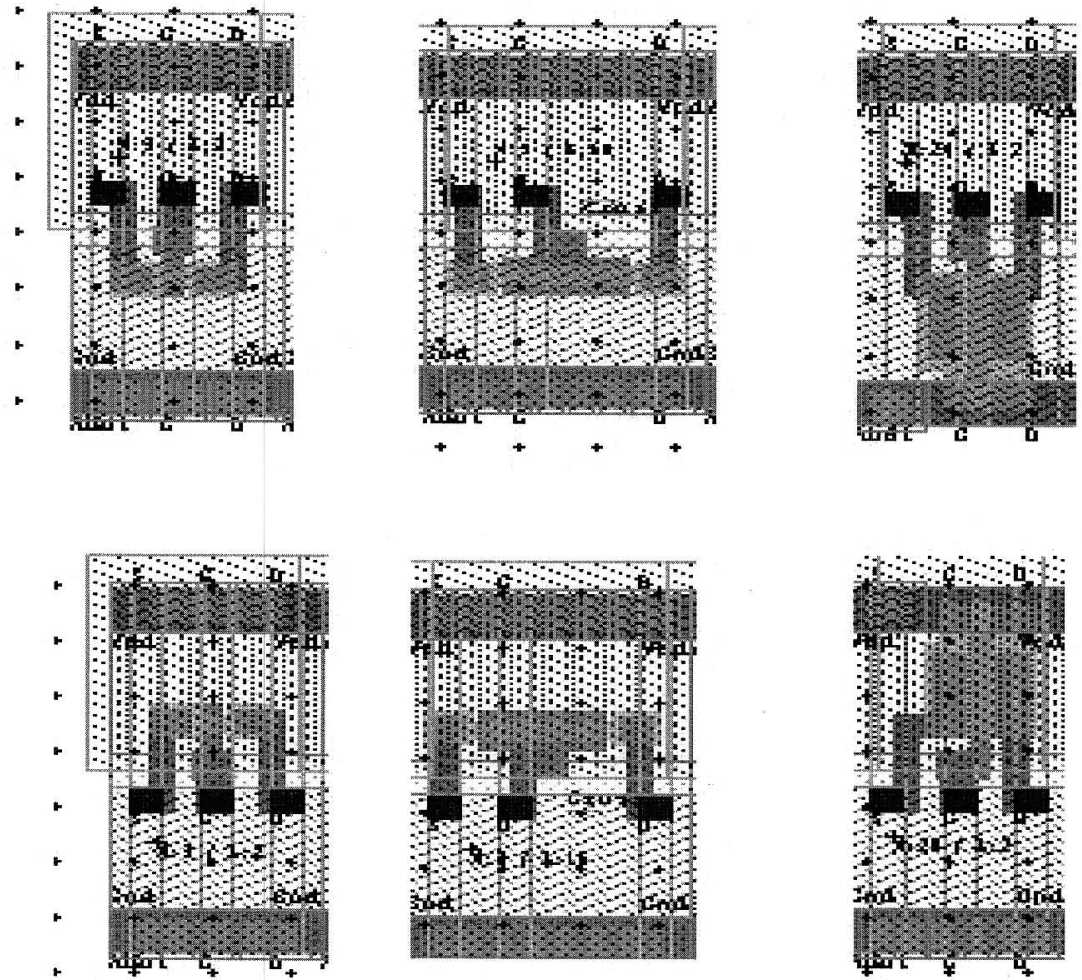

Figure (24) Layout for the FETs. 


\subsection{Poly Resistors}

The measured resistance was compared with that obtained from the calculations. The calculations used for the resistance measurements were discussed in Chapter 2. From the calculations, it was noticed that the resistor designed at UofL was more accurate than the one designed by Tanner Research Inc. The error calculations were obtained without considering the contact resistance since, this data was unavailable from MOSIS. The Error relationship between the measured and calculated resistances is shown in Figure (25).

Table 10 - Resistor Calculations.

\begin{tabular}{|c|c|c|c|c|c|c|c|c|c|c|c|c|}
\hline \multicolumn{4}{|c|}{ Resistor Values (KOhms) } & & & & \multicolumn{4}{|c|}{ Error Calculation } & \multirow{3}{*}{$\begin{array}{l}\text { Avg } \\
\text { Error }\end{array}$} & \multirow[b]{2}{*}{$\begin{array}{c}S D \\
\text { Error }\end{array}$} \\
\hline \multicolumn{4}{|c|}{ Measured Data } & $\begin{array}{l}\text { Avg } \\
\text { Resis } \\
\text { Value }\end{array}$ & $\begin{array}{c}\mathrm{SD} \\
\text { Error }\end{array}$ & $\begin{array}{l}\text { Calculated } \\
\text { Resistor } \\
\text { value }\end{array}$ & Die\#1 & Die\#2 & Die\#3 & Die\#4 & & \\
\hline Die\#1 & Die\#2 & Die\#3 & Die\#4 & & KOhm & & Abs & $(($ Act -1$)$ & meas)// & Act) & & \\
\hline 1.273 & 1.295 & 1.323 & 1.292 & 1.296 & 0.021 & 0.884 & $44.00 \%$ & $46.49 \%$ & $49.66 \%$ & 46.150 & $46.58 \%$ & $2.33 \%$ \\
\hline 13.71 & 14.03 & 14.36 & 13.96 & 14.01 & 0.268 & 12.656 & $8.32 \%$ & $10.87 \%$ & $13.46 \%$ & $10.27 \%$ & $10.73 \%$ & $2.12 \%$ \\
\hline
\end{tabular}

Calculated Resistor value

$R=R s^{*}\left(L^{*}\right.$ lambda $+0.56^{*}$ no: of corner sq. $) /\left(W^{*}\right.$ lambda $)$

Rsh $=25.9 \mathrm{ohm} / \mathrm{sq}$. (this value was obtained from the mask data)

1 corner $\mathrm{sq}=0.56 \mathrm{ohm}$

$1 \mathrm{sq}=1$ lambda, 1 lambda $=0.8 \mathrm{um}$.

1.1 Kohm resistor: $L=204.72$ lambda

$$
W=6 \text { lambda }
$$

12 Kohm resistor: $L=977.36$ lambda

$$
W=2 \text { lambda }
$$

Average Error between measured and calculated resistor values:

$1.1 \mathrm{~K}: 1.296-0.884 / 0.884=46.58 \%$ 


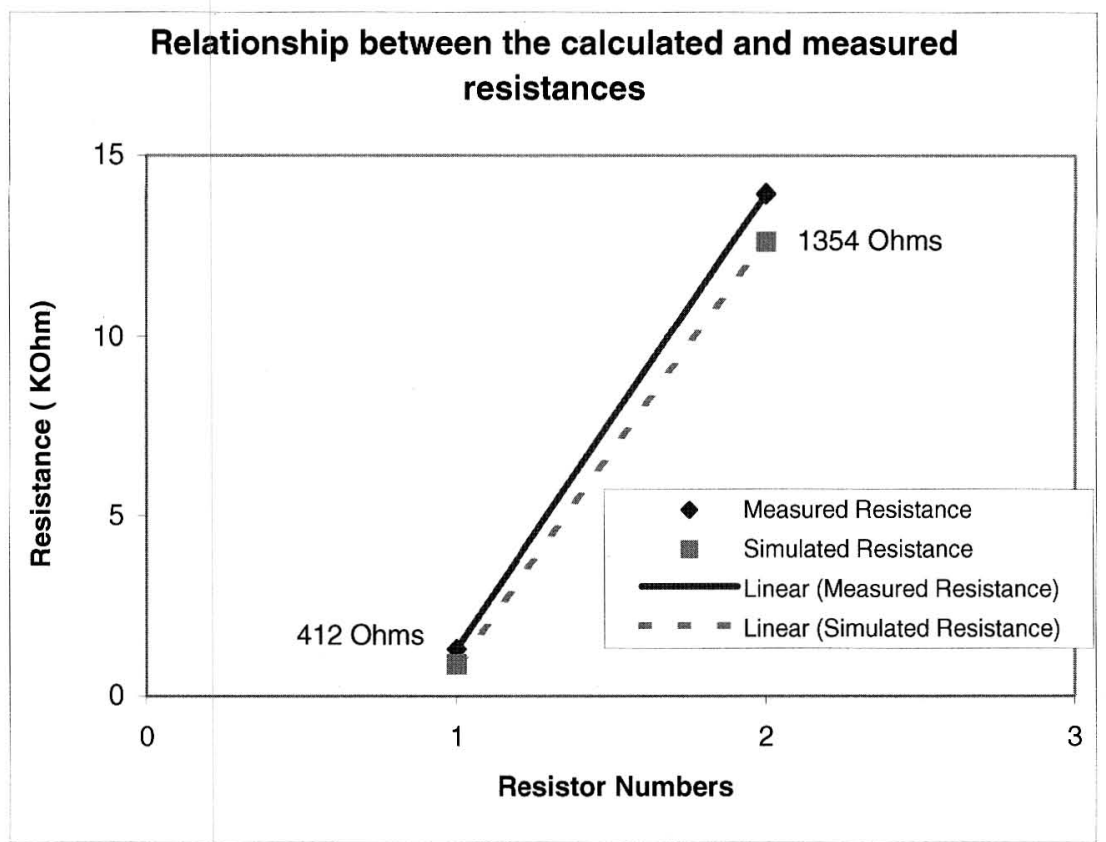

Figure (25) Relationship between the Measured and Calculated Poly-Silicon Resistors

The I-V measurements were taken for the two resistors and the plots shown in the figures below. From the plots, the I-V relationship was found to be linear from 0-20V. (Max. limit for the power supply set in the program is $20 \mathrm{~V}$.) The resistors exhibit linearity out to at least a current density of $2.3 \mathrm{~mA} / \mathrm{um}$. From Figure (25), it is seen that the measured resistance was off from the calculated resistance by $47 \%$, i.e., $\Delta R$ was 412 Ohms and by $11 \%$, i.e., $\Delta R$ was 1354 Ohms, respectively, for resistors 1 and 2, where $\Delta R$ is the error between the measured and calculated resistances. Using the $\Delta R$ values, to obtain the generalized error term between the resistances, a plot between the calculated resistances and $\Delta \mathrm{R}$ was obtained, which is indicated in Figure (26). Using the line equation, the slope and the intercept for Figure (26) was calculated to be $\mathrm{m}$ equals 0.08 and $b$ equals 341 . Hence, the final resistance calculation equation was found to be as follows:

$$
\text { Final Resistance }=\text { Calculated resistance }+ \text { Error term }
$$

where, error term $=0.08^{*}$ Calculated resistance +341 
Max. Measured current density $=14 \mathrm{~mA} / 6$ um $=2.3 \mathrm{~mA} / \mathrm{um}$ for Figure (27) and Max. Measured current density $=1.4 \mathrm{~mA} / 2 \mathrm{um}=0.7 \mathrm{~mA} / \mathrm{um}$ for Figure (28).

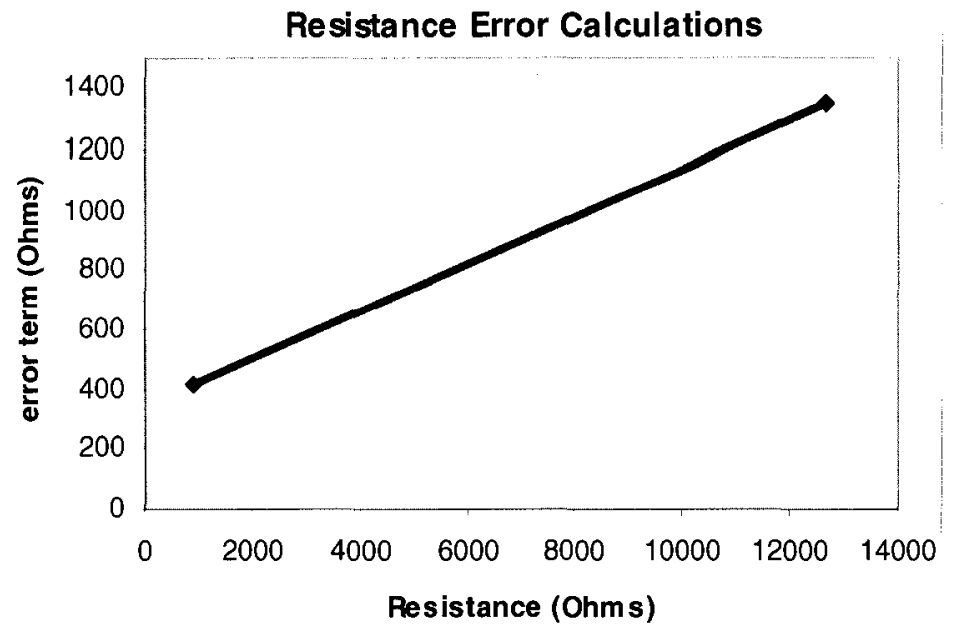

Figure (26) Resistance Error Calculation.

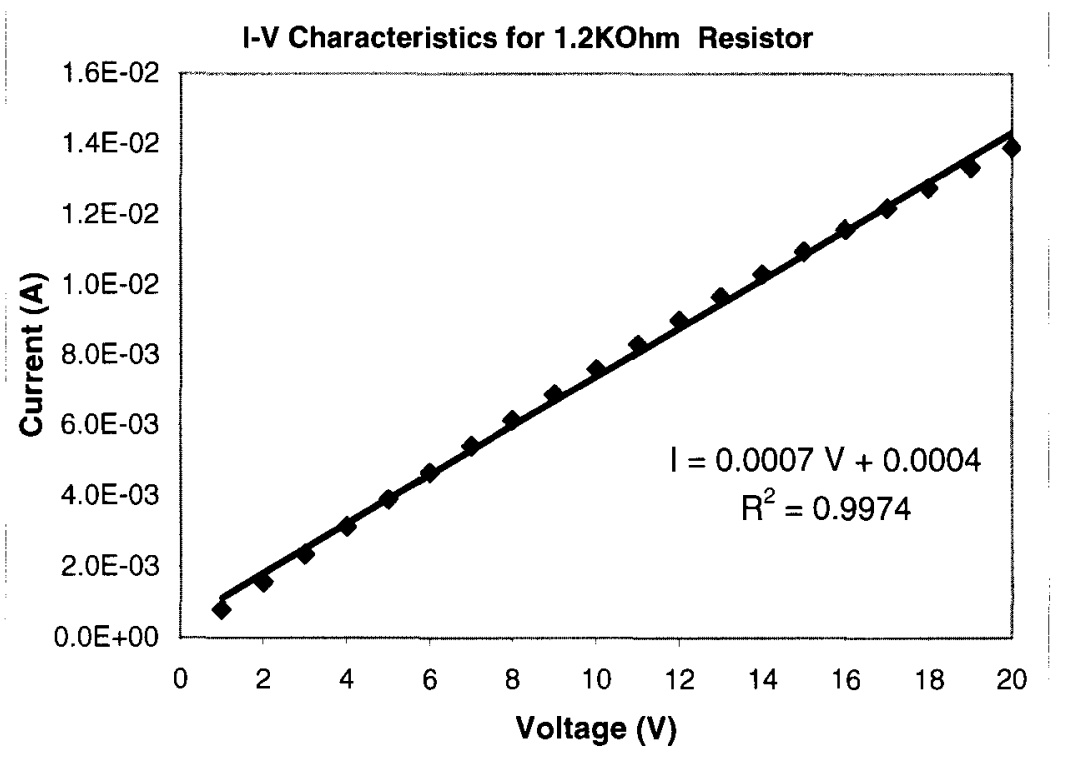

Figure (27): $1.2 \mathrm{~K}$ ohm I-V Curve. 


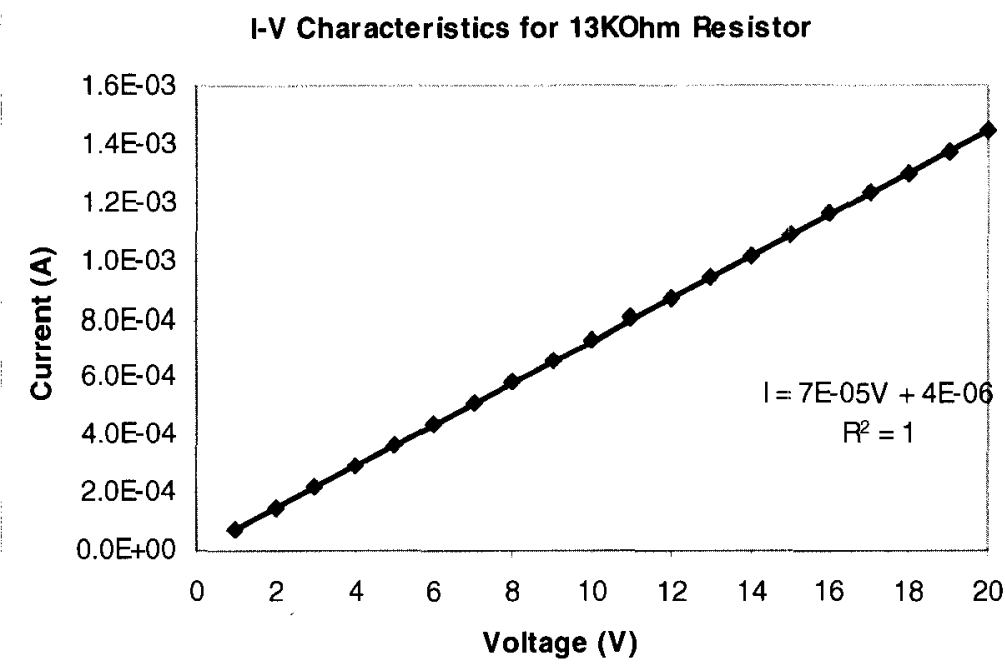

Figure (28) $13 \mathrm{~K}$ ohm I-V Curve

\subsection{Voltage Reference}

The focus of this test was to obtain a good regulation in the circuit rather than the accuracy. The regulation, calculated from $2 \mathrm{~V}-5 \mathrm{~V}$, for both the measured data as well as simulated data was $34 \mathrm{mV} / \mathrm{N}$. This was indicative enough that the voltage reference had a very good voltage regulation. The data for the 0 and $1 \mathrm{~V}$ were not considered due to the large error obtained between the measured and simulated data. The average error calculated between the measured and simulated data was about $2.17 \%$ (calculated from $2 \mathrm{~V}-5 \mathrm{~V}$ ), which is a small value. Table 11 shows the calculation of the Bias with different supply voltage values. A plot of the simulated and measured data is as shown in the specification sheet attached in [Appendix C]. 
Table 11 - Voltage Reference Characteristics

\begin{tabular}{|c|c|c|c|c|}
\hline & $\begin{array}{c}\text { Measured } \\
\text { Data }\end{array}$ & \multicolumn{2}{|c|}{ Simulated Data } & $\begin{array}{c}\text { Error } \\
\text { Calculation }\end{array}$ \\
\hline Vdd (V) & $\begin{array}{c}\text { VNBias (V) } \\
\text { Die\#3 }\end{array}$ & VNBias (V) & (Vdd) (A) & $\begin{array}{c}\text { Abs (meas- } \\
\text { sim)/sim }\end{array}$ \\
\hline & & & & \\
\hline 0 & 0.045 & 0.001 & $-1.90 \mathrm{E}-32$ & 44.000 \\
\hline 1 & 0.500 & 0.065 & $-3.11 \mathrm{E}-10$ & 6.648 \\
\hline 2 & 0.613 & 0.630 & $-3.25 \mathrm{E}-05$ & 0.027 \\
\hline 3 & 0.654 & 0.669 & $-5.23 \mathrm{E}-05$ & 0.022 \\
\hline 4 & 0.687 & 0.699 & $-7.21 \mathrm{E}-05$ & 0.018 \\
\hline 5 & 0.716 & 0.730 & $-9.42 \mathrm{E}-05$ & 0.020 \\
\hline & & & & \\
\hline & & \multicolumn{2}{|c|}{ Average Error } & $\mathbf{2 . 1 7 \%}$ \\
\hline
\end{tabular}

\subsection{Bias Generator}

The focus of this test was to obtain a relationship between the input and the outputs rather than accuracy. With the errors calculated the relationship between the outs and the inputs were determined. The errors indicate that the error was still less than $25 \%$, which meant that there was still a good agreement between the two sets of compared data. Based on the outputs obtained a correlation can be drawn between the input and the outputs, the input being the supply voltage. The correlation is as follows: OUT1 $=\mathrm{VDD} / 1.7=0.6 \mathrm{VDD}$, OUT2 $=\mathrm{VDD} / 2=0.5$ VDD, $\mathrm{OUT} 3=\mathrm{VDD} / 3.5=0.3 \mathrm{VDD}$

Table 12 - Bias Generator Characteristics

\begin{tabular}{|c|c|c|c|c|c|c|c|c|c|}
\hline & \multicolumn{3}{|c|}{ OUT1 (V) } & \multicolumn{3}{|c|}{ OUT2 (V) } & \multicolumn{3}{|c|}{ OUT3 (V) } \\
\hline $\begin{array}{l}\text { Vin/ } \\
\text { Vdd }\end{array}$ & $\begin{array}{l}\text { Meas } \\
\text { Data }\end{array}$ & $\begin{array}{l}\text { Sim } \\
\text { Data }\end{array}$ & $\begin{array}{l}\text { Error abs } \\
(\text { meas- } \\
\text { sim)/sim }\end{array}$ & $\begin{array}{l}\text { Meas } \\
\text { Data }\end{array}$ & $\begin{array}{l}\text { Sim } \\
\text { Data }\end{array}$ & \begin{tabular}{|l} 
Error abs \\
$($ meas- \\
sim)/sim
\end{tabular} & $\begin{array}{l}\text { Meas } \\
\text { Data }\end{array}$ & Sim Data & $\begin{array}{l}\text { Error abs } \\
\text { (meas- } \\
\text { sim)/sim }\end{array}$ \\
\hline (V) & Die\#1 & T32q.md & & Die\#1 & T32q.md & & Die\#1 & T32q.md & \\
\hline 2 & 0.47 & 0.63 & $26.48 \%$ & 1.02 & 1.037 & $1.96 \%$ & 0.66 & 1.33 & $50.05 \%$ \\
\hline 3 & 0.85 & 0.99 & $14.39 \%$ & 1.51 & 1.522 & $0.59 \%$ & 1.81 & 2.06 & $11.99 \%$ \\
\hline 4 & 1.15 & 1.39 & $17.64 \%$ & 1.99 & 2.002 & $0.77 \%$ & 2.35 & 2.79 & $15.58 \%$ \\
\hline 5 & 1.43 & 1.79 & $20.21 \%$ & 2.45 & 2.482 & $1.23 \%$ & 2.86 & 3.50 & $18.36 \%$ \\
\hline & & $\begin{array}{c}\text { Average } \\
\text { Error }\end{array}$ & $19.68 \%$ & & & $1.14 \%$ & & & $24.00 \%$ \\
\hline
\end{tabular}




\subsection{Current Mirror}

The tables below show the $\mathrm{N}$ as well as the $\mathrm{P}$ current mirror characteristics for the 2-1803 and 9-15-03 mask sets. Due to the large discrepancy in the error calculation at $0 \mathrm{uA}$, this value was not considered for this calculation. The error in the current value is $<2 \%$, which shows good agreement between the measured and simulated values though the error in the input voltage is around $30 \%$. The optimized multiplicity value, $M=1.05$ was used for the simulations. There is a 25.6 um long gate length NMOS FETs used to pull-down the output to ground. There is a $25.6 \mathrm{um}$ long gate length PMOS FETs used to pull-down the output to Vdd. Since there is not much information of how the model scales as a function of gate length, this FET model does not scale linearly as a function of gate length and is causing the large discrepancy between the measured and simulated data for Input voltages. In other words, in simulation more current is sourced than in actuality and as a result, this pulls the output down prematurely as the transistors turn on harder. This explanation holds for the P-current mirrors as well.

Table 13 - N-Current Mirror Characteristics for the 2-18-03 Mask-Set

\begin{tabular}{|c|c|c|c|c|c|c|}
\hline & \multicolumn{2}{|c|}{ Measured Results } & \multicolumn{2}{|c|}{ Simulated Results } & \multicolumn{2}{|c|}{ Error Calculation } \\
\hline & Die \#1 & $\begin{array}{c}R=0 \\
\text { Ohms }\end{array}$ & & & $\begin{array}{l}\text { abs((sim- } \\
\text { meas }) / \text { me } \\
\text { as) }\end{array}$ & $\begin{array}{l}\text { abs ((sim- } \\
\text { meas)/me } \\
\text { as) }\end{array}$ \\
\hline I(IN) & I(OUT) & $\mathrm{V}(\mathrm{IN})$ & (OUT) & $\mathrm{V}(\mathrm{IN})$ & I (OUT) & $\mathrm{V}(\mathrm{IN})$ \\
\hline (UA) & (A) & (V) & (A) & (V) & & \\
\hline 0 & $2.00 \mathrm{E}-09$ & 0.02 & $6.63 \mathrm{E}-12$ & 0.023 & $99.67 \%$ & 0.15 \\
\hline 50 & $5.03 E-05$ & 2.24 & 5.04E-05 & 1.738 & $0.20 \%$ & 0.22 \\
\hline 100 & 9.97E-05 & 2.957 & $1.00 \mathrm{E}-04$ & 2.259 & $0.30 \%$ & 0.24 \\
\hline 150 & $1.50 \mathrm{E}-04$ & 3.515 & 1.50E-04 & 2.663 & $0.00 \%$ & 0.24 \\
\hline 200 & $1.99 \mathrm{E}-04$ & 3.989 & 2.00 E-04 & 3.005 & $0.50 \%$ & 0.25 \\
\hline 250 & $2.47 \mathrm{E}-04$ & 4.411 & $2.50 E-04$ & 3.311 & $121 \%$ & 0.25 \\
\hline 300 & $2.91 \mathrm{E}-04$ & 4.799 & $3.00 E-04$ & 3.591 & $3.09 \%$ & 0.25 \\
\hline 350 & 3.39E-04 & 5.155 & $3.49 E-04$ & 3.852 & $295 \%$ & 0.25 \\
\hline \multirow[t]{2}{*}{400} & 3.80E-04 & 5.495 & 3.99E-04 & 4.096 & $5.00 \%$ & 0.25 \\
\hline & & & \multicolumn{2}{|c|}{ Average Error } & $1.66 \%$ & $24.47 \%$ \\
\hline
\end{tabular}


Table 14 - N-Current Mirror Characteristics for the 9-15-03 Mask-Set

\begin{tabular}{|c|c|c|c|c|c|c|}
\hline & \multicolumn{2}{|c|}{ Measured Results } & \multicolumn{2}{|c|}{ Simulated Results } & \multicolumn{2}{|c|}{ Error Calculation } \\
\hline & Die \#1 & $\begin{array}{l}R=0 \\
\text { Ohms }\end{array}$ & & & $\begin{array}{l}\text { abs }((\operatorname{sim}- \\
\text { meas }) / \text { me } \\
\text { as) }\end{array}$ & $\begin{array}{l}\text { abs }((\text { sim- } \\
\text { meas }) / \text { meas } \\
\text { ) }\end{array}$ \\
\hline $\mathrm{I}(\mathrm{IN})$ & I(OUT) & $\mathrm{V}(\mathrm{IN})$ & $\mathrm{I}(\mathrm{OUT})$ & $\mathrm{V}(\mathbf{I N})$ & I (OUT) & $\mathrm{V}(\mathrm{IN})$ \\
\hline (uA) & (A) & (V) & (A) & (V) & & \\
\hline 0 & 2.00E-09 & 0.1 & $7.27 E-12$ & 0.026 & $99.64 \%$ & 0.74 \\
\hline 50 & 5.01E-05 & 2.195 & 5.04E-05 & 1.746 & $0.60 \%$ & 0.20 \\
\hline 100 & $1.00 \mathrm{E}-04$ & 2.901 & 1.00 E-04 & 2.283 & $0.00 \%$ & 0.21 \\
\hline 150 & 1.50E-04 & 3.452 & $1.50 \mathrm{E}-04$ & 2.698 & $0.00 \%$ & 0.22 \\
\hline 200 & $2.00 E-04$ & 3.928 & $2.00 \mathrm{E}-04$ & 3.053 & $0.00 \%$ & 0.22 \\
\hline 250 & $2.50 \mathrm{E}-04$ & 4.353 & $2.50 \mathrm{E}-04$ & 3.366 & $0.00 \%$ & 0.23 \\
\hline 300 & 2.95E-04 & 4.725 & 3.00E-04 & 3.651 & $169 \%$ & 0.23 \\
\hline 350 & 3.44E-04 & 5.082 & 3.50E-04 & 3.916 & $1.74 \%$ & 0.23 \\
\hline \multirow[t]{2}{*}{400} & 3.86E-04 & 5.413 & 3.99E-04 & 4.164 & $3.37 \%$ & 0.23 \\
\hline & & & \multicolumn{2}{|c|}{ Average Error } & $0.93 \%$ & $22.16 \%$ \\
\hline
\end{tabular}

Table 15 - P-Current Mirror Characteristics for the 2-18-03 Mask-Set

\begin{tabular}{|c|c|c|c|c|c|c|}
\hline & \multicolumn{2}{|c|}{$\begin{array}{l}\text { Measured } \\
\text { Results }\end{array}$} & \multicolumn{2}{|l|}{$\begin{array}{l}\text { Simulated } \\
\text { Results } \\
\end{array}$} & \multicolumn{2}{|c|}{ Error Calculation } \\
\hline & Die \#1 & $\begin{array}{l}R=0 \\
\text { Ohms }\end{array}$ & & & $\begin{array}{l}\text { abs }((\mathrm{sim}- \\
\text { meas }) / \text { meas })\end{array}$ & $\begin{array}{l}\text { abs }((\mathrm{sim}- \\
\text { meas }) / \text { meas })\end{array}$ \\
\hline $\mathrm{I}(\mathrm{IN})$ & I(OUT) & $\mathrm{V}(\mathrm{IN})$ & I(OUT) & $\mathrm{V}(\mathrm{IN})$ & I(OUT) & $\mathrm{V}(\mathrm{IN})$ \\
\hline (uA) & (A) & (V) & (A) & (V) & & \\
\hline 0 & 2.00E-09 & 4.69 & $1.00 \mathrm{E}-11$ & 5 & $99.50 \%$ & $6.61 \%$ \\
\hline 5.00E-05 & 5.07E-05 & 2.01 & $5.03 E-05$ & 2.64 & $0.79 \%$ & $3134 \%$ \\
\hline $1.00 \mathrm{E}-04$ & $1.01 \mathrm{E}-04$ & 0.564 & $1.00 \mathrm{E}-04$ & 1.97 & $0.99 \%$ & $249.29 \%$ \\
\hline $1.50 \mathrm{E}-04$ & $1.50 \mathrm{E}-04$ & -0.581 & $1.50 \mathrm{E}-04$ & 1.45 & $0.00 \%$ & $349.57 \%$ \\
\hline $2.00 \mathrm{E}-04$ & $1.98 \mathrm{E}-04$ & -1.599 & 2.00E-04 & 1 & $1.01 \%$ & $16254 \%$ \\
\hline $2.50 \mathrm{E}-04$ & $2.41 \mathrm{E}-04$ & -2.541 & $2.50 \mathrm{E}-04$ & 0.6 & $3.73 \%$ & $123.61 \%$ \\
\hline $3.00 \mathrm{E}-04$ & 2.77E-04 & -3.381 & $3.00 \mathrm{E}-04$ & 0.23 & $8.30 \%$ & $106.80 \%$ \\
\hline $3.50 \mathrm{E}-04$ & $3.16 \mathrm{E}-04$ & -4.187 & $3.50 \mathrm{E}-04$ & -0.11 & $10.76 \%$ & $9737 \%$ \\
\hline \multirow[t]{2}{*}{ 4.00E-04 } & 3.47E-04 & -4.96 & 4.00E-04 & -0.43 & $15.27 \%$ & $91.33 \%$ \\
\hline & & & \multicolumn{2}{|c|}{ Average Error } & $15.60 \%$ & $151.48 \%$ \\
\hline
\end{tabular}


Table 16 - P-Current Mirror Characteristics for the 9-15-03 Mask-Set

\begin{tabular}{|c|c|c|c|c|c|c|}
\hline & \multicolumn{2}{|c|}{\begin{tabular}{|l|} 
Measured \\
Results \\
\end{tabular}} & \multicolumn{2}{|l|}{$\begin{array}{l}\text { Simulated } \\
\text { Results }\end{array}$} & \multicolumn{2}{|c|}{ Error Calculation } \\
\hline & Die \#3 & $\begin{array}{l}R=0 \\
\text { Ohms }\end{array}$ & & & $\begin{array}{l}\text { abs }((\text { sim- } \\
\text { meas }) / \text { me } \\
\text { as }\end{array}$ & $\begin{array}{l}\text { abs }((\text { sim- } \\
\text { meas }) / \text { me } \\
\text { as }\end{array}$ \\
\hline $\mathrm{I}(\mathrm{IN})$ & I(OUT) & $\mathrm{V}(\mathrm{IN})$ & I(OUT) & $\mathrm{V}(\mathrm{IN})$ & $\mathrm{I}(\mathrm{OUT})$ & $\mathrm{V}(\mathrm{IN})$ \\
\hline (A) & (A) & (V) & (A) & (V) & & \\
\hline 0 & 6.03E-07 & 4.671 & $1.00 \mathrm{E}-11$ & 5 & $100.00 \%$ & $6.58 \%$ \\
\hline 5.00E-05 & $5.12 \mathrm{E}-05$ & 1.815 & $5.03 E-05$ & 2.54 & $1.76 \%$ & $39.94 \%$ \\
\hline $1.00 \mathrm{E}-04$ & $1.00 \mathrm{E}-04$ & 0.375 & $1.00 \mathrm{E}-04$ & 1.82 & $0.00 \%$ & $385.33 \%$ \\
\hline $1.50 \mathrm{E}-04$ & 1.50E-04 & -0.807 & $1.50 \mathrm{E}-04$ & 1.24 & $0.00 \%$ & $253.66 \%$ \\
\hline $2.00 \mathrm{E}-04$ & $1.98 \mathrm{E}-04$ & -1.848 & $2.00 \mathrm{E}-04$ & 0.75 & $1.01 \%$ & $140.58 \%$ \\
\hline 2.50E-04 & 2.41E-04 & -2.789 & $2.50 E-04$ & 0.29 & $3.73 \%$ & $110.40 \%$ \\
\hline 3.00E-04 & 2.77E-04 & -3.663 & 3.00E-04 & -0.12 & $8.30 \%$ & $96.72 \%$ \\
\hline 3.50E-04 & 3.15E-04 & -4.466 & 3.50E-04 & -0.52 & $11.11 \%$ & 88.36\% \\
\hline 4.00E-04 & 3.46E-04 & -5.259 & 4.00E-04 & -0.92 & $15.61 \%$ & $82.51 \%$ \\
\hline & & & Averag & Error & $5.19 \%$ & $63.50 \%$ \\
\hline
\end{tabular}

\subsection{Analog Buffer}

The data for the three tests performed for the buffer are shown in the tables below. Table 17 shows the DC characteristics obtained with an infinite load. Since the Analog buffer consists of many NMOS and PMOS FETs connected together, the error obtained at the output is the compounded error at each of these individual FETs. The two highlighted values at input voltages of 0 and $0.5 \mathrm{~V}$ were omitted due to an error larger than $50 \%$. This maybe due to the body effect. The AC characteristics are as shown in the Table 18. 
Table 17 - DC Characteristics of an Analog Buffer with infinite Load Resistance

\begin{tabular}{|c|c|c|c|c|c|c|c|c|}
\hline \multirow[t]{3}{*}{$\begin{array}{l}\text { Vin } \\
\text { (V) }\end{array}$} & \multicolumn{4}{|c|}{$\begin{array}{c}\text { Vdd }=3 \mathrm{~V} \\
\text { Performed with infinite Load }\end{array}$} & \multicolumn{4}{|c|}{$\begin{array}{c}\qquad \text { Vdd }=5 \mathrm{~V} \\
\text { Performed with infinite Load }\end{array}$} \\
\hline & \multirow{2}{*}{\begin{tabular}{|l|} 
Measured \\
Data
\end{tabular}} & \multicolumn{2}{|c|}{ Simulated Data } & \multirow{2}{*}{\begin{tabular}{|c} 
Error \\
Calculation \\
Abs ((Meas- \\
Sim)/Sim) \\
\end{tabular}} & \multirow{2}{*}{\begin{tabular}{||l|} 
Measured \\
Data
\end{tabular}} & \multicolumn{2}{|c|}{ Simulated Data } & \multirow{2}{*}{\begin{tabular}{|l}
$\begin{array}{l}\text { Error } \\
\text { Calculation }\end{array}$ \\
$\begin{array}{c}\text { Abs ((Meas- } \\
\text { Sim)/Sim) }\end{array}$ \\
\end{tabular}} \\
\hline & & Vout (V) & IDD (A) & & & $\begin{array}{l}\text { Vout } \\
\text { (V) }\end{array}$ & IDD (A) & \\
\hline 0 & 0.035 & 1.10 & $-1.01 E-04$ & $96.83 \%$ & 0.129 & 2.19 & $-4.14 \mathrm{E}-04$ & $94.11 \%$ \\
\hline 0.5 & 0.542 & 1.12 & $-1.01 \mathrm{E}-04$ & $51.44 \%$ & 0.634 & 2.19 & $-4.14 \mathrm{E}-04$ & $71.11 \%$ \\
\hline 1 & 1.050 & 1.38 & $-1.13 E-04$ & $23.79 \%$ & 1.130 & 2.22 & $-4.15 \mathrm{E}-04$ & $49.00 \%$ \\
\hline 1.5 & 1.532 & 1.72 & $-1.14 \mathrm{E}-04$ & $11.10 \%$ & 1.615 & 2.55 & $-4.37 E-04$ & $36.79 \%$ \\
\hline 2 & 2.004 & 2.17 & $-1.09 E-04$ & $7.52 \%$ & 2.105 & 2.96 & $-4.50 \mathrm{E}-04$ & $28.92 \%$ \\
\hline 2.5 & 2.502 & 2.60 & $-1.09 \mathrm{E}-04$ & $3.73 \%$ & 2.580 & 3.24 & $-4.41 E-04$ & $20.34 \%$ \\
\hline 3 & 2.997 & 2.68 & $-1.09 \mathrm{E}-04$ & $12.00 \%$ & 3.060 & 3.54 & $-4.26 \mathrm{E}-04$ & $13.55 \%$ \\
\hline 3.5 & & & & & 3.520 & 3.89 & $-4.07 \mathrm{E}-04$ & $9.52 \%$ \\
\hline 4 & & & & & 3.994 & 4.25 & $-3.93 \mathrm{E}-04$ & $6.08 \%$ \\
\hline 4.5 & & & & & 4.479 & 4.39 & $-3.90 E-04$ & $2.05 \%$ \\
\hline 5 & & & & & 4.952 & 4.44 & $-3.89 \mathrm{E}-04$ & $11.59 \%$ \\
\hline & & & & & & & & \\
\hline & Average $\mathrm{E}$ & rror & & $11.63 \%$ & & & & $19.76 \%$ \\
\hline
\end{tabular}


Table 18 - AC Characteristics for a Buffer

\begin{tabular}{|c|c|c|c|c|c|}
\hline & \multirow[b]{2}{*}{\begin{tabular}{|l} 
Measured \\
Data
\end{tabular}} & & & \multicolumn{2}{|c|}{ Error Calculation } \\
\hline Vin= $1 \mathrm{~V}$ & & \multicolumn{2}{|c|}{ Simulated Data } & Dsub $=0.2873$ & Dsub $=0.4373$ \\
\hline $\begin{array}{c}\text { Frequency } \\
(\mathrm{Hz})\end{array}$ & Die \#1 & $\begin{array}{l}\text { Dsub = } \\
0.2873\end{array}$ & $\begin{array}{l}\text { Dsub }= \\
0.4373\end{array}$ & & \\
\hline 1 & $1.00 \mathrm{E}+00$ & $5.48 \mathrm{E}-01$ & 4.86E-04 & 0.452 & 1.000 \\
\hline 10 & $1.00 \mathrm{E}+00$ & $5.48 \mathrm{E}-01$ & $5.08 \mathrm{E}-04$ & 0.452 & 0.999 \\
\hline 100 & $1.00 \mathrm{E}+00$ & $5.48 \mathrm{E}-01$ & 8.56E-04 & 0.452 & 0.999 \\
\hline $1.00 \mathrm{E}+03$ & $1.00 \mathrm{E}+00$ & $5.48 \mathrm{E}-01$ & 5.44E-03 & 0.452 & 0.995 \\
\hline $1.00 \mathrm{E}+04$ & $1.00 \mathrm{E}+00$ & $5.48 \mathrm{E}-01$ & $8.27 \mathrm{E}-03$ & 0.452 & 0.992 \\
\hline $1.00 \mathrm{E}+05$ & $1.00 \mathrm{E}+00$ & $5.42 \mathrm{E}-01$ & $1.95 \mathrm{E}-03$ & 0.458 & 0.998 \\
\hline $1.00 \mathrm{E}+06$ & $1.00 \mathrm{E}+00$ & $3.17 E-01$ & $2.88 \mathrm{E}-04$ & 0.683 & 1.000 \\
\hline $2.00 E+06$ & $9.70 E-01$ & 1.83E-01 & $1.24 \mathrm{E}-04$ & 0.811 & 1.000 \\
\hline $3.00 \mathrm{E}+06$ & $9.40 \mathrm{E}-01$ & $1.25 \mathrm{E}-01$ & $7.65 \mathrm{E}-05$ & 0.867 & 1.000 \\
\hline $4.00 \mathrm{E}+06$ & 8.80E-01 & $9.61 \mathrm{E}-02$ & $5.68 \mathrm{E}-05$ & 0.891 & 1.000 \\
\hline $5.00 \mathrm{E}+06$ & $8.40 \mathrm{E}-01$ & $7.68 \mathrm{E}-02$ & $4.52 \mathrm{E}-05$ & 0.909 & 1.000 \\
\hline $6.00 \mathrm{E}+06$ & $8.40 \mathrm{E}-01$ & 6.40E-02 & $3.82 \mathrm{E}-05$ & 0.924 & 1.000 \\
\hline $7.00 \mathrm{E}+06$ & 8.10E-01 & 5.46E-02 & $3.33 \mathrm{E}-05$ & 0.933 & 1.000 \\
\hline $8.00 E+06$ & 7.50E-01 & 4.87E-02 & $2.99 \mathrm{E}-05$ & 0.935 & 1.000 \\
\hline $9.00 \mathrm{E}+06$ & $7.20 \mathrm{E}-01$ & $4.25 \mathrm{E}-02$ & $2.75 \mathrm{E}-05$ & 0.941 & 1.000 \\
\hline $1.00 \mathrm{E}+07$ & 6.90E-01 & $3.88 \mathrm{E}-02$ & $2.58 \mathrm{E}-05$ & 0.944 & 1.000 \\
\hline $1.10 \mathrm{E}+07$ & $6.90 \mathrm{E}-01$ & $3.54 \mathrm{E}-02$ & $2.44 \mathrm{E}-05$ & 0.949 & 1.000 \\
\hline $1.20 \mathrm{E}+07$ & $6.60 \mathrm{E}-01$ & $3.23 E-02$ & $2.31 \mathrm{E}-05$ & 0.951 & 1.000 \\
\hline $1.30 \mathrm{E}+07$ & 6.30E-01 & $2.94 \mathrm{E}-02$ & $2.20 \mathrm{E}-05$ & 0.953 & 1.000 \\
\hline $1.40 \mathrm{E}+07$ & 5.90E-01 & $2.75 \mathrm{E}-02$ & $2.12 \mathrm{E}-05$ & 0.953 & 1.000 \\
\hline $1.50 \mathrm{E}+07$ & $5.60 \mathrm{E}-01$ & $2.56 \mathrm{E}-02$ & $2.06 \mathrm{E}-05$ & 0.954 & 1.000 \\
\hline $1.60 \mathrm{E}+07$ & 5.00E-01 & $2.39 \mathrm{E}-02$ & $2.02 E-05$ & 0.952 & 1.000 \\
\hline $1.70 \mathrm{E}+07$ & $5.00 \mathrm{E}-01$ & $2.29 E-02$ & $1.96 \mathrm{E}-05$ & 0.954 & 1.000 \\
\hline $1.80 \mathrm{E}+07$ & $5.00 \mathrm{E}-01$ & $2.13 \mathrm{E}-02$ & 1.92E-05 & 0.957 & 1.000 \\
\hline $1.90 \mathrm{E}+07$ & 4.70E-01 & $2.04 \mathrm{E}-02$ & $1.89 \mathrm{E}-05$ & 0.957 & 1.000 \\
\hline $2.00 \mathrm{E}+07$ & $4.40 \mathrm{E}-01$ & $1.95 \mathrm{E}-02$ & $1.86 \mathrm{E}-05$ & 0.956 & 1.000 \\
\hline & & & & $52.67 \%$ & $99.78 \%$ \\
\hline
\end{tabular}

The $3 \mathrm{~dB}$ point for the measured die is approximately $9.9 \mathrm{MHz}$. The $3 \mathrm{~dB}$ point for the $02-$ 18-03 mask is at approximately 7.1 MHz. The error calculated with the default value is better than that observed for the optimized data. The error for a DC simulation is comparable to the error measured from FET I-V curves, which is $<1 \%$ for NMOS and $<25 \%$ for PMOS The agreement was reasonable (around $5 \%$ ) when the load was small, but the simulated load FETs were not sourcing enough current to keep the output high (around $5 \mathrm{~V}$ ). There is a 20 um long gate length NMOS device used to pull-down the output to ground. Since there is not much information of how 
the model scales as a function of gate length, this FET model does not scale linearly as a function of gate length and is causing the large discrepancy between the measured and simulated results. In other words, in simulation more current is sourced than in actuality and as a result, this pulls the output down prematurely as the transistors turn on harder. This explanation holds for the buffer load test as well. The output obtained from the load test is tabulated in Table 19.

Table 19 - Buffer Load Test

\begin{tabular}{|c|c|c|c|c|c|}
\hline $\begin{array}{l}\text { Resistor } \\
\text { values }\end{array}$ & Measured & \multicolumn{2}{|c|}{ Simulated } & \multicolumn{2}{c|}{ Error Calculation } \\
\hline (Ohms) & & $\begin{array}{l}\text { Dsub- } \\
\mathbf{0 . 4 3 7 3}\end{array}$ & $\begin{array}{l}\text { Dsub- } \\
\mathbf{0 . 2 8 7 3}\end{array}$ & $\begin{array}{l}\text { Dsub- } \\
\mathbf{0 . 4 3 7 3}\end{array}$ & Default \\
\hline $1.10 \mathrm{E}+06$ & 4.95 & 4.3906 & 4.3739 & $11.30 \%$ & $11.64 \%$ \\
\hline $1.00 \mathrm{E}+05$ & 4.93 & 3.9528 & 3.979 & $19.82 \%$ & $19.29 \%$ \\
\hline $1.00 \mathrm{E}+04$ & 4.62 & 1.898 & 1.911 & $58.92 \%$ & $58.64 \%$ \\
\hline $5.00 \mathrm{E}+03$ & 4.3 & 0.977 & 1.017 & $77.28 \%$ & $76.35 \%$ \\
\hline $1.00 \mathrm{E}+03$ & 2.76 & 0.199 & 0.214 & $92.78 \%$ & $92.26 \%$ \\
\hline 495 & 1.89 & 0.099 & 0.107 & $94.77 \%$ & $94.37 \%$ \\
\hline & & \multicolumn{5}{|c|}{ Average Value } & $59.15 \%$ & $58.76 \%$ \\
\hline
\end{tabular}

\subsection{Comparator}

The focus of this test was to indicate that the switching of the comparator took place at around the same points for the simulated and measured data rather than the accuracy. The comparator characteristics are shown in the Tables 20 and 21. The highlighted cells in Table 20 show the outliers, which is due to the fact that simulated data and measured data switch at different voltages. This maybe due to the early voltage effect that is part of the DIBL phenomenon, which causes the comparator to switch earlier. This effect may also be due to the biasing of the comparator. Hence, these values are excluded in the error calculations. The error calculated by changing the Dsub value for the PMOS gives a $1.74 \%$ improvement. From the table, it is noticed that when the transistors in the comparator were turned on hard, the error between the voltages were small while that around the threshold value shows a large difference. The value obtained for the simulations was so small that the instrument used for the 
measurement is not calibrated for such small readings and this maybe the reason behind the large discrepancies.

Table 20 - Comparator Output Characteristics

\begin{tabular}{|c|c|c|c|c|c|c|}
\hline \multirow[t]{2}{*}{ Vref $=2.5 \mathrm{~V}$} & \multicolumn{2}{|c|}{ Simulated data } & & \multirow{2}{*}{$\begin{array}{l}\text { Measured } \\
\text { data }\end{array}$} & \\
\hline & & & & & & \\
\hline \multirow[t]{2}{*}{$\operatorname{Vin}(\mathrm{V})$} & Vout (V) & $V$ (out) & $\operatorname{IDD}(\mathrm{A})$ & Vout (V) & Error Calculatic & \\
\hline & Dsub -0.4373 & $\begin{array}{l}\text { Default } \\
(0.2873)\end{array}$ & & & Dsub - 0.4373 & $\begin{array}{c}\text { Default } \\
(0.2873)\end{array}$ \\
\hline 0.00 & 0.072 & 0.15 & $-5.64 E-04$ & 0.004 & 0.939 & 0.971 \\
\hline 0.50 & 0.072 & 0.15 & $-5.63 E-04$ & 0.004 & 0.939 & 0.971 \\
\hline 1.00 & 0.073 & 0.15 & $-5.62 E-04$ & 0.004 & 0.940 & 0.972 \\
\hline 1.50 & 0.074 & 0.16 & $-5.61 E-04$ & 0.005 & 0.940 & 0.971 \\
\hline 2.00 & 0.077 & 0.16 & $-5.59 \mathrm{E}-04$ & 0.005 & 0.942 & 0.972 \\
\hline 2.50 & 0.084 & 0.17 & $-5.55 \mathrm{E}-04$ & 4.900 & 57.676 & 27.358 \\
\hline 3.00 & 0.167 & 0.27 & $-5.64 \mathrm{E}-04$ & 4.900 & 28.415 & 16.943 \\
\hline 3.50 & 4.977 & 4.98 & $-3.07 \mathrm{E}-04$ & 4.900 & 0.016 & 0.015 \\
\hline 4.00 & 4.977 & 4.98 & $-2.08 \mathrm{E}-04$ & 4.900 & 0.016 & 0.016 \\
\hline 4.50 & 4.977 & 4.98 & $-1.97 \mathrm{E}-04$ & 4.900 & 0.016 & 0.016 \\
\hline \multirow[t]{2}{*}{5.00} & 4.977 & 4.98 & $-1.97 \mathrm{E}-04$ & 4.900 & 0.016 & 0.016 \\
\hline & & & \multicolumn{2}{|c|}{ Average Error } & $52.93 \%$ & $54.67 \%$ \\
\hline
\end{tabular}

Table 21 - Output characteristics with different supply voltages

\begin{tabular}{|c|c|c|c||c||c|c|}
\hline \multicolumn{5}{|c|}{} & $\begin{array}{c}\text { Measured } \\
\text { Values }\end{array}$ & \multicolumn{2}{c|}{ Simulated Values } \\
\hline Vin & Vbias & Vref & Vdd & Vout & Vout & IDD \\
\hline (V) & (V) & (V) & (V) & (V) & (V) & (A) \\
\hline & & & & & & \\
\hline 0 & 0 & 1 & 2 & $1.790 \mathrm{E}-03$ & $1.19 \mathrm{E}-08$ & $-3.21 \mathrm{E}-05$ \\
\hline 2 & 0 & 1 & 2 & 1.976 & 1.976 & $-1.36 \mathrm{E}-05$ \\
\hline & & & & & & \\
\hline 0 & 0 & 1.5 & 3 & $2.560 \mathrm{E}-03$ & $4.978 \mathrm{E}-03$ & $-1.58 \mathrm{E}-04$ \\
\hline 3 & 0 & 1.5 & 3 & 2.990 & 2.979 & $-6.10 \mathrm{E}-05$ \\
\hline & & & & & & \\
\hline 0 & 0 & 2.5 & 5 & $4.390 \mathrm{E}-03$ & $7.162 \mathrm{E}-02$ & $-5.64 \mathrm{E}-04$ \\
\hline 5 & 0 & 2.5 & 5 & 4.900 & 4.977 & $-1.97 \mathrm{E}-04$ \\
\hline
\end{tabular}




\subsection{Op-Amp}

Due to the unavailability of good test setup and instrumentation, the open-loop gain test was not performed, though on simulation, the open-loop gain was obtained to be $65 \mathrm{~dB}$. The $\mathrm{AC}$ tests were performed for both the modes and these tests focus more on obtaining the $3 \mathrm{~dB}$ Roll Off frequencies and resistances rather than the accuracy. The data in the tables that follow are plotted in [Appendix C] under the Op-Amp section. For simulated data, using Dsub - PMOS = $0.4373,3 \mathrm{~dB}$ Roll off was at $300 \mathrm{KHz}$. For Simulated data using Dsub for PMOS $=0.2873,3 \mathrm{~dB}$ Roll off is at $2 \mathrm{MHz}$. For Measured data, $3 \mathrm{~dB}$ Roll off is at $2 \mathrm{MHz}$. Due to the large variation in the $3 \mathrm{~dB}$ Roll off frequency between the measured data and the simulated data with $\mathrm{Dsub}=0.4373$, this value is not considered while performing the $A C$ Tests. In addition to the inverting mode $A C$ characteristics, the AC characteristics were also performed in the non-inverting mode. Due to the larger discrepancies at the higher frequency ranges, these values were omitted in the error calculation. The change in the Dsub value affects the C-V calculations in the circuit and hence, there is a large discrepancy seen in the load as well as the AC charcteristics. The simulation performed with the default parameters gave a $3 \mathrm{~dB}$ point which agreed closer to the measured data where as the simulation with the Dsub value changed, reduced the $3 \mathrm{~dB}$ Roll Off point considerably by about 9 times. Hence, the default value is considered over the optimized value of Dsub for the AC tests performed. The $3 \mathrm{~dB}$ Roll Off occurred at $2 \mathrm{Kohm}$ for the measured data and at $3 \mathrm{KOhm}$ for the simulated data and hence, the 3dB point for the Op-Amp occurred at around 2.5KOhms. 
Table 22 - Inverting Op-Amp AC Characteristics

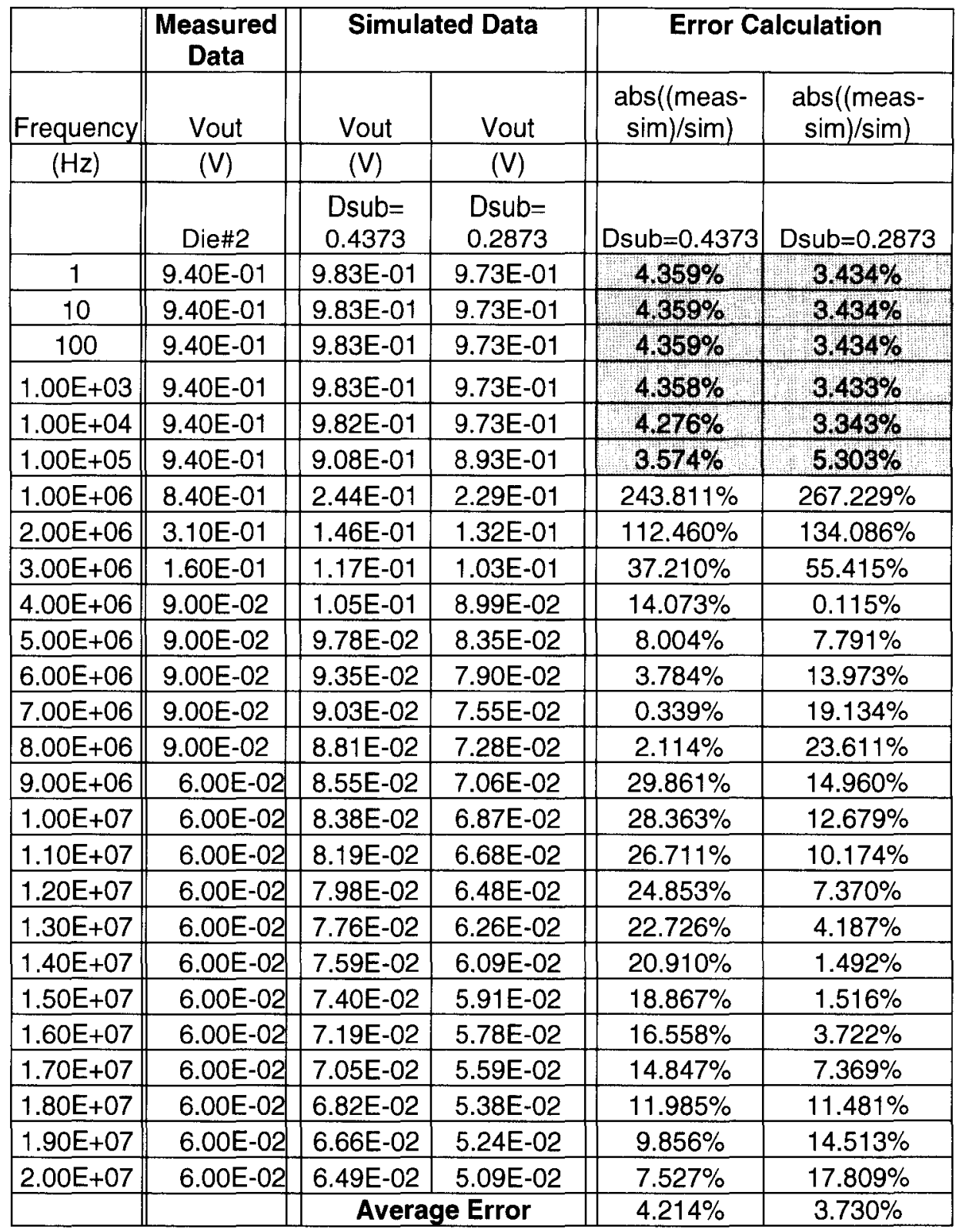


Table 23 - Non Inverting Op-Amp AC Characteristics

\begin{tabular}{|c|c|c|c|c|c|}
\hline \multirow[b]{2}{*}{ Frequency } & \multirow{2}{*}{\begin{tabular}{||c|}
$\begin{array}{c}\text { Measured } \\
\text { Data }\end{array}$ \\
\\
Vout \\
\end{tabular}} & \multirow{2}{*}{$\begin{array}{c}\begin{array}{c}\text { Simulated } \\
\text { Data }\end{array} \\
\text { Vout }\end{array}$} & \multirow[b]{2}{*}{ Vout } & \multicolumn{2}{|c|}{ Error Calculation } \\
\hline & & & & $\begin{array}{c}\text { Abs } \\
((\text { meas- } \\
\text { sim }) / \text { sim })\end{array}$ & $\begin{array}{c}\text { Abs } \\
\text { ((meas- } \\
\text { sim)/sim) }\end{array}$ \\
\hline \multirow[t]{2}{*}{$(\mathrm{Hz})$} & $(\mathrm{V})$ & $(\mathrm{V})$ & (V) & & \\
\hline & Die\#2 & $\begin{array}{l}\text { Dsub= } \\
0.4373\end{array}$ & $\begin{array}{l}\text { Dsub= } \\
0.2873\end{array}$ & $\begin{array}{l}\text { Dsub= } \\
0.4373\end{array}$ & $\begin{array}{l}\text { Dsub= } \\
0.2873\end{array}$ \\
\hline 1 & 1.03 & $1.14 E+00$ & $1.08 \mathrm{E}+00$ & $9.435 \%$ & $4.488 \%$ \\
\hline 10 & 1.03 & $1.14 \mathrm{E}+00$ & $1.08 \mathrm{E}+00$ & $9.435 \%$ & $4.453 \%$ \\
\hline 100 & 1.03 & $1.14 \mathrm{E}+00$ & $1.08 \mathrm{E}+00$ & $9.435 \%$ & $4.488 \%$ \\
\hline $1.00 E+03$ & 1.03 & $1.14 \mathrm{E}+00$ & $1.08 \mathrm{E}+00$ & $9.435 \%$ & $4.488 \%$ \\
\hline $1.00 \mathrm{E}+04$ & 1.03 & $1.14 \mathrm{E}+00$ & $1.08 \mathrm{E}+00$ & $9.355 \%$ & $188 \%$ \\
\hline $1.00 \mathrm{E}+05$ & 1.03 & $1.05 \mathrm{E}+00$ & 9.89E-01 & $1.811 \%$ & $4.160 \%$ \\
\hline $1.00 \mathrm{E}+06$ & $8.10 \mathrm{E}-01$ & $2.81 \mathrm{E}-01$ & $2.54 \mathrm{E}-01$ & $188.195 \%$ & $219.464 \%$ \\
\hline $2.00 \mathrm{E}+06$ & 3.80E-01 & 1.69E-01 & $1.52 \mathrm{E}-01$ & $125.506 \%$ & $150.148 \%$ \\
\hline $3.00 E+06$ & $2.20 \mathrm{E}-01$ & $1.35 \mathrm{E}-01$ & 1.15E-01 & $62.398 \%$ & $91.972 \%$ \\
\hline $4.00 \mathrm{E}+06$ & $1.60 \mathrm{E}-01$ & $1.23 \mathrm{E}-01$ & $1.00 \mathrm{E}-01$ & $30.591 \%$ & $59.633 \%$ \\
\hline $5.00 \mathrm{E}+06$ & 1.30E-01 & 1.15E-01 & 9.32E-02 & $12.593 \%$ & $39.509 \%$ \\
\hline $6.00 \mathrm{E}+06$ & 1.30E-01 & 1.12E-01 & $8.82 E-02$ & $16.550 \%$ & $47.397 \%$ \\
\hline $7.00 \mathrm{E}+06$ & $9.00 \mathrm{E}-02$ & 1.09E-01 & $8.44 \mathrm{E}-02$ & $17.454 \%$ & $6.602 \%$ \\
\hline $8.00 \mathrm{E}+06$ & $9.00 \mathrm{E}-02$ & 1.07E-01 & $8.14 \mathrm{E}-02$ & & $10.558 \%$ \\
\hline $9.00 \mathrm{E}+06$ & $6.00 E-02$ & 1.06E-01 & 7.94E-02 & $43.657 \%$ & $24.447 \%$ \\
\hline $1.00 \mathrm{E}+07$ & $6.00 \mathrm{E}-02$ & $1.06 \mathrm{E}-01$ & $7.69 \mathrm{E}-02$ & $43.166 \%$ & $21.948 \%$ \\
\hline $1.10 \mathrm{E}+07$ & $6.00 \mathrm{E}-02$ & 1.05E-01 & 7.47E-02 & $42.824 \%$ & $19.729 \%$ \\
\hline $1.20 \mathrm{E}+07$ & $6.00 \mathrm{E}-02$ & 1.04E-01 & $7.25 \mathrm{E}-02$ & $42.534 \%$ & $17.247 \%$ \\
\hline $1.30 \mathrm{E}+07$ & $6.00 \mathrm{E}-02$ & 1.04E-01 & $7.01 \mathrm{E}-02$ & $42.274 \%$ & $14.425 \%$ \\
\hline $1.40 \mathrm{E}+07$ & $6.00 \mathrm{E}-02$ & 1.04E-01 & $6.82 \mathrm{E}-02$ & $42.102 \%$ & $12.038 \%$ \\
\hline $1.50 \mathrm{E}+07$ & $6.00 \mathrm{E}-02$ & $1.03 E-01$ & $6.62 \mathrm{E}-02$ & $41.939 \%$ & $9.371 \%$ \\
\hline $1.60 \mathrm{E}+07$ & $6.00 \mathrm{E}-02$ & $1.03 \mathrm{E}-01$ & $6.41 \mathrm{E}-02$ & $41.787 \%$ & $6.383 \%$ \\
\hline $1.70 \mathrm{E}+07$ & $6.00 \mathrm{E}-02$ & 1.03E-01 & $6.26 \mathrm{E}-02$ & $41.691 \%$ & $4.185 \%$ \\
\hline $1.80 \mathrm{E}+07$ & $6.00 \mathrm{E}-02$ & $1.03 \mathrm{E}-01$ & $6.03 \mathrm{E}-02$ & $41.549 \%$ & $0.544 \%$ \\
\hline $1.90 \mathrm{E}+07$ & $6.00 \mathrm{E}-02$ & 1.02E-01 & 5.87E-02 & $41.458 \%$ & $2.143 \%$ \\
\hline $2.00 \mathrm{E}+07$ & $6.00 \mathrm{E}-02$ & $1.02 E-01$ & $5.71 \mathrm{E}-02$ & $41.366 \%$ & $5.060 \%$ \\
\hline & & $\begin{array}{r}\text { Avera } \\
\text { Erro }\end{array}$ & & $8.151 \%$ & $4.428 \%$ \\
\hline
\end{tabular}


Table 24 - Inverting Op-Amp Load Characteristics

\begin{tabular}{|l|c|c||r|}
\hline & $\begin{array}{r}\text { Measured } \\
\text { Data }\end{array}$ & $\begin{array}{c}\text { Simulated } \\
\text { Data }\end{array}$ & $\begin{array}{l}\text { Error } \\
\text { Calculation }\end{array}$ \\
\hline$R($ Ohm) & Vout (V) & Vout (V) & $\begin{array}{l}\text { Abs ((Meas- } \\
\text { sim)/sim) }\end{array}$ \\
\hline & & & $44.42 \%$ \\
\hline $1.00 E+06$ & 0.67 & 1.2 & $44.44 \%$ \\
\hline $5.00 E+05$ & 0.67 & 1.2 & $44.53 \%$ \\
\hline $1.00 \mathrm{E}+05$ & 0.67 & 1.2 & $44.62 \%$ \\
\hline $5.00 \mathrm{E}+04$ & 0.66 & 1.2 & $48.16 \%$ \\
\hline $1.00 \mathrm{E}+04$ & 0.64 & 1.2 & $46.66 \%$ \\
\hline $5.00 \mathrm{E}+03$ & 0.63 & 1.2 & $47.28 \%$ \\
\hline $4.00 \mathrm{E}+03$ & 0.62 & 1.2 & $43.41 \%$ \\
\hline $3.00 \mathrm{E}+03$ & 0.62 & 1.1 & $34.01 \%$ \\
\hline $2.00 \mathrm{E}+03$ & 0.60 & 0.91 & $33.61 \%$ \\
\hline $1.00 \mathrm{E}+03$ & 0.52 & 0.392 & $11.56 \%$ \\
\hline $5.20 \mathrm{E}+02$ & 0.31 & 0.147 & $2.57 \%$ \\
\hline $1.00 \mathrm{E}+02$ & 0.03 & $3.00 \mathrm{E}-02$ & $45.44 \%$ \\
\hline & & Average Error & \\
\hline
\end{tabular}

\subsection{Adjustable Voltage Regulator}

This circuit was designed keeping the voltage regulation in mind and not the accuracy of the model. The values obtained for the load test for the two standard outputs, $3.3 \mathrm{~V}$ and $5 \mathrm{~V}$, are tabulated in Tables 25 and 26 below. The terms unoptimized and optimized stand for the change in the Dsub value for the PMOS FET from 0.2873 to 0.4373 respectively. Since, this circuit was designed using the other circuits characterized before, the error was not calculated. 
Table 25 - Regulator Load Test at VIN=5V for Vout=3.3V

\begin{tabular}{|c|c|c|c|c|c|}
\hline \multirow{3}{*}{$\begin{array}{c}\text { VIN=5V, } \\
\text { VOUT=3.3 } \\
V \\
R(O h m) \\
\end{array}$} & \multirow{3}{*}{$\begin{array}{c}\text { Measured } \\
\text { Data } \\
\text { Die\#2 } \\
\text { Vout }(\mathrm{V}) \\
\end{array}$} & \multicolumn{4}{|c|}{ Simulated Data } \\
\hline & & \multicolumn{2}{|c|}{ Optimized } & \multicolumn{2}{|c|}{ Unoptimized } \\
\hline & & Vout (V) & $\operatorname{IDD}(A)$ & Vout (V) & $\operatorname{IDD}(\mathrm{A})$ \\
\hline $5.00 \mathrm{E}+04$ & 3.29 & 1.10 & $-1.79 \mathrm{E}-04$ & 1.27 & $-3.34 E-04$ \\
\hline $2.50 \mathrm{E}+04$ & 3.29 & 1.10 & $-2.00 E-04$ & 1.27 & $-3.57 \mathrm{E}-04$ \\
\hline $1.00 \mathrm{E}+04$ & 3.28 & 1.10 & $-2.67 E-04$ & 1.27 & $-4.35 \mathrm{E}-04$ \\
\hline $5.00 \mathrm{E}+03$ & 3.26 & 1.10 & $-3.76 \mathrm{E}-04$ & 1.27 & $-5.61 \mathrm{E}-04$ \\
\hline $1.00 \mathrm{E}+03$ & 2.77 & 1.09 & $-1.24 \mathrm{E}-03$ & $9.82 \mathrm{E}-09$ & $-9.97 E-10$ \\
\hline $5.20 \mathrm{E}+02$ & 2.10 & $5.04 \mathrm{E}-07$ & $-2.52 \mathrm{E}-10$ & 5.33E-09 & $-1.27 E-09$ \\
\hline $1.00 \mathrm{E}+02$ & 1.43 & $5.81 \mathrm{E}-08$ & $-4.77 \mathrm{E}-10$ & 0.64 & $-6.56 \mathrm{E}-03$ \\
\hline
\end{tabular}

Table 26 - Regulator Load Test at VIN=5V for Vout=5V

\begin{tabular}{|c|c|c|c|c|c|}
\hline & $\begin{array}{l}\text { Measured } \\
\text { Data }\end{array}$ & \multicolumn{4}{|c|}{ Simulated Data } \\
\hline Vdd=5V & Die\#2 & & \multicolumn{2}{|c|}{ Optimized } & \multicolumn{2}{c|}{ UnOptimized } \\
\hline $\mathbf{R}(\mathbf{O h m})$ & $\begin{array}{c}\text { Vout } \\
\text { (V) }\end{array}$ & Vout (V) & IDD (A) & $\begin{array}{c}\text { Vout } \\
\text { (V) }\end{array}$ & IDD (A) \\
\hline & & & & & \\
\hline $5.00 \mathrm{E}+04$ & 4.93 & 1.71 & $-1.93 \mathrm{E}-04$ & 1.98 & $-3.50 \mathrm{E}-04$ \\
\hline $2.50 \mathrm{E}+04$ & 4.86 & 1.71 & $-2.24 \mathrm{E}-04$ & 1.98 & $-3.87 \mathrm{E}-04$ \\
\hline $5.00 \mathrm{E}+03$ & 4.35 & 1.70 & $-4.99 \mathrm{E}-04$ & 1.97 & $-7.05 \mathrm{E}-04$ \\
\hline $5.20 \mathrm{E}+02$ & 1.69 & $3.67 \mathrm{E}-09$ & $-6.23 \mathrm{E}-11$ & 1.93 & $-4.01 \mathrm{E}-03$ \\
\hline $1.00 \mathrm{E}+02$ & 0.43 & $-8.85 \mathrm{E}-08$ & $-2.90 \mathrm{E}-10$ & 0.64 & $-6.57 \mathrm{E}-03$ \\
\hline
\end{tabular}

From the above data, it is noticed that the $3 \mathrm{~dB}$ Roll Off points for the measured data as well as the optimized simulated data occurred at around $800-900$ Ohms for an output of $3.3 \mathrm{~V}$ and at around $2.5 \mathrm{~K}-3.5 \mathrm{~K}$ for an output of $5 \mathrm{~V}$, while that for the unoptimized simulated data, the $3 \mathrm{~dB}$ roll off occurred at $5 \mathrm{~K}$ Ohms for the $3.3 \mathrm{~V}$ output and 250 Ohms at the $5 \mathrm{~V}$ output. Since there was a lot of variation between the simulated and measured data, the optimized model fit better with the measured results. 
Table 27 - Regulator VDD Characteristics at Vout $=3.3 \mathrm{~V}$

\begin{tabular}{|c|c|c|c|c|c|c|}
\hline \multirow[b]{2}{*}{$\operatorname{Vdd}(\mathrm{V})$} & \multicolumn{2}{|c|}{ Measured Data } & \multicolumn{2}{|c|}{$\begin{array}{l}\text { Optimized } \\
\text { Simulated }\end{array}$} & \multicolumn{2}{|c|}{$\begin{array}{l}\text { Unoptimized } \\
\text { Simulated }\end{array}$} \\
\hline & $\operatorname{Vin}(V)$ & Vout (V) & Vout (V) & IDD (A) & Vout (V) & IDD (A) \\
\hline & (Die\#1) & (Die\#1) & & & & \\
\hline & & & & & & \\
\hline 2 & 0.611 & 0.617 & $1.56 \mathrm{E}-07$ & $-6.56 E-11$ & $2.52 \mathrm{E}-07$ & $-1.42 E-10$ \\
\hline 3 & 0.651 & 1.996 & 2.34E-07 & $-1.34 E-10$ & 1.08 & $-1.38 E-04$ \\
\hline 4 & 0.682 & 3.165 & $3.12 E-07$ & $-1.03 E-09$ & 1.17 & $-2.14 \mathrm{E}-04$ \\
\hline 5 & 0.711 & 3.287 & 1.10 & $-1.57 E-04$ & 1.27 & $-3.08 E-04$ \\
\hline 6 & 0.737 & 3.322 & 1.15 & $-1.96 E-04$ & 1.38 & $-4.21 E-04$ \\
\hline 7 & 0.763 & 3.354 & 1.19 & $-2.35 E-04$ & 1.48 & $-5.44 \mathrm{E}-04$ \\
\hline 8 & 0.791 & 3.387 & 1.24 & $-2.78 E-04$ & 1.60 & $-6.84 \mathrm{E}-04$ \\
\hline 9 & 0.821 & 3.428 & 1.28 & $-3.21 E-04$ & 1.71 & $-8.36 \mathrm{E}-04$ \\
\hline 10 & 0.858 & 3.476 & 1.32 & $-3.67 E-04$ & 1.81 & $-9.83 E-04$ \\
\hline
\end{tabular}

Table 28 - Regulator VDD Characteristics at Vout $=5 \mathrm{~V}$

\begin{tabular}{|c|c|c|c|c|c|c|}
\hline \multirow[b]{2}{*}{$\operatorname{Vdd}(\mathrm{V})$} & \multicolumn{2}{|c|}{ Measured Data } & \multicolumn{2}{|c|}{$\begin{array}{l}\text { Optimized } \\
\text { Simulated }\end{array}$} & \multicolumn{2}{|c|}{ UnOptimized Simulated } \\
\hline & $\operatorname{Vin}(V)$ & $\begin{array}{l}\text { Vout } \\
\text { (V) }\end{array}$ & $\begin{array}{l}\text { Vout } \\
\text { (V) }\end{array}$ & IDD (A) & Vout (V) & IDD (A) \\
\hline & (Die\#1) & $\begin{array}{c}\text { (Die\# } \\
\text { 1) }\end{array}$ & & & & \\
\hline & & & & & & \\
\hline 2 & 0.611 & 0.934 & $2.43 \mathrm{E}-07$ & $-6.38 \mathrm{E}-11$ & $3.92 \mathrm{E}-07$ & $-1.42 \mathrm{E}-10$ \\
\hline 3 & 0.652 & 2.821 & 1.57 & $-9.53 \mathrm{E}-05$ & 1.67 & $-1.39 \mathrm{E}-04$ \\
\hline 4 & 0.683 & 3.901 & 1.65 & $-1.26 \mathrm{E}-04$ & 1.83 & $-2.16 \mathrm{E}-04$ \\
\hline 5 & 0.711 & 4.992 & 1.71 & $-1.58 \mathrm{E}-04$ & 1.98 & $-3.11 \mathrm{E}-04$ \\
\hline 6 & 0.737 & 5.173 & 1.79 & $-1.98 \mathrm{E}-04$ & 2.15 & $-4.25 \mathrm{E}-04$ \\
\hline 7 & 0.763 & 5.223 & 1.85 & $-2.37 \mathrm{E}-04$ & 2.31 & $-5.49 \mathrm{E}-04$ \\
\hline 8 & 0.791 & 5.277 & 1.93 & $-2.80 \mathrm{E}-04$ & 2.48 & $-6.90 \mathrm{E}-04$ \\
\hline 9 & 0.821 & 5.377 & 1.99 & $-3.23 \mathrm{E}-04$ & 2.66 & $-8.43 E-04$ \\
\hline 10 & 0.858 & 5.411 & 2.06 & $-3.70 E-04$ & 2.82 & $-9.92 E-04$ \\
\hline
\end{tabular}

From the above tables on the output characteristics, it was noticed that the regulation obtained from $5 \mathrm{~V}$ to $10 \mathrm{~V}$, for the $3.3 \mathrm{~V}$ Output, the unoptimized model outputted a better regulation over the optimized model by hundreds of Ohms. From the regulation obtained for the $5 \mathrm{~V}$ output, it was noticed that the optimized model gave a better regulation and one closer to the measured data as well. Hence, there is a tradeoff between the optimized and unoptimized model at the $3.3 \mathrm{~V}$ 
while the data points out that the optimized model outweighed the unoptimized model in the other DC tests performed. The Plots as well as the regulation values are indicated in [Appendix C] under the voltage regulator section. 


\section{CHAPTER 5}

\section{CONCLUSIONS AND FUTURE WORK}

NMOS and PMOS FETs as well as nine different analog IC standard cell designs have been tested and characterized under $D C$ and $A C$ conditions. Furthermore, these FETs and standard cells have been simulated in TSpice and the BSIM3 model parameters optimized to improve the accuracy between the measured and simulated results. The effect of the Multiplicity factor, $\mathrm{M}$ and some other model parameters that were influenced by the DIBL effects have been studied in depth to improve the accuracy of the model. The new model improved the overall accuracy in characterizing most of the analog circuits under DC conditions. While the change in the DIBL parameter, Dsub improved the PMOS FET behavior under DC conditions; the accuracy in the data was lost under the AC conditions. Hence, by tweaking this parameter, tradeoff was made between accuracy under DC and AC conditions. Since, the accuracy modeling under the $A C$ conditions was out of the scope of this thesis, attempting to improve the modeling under $A C$ conditions was not investigated. The current error calculation indicated the optimized model for the PMOS FET showed about a $60 \%$ improvement over the unoptimized model. For the NMOS FET, about a $17 \%$ improvement was obtained from the optimized model over the unoptimized model. The DC fit using the optimized model over the unoptimized model showed an improvement of $\sim 2 \%$ (Voltage reference), $<24 \%$ (Bias Generator), $2 \%$ ( $N$-Current mirror), $5 \%$ ( $P$ Current mirror), $<30 \%$ (Analog Buffer) and $2 \%$ (Op-Amp).

Future work should include the modeling optimization under $A C$ conditions and improving PMOS model accuracy. Also, the scalability of the model as a function of the gate length should be investigated. The data measured from the FETs for modeling purposes all came from devices 
with a channel length of 1.6 um. However, FETs used within some of the standard cells had channel lengths greater than 25 um. 


\section{REFERENCES}

1. Toh Hong Ting, Mohd Rais Ahmad, Roy Kooh Jinn Chye, Rahman Wagiran and Sunayo Suparjo, "Device Design, Fabrication and Characterization of 0.8um CMOS Technology,"ICSE'98 Pro., Nov. 1998, Bangi, Malaysia , pgs: 147-151

2. Byung-Jong Moon, Chan-Kwang Park, Kwryo Lee, and Michael Shur, "New Shortchannel n-MOSFET current-voltage model in strong inversion and unified parameter extraction method," IEEE transactions on Electron Devices, Vol. 38, No. 3, March 1991, pgs:592-602

3. Amitava Chatterjee, Charles F. Machala,III, and Ping Yang, "A submicron DC MOSFET model for simulation of Analog Circuits," IEEE transactions on computer-aided design of integrated circuits and systems, Vol.14, No. 10, October 1995, pgs:1193-1207

4. Rafael M. Coitinho, Luis H Spiller, Marcio C. Schneider, and Carlos Galup-Montoro, "A simplified Methodology for the extraction of the ACM MOST Model Parameters," Symposium on Integrated Circuits and Systems Design, 2001, pgs:136-41

5. Tadanori Yamaguchi and Seiichi Morimoto, "Analytical Model and Characterization of small geometry MOSFETs," IEEE transactions on electron devices, Vol. ED-30, No.6, June 1983, pgs: 559-566

6. Baker, R. Jacob, 1998, CMOS circuit design, layout, and simulation / R. Jacob Baker, Harry W. Li, and David E. Boyce, pgs: 410, 685-710

7. Boylestad, Robert L., 2002 Electronic devices and circuit theory

8. Buchsbaum, Walter H., 1981, Encyclopedia of integrated circuits: a practical handbook of essential reference data / Walter $\mathrm{H}$. Buchsbaum.

9. Foty, D. (Daniel), 1997, MOSFET modeling with SPICE: principles and practice

10. Geiger, Randall L, 1990, VLSI Design Techniques for Analog and Digital Circuits Randall L. Geiger, Phillip E. Allen, Noel R. Strader, pgs: 213-215

11. Grebene, Alan B., 1984 Bipolar and MOS analog integrated circuit design, pgs: $309-390$.

12. Greeneich, Edwin W., 1997 Analog integrated circuits

13. Hastings, Alan (Ray Alan), 2001, The Art of Analog layout, pgs:160-167

14. Hughes, Fredrick W., 1936- Op-amp handbook, pgs: 2-8

15. Johns, David, 1997 Analog integrated circuit design / David Johns, Ken Martin.

16. Lenk, John D. Handbook for transistors, pgs: $478,685-710$. 
17. Lenk, John D. Manual for operational amplifier users

18. Liu, William. , 2001,MOSFET models for SPICE simulation including BSIM3v3 and BSIM4, pgs: 158-252

19. Millman, Jacob, 1987 , Microelectronics

20. Razavi, Behzad, 2001, Design of Analog CMOS Integrated Circuits, pgs: 10-15, 135-139, and 178-183.

21. Rutkowski, George B., 1986 Handbook of integrated-circuit operational amplifiers, pgs: 21- 25, 54.

22. Tanner Tools, T-SPICE Help Manual 


\section{Appendix (A)}

\section{S-EditTM Getting Started Manual}

S-Edit is the schematic editor, which is a part of Tanner Tools ${ }^{\mathcal{O}}$. To create a new schematic, the following steps have to be followed.

1. Create a new file by using $\mathrm{Ctrl}+\mathrm{N}$ or by using "File>new". Note: All the main circuit connections should be made on the schematic mode. To select this, click "View>Schematic Mode". The views can also be toggled using the shortcut buttons 国医 for the symbol and schematic mode respectively.

2. Add the necessary library file by using "Module>Symbol Browser" or by clicking the

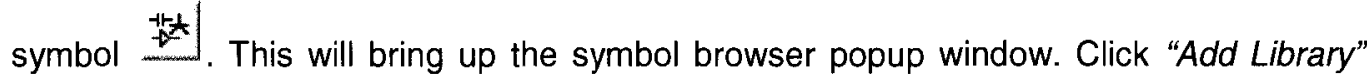
and add the library, in this case, the library file used was Mami150L.sdb. This is located in the "C:ITanner DesignkitsIMOSISIAMI_150/LinCMOS" folder.

3. Highlight this library and scroll down the list box and place the required cell that is being simulated by highlighting the cell and clicking "Place".

4. Once this cell has been placed, rename the module by using "Module>Rename" and the page can also be renamed using "Page>Rename".

5. Place the other voltage/current sources (this is obtained from the Spice Library which is added as in step (2), located in C:ITannerlS-Editlibrary).

6. Clicking on the cell and dragging this by holding down the ALT button on the keyboard can move the cell.

7. Clicking on the cell and dragging this by holding down the CTRL button on the keyboard can create duplicates of the cell.

8. Once all the necessary circuit elements were placed, they should be connected using 
the wire button 国! Make sure not to use the line buttons as shown

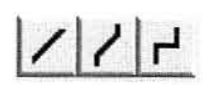

9. Ports can be placed using the buttons $\left.\left.\square\right|_{\text {for input port, }} \square\right|_{\text {for output port and }} \bar{Q}$ for bi-directional port located on the left side pane.

10. Once, the above steps were performed, the other simulation commands can also be embedded in the S-Edit file. To create this, click "Module>New" and create all the commands in the symbol mode (only then, they can be Instanced). In the symbol mode, many of the buttons on the schematic toolbar, which appears on the left side of the layout area, will be grayed out.

11. To create a simulation command, place the rectangle $\square$ on the work area and to place the text click $a$ and click anywhere on the work area and type the text.

12. To add a property click $\sqrt{\mathbf{P} /}$ and create a property. For Spice simulations, on the name field, type "SPICE OUTPUT" in uppercase and under the value field, add the simulation command. In the Format area, select the necessary format required. Click OK once the actions are completed.

13. To open the main module, click "Module>Open" or use the shortcut, $\mathrm{O}$.

14. To create an Instance of a module or another cell, use "Module>Instance" or use I.

15. The simulation commands can also be added using T-Spice. Save the schematic file with the .sdb extension and to export the netlist click "File>Export" or to obtain the SPICE netlist. Other netlists can also be exported.

Using the above steps, a simple schematic can be created. To learn more about the other buttons and menus, use the S-Edit Help Manual. Figure below shows the S-Edit user interface. 
Figure: S-Edit User Interface

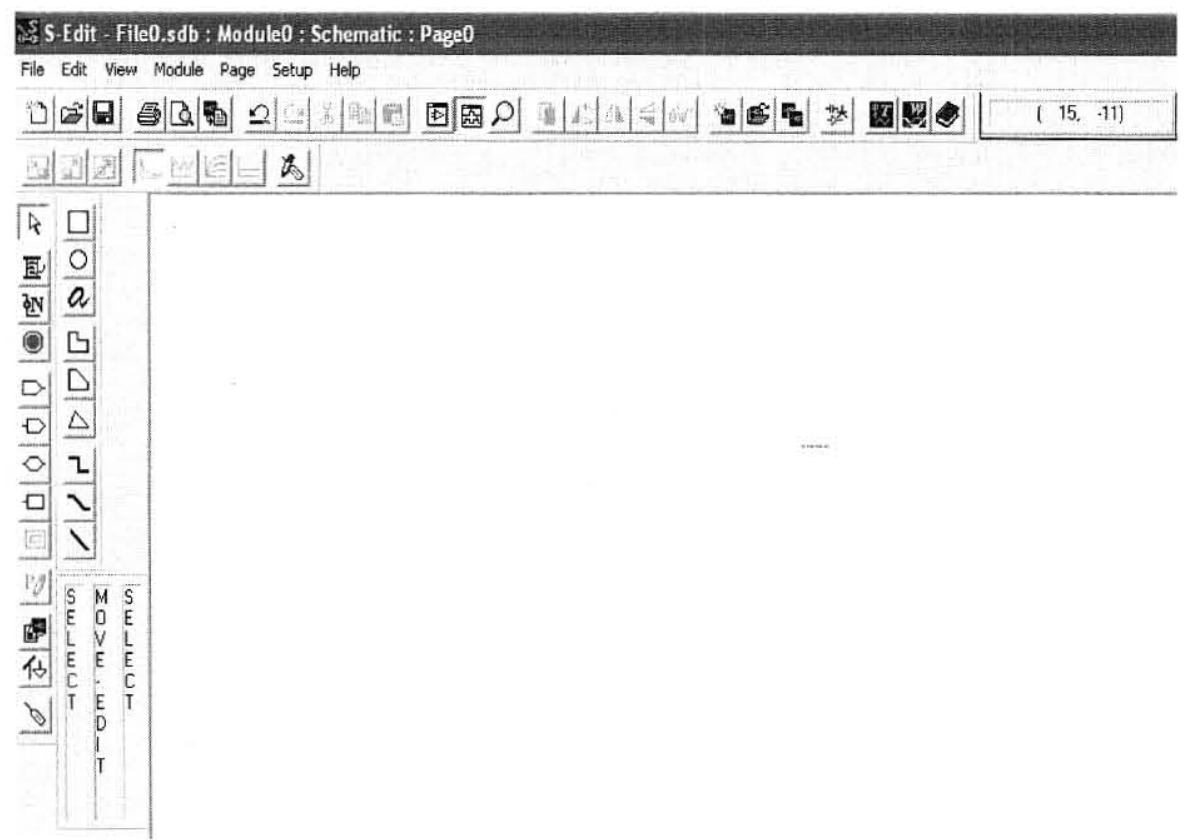




\section{Appendix (B)}

\section{T-Spice Getting Started Manual}

T-Spice is the Simulation programming software used by $\operatorname{Tanner}$ Tools $^{\circledR}$ for electrical circuit simulator. In order to run a simulation, you must first obtain the circuit netlist. This can be generated in two ways, one by entering all the simulation commands in the S-Edit ${ }^{\mathrm{TM}}$ file and then

clicking the T-Spice symbol This automatically creates the spice file and by using the "Simulation>Run simulation" command or the run button that appears on the toolbar, generates an output. Note: Before running any simulation, the model file, containing the process parameters library for the circuit, should be loaded in the same folder where the spice file resides.

The second method: If the netlist hasn't been exported from the S-Edit file, then use the "File>Export" option and select the Export data type as .sp from the pull-down menu in the SEdit ${ }^{\mathrm{TM}}$ program. This netlist can then be opened using the T-Spice program. The simulation commands can be entered for the different types of analysis using the Insert Command submenu under the Edit Menu option. Once this is clicked, the T-Spice Command Tool appears, which is as shown below. 


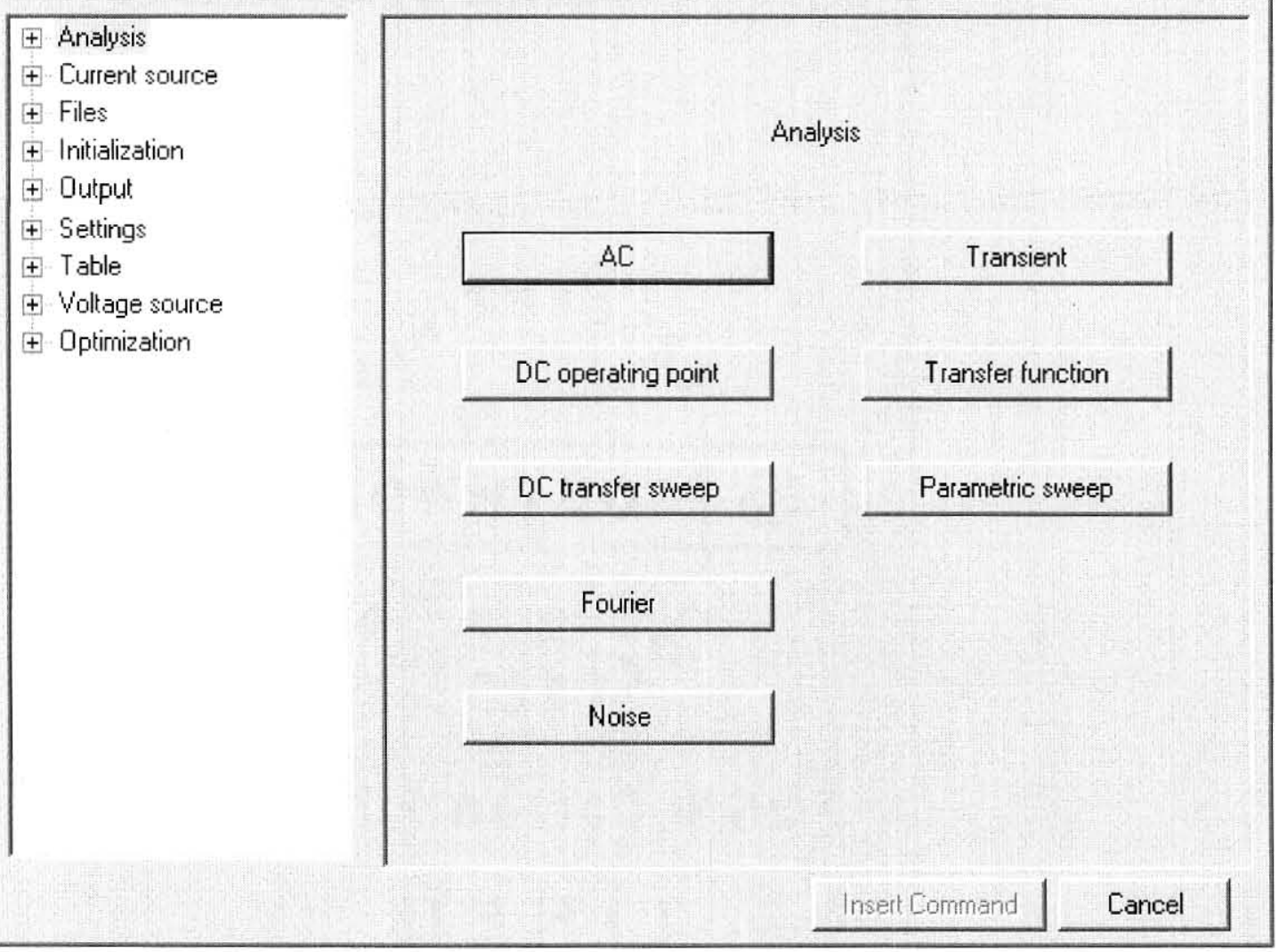

Using the above tool, the user can insert the type of analysis, type of current sources and voltage sources, the tables or library files needed to run the simulation, initialization and optimization commands etc. Once the desired set of commands were inserted using the insert command tool, the type of output desired (this too has to be specified using the Output option), and then click the run simulation button. The simulation status window shows the number of nodes, sources used etc. It also outputs if there were any errors or warnings in the simulation file. If there were errors, the simulation fails and user should fix the error and run the simulation again. 


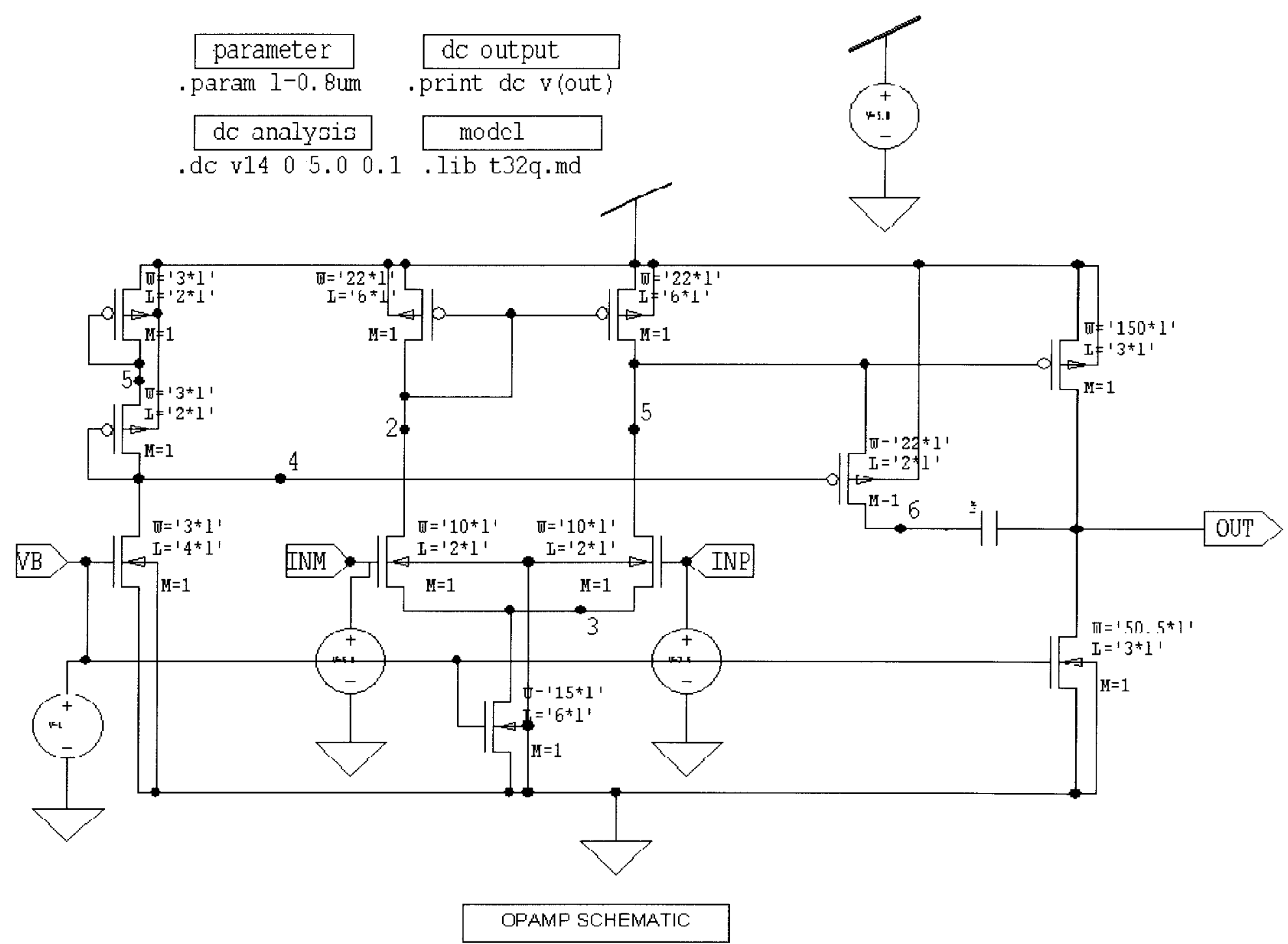


* SPICE netlist written by S-Edit Win32 8.10

* Written on Aug 5, 2004 at 14:30:26

${ }^{*}$ Waveform probing commands

.probe

.options probefilename="OPAMP"

+ probesdbfile $=$ "C:IseditloutputsIOPAMPIOPAMP.sdb"

+ probetopmodule="Op-Amp"

* Main circuit: Op-Amp

.$d c$ v15 05.00 .5

.print dc $v($ out) $v(2) v(3) v(4) v(5) v(6)$

.lib t32q.md

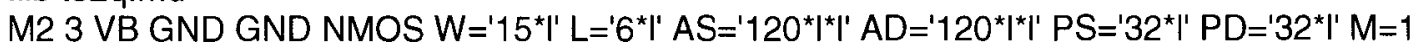

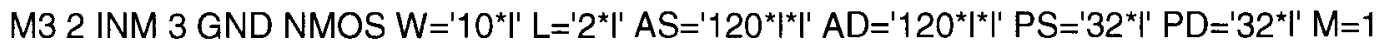

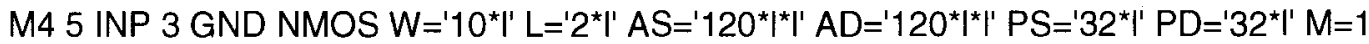

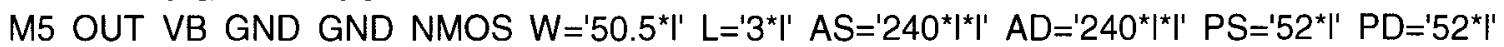

$M=1$

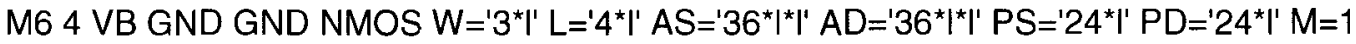

.param $\mathrm{I}=0.8 \mathrm{um}$

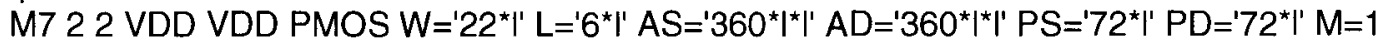

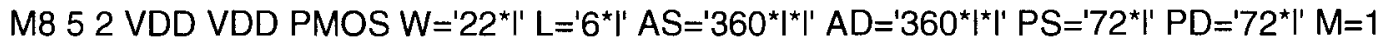

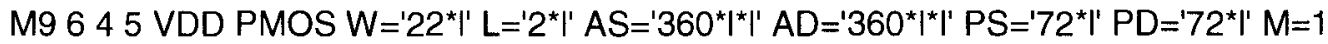

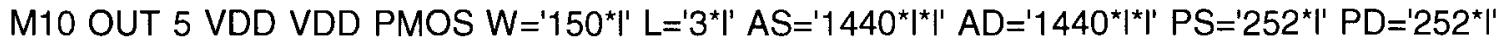

$\mathrm{M}=1$

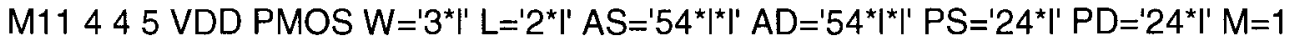

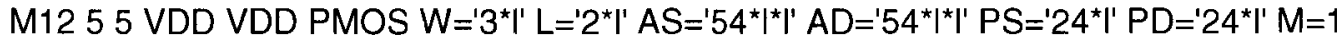

V13 VB Gnd 1

v14 INM Gnd 5.0

v15 INP Gnd 2.5

v16 VDD Gnd 5.0

* End of main circuit: 


\section{Appendix (C)}

\section{BSIM3 Models}

The Cell library shown below consists of 7 Analog Circuits that have been measured as well as simulated. The seventh cell, voltage regulator was formed using the Op-Amp circuit and the voltage reference circuit with a $25 \mathrm{~K} \mathrm{ohm}$ resistor for the built-in resistor. The other cells were the standard cells taken from the Tanner Tools 1.5 um-linear CMOS library and were fabricated by MOSIS. 
Description: N Current mirror consists of two matched $n$-channel transistors which fulfills the following relationship:

$$
\text { lout }=\operatorname{lin}
$$

Library : UofL Analog Cell Library

Primitive Set: UofL LINCMOS2 Cells

Schematic: S-Edit

Mask Layout: L-Edit

File: mir_n.sdb Module: Mir_N

File: mir_n.tdb Cell: Mir_N

L-Edit/SPR: $(1 \lambda=0.8 \mathrm{um})$

\begin{tabular}{|c|c|c|}
\hline Height & Width & Area \\
\hline $66 \lambda$ & $117 \lambda$ & $7722 \lambda^{2}$ \\
\hline
\end{tabular}

ECE Dept.

University of Louisville
Page

Rev 1

1 of 4 
\{All dimensions in $\lambda$ where $1 \lambda=0.8 \mathrm{um}$ )

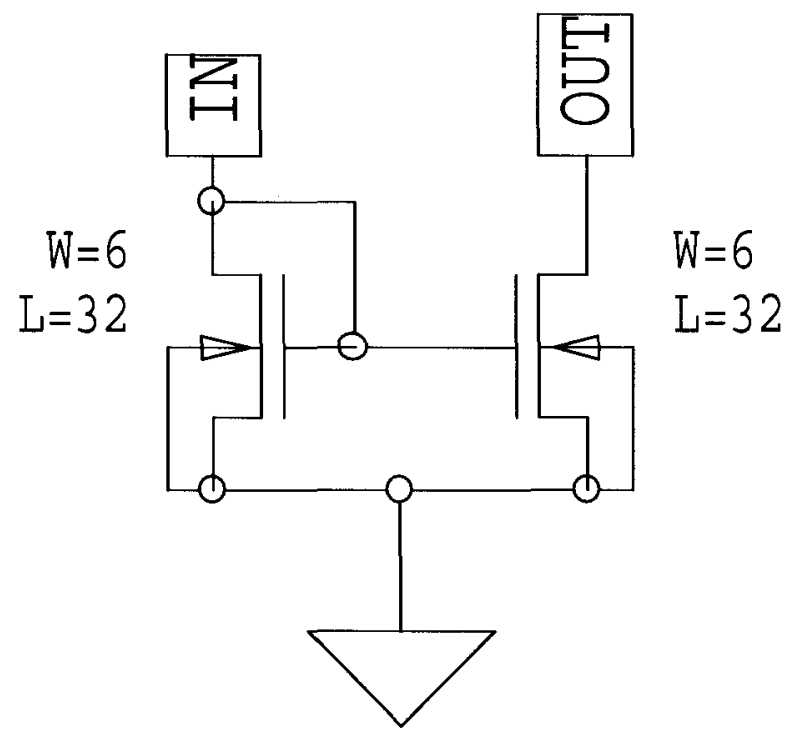

ECE Dept.

University of Louisville

University of Louisville
CMOS Analog Cell Library
AMI 1.5um Process

University of Louisville

AMI 1.5um Process
Rev 1

Mir_N

Page

1 of 4 


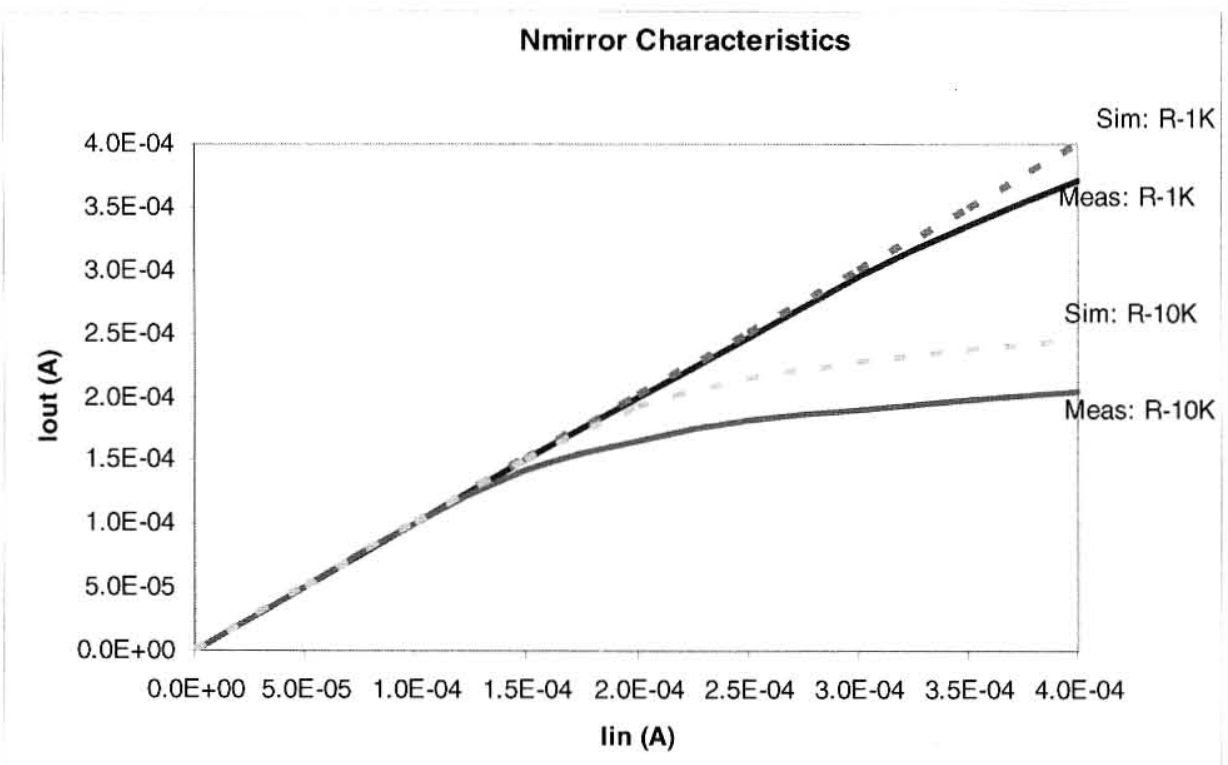

Simulation Error using the t39t.md with a load of $1 \mathrm{~K}: 1.87 \%$

$10 \mathrm{~K}: 10.48 \%$

ECE Dept.

University of Louisville
University of Louisville

CMOS Analog Cell Library

AMI 1.5um Process
Rev 1

Mir_N
Page

3 of 4 


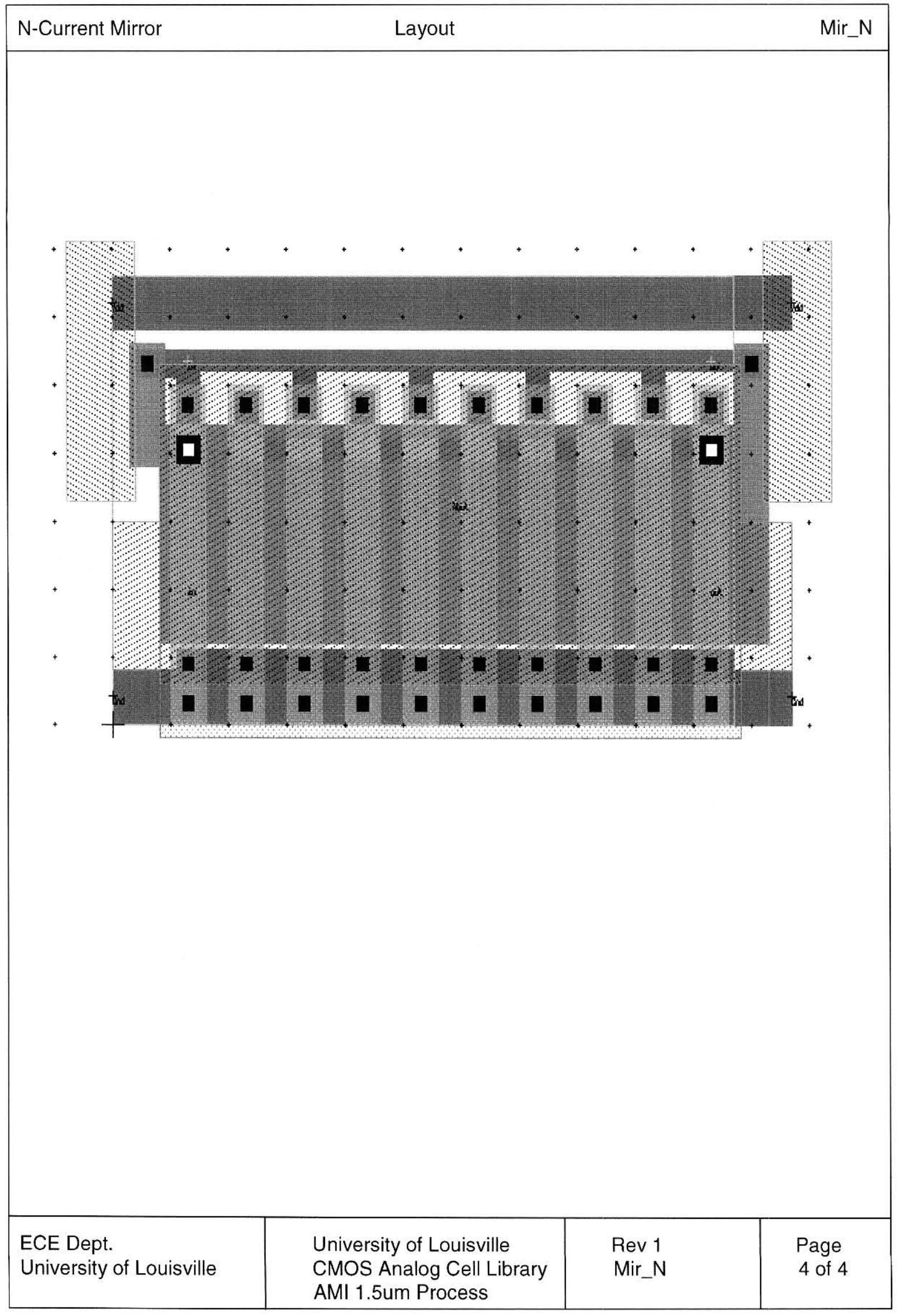


Description: P Current mirror consists of two matched $p$-channel transistors which fulfills the following relationship:

$$
\text { lout }=\operatorname{lin}
$$

Library: UofL Analog Cell Library

Primitive Set: UofL LINCMOS2 Cells

Schematic: S-Edit
SYMBOL

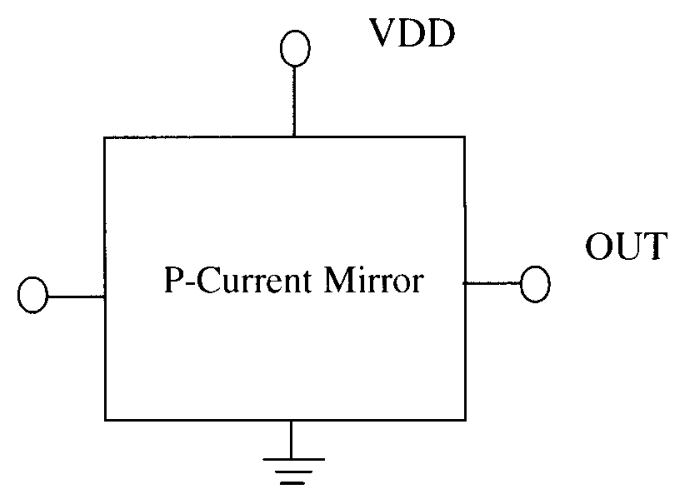

Mask Layout: L-Edit

L-Edit/SPR: $(1 \lambda=0.8 \mathrm{um})$

\begin{tabular}{|c|c|c|}
\hline Height & Width & Area \\
\hline $66 \lambda$ & $117 \lambda$ & $7722 \lambda^{2}$ \\
\hline
\end{tabular}

File: Mir_P.sdb Module: Mir_P

File: Mir_P.tdb

Cell: Mir_P 
\{All dimensions in $\lambda$ where $1 \lambda=0.8 \mathrm{um}$ )

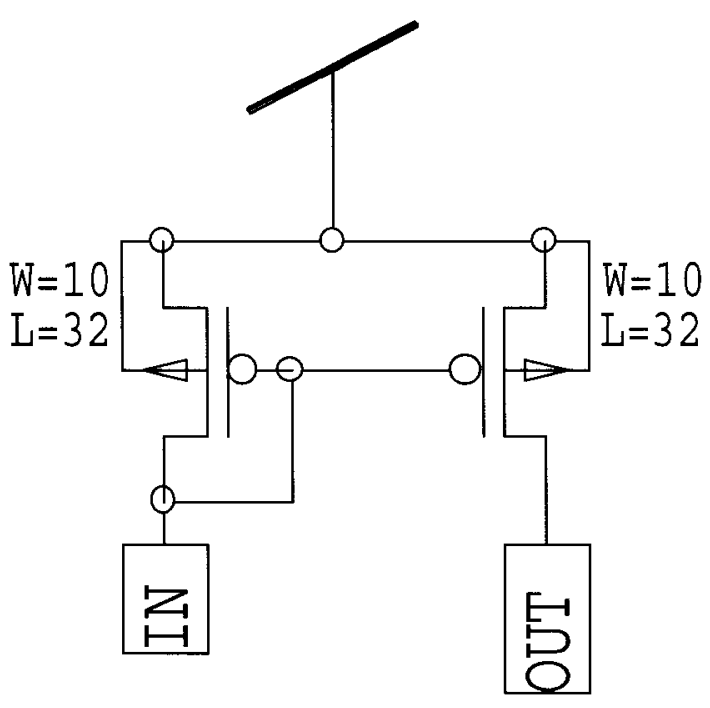

ECE Dept.

University of Louisville
Rev 1

Mir_P

Page

2 of 4 


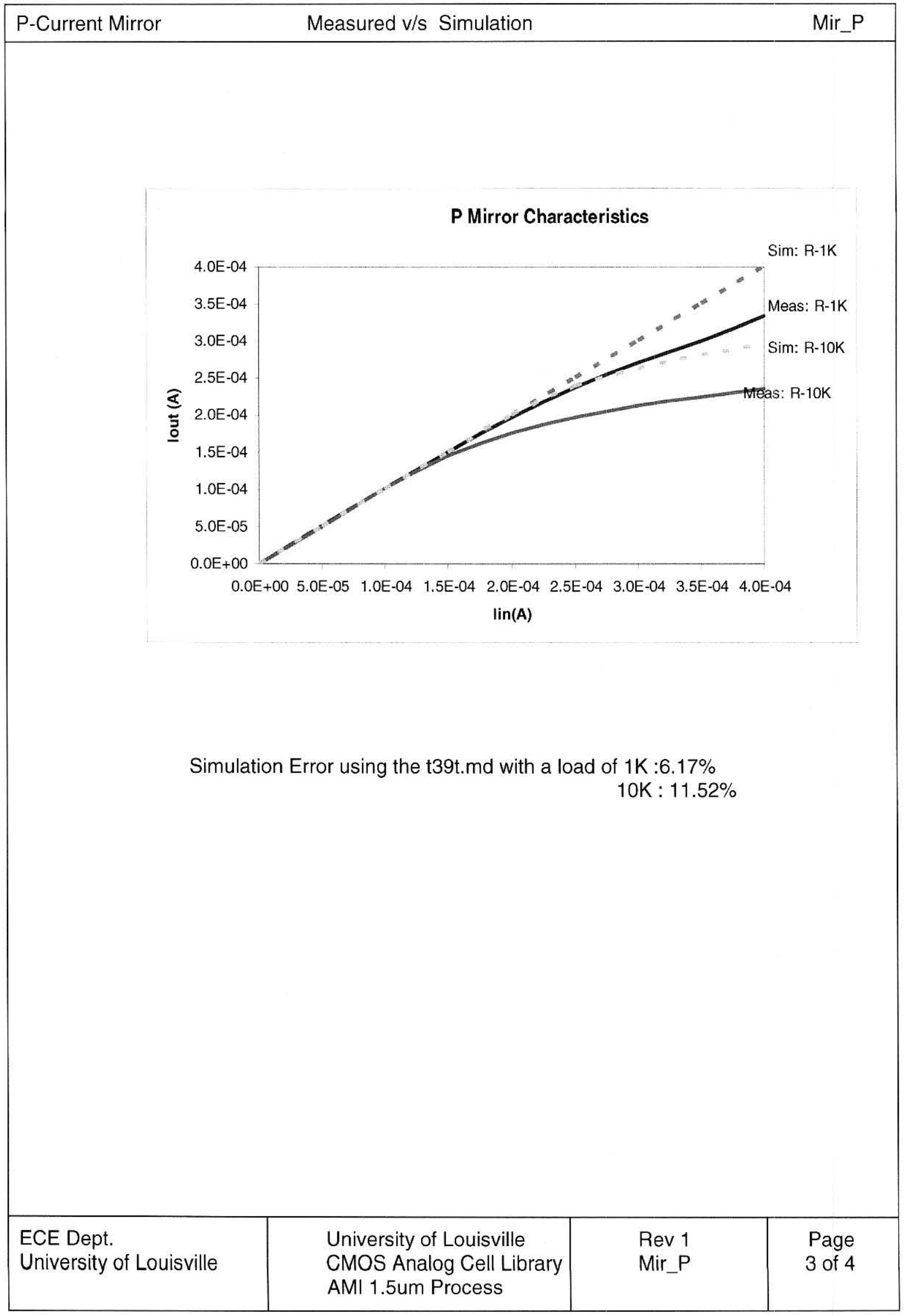




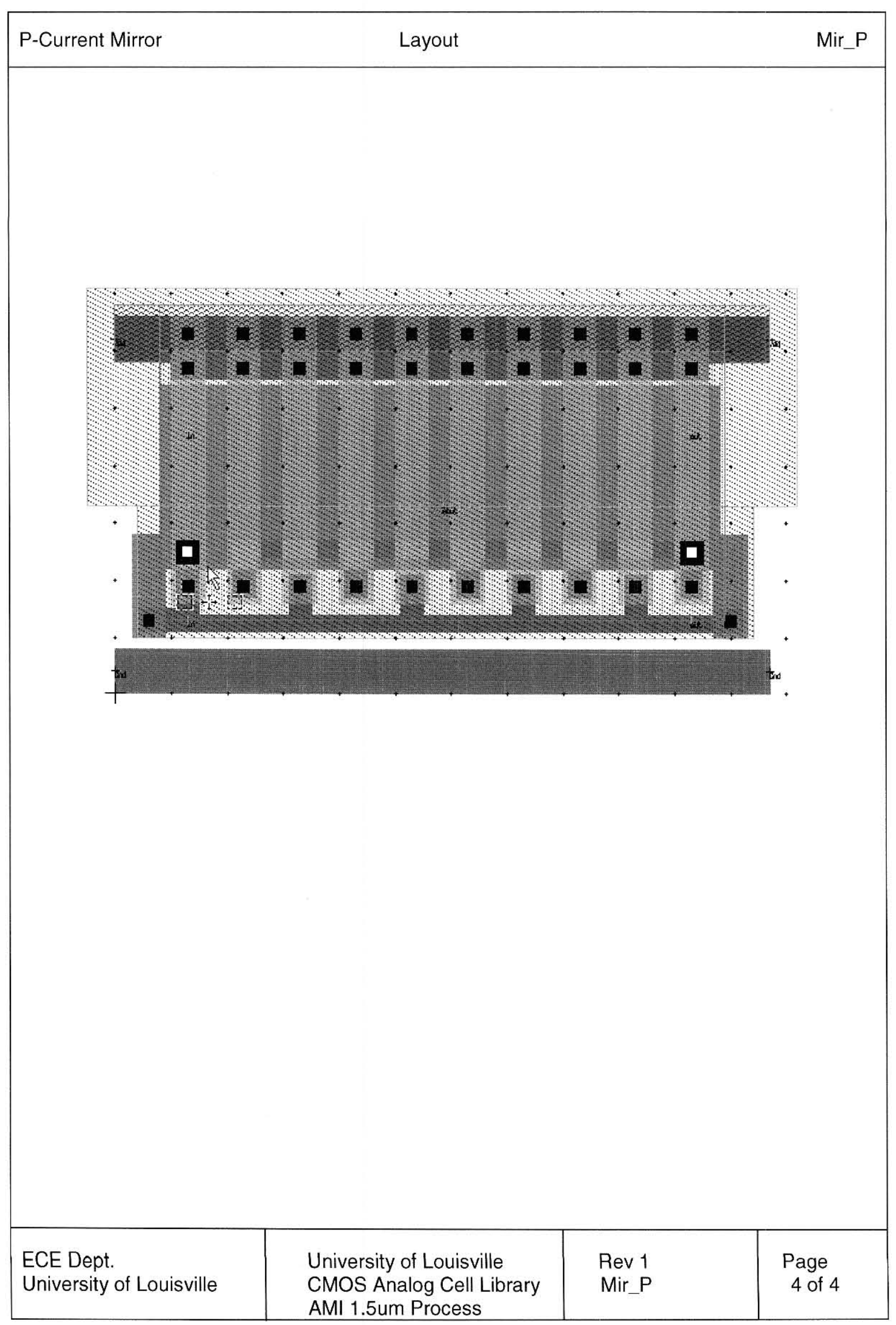


Description: Bias Generator uses a single

Supply to generate the following voltages:

OUT1 $=\mathrm{VDD} / 1.7=0.6 \mathrm{VDD}$

OUT2 $=\mathrm{VDD} / 2=0.5 \mathrm{VDD}$

OUT3 $=$ VDD $/ 3.5=0.3 \mathrm{VDD}$

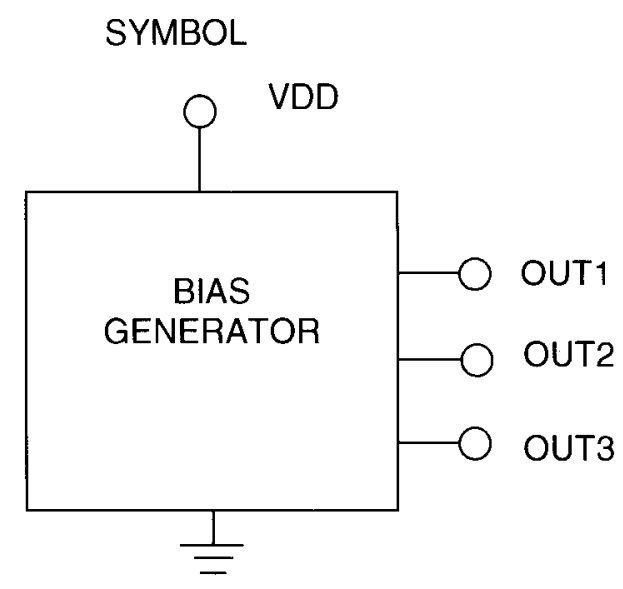

Library : UofL Analog Cell Library

Primitive Set: UofL LINCMOS2 Cells

Schematic: S-Edit

File: Bias_Gen.sdb Module: Bias_Gen

Mask Layout: L-Edit

File: Bias_Gen.tdb Cell: Bias_Gen

L-Edit/SPR: $(1 \lambda=0.8 \mathrm{um})$

\begin{tabular}{|c|c|c|}
\hline Height & Width & Area \\
\hline $66 \lambda$ & $45 \lambda$ & $2970 \lambda^{2}$ \\
\hline
\end{tabular}

Specifications:

\begin{tabular}{c|c|c|c} 
& Min & Nom & Max \\
\hline VDD Range & $2 \mathrm{~V}$ & $3 \mathrm{~V}$ & $5 \mathrm{~V}$ \\
\hline IDD & $0.47 \mathrm{uA}$ & $15 \mathrm{uA}$ & $94 \mathrm{uA}$
\end{tabular}

ECE Dept.

University of Louisville
University of Louisville CMOS Analog Cell Library AMI 1.5um Process
Rev 1

Bias_Gen

Page

1 of 4 


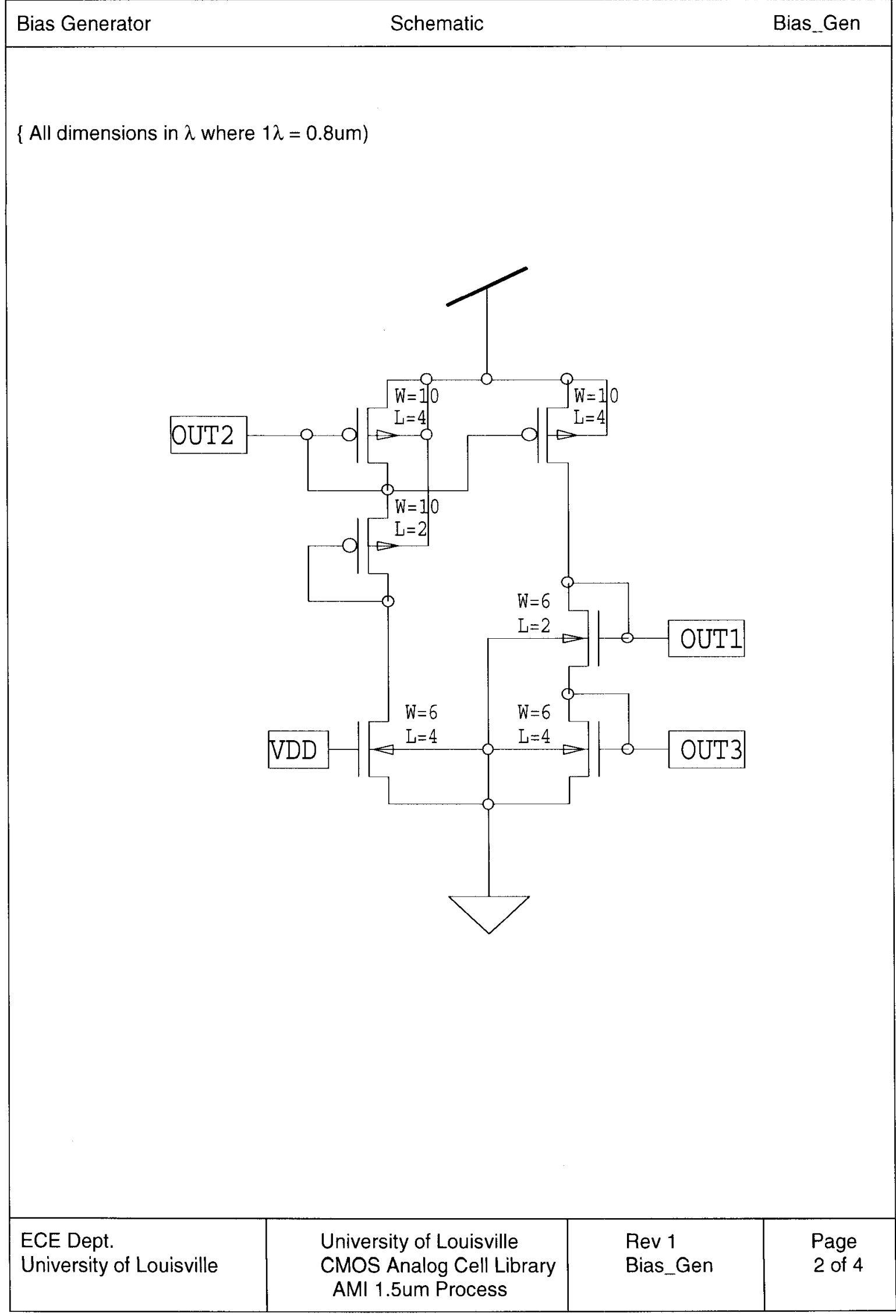




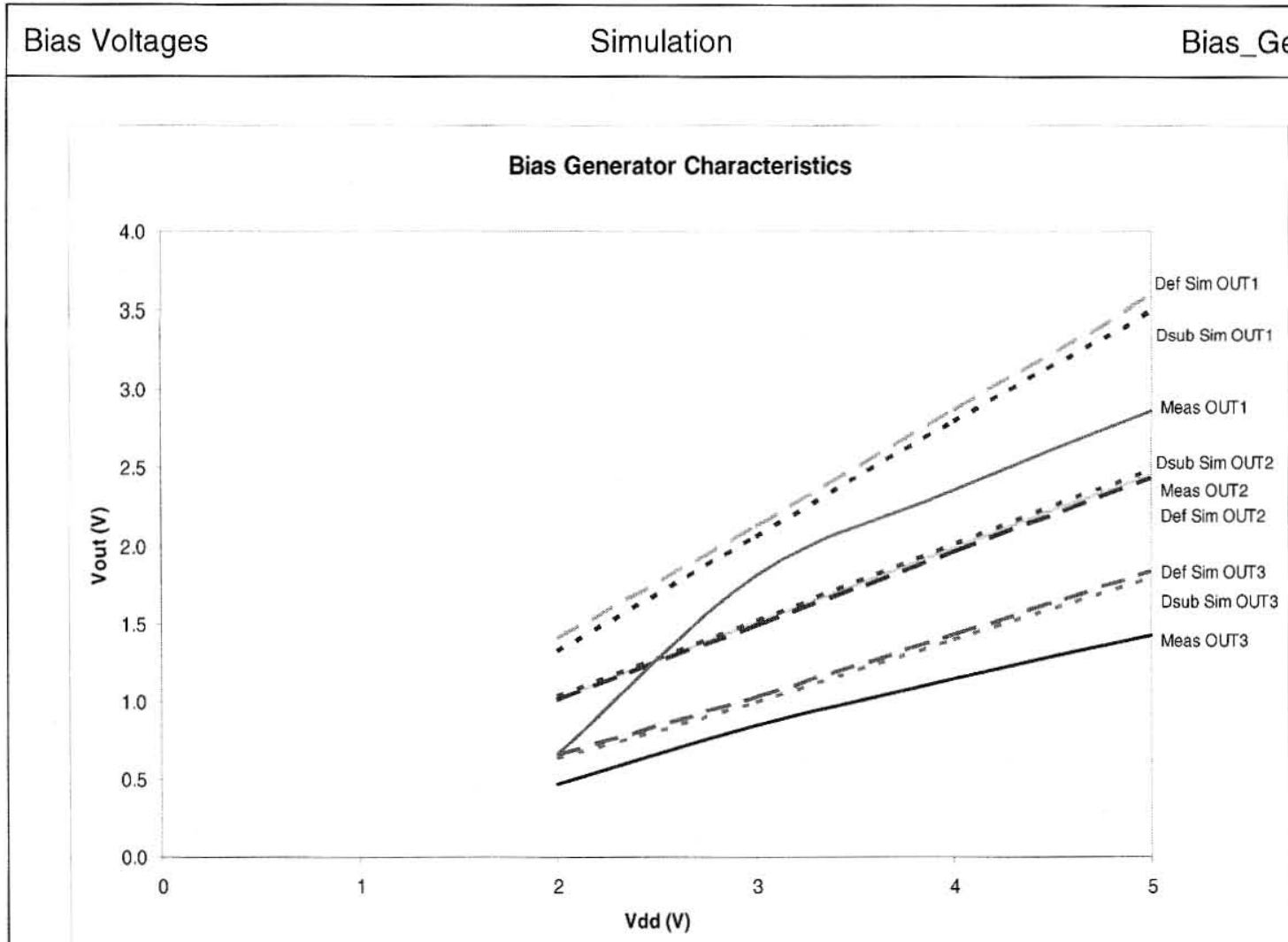

Simulation Error using T32Q BSIM3 model from 2-18-03 Mask:

(from $\mathrm{VDD}=3,4$ and $5 \mathrm{~V}$ )

$$
\begin{aligned}
& \text { OUT1 }=15.31 \% \text { over } 17.47 \% \text { (default ) } \\
& \text { OUT2 }=0.87 \% \text { over } 1.45 \% \text { (default ) } \\
& \text { OUT3 }=17.41 \% \text { over } 19.8 \% \text { (default) }
\end{aligned}
$$

ECE Dept.

University of Louisville
University of Louisville CMOS Analog Cell Library AMI 1.5um Process
Rev 1

Bias-Gen

Page 3 of 4 


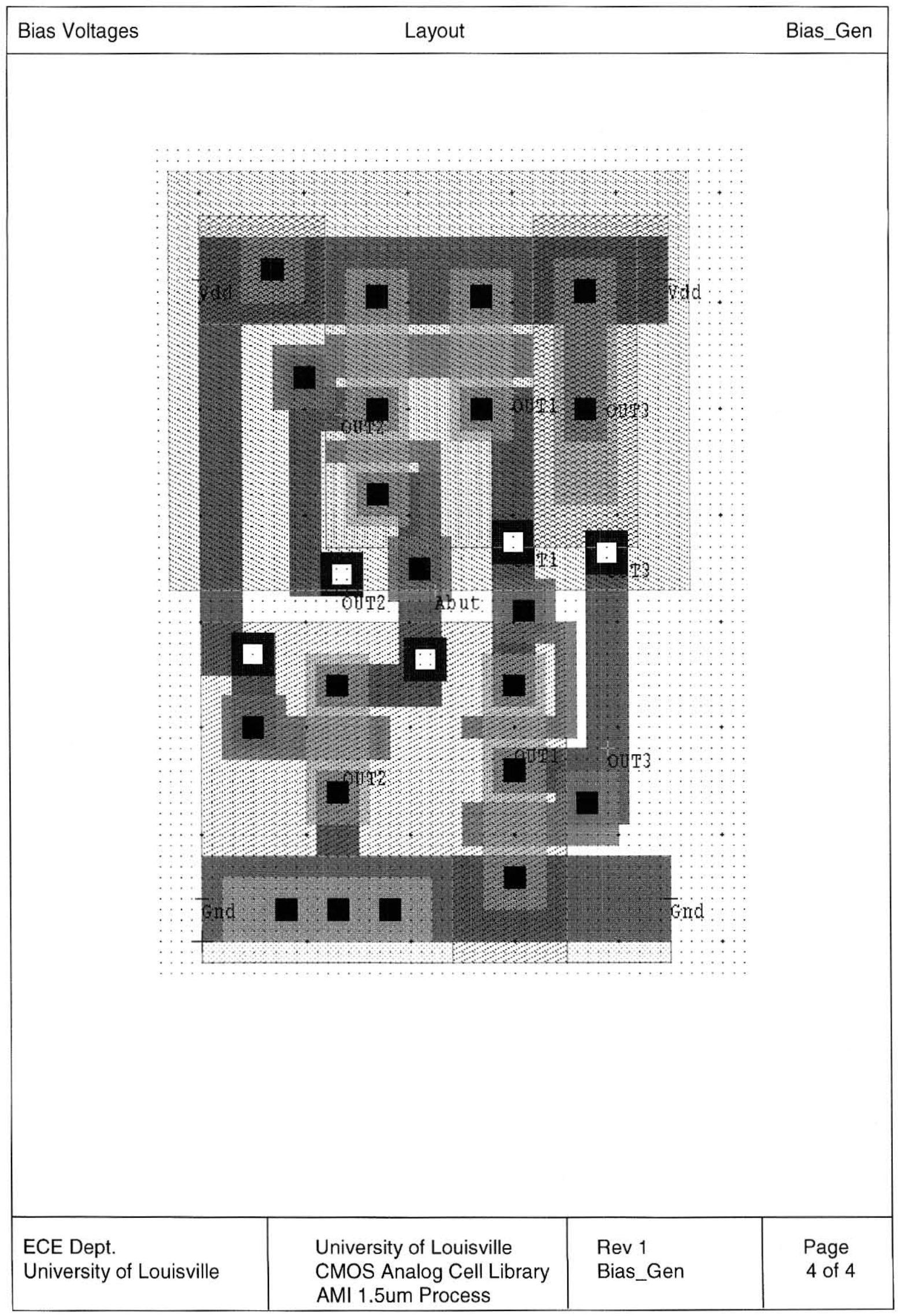


Description: Voltage Reference uses a single supply voltage to generate the output voltage: VREF $=0.7$ VDD

Library : UofL Analog Cell Library

Primitive Set: UofL LINCMOS2 Cells

Schematic: S-Edit

Mask Layout: L-Edit

L-Edit/SPR: $(1 \lambda=0.8 \mathrm{um})$
SYMBOL

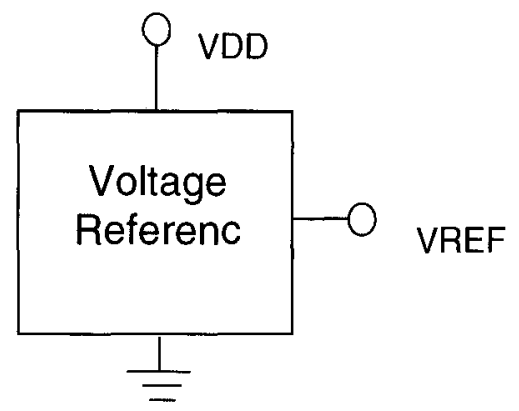

File: Voltage_Ref.sdb Module: Voltage_Ref

File: Voltage_Ref.tdb Cell: Voltage_Ref

\begin{tabular}{|c|c|c|}
\hline Height & Width & Area \\
\hline $66 \lambda$ & $209.5 \lambda$ & $13827 \lambda^{2}$ \\
\hline
\end{tabular}

Specifications:

\begin{tabular}{c|c|c|c} 
& Min & Nom & Max \\
\hline VDD Range & $2 \mathrm{~V}$ & $3 \mathrm{~V}$ & $5 \mathrm{~V}$ \\
\hline IDD & $32.5 \mathrm{uA}$ & $52.3 \mathrm{uA}$ & $94.2 \mathrm{uA}$ \\
\hline $\begin{array}{c}\text { Regulation } \\
(\text { VDD }=2 \text { (V to } 5 \mathrm{~V})\end{array}$ & - & $34 \mathrm{mV} N$ & -
\end{tabular}

ECE Dept.

University of Louisville
University of Louisville

CMOS Analog Cell Library AMI 1.5um Process

Rev 1
Voltage_Ref

Page

1 of 4 
$\{$ All dimensions in $\lambda$ where $1 \lambda=0.8 u m$ )

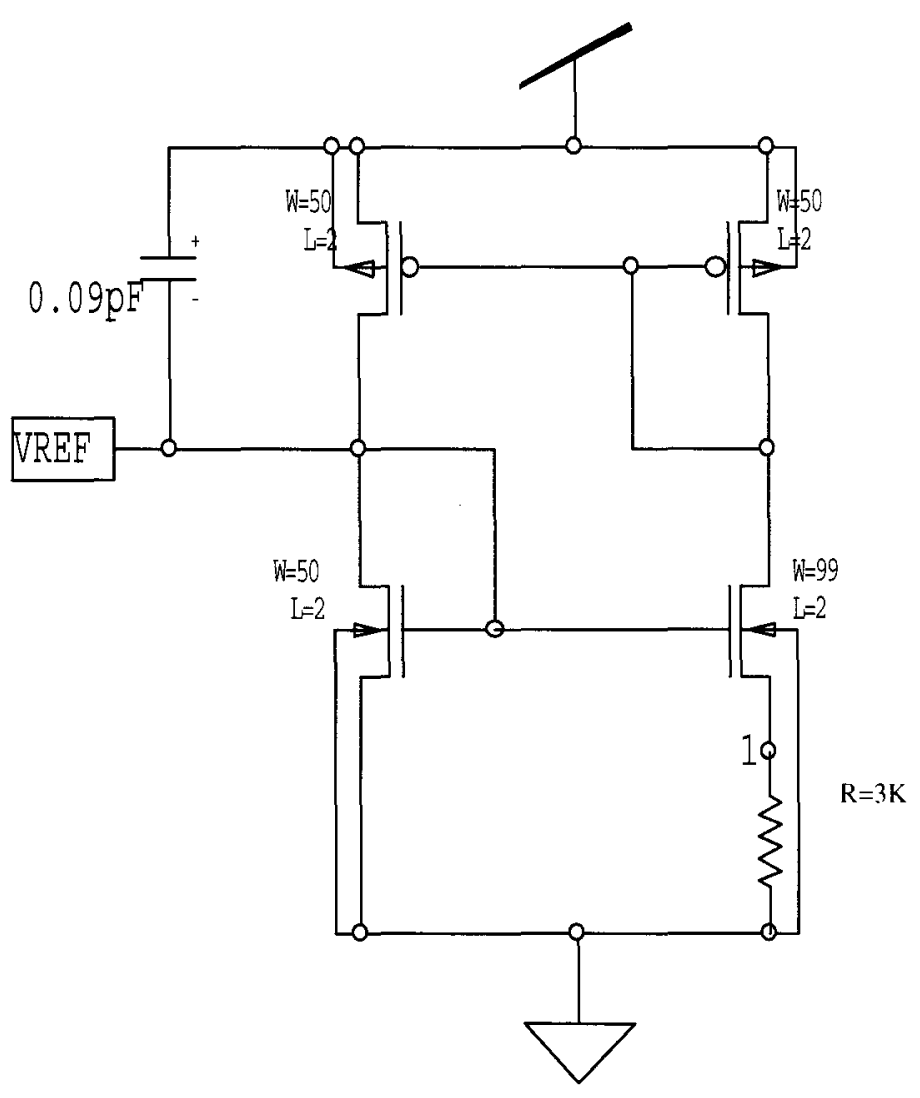

ECE Dept.

University of Louisville
University of Louisville CMOS Analog Cell Library AMI 1.5um Process
Rev 1

Voltage_Ref
Page

2 of 4 


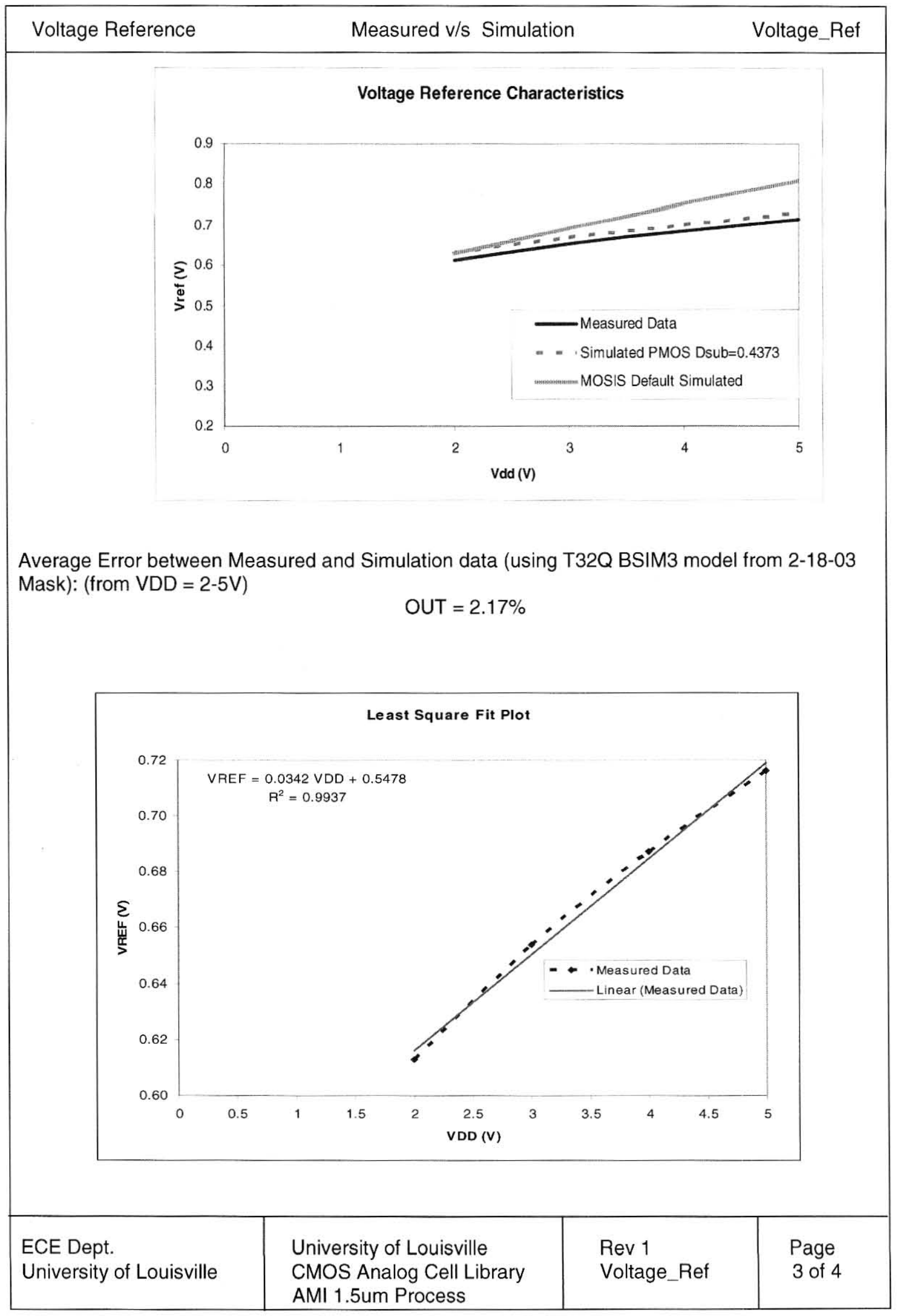




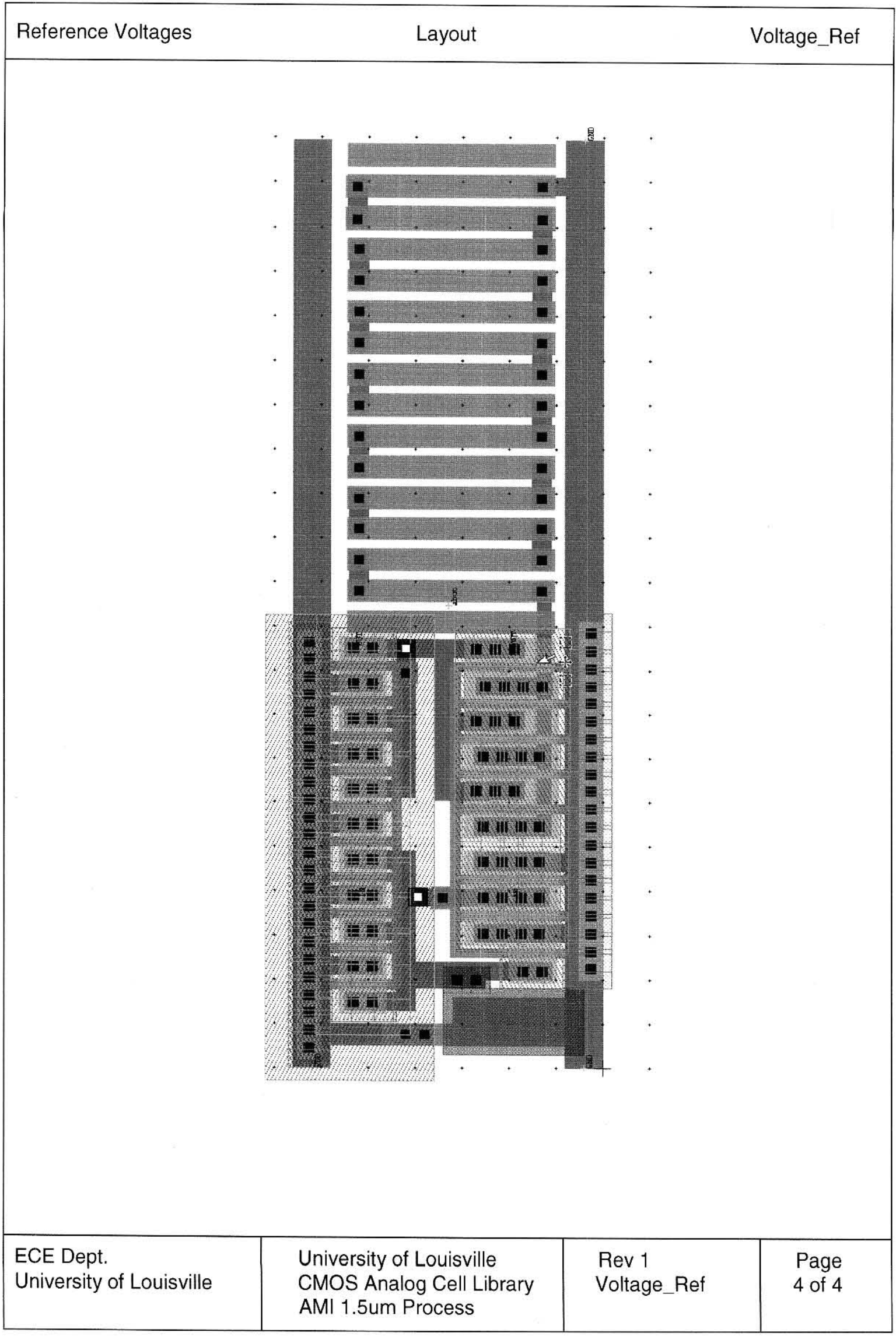


Description: : Analog Buffer uses a single supply voltage SYMBOL

To drive up to a $2 \mathrm{~K}$ load, where Vin = Vout

Library : UofL Analog Cell Library

Primitive Set: UofL LINCMOS2 Cells

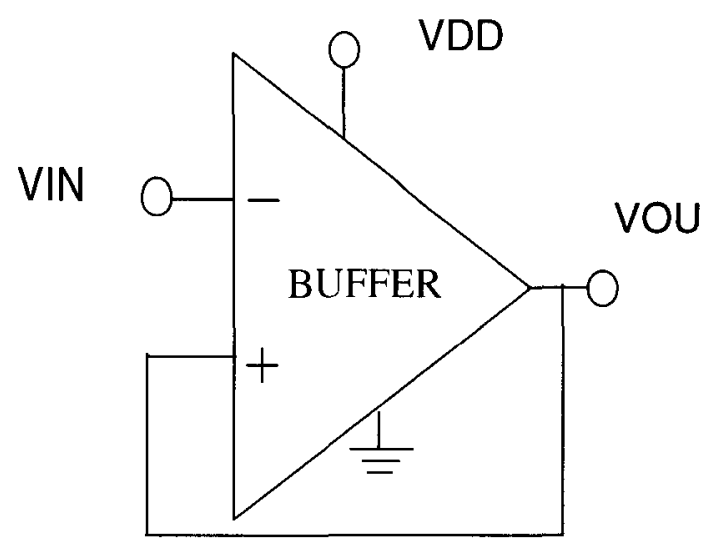

Schematic: S-Edit

File: ABuf.sdb

Module: ABuf

Mask Layout: L-Edit

File: ABuf.tdb

Cell: ABuf

L-Edit/SPR: $(1 \lambda=0.8 \mathrm{um})$

\begin{tabular}{|c|c|c|}
\hline Height & Width & Area \\
\hline $66 \lambda$ & $108.5 \lambda$ & $7161 \lambda^{2}$ \\
\hline
\end{tabular}

Specifications:

\begin{tabular}{c|c|c|c} 
& Min & Nom & Max \\
\hline VDD Range & $2 \mathrm{~V}$ & $3 \mathrm{~V}$ & $5 \mathrm{~V}$ \\
\hline IDD & $30.55 \mathrm{uA}$ & $109 \mathrm{uA}$ & $414 \mathrm{uA}$
\end{tabular}

ECE Dept.

University of Louisville
University of Louisville

CMOS Analog Cell Library

AMI 1.5um Process
Page

1 of 5 
\{All dimensions in $\lambda$ where $1 \lambda=0.8 \mathrm{um}$ )

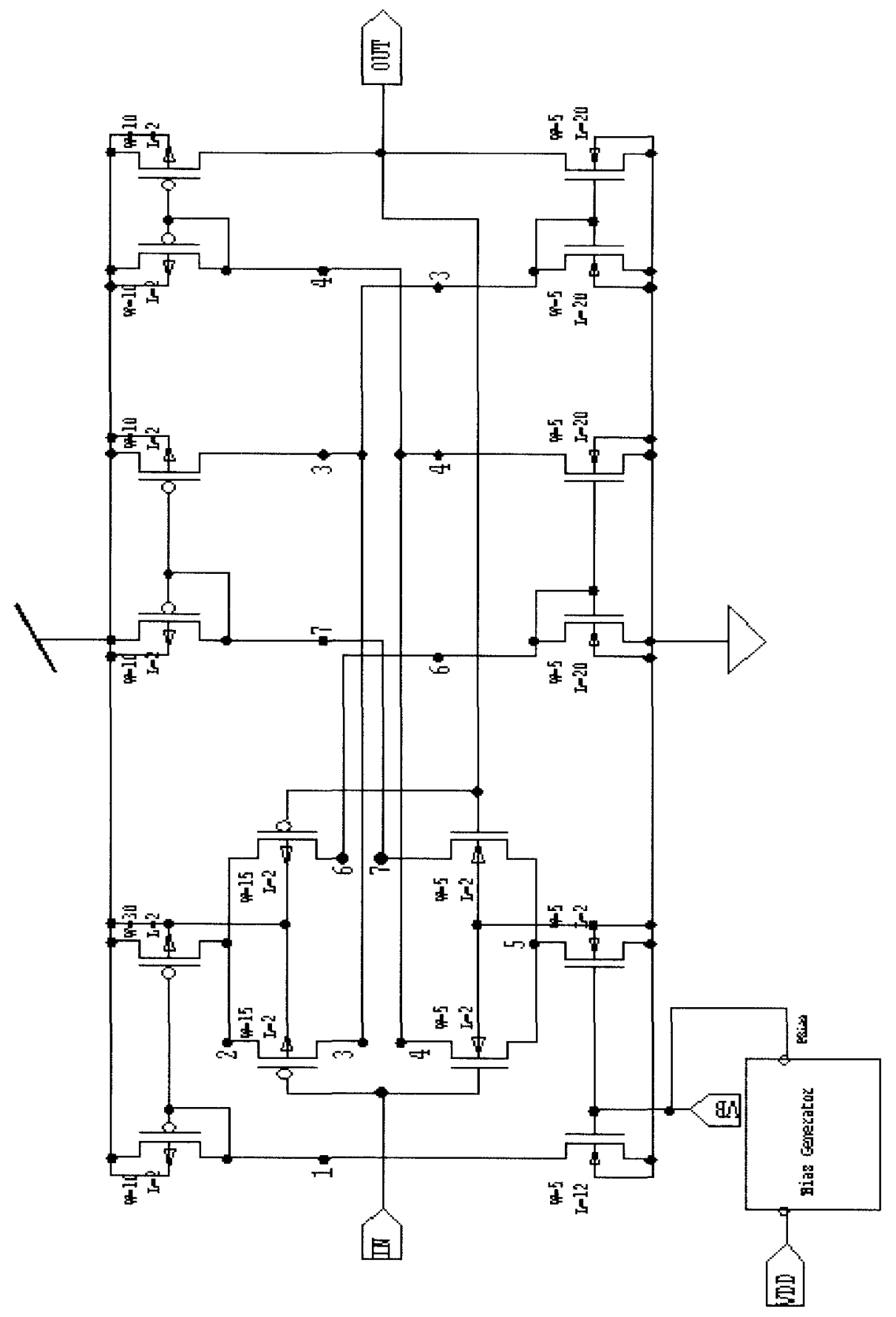

ECE Dept.

University of Louisville
University of Louisville CMOS Analog Cell Library AMI 1.5um Process
Rev 1

ABuf
Page

2 of 5 


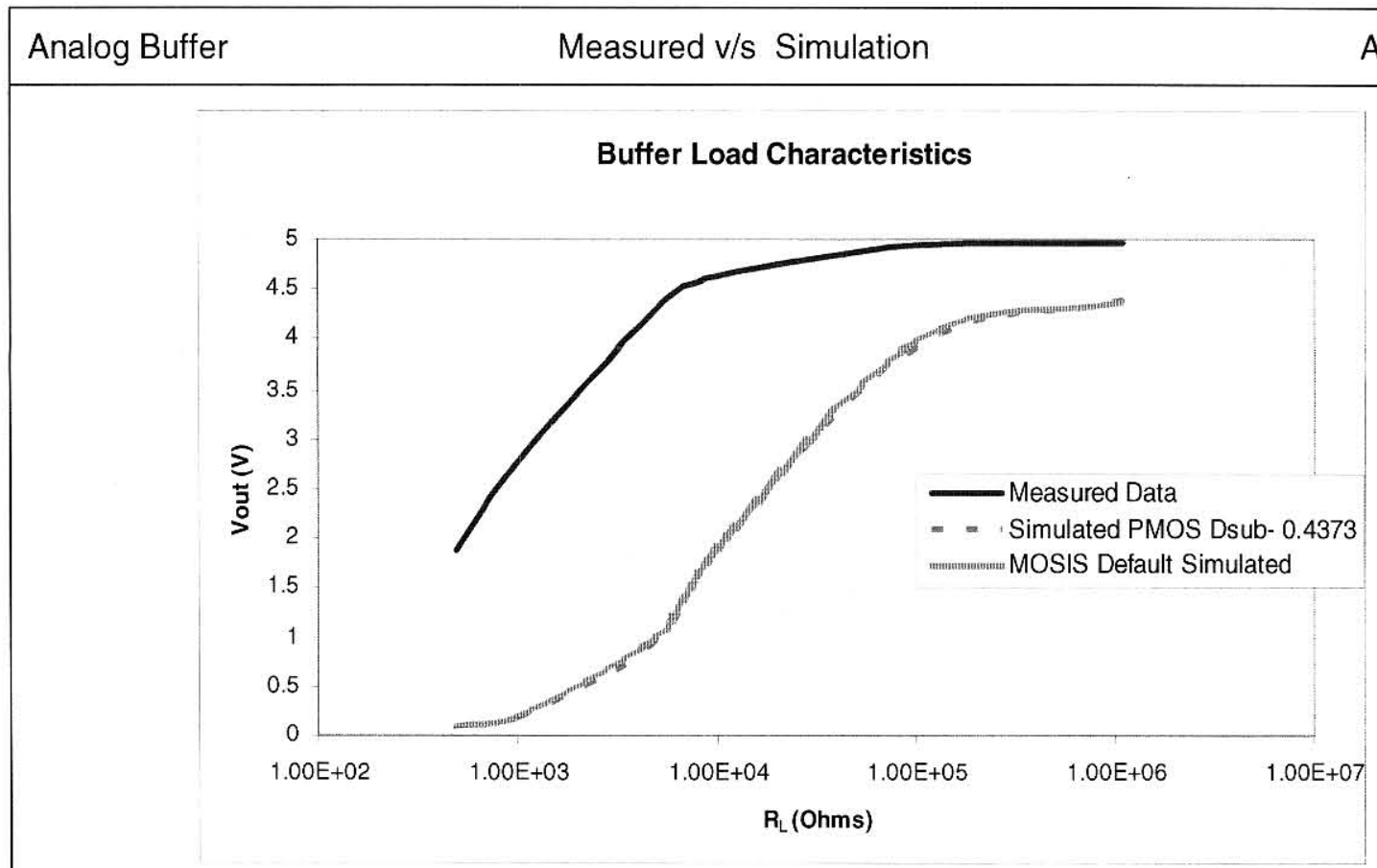

$\mathrm{R}_{\mathrm{L}}=2.5 \mathrm{~K}$ (measured Data), 600K (Simulated Data)

\section{Buffer DC Characteristics}

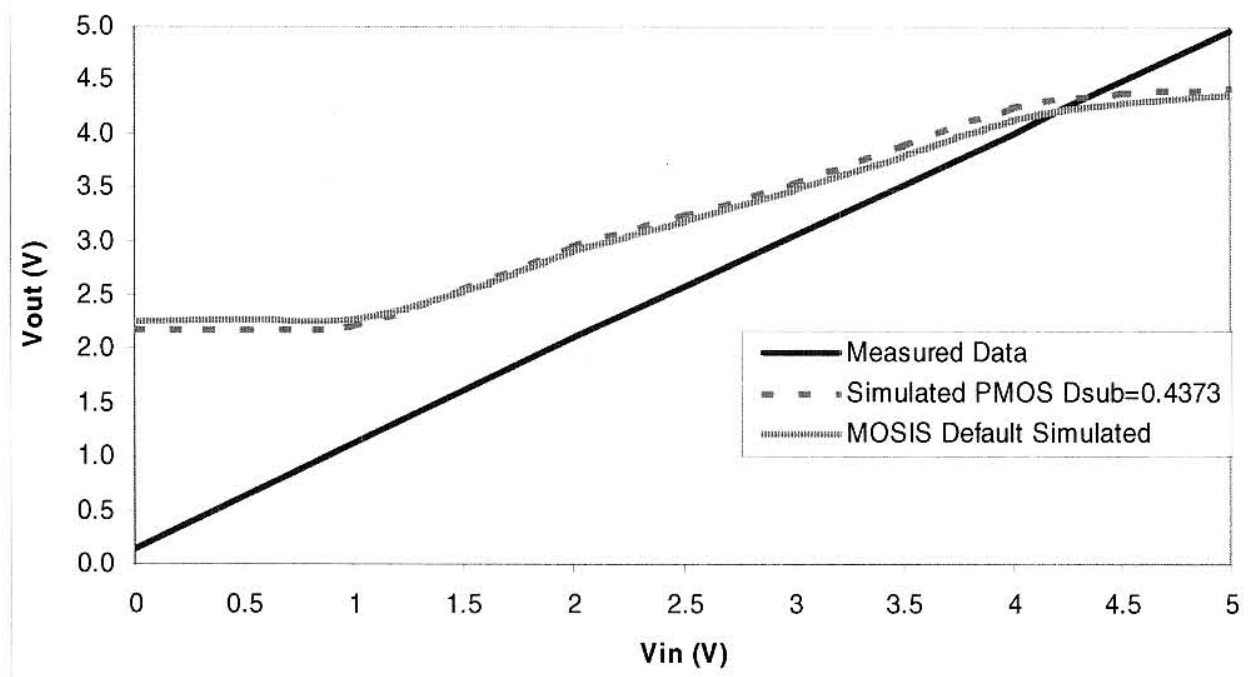

No Load Connected.

ECE Dept.

University of Louisville
University of Louisville CMOS Analog Cell Library AMI 1.5um Process 


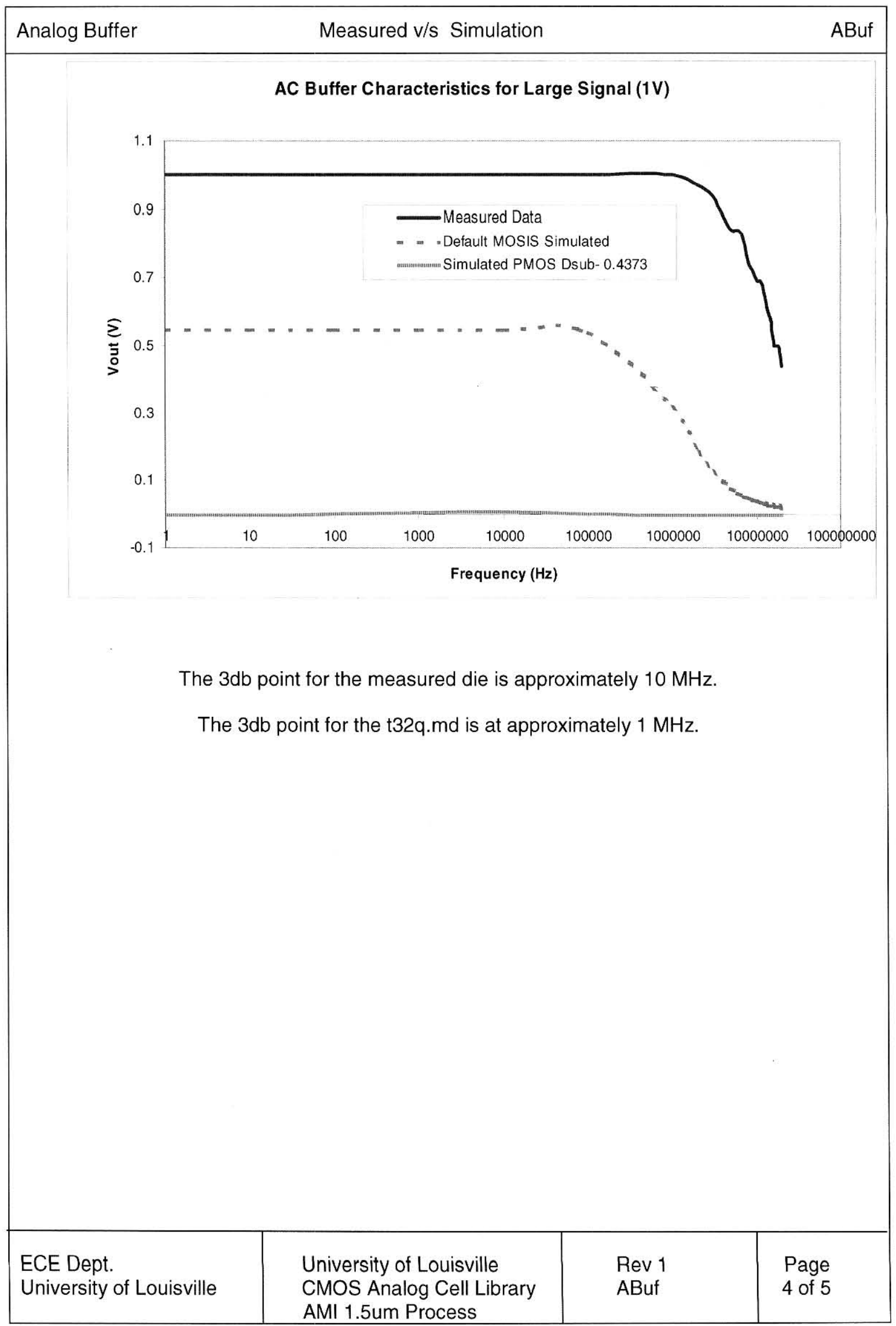




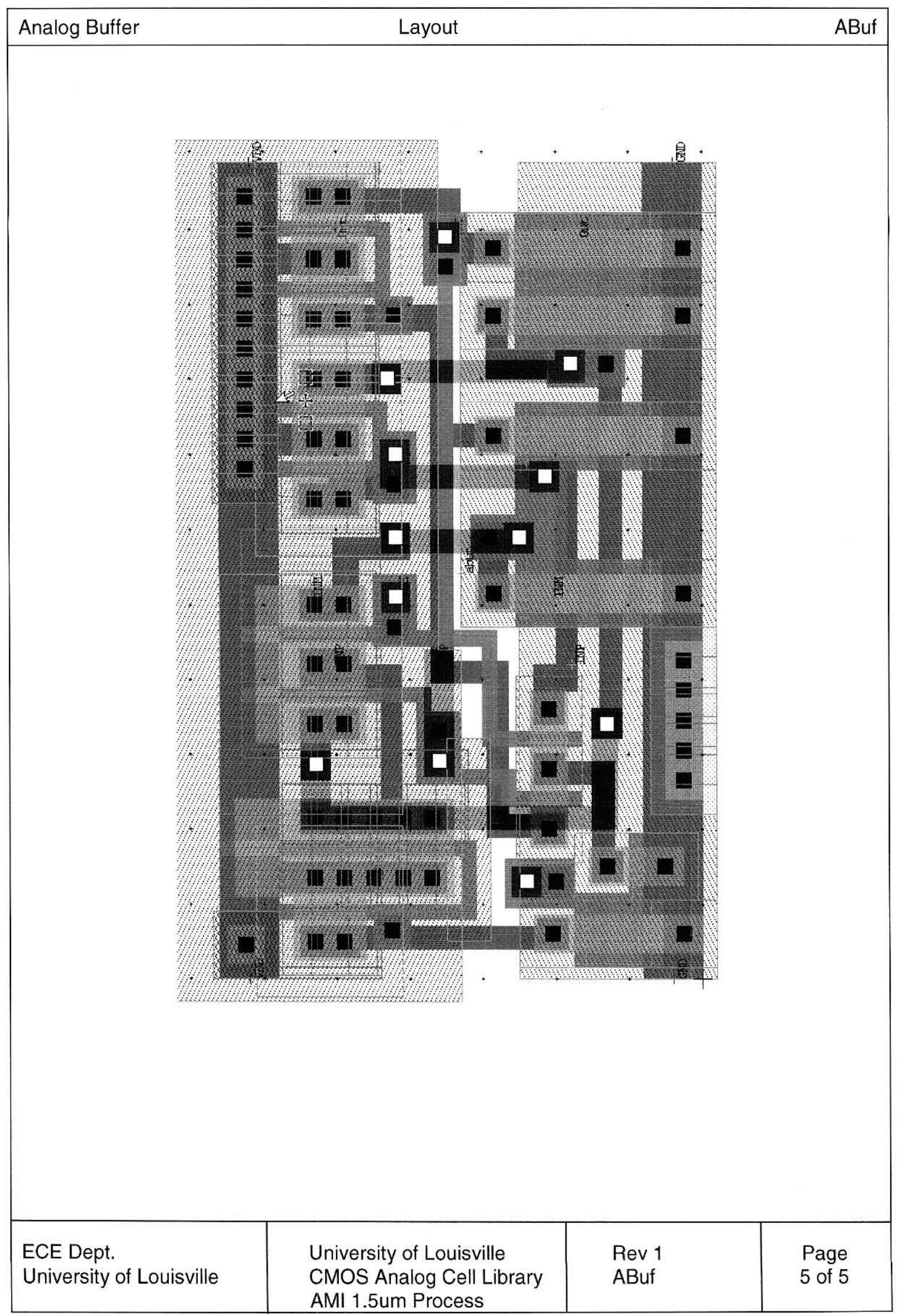




\section{Comparator}

Comp

Description: Comparator consists of two input voltages,

VIN and VREF. The output is determined as follows:

If $\mathrm{VIN}>\mathrm{VREF}-\mathrm{VOUT}=\mathrm{VDD}$

$\mathrm{VIN}<\mathrm{VREF}-\mathrm{VOUT}=0$.

SYMBOL

Library : UofL Analog Cell Library

Primitive Set: UofL LINCMOS2 Cells

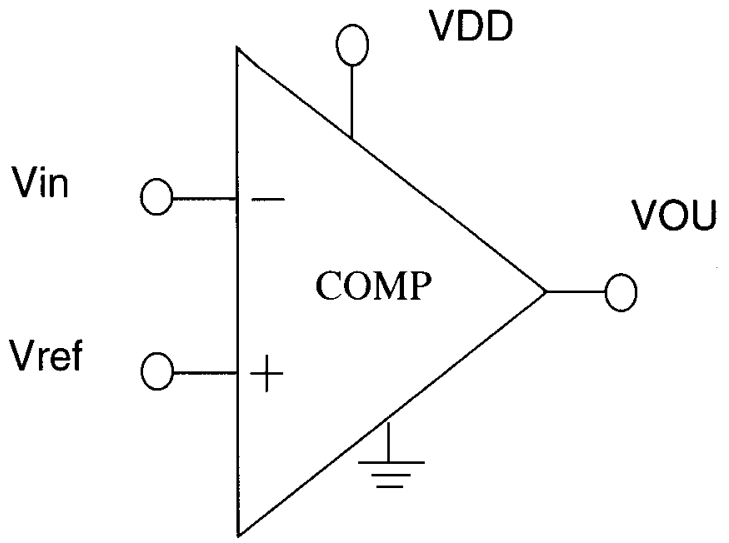

Schematic: S-Edit

File: Comp.sdb

Module: Comp

Mask Layout: L-Edit

File: Comp.tdb

Cell: Comp

L-Edit/SPR: $(1 \lambda=0.8 \mathrm{um})$

\begin{tabular}{|c|c|c|}
\hline Height & Width & Area \\
\hline $105 \lambda$ & $136 \lambda$ & $14280 \lambda^{2}$ \\
\hline
\end{tabular}

Specifications:

\begin{tabular}{c|c|c|c} 
& Min & Nom & Max \\
\hline VDD Range & $2 \mathrm{~V}$ & $3 \mathrm{~V}$ & $5 \mathrm{~V}$ \\
\hline IDD & $32.1 \mathrm{uA}$ & $158 \mathrm{uA}$ & $564 \mathrm{uA}$ \\
\hline Switching Voltage & $0.57 \mathrm{~V}$ & $0.81 \mathrm{~V}$ & $2.08 \mathrm{~V}$
\end{tabular}

ECE Dept.

University of Louisville

University of Louisville

CMOS Analog Cell Library

AMI 1.5um Process
Rev 1

Page

Comp 
\{All dimensions in $\lambda$ where $1 \lambda=0.8 \mathrm{um}$ )

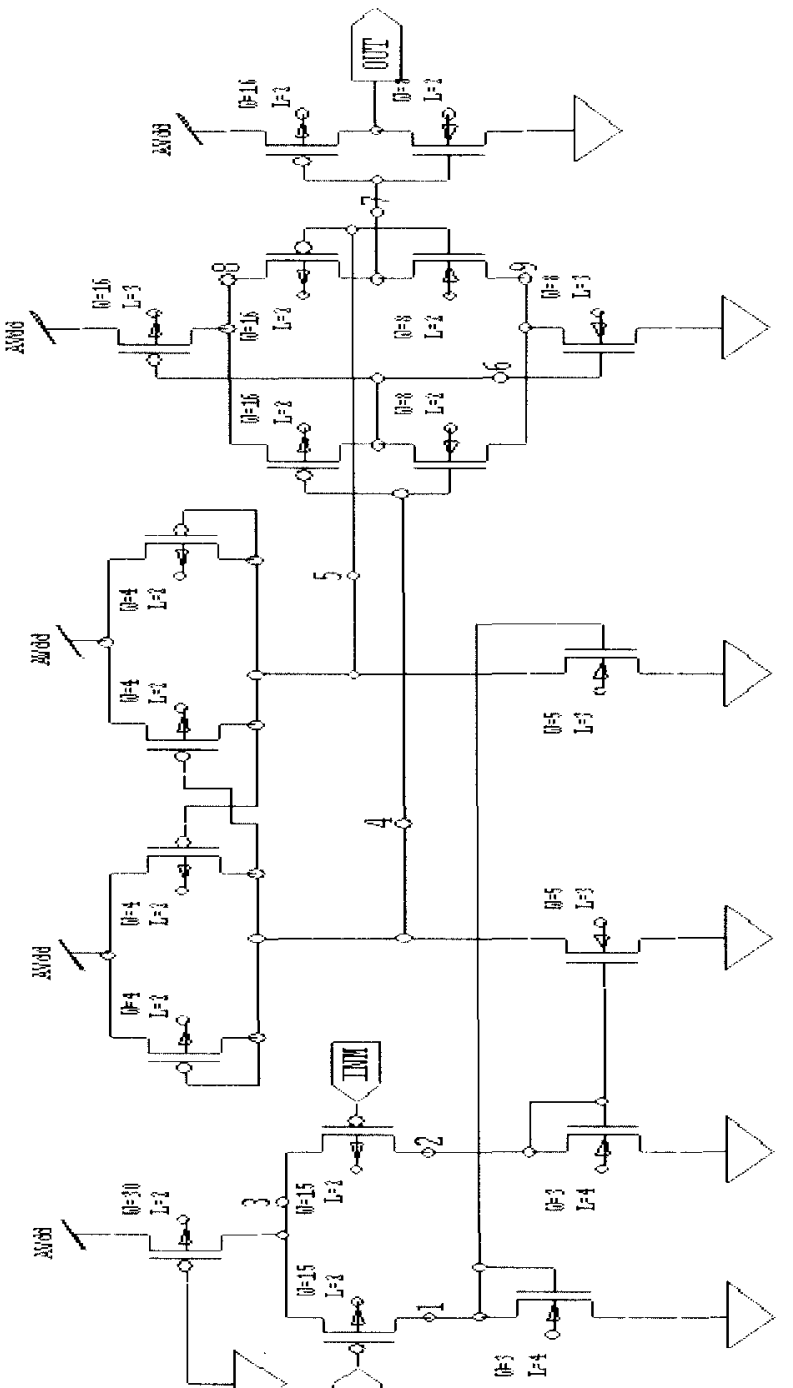

圆

ECE Dept.

University of Louisville
University of Louisville

CMOS Analog Cell Library

AMI 1.5um Process
Rev 1

Comp
Page

2 of 4 


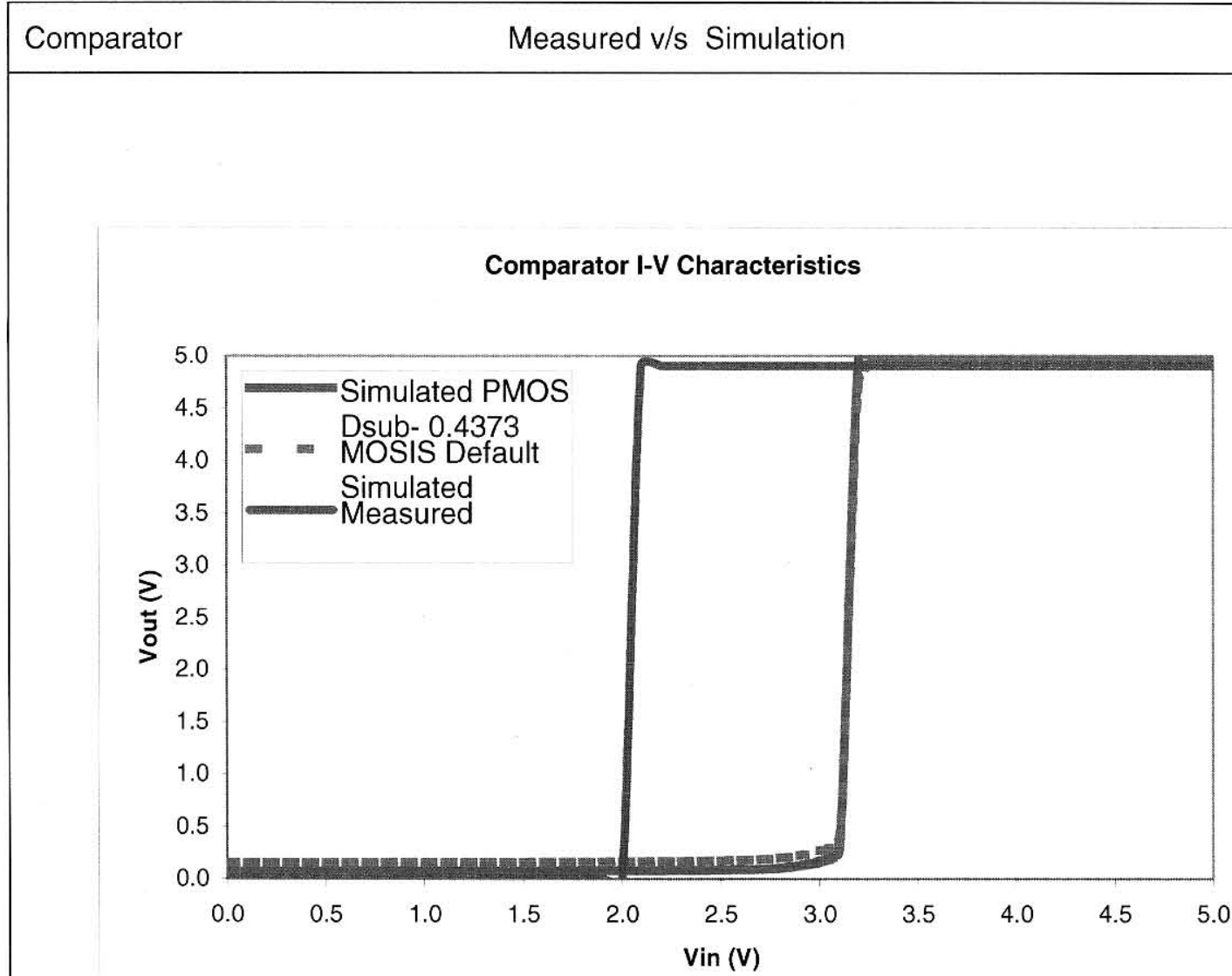

Switching Voltage (Meas): $2 \mathrm{~V},(\mathrm{Sim}): 3 \mathrm{~V}$ for $\mathrm{Vref}=2.5 \mathrm{~V}, \mathrm{Vdd}=5 \mathrm{~V}$

ECE Dept.

University of Louisville
University of Louisville CMOS Analog Cell Library AMI 1.5um Process
Rev 1

Comp 


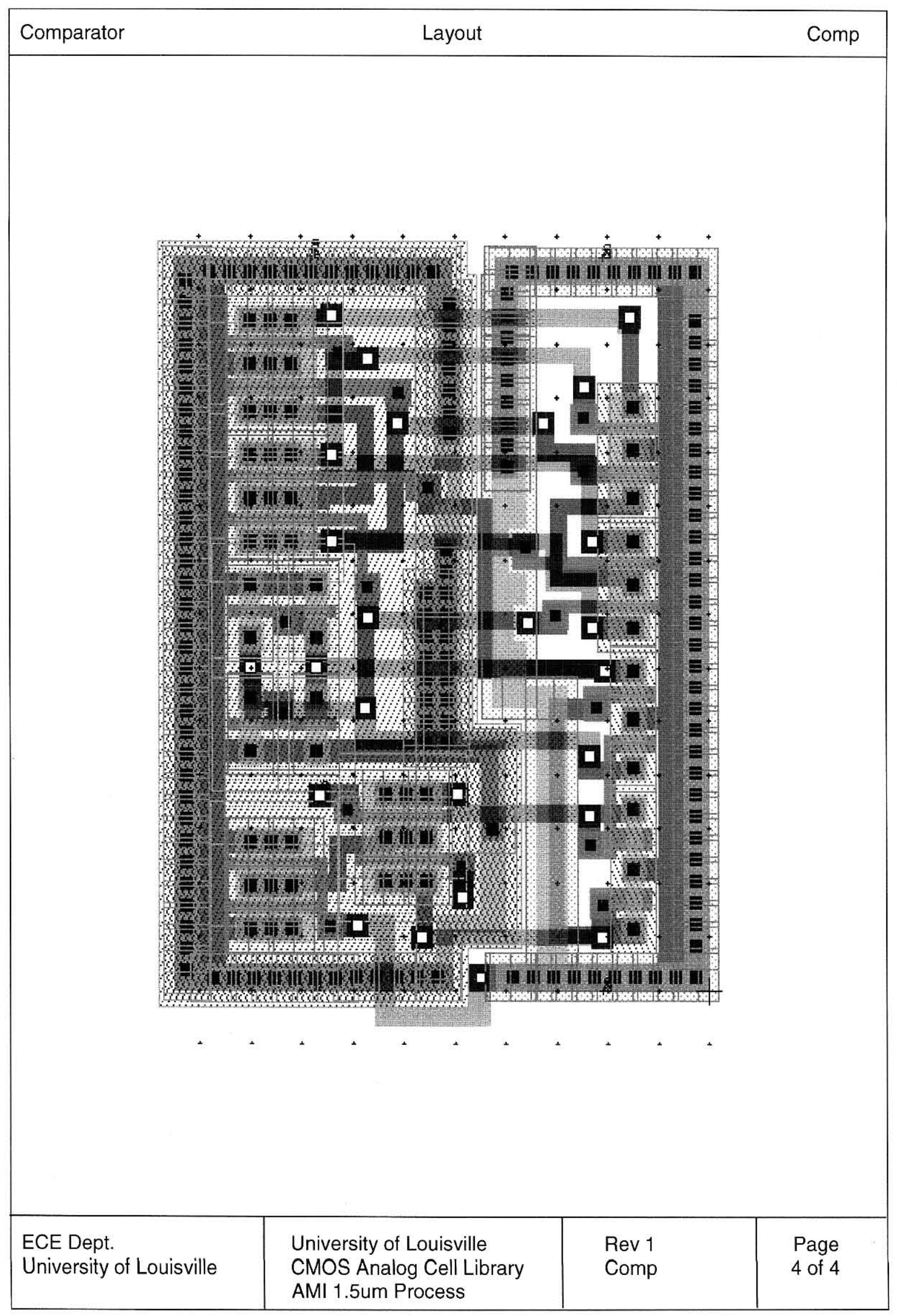




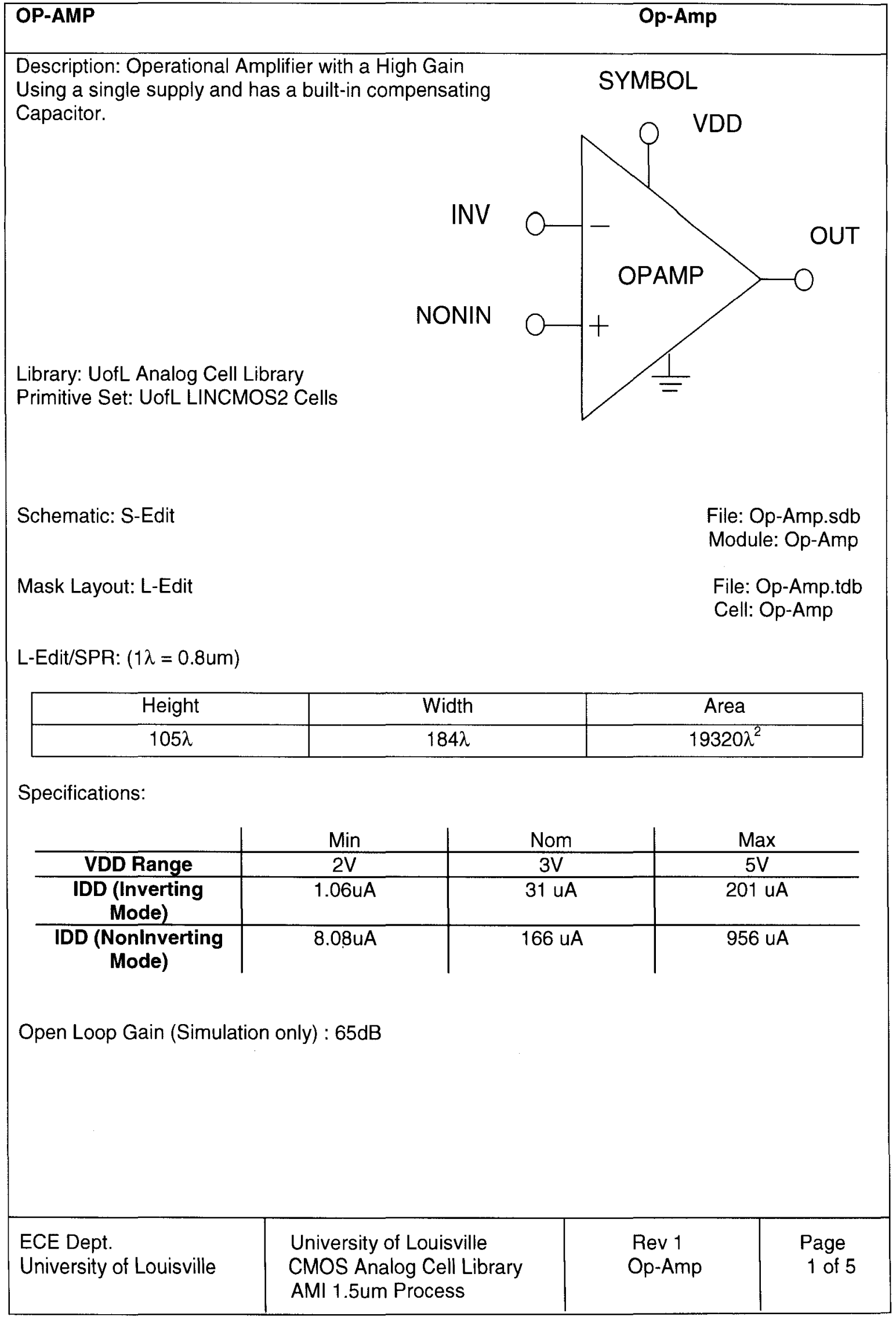




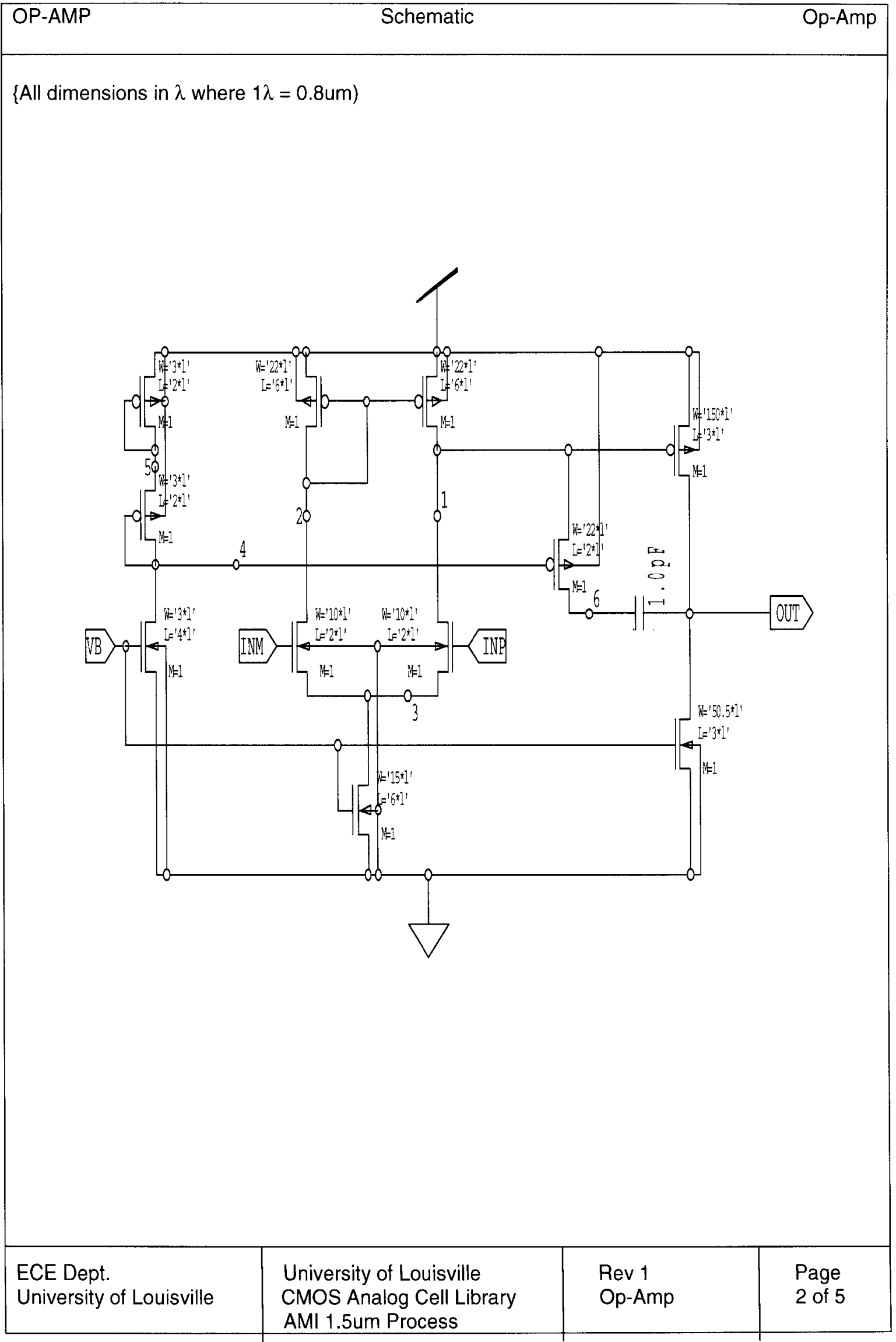




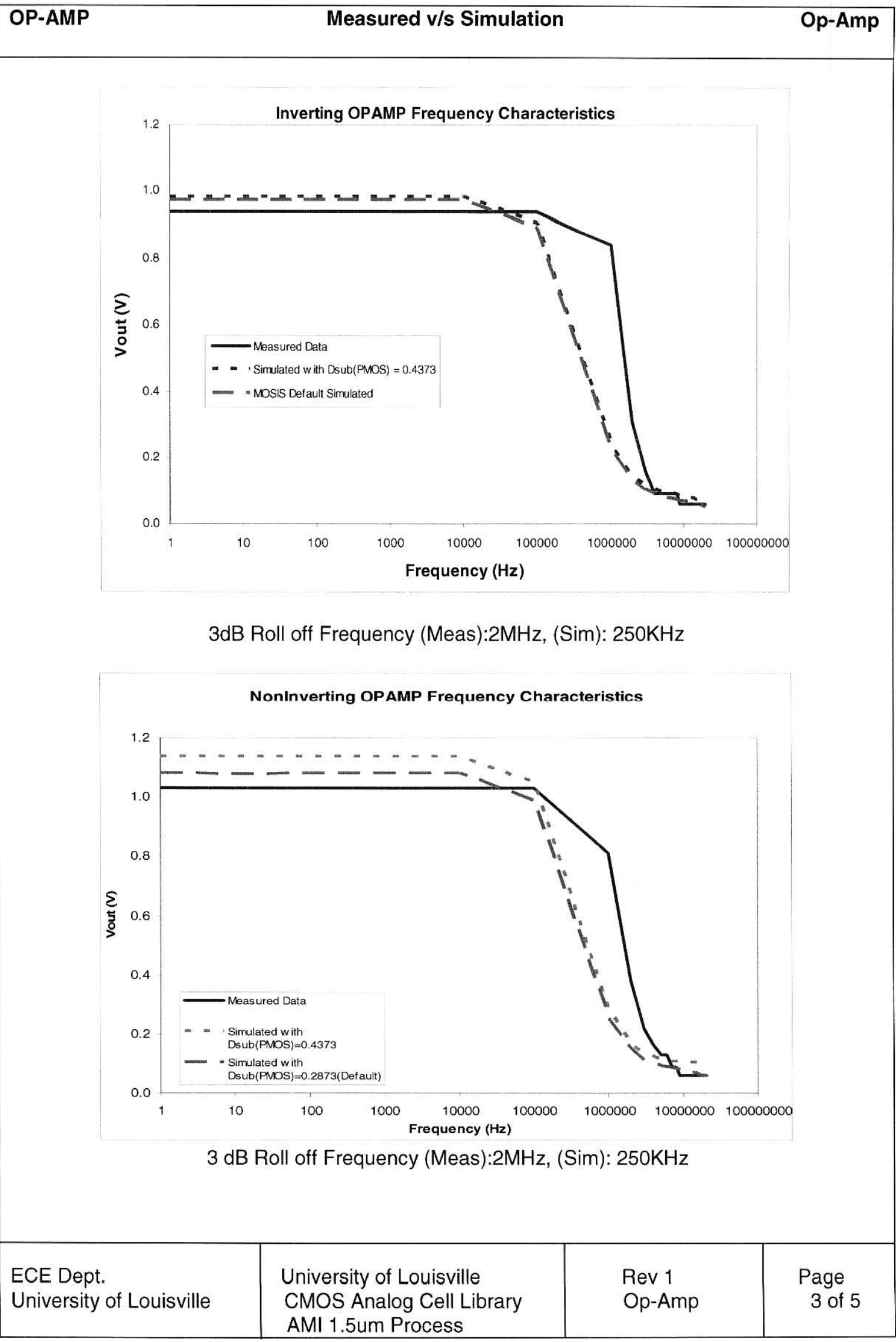




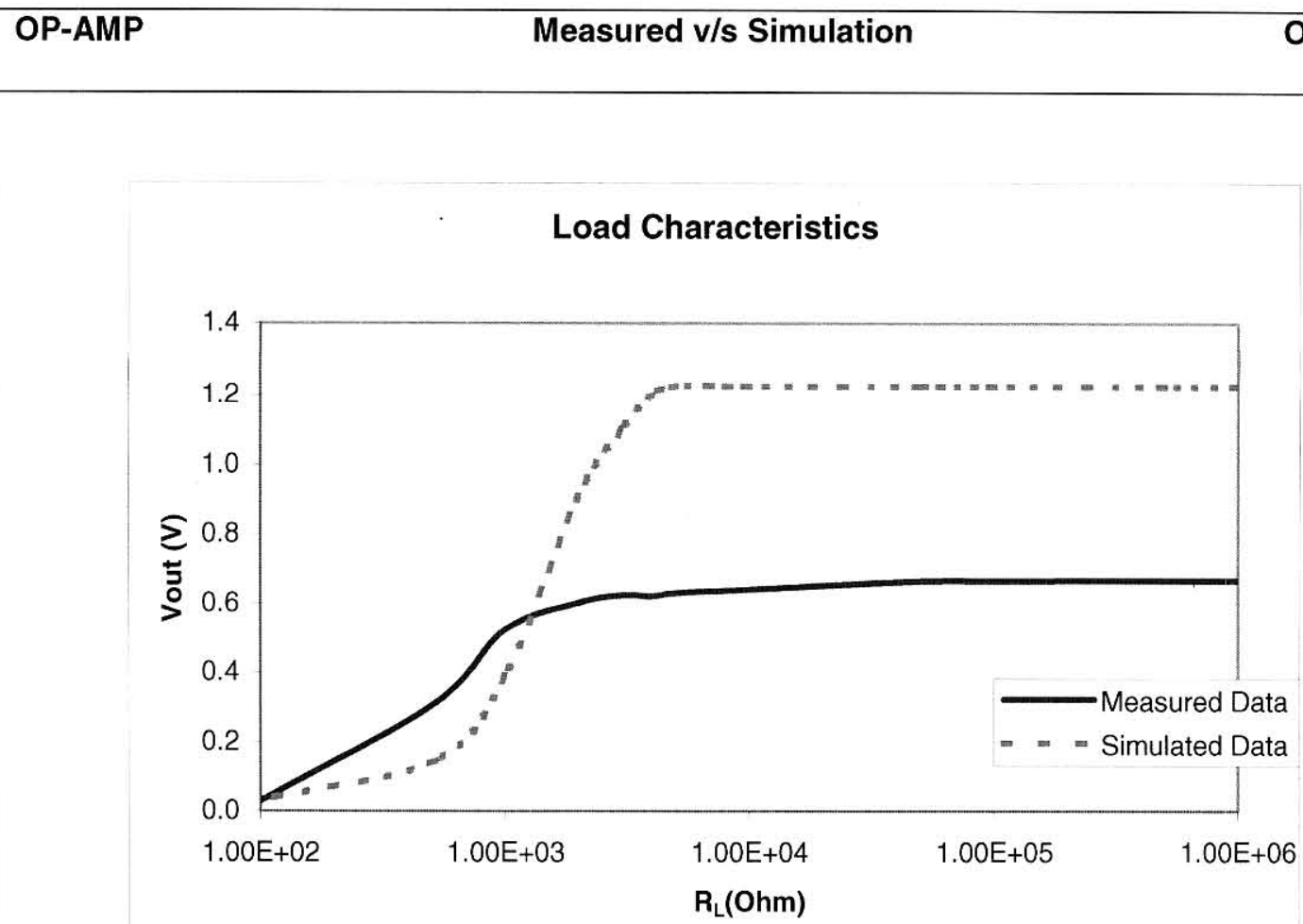

The 3dB Roll off occurs at Meas:1Kohm and Sim: $2.5 \mathrm{Kohm}$

VIN=70mV with 1.35V Offset, closed loop feedback, Rin=10Kohms, RF $=100 \mathrm{Kohms}$

ECE Dept.

University of Louisville
University of Louisville CMOS Analog Cell Library AMI 1.5um Process
Rev 1

Op-Amp
Page

4 of 5 


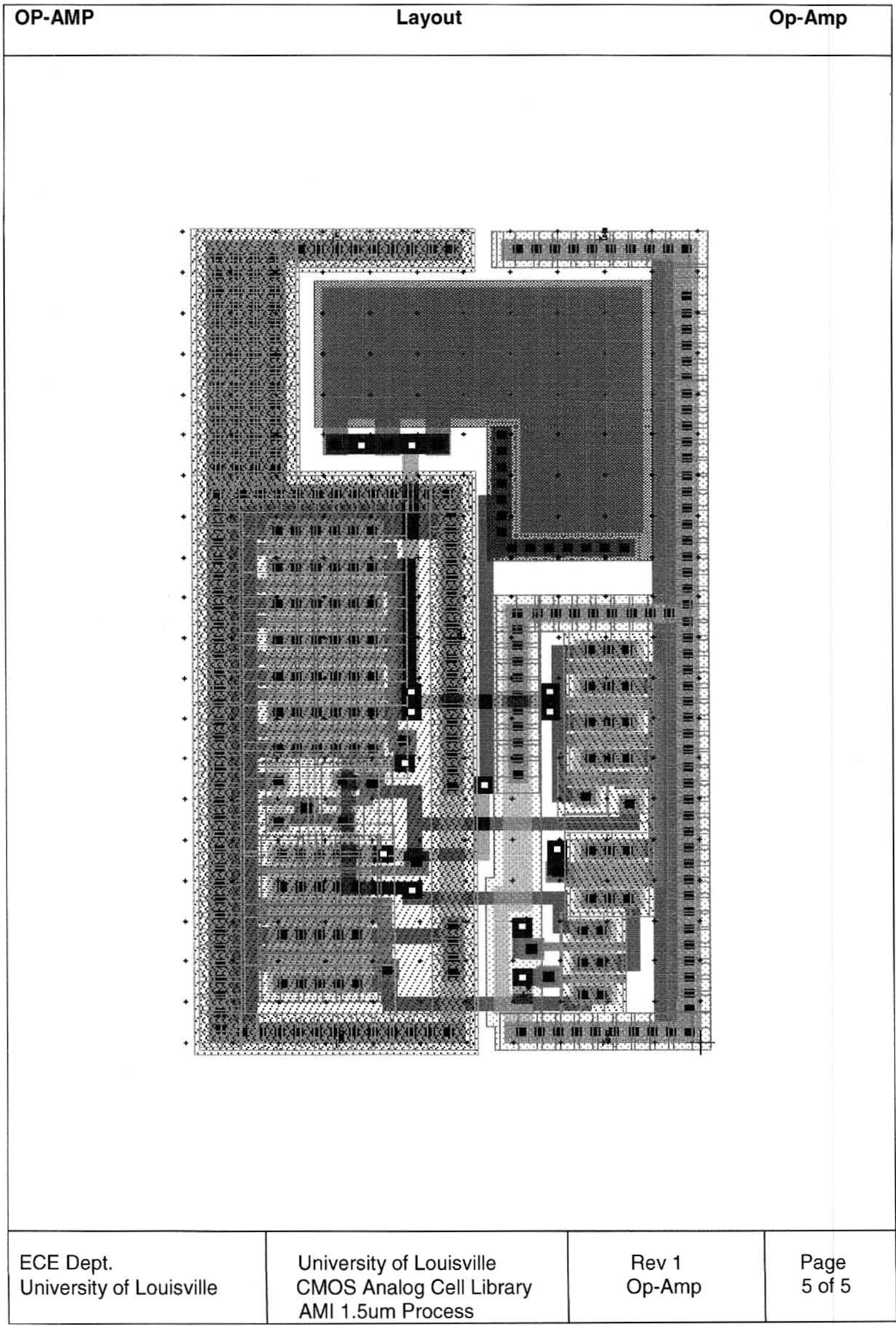




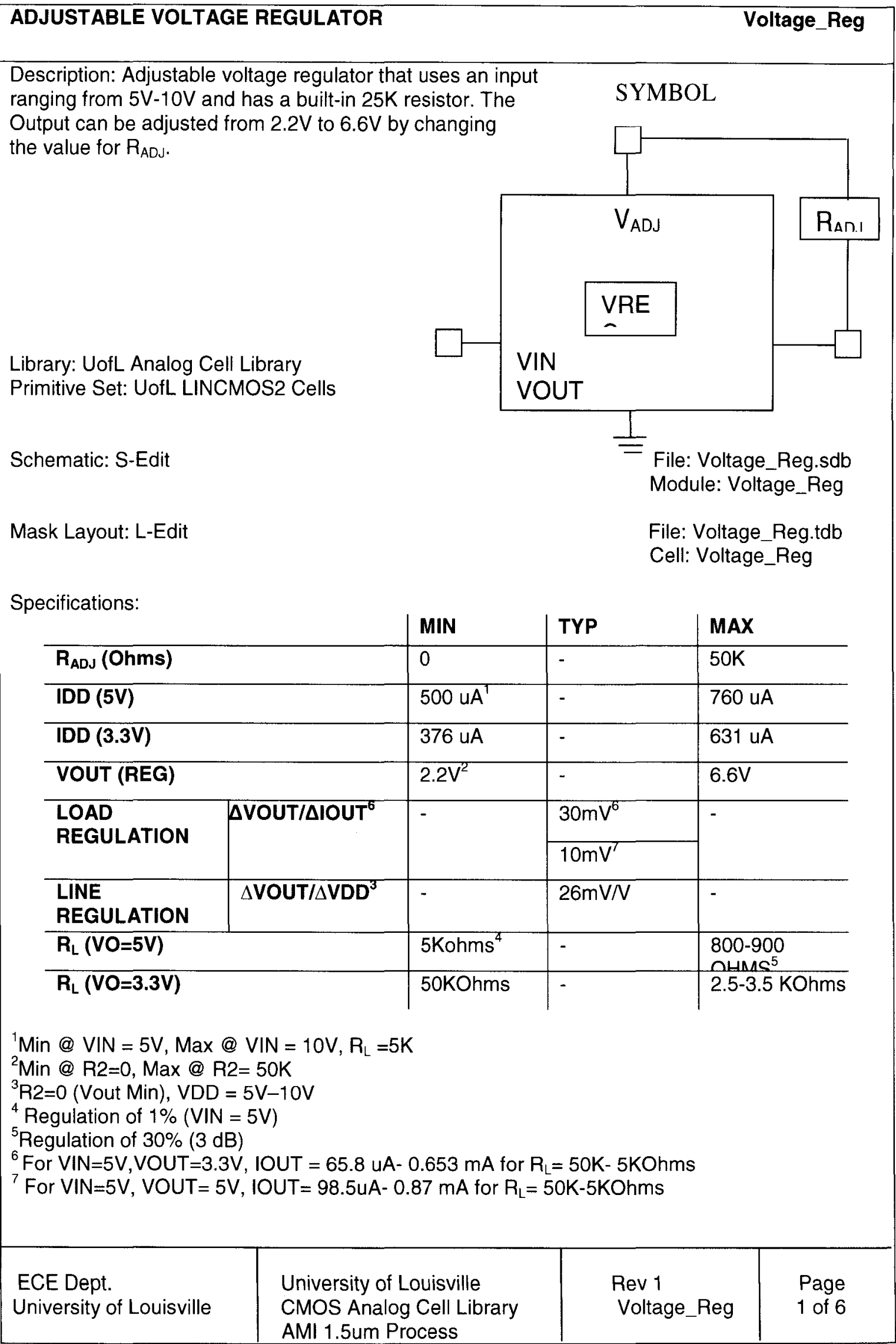




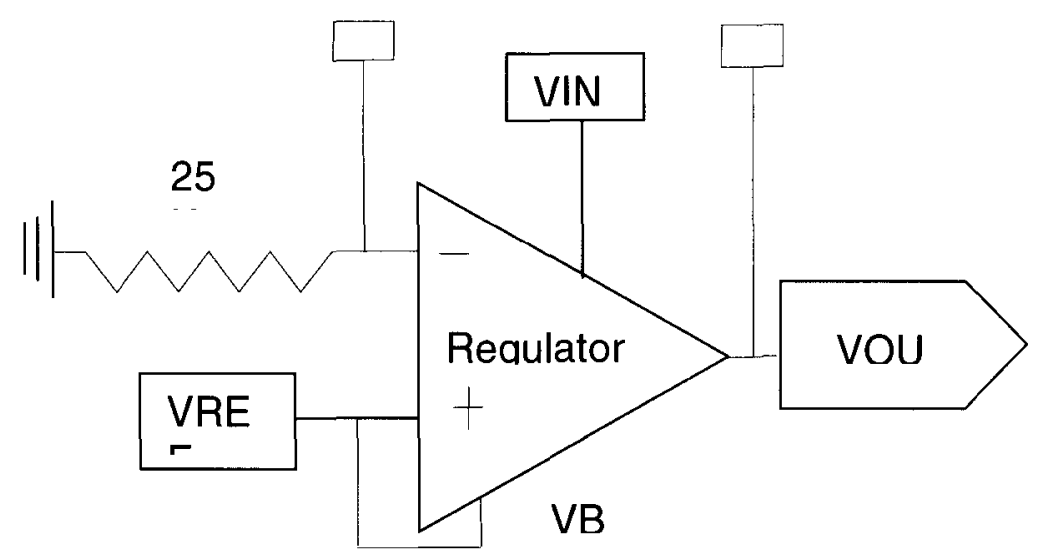

VOUT $=\operatorname{VADJ}(R 2 / 25 K+1)$

Where $\mathrm{VADJ}=$ VOUT when $\mathrm{R} 2=0$

Typical $=2.2 \mathrm{~V}($ for $\mathrm{R} 2=0$ )

$\mathrm{R} 2 \mathrm{MAX}=50 \mathrm{~K}$

\section{ECE Dept.}

University of Louisville
University of Louisville

CMOS Analog Cell Library

AMI 1.5um Process
Rev 1

Voltage_Reg 


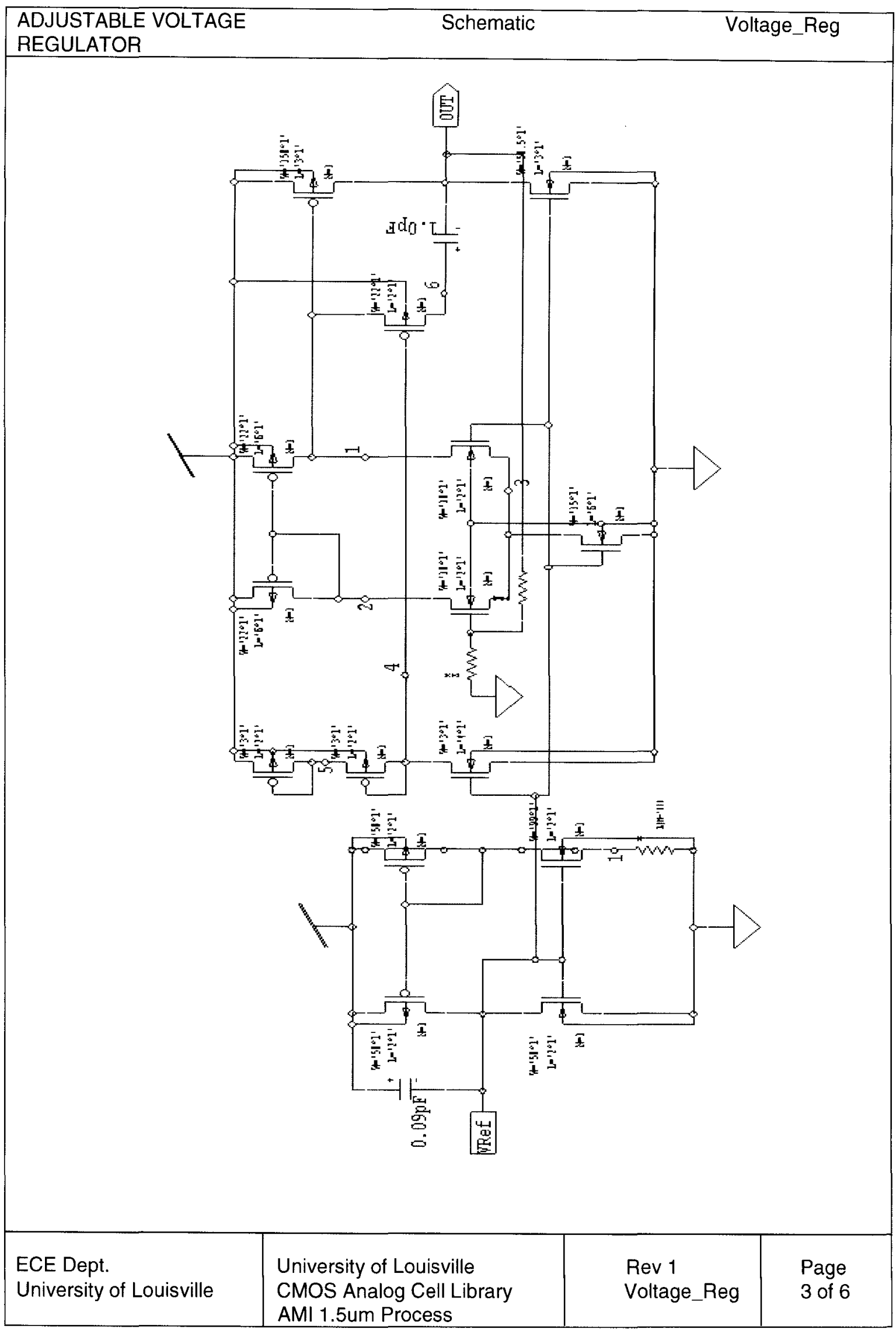



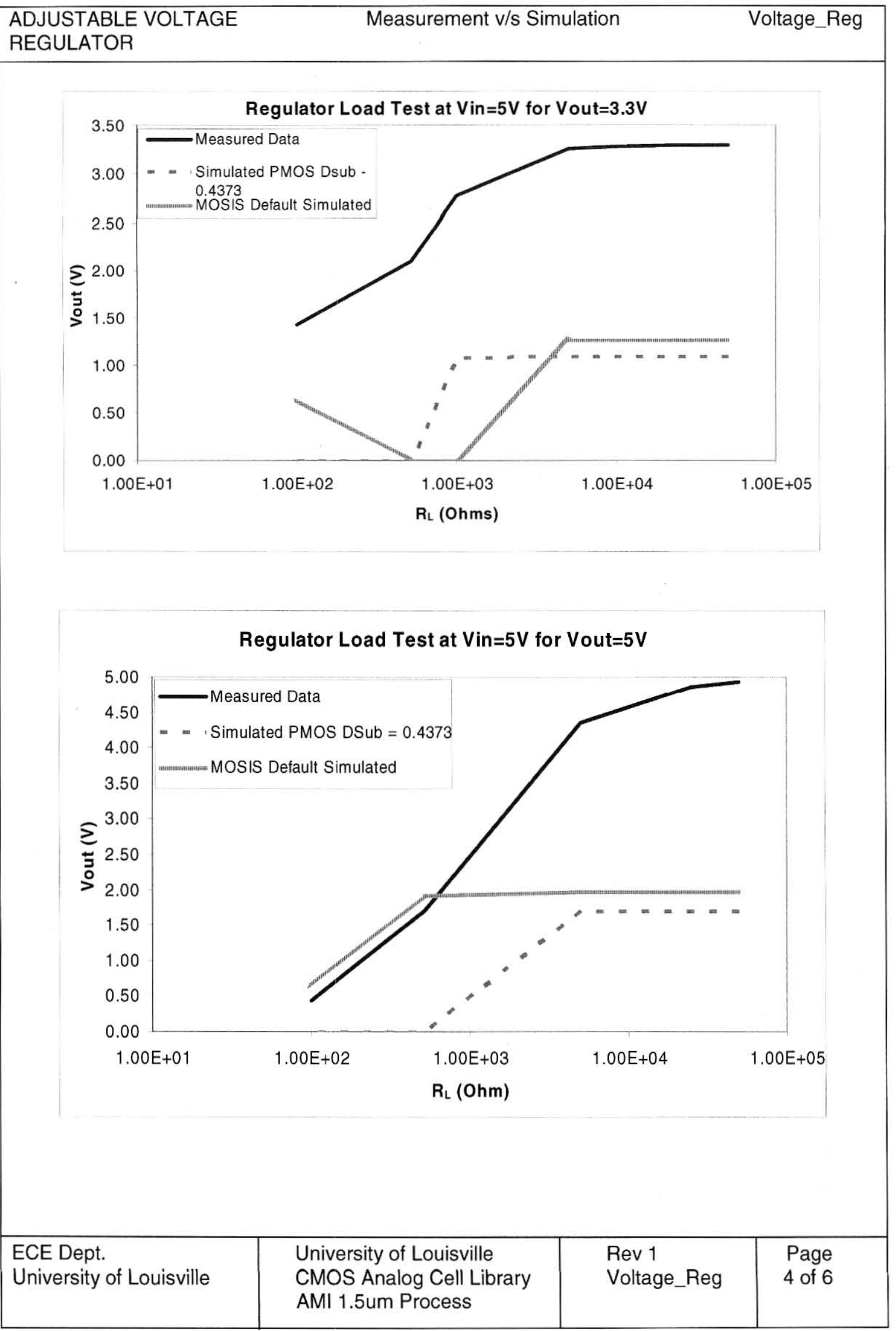


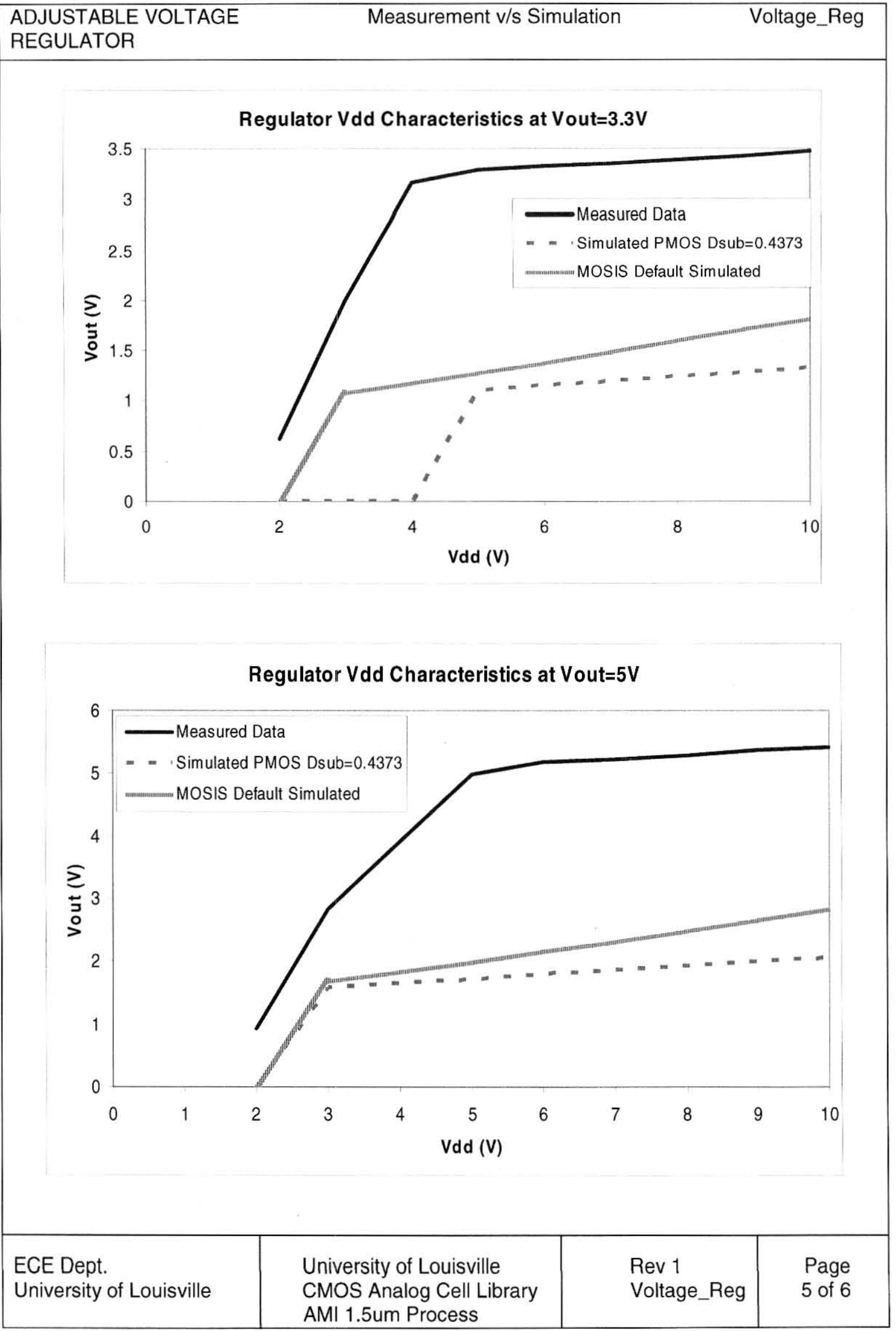




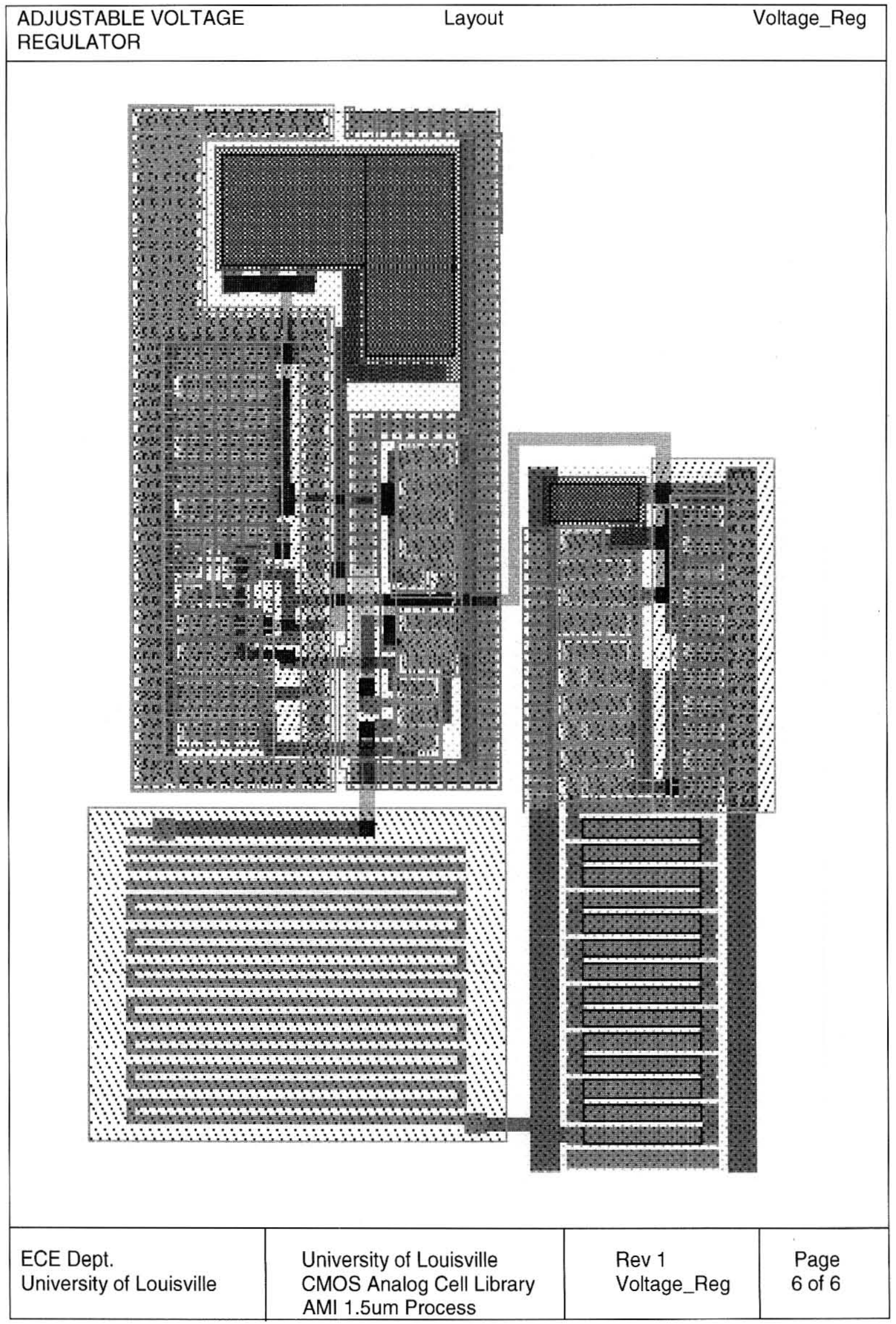




\section{2-18-03 Mask Model}

* T32Q SPICE BSIM3 VERSION 3.1 PARAMETERS

SPICE 345 Level 8, Star-HSPICE Level 49, UTMOST Level 8

* DATE: Mar 31/03

* LOT: T32Q WAF: 3202

Temperature_parameters $=$ Default

MODEL NMOS NMOS $(\quad$ LEVEL $=49$

\begin{tabular}{|c|c|c|}
\hline +VERSION = 3.1 & TNOM $=27$ & TOX $=3.06 \mathrm{E}-8$ \\
\hline$+\mathrm{XJ}=3 \mathrm{E}-7$ & $\mathrm{NCH}=7.5 \mathrm{E} 16$ & VTHO $=0.5069591$ \\
\hline$+\mathrm{K} 1=0.9382614$ & $K 2=-0.0869761$ & $\mathrm{~K} 3=7.5996896$ \\
\hline$+\mathrm{K} 3 \mathrm{~B}=-3.8503851$ & WO $=3.83633 \mathrm{E}-6$ & $\mathrm{NLX}=1 \mathrm{E}-8$ \\
\hline +DVTOW $=0$ & DVT1W $=0$ & DVT2W $=0$ \\
\hline+ DVT0 $=0.7217903$ & DVT1 $=0.302459$ & DVT2 $=-0.3176085$ \\
\hline$+\mathrm{UO}==620.8461075$ & $\mathrm{UA}=6.799942 \mathrm{E}-10$ & $\mathrm{UB}=2.279296 \mathrm{E}-18$ \\
\hline$+\mathrm{UC}=-3.22535 \mathrm{E}-12$ & VSAT $=1.096398 \mathrm{E} 5$ & $\mathrm{AO}=0.552232$ \\
\hline+ AGS $=0.0923316$ & $\mathrm{BO}=2.137463 \mathrm{E}-6$ & $\mathrm{~B} 1=5 \mathrm{E}-6$ \\
\hline$+\mathrm{KETA}=-6.708515 \mathrm{E}-3$ & $=0$ & $\mathrm{~A} 2=1$ \\
\hline$+\mathrm{RDSW}=3 \mathrm{E} 3$ & PRWG $=-0.0230798$ & PRWB $=-0.0214204$ \\
\hline$+W R=1$ & WINT $=6.621444 \mathrm{E}-7$ & LINT $=2.287886 \mathrm{E}-7$ \\
\hline$+\mathrm{XL}$ & $\mathrm{XW}$ & $D W G=-7.13441 \mathrm{E}-10$ \\
\hline +DWB $=3.625667 \mathrm{E}-8$ & VOFF $=-6.267605 E-3$ & NFACTOR $=0.6880885$ \\
\hline$+\mathrm{CIT}=0$ & $\mathrm{CDSC}=0$ & CDSCD $=0$ \\
\hline$+\mathrm{CDSCB}=3.066995 \mathrm{E}-5$ & ETAO $=-1$ & $\mathrm{ETAB}=-0.3960736$ \\
\hline+ DSUB $=0.9097182$ & PCLM $=1.1201574$ & PDIBLC1 = 8.686923E-3 \\
\hline +PDIBLC2 = 3.532968E-3 & PDIBLCB $=-0.1$ & DROUT $=0.0655521$ \\
\hline +PSCBE1 = $1.562881 \mathrm{E} 10$ & PSCBE2 = 3.581697E-9 & PVAG $=0.0353463$ \\
\hline+ DELTA $=0.01$ & $\mathrm{RSH}=53.1$ & MOBMOD $=1$ \\
\hline+ PRT $=0$ & UTE $=-1.5$ & $=-0.11$ \\
\hline
\end{tabular}




\begin{tabular}{|l|l|l|}
\hline$+\mathrm{KT1L}=0$ & $\mathrm{KT2}=0.022$ & $\mathrm{UA1}=4.31 \mathrm{E}-9$ \\
\hline$+\mathrm{UB1}=-7.61 \mathrm{E}-18$ & $\mathrm{UC1}=-5.6 \mathrm{E}-11$ & $\mathrm{AT}=3.3 \mathrm{E} 4$ \\
\hline$+\mathrm{WL}=0$ & $\mathrm{WLN}=1$ & $\mathrm{WW}=0$ \\
\hline$+\mathrm{WWN}=1$ & $\mathrm{WWL}=0$ & $\mathrm{LL}=0$ \\
\hline$+\mathrm{LLN}=1$ & $\mathrm{LW}=0$ & $\mathrm{LWN}=1$ \\
\hline$+\mathrm{LWL}=0$ & $\mathrm{CAPMOD}=2$ & $\mathrm{XPART}=0.5$ \\
\hline$+\mathrm{CGDO}=1.78 \mathrm{E}-10$ & $\mathrm{CGSO}=1.78 \mathrm{E}-10$ & $\mathrm{CGBO}=1 \mathrm{E}-9$ \\
\hline$+\mathrm{CJ}=2.66451 \mathrm{E}-4$ & $\mathrm{~PB}=0.99$ & $\mathrm{MJ}=0.5684277$ \\
\hline$+\mathrm{CJSW}=1.440541 \mathrm{E}-10$ & $\mathrm{PBSW}=0.99$ & $\mathrm{MJSW}=0.1$ \\
\hline$+\mathrm{CJSWG}=6.4 \mathrm{E}-11$ & $\mathrm{PBSWG}=0.99$ & $\mathrm{MJSWG}=0.1$ \\
\hline$+\mathrm{CF}=0$ & ) & * \\
\hline
\end{tabular}

\begin{tabular}{|c|c|c|}
\hline MODEL PMOS PMOS & LEVEL $=49$ & \\
\hline+ VERSION $=3.1$ & TNOM $=27$ & TOX $=3.06 \mathrm{E}-8$ \\
\hline$+\mathrm{XJ}=3 \mathrm{E}-7$ & $\mathrm{NCH}=2.4 \mathrm{E} 16$ & VTHO $=-0.8476404$ \\
\hline$=0.4513608$ & $\mathrm{~K} 2=2.379699 \mathrm{E}-5$ & K3 $=13.3278347$ \\
\hline$+\mathrm{K} 3 \mathrm{~B}=-2.2238332$ & W0 $=9.577236 \mathrm{E}-7$ & $\mathrm{NLX}=1 \mathrm{E}-6$ \\
\hline +DVTOW $=0$ & DVT1W $=0$ & DVT2W $=0$ \\
\hline +DVT0 $=0.6724163$ & DVT1 $=0.4176993$ & DVT2 $=-0.1717942$ \\
\hline$+\mathrm{U} 0=236.8923827$ & UA $=3.833306 \mathrm{E}-9$ & UB $=1.487688 \mathrm{E}-21$ \\
\hline$+\mathrm{UC}=-1.08562 \mathrm{E}-10$ & VSAT $=1.112594 \mathrm{E} 5$ & $A 0=0.1$ \\
\hline +AGS $=1.1986658$ & BO $=5.603955 \mathrm{E}-6$ & $\mathrm{~B} 1=5 \mathrm{E}-6$ \\
\hline+ KETA $=-8.674697 \mathrm{E}-3$ & $A 1=0$ & A2 $=0.364$ \\
\hline$+\mathrm{RDSW}=2.450082 \mathrm{E} 3$ & PRWG $=0.1090564$ & PRWB $=-0.1907452$ \\
\hline$+W R=1$ & WINT $=7.565065 \mathrm{E}-7$ & LINT $=7.036681 \mathrm{E}-8$ \\
\hline$+\mathrm{XL}$ & $\mathrm{XW}=0$ & $D W G \quad=-2.13917 \mathrm{E}-8$ \\
\hline+ DWB $=3.857544 \mathrm{E}-8$ & VOFF $=-0.0877184$ & NFACTOR $=0.2508342$ \\
\hline$+\mathrm{CIT}=0$ & $\mathrm{CDSC}=2.924806 \mathrm{E}-5$ & $\mathrm{CDSCD}=1.497572 \mathrm{E}-4$ \\
\hline
\end{tabular}




\begin{tabular}{|c|c|c|}
\hline$+\mathrm{CDSCB}=1.091488 \mathrm{E}-4$ & ETA0 $=0.26103$ & $\mathrm{ETAB}=-9.416814 \mathrm{E}-3$ \\
\hline+ DSUB $=0.2873$ & $\mathrm{PCLM}=1 \mathrm{E}-10$ & PDIBLC1 = 4.12957E-4 \\
\hline +PDIBLC2 $=1.001244 \mathrm{E}-3$ & PDIBLCB $=-1 E-3$ & DROUT $=9.994612 \mathrm{E}-4$ \\
\hline$+\mathrm{PSCBE} 1=3.506856 \mathrm{E} 9$ & PSCBE2 $=5.261344 \mathrm{E}-10$ & PVAG $=15$ \\
\hline+ DELTA $=0.01$ & $\mathrm{RSH}=77.5$ & MOBMOD $=1$ \\
\hline$+\mathrm{PRT}=0$ & UTE $=-1.5$ & $\mathrm{KT} 1=-0.11$ \\
\hline$+\mathrm{KT} 1 \mathrm{~L}=0$ & KT2 $=0.022$ & UA1 $=4.31 \mathrm{E}-9$ \\
\hline+ UB1 $=-7.61 \mathrm{E}-18$ & UC1 $=-5.6 \mathrm{E}-11$ & $\mathrm{AT}=3.3 \mathrm{E} 4$ \\
\hline$+W L=0$ & $W L N=1$ & $W W=0$ \\
\hline$+W W N=1$ & $W W L=0$ & $=0$ \\
\hline$+\mathrm{LLN}=1$ & $\mathrm{LW}=0$ & $\mathrm{LWN}=1$ \\
\hline$+L W L=0$ & CAPMOD $=2$ & XPART $=0.5$ \\
\hline$+\mathrm{CGDO}=2.1 \mathrm{E}-10$ & CGSO $=2.1 \mathrm{E}-10$ & CGBO $=1 \mathrm{E}-9$ \\
\hline$+\mathrm{CJ}=3.023543 \mathrm{E}-4$ & $\mathrm{~PB}=0.7472625$ & $\mathrm{MJ}=0.4301028$ \\
\hline$+\mathrm{CJSW}=1.669058 \mathrm{E}-10$ & PBSW $=0.99$ & MJSW $=0.1191643$ \\
\hline+ CJSWG $=3.9 \mathrm{E}-11$ & PBSWG $=0.99$ & MJSWG $=0.1191643$ \\
\hline$+\mathrm{CF}$ & ) & * \\
\hline
\end{tabular}




\section{9-15-03 Mask Model}

* T39T SPICE BSIM3 VERSION 3.1 PARAMETERS

SPICE 3 f5 Level 8, Star-HSPICE Level 49, UTMOST Level 8

* DATE: Nov $19 / 03$

* LOT: T39T WAF: 7197

Temperature_parameters=Default

MODEL NMOS NMOS $(\quad$ LEVEL $=49$

\begin{tabular}{|c|c|c|}
\hline +VERSION $=3.1$ & TNOM $=27$ & TOX $=3.13 \mathrm{E}-8$ \\
\hline$+\mathrm{XJ}=3 \mathrm{E}-7$ & $\mathrm{NCH}=7.5 \mathrm{E} 16$ & VTHO $=0.4874312$ \\
\hline$+\mathrm{K} 1=0.9259373$ & $K 2=-0.0885238$ & $\mathrm{~K} 3=2.8265559$ \\
\hline$+\mathrm{K} 3 \mathrm{~B}=-2.6808504$ & W0 $=2.909353 \mathrm{E}-6$ & $N L X=1 E-8$ \\
\hline +DVTOW $=0$ & DVT1W $=0$ & DVT2W $=0$ \\
\hline +DVTO $=0.9761574$ & DVT1 $=0.2477734$ & DVT2 $=-0.169518$ \\
\hline$+\mathrm{UO}=635.2886671$ & $\mathrm{UA}=1.138117 \mathrm{E}-9$ & UB $=2.071702 \mathrm{E}-18$ \\
\hline$+\mathrm{UC}=2.106848 \mathrm{E}-11$ & VSAT $=1.108701 \mathrm{E} 5$ & $\mathrm{AO}=0.555546$ \\
\hline+ AGS $=0.1042212$ & $\mathrm{BO}=2.256903 \mathrm{E}-6$ & $\mathrm{~B} 1=5 \mathrm{E}-6$ \\
\hline+ KETA $=-5.820236 \mathrm{E}-3$ & $=0$ & $\mathrm{~A} 2=1$ \\
\hline$+\mathrm{RDSW}=3 \mathrm{E} 3$ & PRWG $=-0.0409513$ & PRWB $=-0.035455$ \\
\hline$+W R=1$ & WINT $=7.497966 \mathrm{E}-7$ & LINT $=2.185322 \mathrm{E}-7$ \\
\hline$+\mathrm{XL}$ & $\mathrm{XW}$ & DWG $=-1.892202 E-8$ \\
\hline +DWB $=3.381348 \mathrm{E}-8$ & VOFF $=0$ & NFACTOR $=0.758523$ \\
\hline$+\mathrm{CIT}=0$ & $\mathrm{CDSC}=0$ & CDSCD $=0$ \\
\hline$+\operatorname{CDSCB}=0$ & ETAO $=-1$ & ETAB $=0.5952967$ \\
\hline$+\mathrm{DSUB}=1$ & PCLM $=1.3342251$ & PDIBLC1 $=0.012041$ \\
\hline +PDIBLC2 = 3.541824E- 3 & PDIBLCB $=-0.1$ & DROUT $=0.0786382$ \\
\hline+ PSCBE $1=2.179583 \mathrm{E} 9$ & PSCBE2 $=5 \mathrm{E}-10$ & PVAG $=0.2119027$ \\
\hline+ DELTA $=0.01$ & $\mathrm{RSH}=54.8$ & MOBMOD $=1$ \\
\hline
\end{tabular}




\begin{tabular}{|c|c|c|}
\hline+ PRT $=0$ & UTE $=-1.5$ & KT1 $=-0.11$ \\
\hline$+\mathrm{KT} 1 \mathrm{~L}=0$ & $\mathrm{KT} 2=0.022$ & $\mathrm{UA1}=4.31 \mathrm{E}-9$ \\
\hline+ UB1 $=-7.61 \mathrm{E}-18$ & UC1 $=-5.6 \mathrm{E}-11$ & AT $=3.3 \mathrm{E} 4$ \\
\hline$+W L=0$ & $\mathrm{WLN}=1$ & $W W=0$ \\
\hline$+W W N=1$ & $W W L=0$ & $\mathrm{LL} \quad=0$ \\
\hline$+\mathrm{LLNN}=1$ & $\mathrm{LW}=0$ & $L W N=1$ \\
\hline$+L W L=0$ & CAPMOD $=2$ & XPART $=0.5$ \\
\hline$+\mathrm{CGDO}=1.74 \mathrm{E}-10$ & $\mathrm{CGSO}=1.74 \mathrm{E}-10$ & CGBO $=1 E-9$ \\
\hline$=2.547314 \mathrm{E}-4$ & $\mathrm{~PB}=0.9802679$ & $=0.5741063$ \\
\hline$+\mathrm{CJSW}=1.433897 \mathrm{E}-10$ & PBSW $=0.99$ & MJSW $=0.1$ \\
\hline$+\mathrm{CJSWG}=6.4 \mathrm{E}-11$ & PBSWG $=0.99$ & MJSWG $=0.1$ \\
\hline$+\mathrm{CF}$ & ) & * \\
\hline
\end{tabular}

MODEL PMOS PMOS (

LEVEL $=49$

\begin{tabular}{|c|c|c|}
\hline+ VERSION = 3.1 & TNOM $=27$ & TOX $=3.13 \mathrm{E}-8$ \\
\hline$+\mathrm{XJ}=3 \mathrm{E}-7$ & $\mathrm{NCH}=2.4 \mathrm{E} 16$ & VTHO $=-0.8476404$ \\
\hline$+\mathrm{K} 1=0.4513608$ & $\mathrm{~K} 2=2.379699 \mathrm{E}-5$ & $\mathrm{~K} 3=13.3278347$ \\
\hline$+\mathrm{K} 3 \mathrm{~B}=-2.2238332$ & $=9.577236 \mathrm{E}-7$ & $\mathrm{NLX}=1 \mathrm{E}-6$ \\
\hline +DVTOW $=0$ & DVT1W $=0$ & DVT2W $=0$ \\
\hline +DVT0 $=3.2953432$ & DVT1 $=0.6916594$ & DVT2 $=-0.0749175$ \\
\hline$+\mathrm{UO}=236.8923827$ & $\mathrm{UA}=3.833306 \mathrm{E}-9$ & $\mathrm{UB}=1.487688 \mathrm{E}-21$ \\
\hline$+\mathrm{UC}=-1.08562 \mathrm{E}-10$ & VSAT $=2 E 5$ & $=0.1587298$ \\
\hline+ AGS $=0.2673437$ & BO $=8.48937 \mathrm{E}-6$ & $=5 \mathrm{E}-6$ \\
\hline$+\mathrm{KETA}=8.561805 \mathrm{E}-3$ & $=0$ & $=0.364$ \\
\hline$+\mathrm{RDSW}=672.5986057$ & PRWG $=0.3$ & PRWB $=-0.3$ \\
\hline$+W R$ & WINT $=7.565065 \mathrm{E}-7$ & LINT $=3.965844 \mathrm{E}-9$ \\
\hline$+\mathrm{XL}$ & $\mathrm{XW}$ & $D W G=-2.13917 E-8$ \\
\hline
\end{tabular}




\begin{tabular}{|c|c|c|}
\hline+ DWB $=3.857544 \mathrm{E}-8$ & VOFF $=-0.0877184$ & NFACTOR $=0.2508342$ \\
\hline$+\mathrm{ClT}=0$ & $\mathrm{CDSC}=2.924806 \mathrm{E}-5$ & $\operatorname{CDSCD}=1.497572 \mathrm{E}-4$ \\
\hline$+\mathrm{CDSCB}=1.091488 \mathrm{E}-4$ & ETA0 $=0.29103$ & ETAB $=-3.520693 \mathrm{E}-3$ \\
\hline+ DSUB $=0.2873$ & PCLM $=1 E-10$ & PDIBLC1 $=6.31939 \mathrm{E}-4$ \\
\hline +PDIBLC2 = 1.350626E-3 & PDIBLCB $=-1 E-3$ & DROUT $=0$ \\
\hline +PSCBE1 = 3.522972E9 & PSCBE2 $=5.285524 \mathrm{E}-10$ & PVAG $=15$ \\
\hline+ DELTA $=0.01$ & $\mathrm{RSH}=78.7$ & MOBMOD $=1$ \\
\hline$+\mathrm{PRT}=0$ & UTE $=-1.5$ & $\mathrm{KT1}=-0.11$ \\
\hline$+\mathrm{KT} 1 \mathrm{~L}=0$ & $\mathrm{KT} 2=0.022$ & UA1 $=4.31 \mathrm{E}-9$ \\
\hline+ UB1 $=-7.61 E-18$ & $=-5.6 \mathrm{E}-11$ & $=3.3 E 4$ \\
\hline$+W L$ & $W L N=1$ & WW \\
\hline$+W W N=1$ & $W W L=0$ & $=0$ \\
\hline+ LLN & LW & LWN \\
\hline$+\mathrm{LWL}=0$ & CAPMOD $=2$ & XPART $=0.5$ \\
\hline+ CGDO $=1.97 \mathrm{E}-10$ & CGSO $=1.97 \mathrm{E}-10$ & CGBO $=1 \mathrm{E}-9$ \\
\hline$=3.024512 \mathrm{E}-4$ & $=0.8$ & $=0.4355571$ \\
\hline$+\mathrm{CJSW}=1.615852 \mathrm{E}-10$ & PBSW $=0.8761424$ & MJSW $=0.1003172$ \\
\hline+ CJSWG $=3.9 \mathrm{E}-11$ & PBSWG $=0.8761424$ & MJSWG $=0.1003172$ \\
\hline$+\mathrm{CF}$ & ) & * \\
\hline
\end{tabular}




\section{Typical MOSIS Models}

* DATE: Jun 6/02

* Tech: AMI_ABN

* LOT: T22X_TT (typical) WAF: 6605

* Temperature_parameters=Optimized

MODEL CMOSN NMOS (

+ VERSION $=3.1$

LEVEL $=49$

TOX $=3.09 \mathrm{E}-8$

$+\mathrm{XJ}=3 \mathrm{E}-7 \quad \mathrm{NCH}=7.5 \mathrm{E} 16 \quad \mathrm{VTHO}=0.5585921$

$+\mathrm{K} 1=0.9300373 \quad \mathrm{~K} 2=-0.0706188 \quad \mathrm{~K} 3=8.0262635$

$+\mathrm{K} 3 \mathrm{~B}=-2.4231517$ WO $=5.489201 \mathrm{E}-7 \quad \mathrm{NLX}=1 \mathrm{E}-8$

+ DVTOW $=0 \quad$ DVT1W $=0 \quad$ DVT2W $=0$

+ DVT0 $=0.7666071$ DVT1 $=0.2843554$ DVT2 $=-0.2195483$

$+\mathrm{UO}=665.4919858$ UA $=1.468437 \mathrm{E}-9$ UB $=1.94634 \mathrm{E}-18$

$+\mathrm{UC}=3.408801 \mathrm{E}-11$ VSAT $=1.059876 \mathrm{E} 5$ AO $=0.560251$

$+\mathrm{AGS}=0.1065613 \quad \mathrm{~B} 0=2.451371 \mathrm{E}-6 \quad \mathrm{~B} 1=5 \mathrm{E}-6$

$+\mathrm{KETA}=-7.033813 \mathrm{E}-3 \mathrm{~A} 1=0 \quad \mathrm{~A} 2=1$

+ RDSW $=3 E 3 \quad$ PRWG $=-0.0415097$ PRWB $=-0.0367395$

$+W R=1 \quad$ WINT $=7.154435 \mathrm{E}-7 \quad$ LINT $=2.218865 \mathrm{E}-7$

$+\mathrm{XL}=0 \quad \mathrm{XW}=0 \quad \mathrm{DWG}=-1.936445 \mathrm{E}-8$

$+\mathrm{DWB}=3.48297 \mathrm{E}-8 \quad \mathrm{VOFF}=-0.0307548 \quad \mathrm{NFACTOR}=0.5740385$

$+\mathrm{CIT}=0 \quad \mathrm{CDSC}=0 \quad \mathrm{CDSCD}=0$

$+\mathrm{CDSCB}=3.251492 \mathrm{E}-5 \quad \mathrm{ETAO}=-1 \quad \mathrm{ETAB}=-0.5546384$

+ DSUB $=1 \quad$ PCLM $=1.2454756 \quad$ PDIBLC1 $=8.119599 \mathrm{E}-3$

+ PDIBLC2 $=1.824339 \mathrm{E}-3 \quad$ PDIBLCB $=-0.1 \quad$ DROUT $=0.0536917$

+ PSCBE1 $=2.410329 E 9 \quad$ PSCBE2 $=1.306019 \mathrm{E}-9 \quad \mathrm{PVAG}=0.149629$

+ DELTA $=0.01 \quad \mathrm{RSH}=52.2 \quad$ MOBMOD $=1$

$+\mathrm{PRT}=182.01 \quad \mathrm{UTE}=-1.5 \quad \mathrm{KT} 1=-0.282143$

$+\mathrm{KT} 1 \mathrm{~L}=3.296 \mathrm{E}-9 \quad \mathrm{KT} 2=0 \quad \mathrm{UA} 1=1.206664 \mathrm{E}-9$

+ UB1 $=-5.06439 \mathrm{E}-18$ UC1 $=-1 \mathrm{E}-10 \quad$ AT $=1 \mathrm{E} 5$

$+W L=0 \quad W L N=1 \quad W W=0$

$+W W N=1 \quad W W L=0 \quad L L=0$

$+\mathrm{LLN}=1 \quad \mathrm{LW}=0 \quad \mathrm{LWN}=1$

$+\mathrm{LWL}=0 \quad \mathrm{CAPMOD}=2 \quad \mathrm{XPART}=0.5$

$+\mathrm{CGDO}=1.8 \mathrm{E}-10 \quad \mathrm{CGSO}=1.8 \mathrm{E}-10 \quad \mathrm{CGBO}=1 \mathrm{E}-9$

$+\mathrm{CJ}=2.830976 \mathrm{E}-4 \quad \mathrm{~PB}=0.99 \quad \mathrm{MJ}=0.537762$

$+\mathrm{CJSW}=1.451536 \mathrm{E}-10 \mathrm{PBSW}=0.99 \quad \mathrm{MJSW}=0.1$

$+\mathrm{CJSWG}=6.4 \mathrm{E}-11 \quad \mathrm{PBSWG}=0.99 \quad \mathrm{MJSWG}=0.1$

$+\mathrm{CF}=0 \quad \mathrm{AF}=1 \quad \mathrm{KF}=0$ )

MODEL CMOSP PMOS

+ VERSION $=3.1$

$\begin{array}{llllll}+\mathrm{XJ} & =3 \mathrm{E}-7 & \mathrm{NCH} & =2.4 \mathrm{E} 16 & \mathrm{VTHO} & =-0.8476404 \\ +\mathrm{K} 1 & =0.4513608 & \mathrm{~K} 2 & =2.379699 \mathrm{E}-5 & \mathrm{~K} 3 & =13.3278347\end{array}$

NTOM $=27$

LEVEL $=49$

$+\mathrm{K} 3 \mathrm{~B}=-2.2238332$ WO $=9.577236 \mathrm{E}-7 \quad \mathrm{NLX}=1 \mathrm{E}-8$

+DVTOW $=0 \quad$ DVT1W $=0 \quad$ DVT2W $=0$

+ DVT0 $=0.2478839$ DVT1 $=0.1169086$ DVT2 $=-0.5$

$+\mathrm{UO}=236.8923827 \quad \mathrm{UA}=3.833306 \mathrm{E}-9 \quad \mathrm{UB}=1.487688 \mathrm{E}-21$

$+\mathrm{UC}=-1.08562 \mathrm{E}-10$ VSAT $=1.019808 \mathrm{E} 5 \mathrm{AO}=0.3104634$

$+\mathrm{AGS}=0.4374691 \quad \mathrm{BO}=3.217752 \mathrm{E}-6 \quad \mathrm{~B} 1=4.959246 \mathrm{E}-6$

$+\mathrm{KETA}=-0.0196746 \quad \mathrm{~A} 1=0 \quad \mathrm{~A} 2=0.364$

$+\mathrm{RDSW}=3 \mathrm{E} 3 \quad \mathrm{PRWG}=0.1198926 \quad \mathrm{PRWB}=-0.2481551$

$+W R=1 \quad$ WINT $=7.565065 \mathrm{E}-7 \quad$ LINT $=9.161352 \mathrm{E}-8$

$+X L=0 \quad X W=0 \quad$ DWG $=-2.13917 \mathrm{E}-8$ 


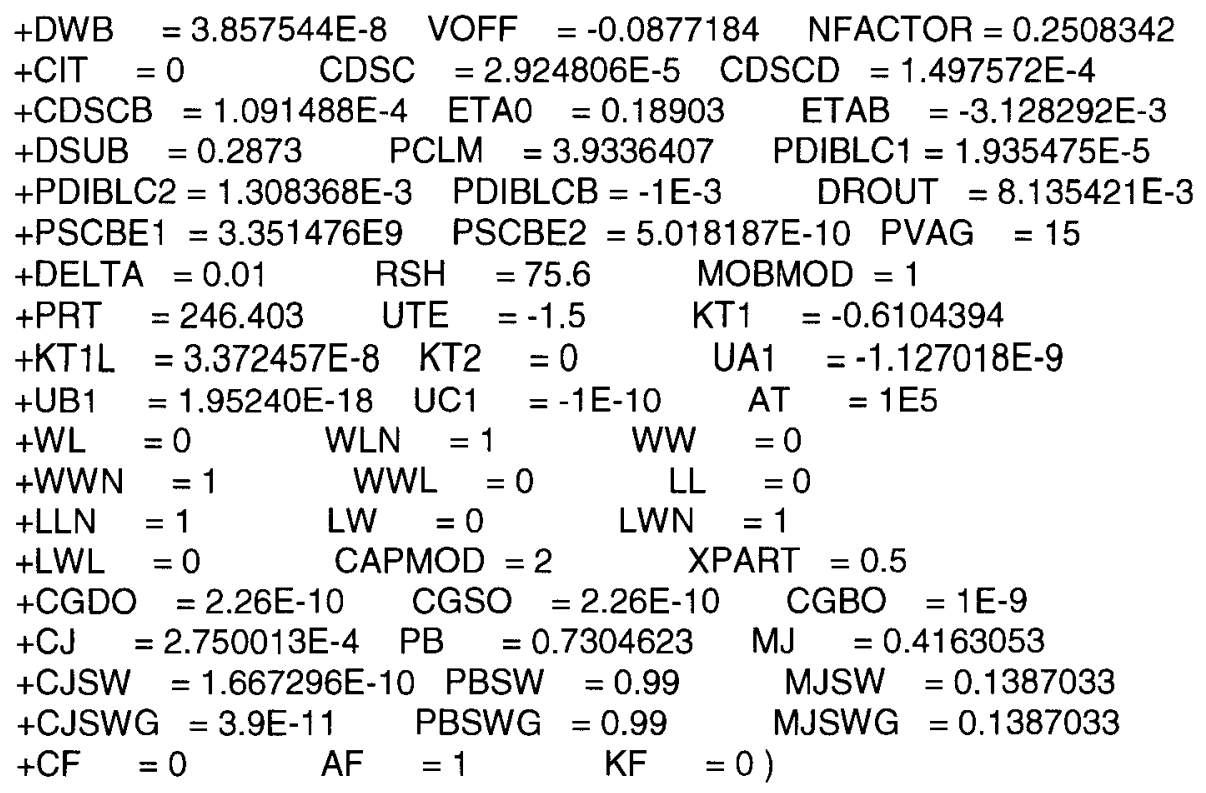

* The fast-slow corner means: NMOS fast and PMOS slow.

* DATE: Jun 6/02

* Tech: AMI_ABN

* LOT: T22X_SS (slow-slow)

* Temperature_parameters=Optimized .MODEL CMOSN NMOS (

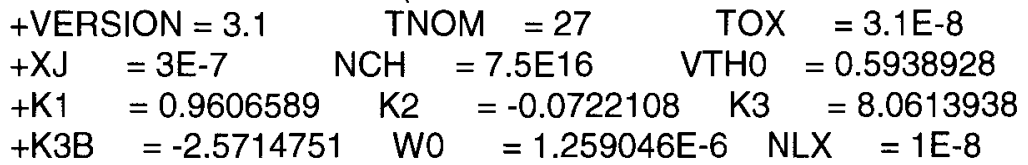

+ DVTOW $=0 \quad$ DVT1W $=0 \quad$ DVT2W $=0$

+ DVT0 $=0.7298898$ DVT1 $=0.3187254$ DVT2 $=-0.2774341$

$+\mathrm{UO}=673.9743329$ UA $=1.655142 \mathrm{E}-9 \quad \mathrm{UB}=1.736126 \mathrm{E}-18$

$+\mathrm{UC}=4.035809 \mathrm{E}-11$ VSAT $=1.083534 \mathrm{E} 5$ AO $=0.4962064$

$+\mathrm{AGS}=0.0873111 \quad \mathrm{BO}=2.346374 \mathrm{E}-6 \quad \mathrm{~B} 1=5 \mathrm{E}-6$

+ KETA $=-0.0107375 \quad A 1=0 \quad A 2=1$

$+\mathrm{RDSW}=3 \mathrm{E} 3 \quad \mathrm{PRWG}=-0.0324038$ PRWB $=-0.0446512$

$+W R=1 \quad$ WINT $=7.242762 E-7 \quad$ LINT $=2.231816 \mathrm{E}-7$

$+\mathrm{XL}=0 \quad \mathrm{XW}=0 \quad \mathrm{DWG}=-2.638688 \mathrm{E}-8$

+ DWB $=3.30262 \mathrm{E}-8 \quad$ VOFF $=-0.0424245 \quad \mathrm{NFACTOR}=0.6653555$

$+\mathrm{CIT}=0 \quad \mathrm{CDSC}=0 \quad \mathrm{CDSCD}=0$

$+\mathrm{CDSCB}=4.394359 \mathrm{E}-5 \quad \mathrm{ETAO}=-1 \quad \mathrm{ETAB}=-0.5939699$

+ DSUB $=0.9988851 \quad$ PCLM $=1.2994807 \quad$ PDIBLC1 $=8.97257 \mathrm{E}-3$

+ PDIBLC2 $=1.811508 \mathrm{E}-3 \quad$ PDIBLCB $=-0.1 \quad$ DROUT $=0.0581877$

+ PSCBE1 $=1 \mathrm{E} 8 \quad$ PSCBE2 $=5.480445 \mathrm{E}-10 \quad$ PVAG $=0.3163861$

+ DELTA $=0.01 \quad$ RSH $=54.2 \quad$ MOBMOD $=1$

+ PRT $=182.01 \quad$ UTE $=-1.5 \quad \mathrm{KT} 1=-0.282143$

$+\mathrm{KT} 1 \mathrm{~L}=3.296 \mathrm{E}-9 \quad \mathrm{KT} 2=0 \quad \mathrm{UA} 1=1.206664 \mathrm{E}-9$

+ UB1 $=-5.06439 \mathrm{E}-18$ UC1 $=-1 \mathrm{E}-10$ AT $=1 \mathrm{E} 5$

$+W L=0 \quad W L N=1 \quad W W=0$

$+W W N=1 \quad W W L=0 \quad \mathrm{LL}=0$

$+L L N=1 \quad L W=0 \quad L W N=1$

$+\mathrm{LWL}=0 \quad \mathrm{CAPMOD}=2 \quad \mathrm{XPART}=0.5$ 


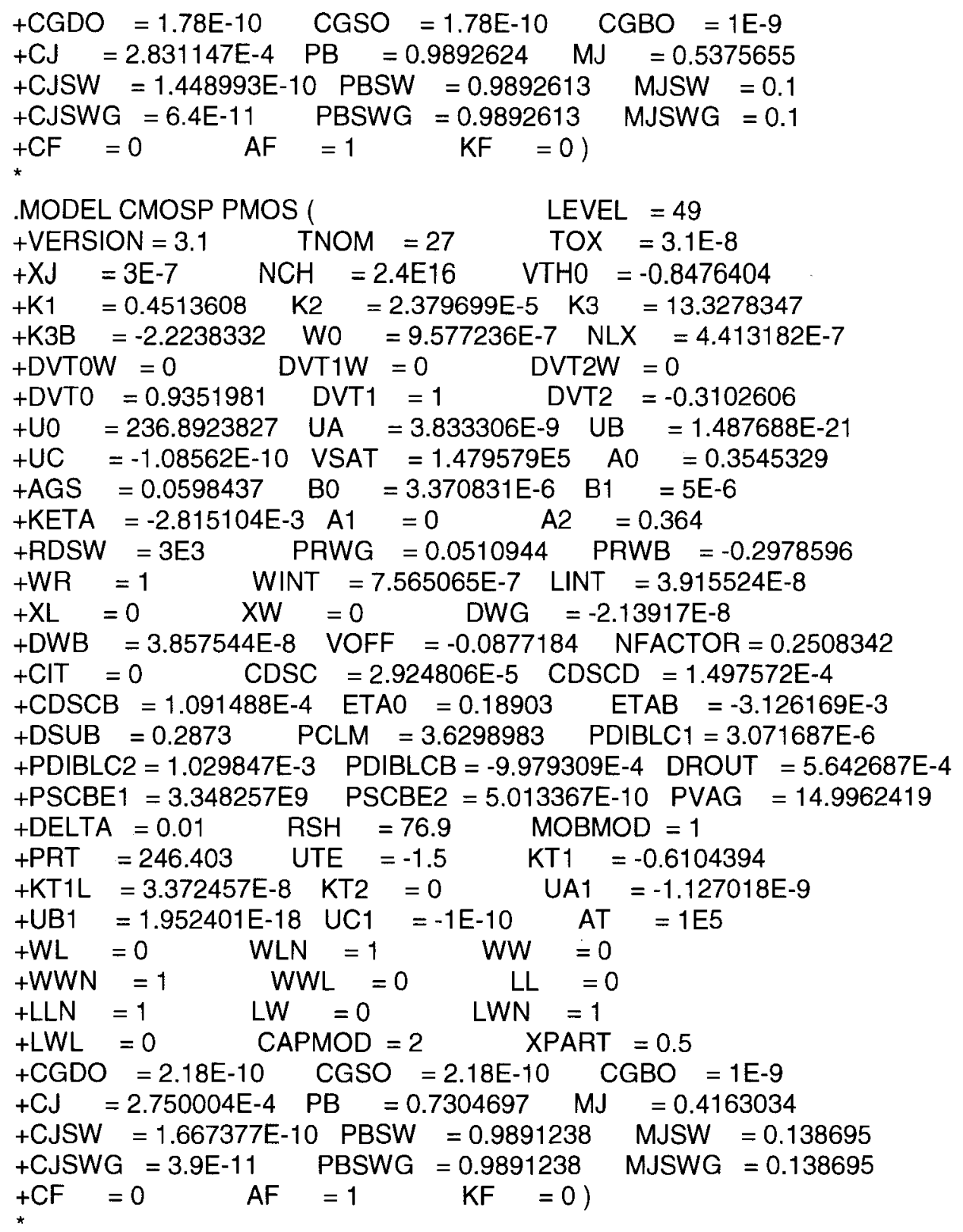

${ }^{*}$ DATE: Jun 7/02

* Tech: AMI_ABN

* LOT: T22X_FF (fast-fast) WAF: 6603

* Temperature_parameters=Optimized MODEL CMOSN NMOS

$\begin{array}{llll}+\mathrm{VERSION}=3.1 & \text { TNOM }=27 & \text { TOX }=3.09 \mathrm{E}-8 \\ +\mathrm{XJ}=1.5 \mathrm{E}-7 & \mathrm{NCH}=1.7 \mathrm{E} 17 & \mathrm{VTHO}=0.3418879 \\ +\mathrm{K} 1 & =1 & \mathrm{~K} 2=-0.0886142 & \mathrm{~K} 3=73.935439\end{array}$

$+\mathrm{K} 3 \mathrm{~B}=-1.7335131 \quad \mathrm{WO}=4.294837 \mathrm{E}-6 \quad \mathrm{NLX}=1.234757 \mathrm{E}-7$

+ DVTOW $=0 \quad$ DVT1W $=0 \quad$ DVT2W $=0$

+DVT0 $=0.9366704$ DVT1 $=0.3952099$ DVT2 $=-0.5$

$+\mathrm{UO}=512.1053322 \quad \mathrm{UA}=1 \mathrm{E}-13 \quad \mathrm{UB}=3.542293 \mathrm{E}-21$

$+\mathrm{UC}=-2.6555 \mathrm{E}-11$ VSAT $=1.262501 \mathrm{E} 5 \quad \mathrm{AO}=0.6976947$

+ AGS $=0.1141915 \quad \mathrm{BO}=1.665024 \mathrm{E}-6 \quad \mathrm{~B} 1=5 \mathrm{E}-6$ 
$+\mathrm{KETA}=1.004654 \mathrm{E}-3 \quad \mathrm{~A} 1=4.087651 \mathrm{E}-3 \quad \mathrm{~A} 2=0.4749696$

$+\mathrm{RDSW}=2.240384 \mathrm{E} 3 \quad \mathrm{PRWG}=0.0865258$ PRWB $=0.1022712$

$+W R=1 \quad$ WINT $=3.502972 \mathrm{E}-7 \quad$ LINT $=2.66482 \mathrm{E}-7$

$+X L=0 \quad X W=0 \quad D W G=8.182647 \mathrm{E}-8$

$+\mathrm{DWB}=1 \mathrm{E}-7 \quad$ VOFF $=0 \quad \mathrm{NFACTOR}=0$

$+\mathrm{CIT}=0 \quad \mathrm{CDSC}=2.4 \mathrm{E}-4 \quad \mathrm{CDSCD}=0$

$+\mathrm{CDSCB}=0 \quad \mathrm{ETAO}=4.931902 \mathrm{E}-3 \quad \mathrm{ETAB}=-2.258513 \mathrm{E}-3$

+ DSUB $=0.0881464 \quad$ PCLM $=2.9105077 \quad$ PDIBLC1 $=1.5770646$

+ PDIBLC2 $=2.55284 E-3 \quad$ PDIBLCB $=-0.0422318$ DROUT $=2$

$+\mathrm{PSCBE} 1=2.446215 \mathrm{E} 8 \quad \mathrm{PSCBE} 2=1.803554 \mathrm{E}-6 \quad \mathrm{PVAG}=0$

+ DELTA $=0.01 \quad$ RSH $=52.9 \quad$ MOBMOD $=1$

+ PRT $=182.01 \quad$ UTE $=-1.5 \quad$ KT1 $=-0.282143$

$+\mathrm{KT} 1 \mathrm{~L}=3.296 \mathrm{E}-9 \quad \mathrm{KT} 2=0 \quad \mathrm{UA} 1=1.206664 \mathrm{E}-9$

$+\mathrm{UB1}=-5.06439 \mathrm{E}-18$ UC1 $=-1 \mathrm{E}-10$ AT $=1 \mathrm{E} 5$

$+W L=0 \quad W L N=1 \quad W W=0$

$+W W N=1 \quad W W L=0 \quad L L=0$

$\begin{array}{llrrl}+\mathrm{LLN}=1 & \mathrm{LW}=0 & \mathrm{LWN}=1 \\ +\mathrm{LWL}=0 & \mathrm{CAPMOD}=2 & \mathrm{XPART}=0.5\end{array}$

$+\mathrm{CGDO}=1.79 \mathrm{E}-10 \quad \mathrm{CGSO}=1.79 \mathrm{E}-10 \quad \mathrm{CGBO}=1 \mathrm{E}-10$

$+\mathrm{CJ}=2.819907 \mathrm{E}-4 \quad \mathrm{~PB}=0.9892543 \quad \mathrm{MJ}=0.5329971$

+ CJSW $=1.60816 \mathrm{E}-10$ PBSW $=0.2095614 \quad \mathrm{MJSW}=0.1$

$+\mathrm{CJSWG}=6.4 \mathrm{E}-11 \quad \mathrm{PBSWG}=0.2095614 \quad \mathrm{MJSWG}=0.1$

$+\mathrm{CF}=0 \quad \mathrm{AF}=1 \quad \mathrm{KF}=0$ )

MODEL CMOSP PMOS (

+ VERSION $=3.1 \quad$ TNOM $=27 \quad$ TOX $=3.09 \mathrm{E}-8$

$+\mathrm{XJ}=1.5 \mathrm{E}-7 \quad \mathrm{NCH}=1.7 \mathrm{E} 17 \quad \mathrm{VTHO}=-0.5412091$

$+\mathrm{K} 1=0.4956702 \quad \mathrm{~K} 2=-0.0172116 \quad \mathrm{~K} 3=29.1047334$

$+\mathrm{K} 3 \mathrm{~B}=-0.349145 \quad \mathrm{~W} 0=6.643926 \mathrm{E}-7 \quad \mathrm{NLX}=9.869849 \mathrm{E}-7$

$\begin{array}{lll}+ \text { DVTOW }=0 & \text { DVT1W }=0 & \text { DVT2W }=0\end{array}$

+ DVTO $=1.2567763$ DVT1 $=0.1934763$ DVT2 $=-0.1101939$

$+\mathrm{UO}=213.8783744$ UA $=2.609406 \mathrm{E}-9 \quad \mathrm{UB}=2.126194 \mathrm{E}-19$

$+\mathrm{UC}=-9.91697 \mathrm{E}-11$ VSAT $=2 \mathrm{E} 5 \quad \mathrm{AO}=1.0812191$

$+\mathrm{AGS}=0.2151663 \quad \mathrm{BO}=3.026533 \mathrm{E}-6 \quad \mathrm{~B} 1=5 \mathrm{E}-6$

$+\mathrm{KETA}=-4.041454 \mathrm{E}-4 \mathrm{~A} 1=0 \quad \mathrm{~A} 2=0.3$

$+\mathrm{RDSW}=3 \mathrm{E} 3 \quad \mathrm{PRWG}=0.1606075$ PRWB $=0.026623$

$+W R=1 \quad$ WINT $=5 \mathrm{E}-7 \quad$ LINT $=1.070949 \mathrm{E}-7$

$+X L=0 \quad X W=0 \quad D W G=5.26422 E-8$

$+\mathrm{DWB}=1 \mathrm{E}-7 \quad$ VOFF $=-6.706867 \mathrm{E}-3 \quad \mathrm{NFACTOR}=0.1930646$

$+\mathrm{CIT}=0 \quad \mathrm{CDSC}=2.4 \mathrm{E}-4 \quad \mathrm{CDSCD}=0$

$+\mathrm{CDSCB}=0 \quad \mathrm{ETAO}=1 \quad \mathrm{ETAB}=0.422708$

+ DSUB $=0.7758321 \quad \mathrm{PCLM}=10 \quad$ PDIBLC1 $=0.5648689$

+ PDIBLC2 $=0 \quad$ PDIBLCB $=5.712687 \mathrm{E}-3 \quad$ DROUT $=0.2362627$

$+\mathrm{PSCBE} 1=1 \mathrm{E} 8 \quad \mathrm{PSCBE} 2=5 \mathrm{E}-10 \quad \mathrm{PVAG}=7.4222093$

+ DELTA $=0.01 \quad \mathrm{RSH}=75.5 \quad$ MOBMOD $=1$

+ PRT $=246.403$ UTE $=-1.5 \quad \mathrm{KT} 1=-0.6104394$

$+\mathrm{KT} 1 \mathrm{~L}=3.372457 \mathrm{E}-8 \quad \mathrm{KT} 2=0 \quad$ UA1 $=-1.127018 \mathrm{E}-9$

$+\mathrm{UB} 1=1.952401 \mathrm{E}-18 \quad \mathrm{UC} 1=-1 \mathrm{E}-10 \quad$ AT $=1 \mathrm{E} 5$

$+W L=0 \quad W L N=1 \quad W W=0$

$+W W N=1 \quad W W L=0 \quad L L=0$

$+\mathrm{LLN}=1 \quad \mathrm{LW}=0 \quad \mathrm{LWN}=1$

$+\mathrm{LWL}=0 \quad \mathrm{CAPMOD}=2 \quad \mathrm{XPART}=0.5$

$+\mathrm{CGDO}=2.26 \mathrm{E}-10 \quad \mathrm{CGSO}=2.26 \mathrm{E}-10 \quad \mathrm{CGBO}=1 \mathrm{E}-10$

$+\mathrm{CJ}=2.750024 \mathrm{E}-4 \mathrm{~PB}=0.7311843 \quad \mathrm{MJ}=0.4165128$

$+\mathrm{CJSW}=1.665418 \mathrm{E}-10 \mathrm{PBSW}=0.9889114 \quad \mathrm{MJSW}=0.1377668$

+ CJSWG $=3.9 \mathrm{E}-11 \quad$ PBSWG $=0.9889114 \quad$ MJSWG $=0.1377668$ 
${ }_{*}^{+\mathrm{CF}}=0 \quad \mathrm{AF}=1 \quad \mathrm{KF}=0$ )

* DATE: Jun 13/02

* Tech: AMI_ABN

* LOT: T22X_SF (slow-fast)

WAF: 6607

* Temperature_parameters=Optimized MODEL CMOSN NMOS (

+ VERSION $=3.1$

$$
\text { TNOM }=27
$$

LEVEL $=49$

$+\mathrm{XJ}=1.5 \mathrm{E}-7 \quad \mathrm{NCH}=1.7 \mathrm{E} 17$

TOX $=3.1 \mathrm{E}-8$

$+\mathrm{K} 1=1$

$\mathrm{K} 2=-0.0705094$

$\mathrm{VTHO}=0.4614515$

$+\mathrm{K} 3 \mathrm{~B}=-1.6803968$ WO $=4.639473 \mathrm{E}-6 \quad \mathrm{NLX}=1.585868 \mathrm{E}-7$

+ DVTOW $=0$ DVT1W $=0$

DVT2W $=0$

+ DVT0 $=1.0455678$ DVT1 $=0.354009$ DVT2 $=-0.3737356$

$+\mathrm{UO}=520.9170195 \mathrm{UA}=1.765927 \mathrm{E}-12 \mathrm{UB}=9.213525 \mathrm{E}-20$

$+\mathrm{UC}=-4.60095 \mathrm{E}-11$ VSAT $=1.417942 \mathrm{E} 5 \quad \mathrm{AO}=0.5127879$

+ AGS $=7.742278 \mathrm{E}-4 \quad \mathrm{BO}=1.213886 \mathrm{E}-6 \quad \mathrm{~B} 1=5 \mathrm{E}-6$

+ KETA $=-9.726449 E-3 \quad A 1=0.0285695 \quad A 2=0.31575$

$+\mathrm{RDSW}=2.817964 \mathrm{E} 3$ PRWG $=0.0426905$ PRWB $=0.0385776$

$+W R=1 \quad$ WINT $=4.015258 \mathrm{E}-7 \quad$ LINT $=2.806234 \mathrm{E}-7$

$+\mathrm{XL}=0 \quad \mathrm{XW}=0 \quad \mathrm{DWG}=7.86338 \mathrm{E}-8$

$+\mathrm{DWB}=1 \mathrm{E}-7 \quad$ VOFF $=0 \quad \mathrm{NFACTOR}=0.0395355$

$+\mathrm{CIT}=0 \quad \mathrm{CDSC}=2.4 \mathrm{E}-4 \quad \mathrm{CDSCD}=0$

$+\mathrm{CDSCB}=0 \quad \mathrm{ETAO}=2.168868 \mathrm{E}-3 \quad \mathrm{ETAB}=-6.298812 \mathrm{E}-4$

+ DSUB $=0.0291404 \quad$ PCLM $=2.9949477 \quad$ PDIBLC1 $=2$

+ PDIBLC2 $=1.045548 \mathrm{E}-3 \quad$ PDIBLCB $=-0.1985476 \quad$ DROUT $=1.0985508$

$+\mathrm{PSCBE} 1=1.687442 \mathrm{E} 8 \quad \mathrm{PSCBE} 2=2.05305 \mathrm{E}-7 \quad \mathrm{PVAG}=0$

+ DELTA $=0.01 \quad \mathrm{RSH}=52.2 \quad$ MOBMOD $=1$

+ PRT $=182.01 \quad$ UTE $=-1.5 \quad$ KT1 $=-0.282143$

$+\mathrm{KT} 1 \mathrm{~L}=3.296 \mathrm{E}-9 \quad \mathrm{KT} 2=0 \quad \mathrm{UA} 1=1.206664 \mathrm{E}-9$

$+\mathrm{UB} 1=-5.06439 \mathrm{E}-18$ UC1 $=-1 \mathrm{E}-10$ AT $=1 \mathrm{E} 5$

$+W L=0 \quad W L N=1 \quad W W=0$

$+W W N=1 \quad W W L=0 \quad L L=0$

$+\mathrm{LLN}=1 \quad \mathrm{LW}=0 \quad \mathrm{LWN}=1$

$+\mathrm{LWL}=0 \quad \mathrm{CAPMOD}=2 \quad \mathrm{XPART}=0.5$

$+\mathrm{CGDO}=1.78 \mathrm{E}-10 \quad \mathrm{CGSO}=1.78 \mathrm{E}-10 \quad \mathrm{CGBO}=1 \mathrm{E}-10$

$+\mathrm{CJ}=2.819905 \mathrm{E}-4 \quad \mathrm{~PB}=0.9892687 \quad \mathrm{MJ}=0.5330165$

$+\mathrm{CJSW}=1.608294 \mathrm{E}-10$ PBSW $=0.2096834 \quad \mathrm{MJSW}=0.1$

$+\mathrm{CJSWG}=6.4 \mathrm{E}-11 \quad$ PBSWG $=0.2096834 \quad \mathrm{MJSWG}=0.1$

$+\mathrm{CF}=0 \quad \mathrm{AF}=1 \quad \mathrm{KF}=0$ )

MODEL CMOSP PMOS (
+ VERSION $=3.1$

+ VERSION = 3.1

$\begin{array}{llrlrl}+\mathrm{XJ} & =1.5 \mathrm{E}-7 & \mathrm{NCH} & =1.7 \mathrm{E} 17 & \mathrm{VTHO} & =-0.7203002 \\ +\mathrm{K} 1 & =0.5028415 & \mathrm{~K} 2 & =-6.420434 \mathrm{E}-3 & \mathrm{~K} 3 & =25.7018529\end{array}$

$=27$

LEVEL $=49$

$+\mathrm{K} 3 \mathrm{~B}=-0.6650859$ WO $=7.616826 \mathrm{E}-7 \quad \mathrm{NLX}=1 \mathrm{E}-6$

+DVTOW $=0 \quad$ DVT1W $=0 \quad$ DVT2W $=0$

+ DVT0 $=1.5853422 \quad$ DVT1 $=0.2256511 \quad$ DVT2 $=-0.0761088$

$+\mathrm{UO}=225.9995164 \quad \mathrm{UA}=3.243723 \mathrm{E}-9 \quad \mathrm{UB}=3.53857 \mathrm{E}-19$

$+\mathrm{UC}=-9.47707 \mathrm{E}-11$ VSAT $=2 \mathrm{E} 5 \quad \mathrm{AO}=0.5399018$

$+\mathrm{AGS}=0.1772438 \quad \mathrm{BO}=4.276792 \mathrm{E}-6 \quad \mathrm{~B} 1=5 \mathrm{E}-6$

$+\mathrm{KETA}=-6.330167 \mathrm{E}-3 \mathrm{~A} 1=0 \quad \mathrm{~A} 2=0.3$

$+\mathrm{RDSW}=3 \mathrm{E} 3 \quad \mathrm{PRWG}=0.0916148 \quad \mathrm{PRWB}=-0.0744168$

$+W R=1 \quad$ WINT $=5 \mathrm{E}-7 \quad$ LINT $=8.263378 \mathrm{E}-8$

$+\mathrm{XL}=0 \quad \mathrm{XW}=0 \quad \mathrm{DWG}=6.663649 \mathrm{E}-8$

$+\mathrm{DWB}=1 \mathrm{E}-7 \quad$ VOFF $=-0.0375864 \quad \mathrm{NFACTOR}=0.1597389$

$+\mathrm{CIT}=0 \quad \mathrm{CDSC}=2.4 \mathrm{E}-4 \quad \mathrm{CDSCD}=0$ 


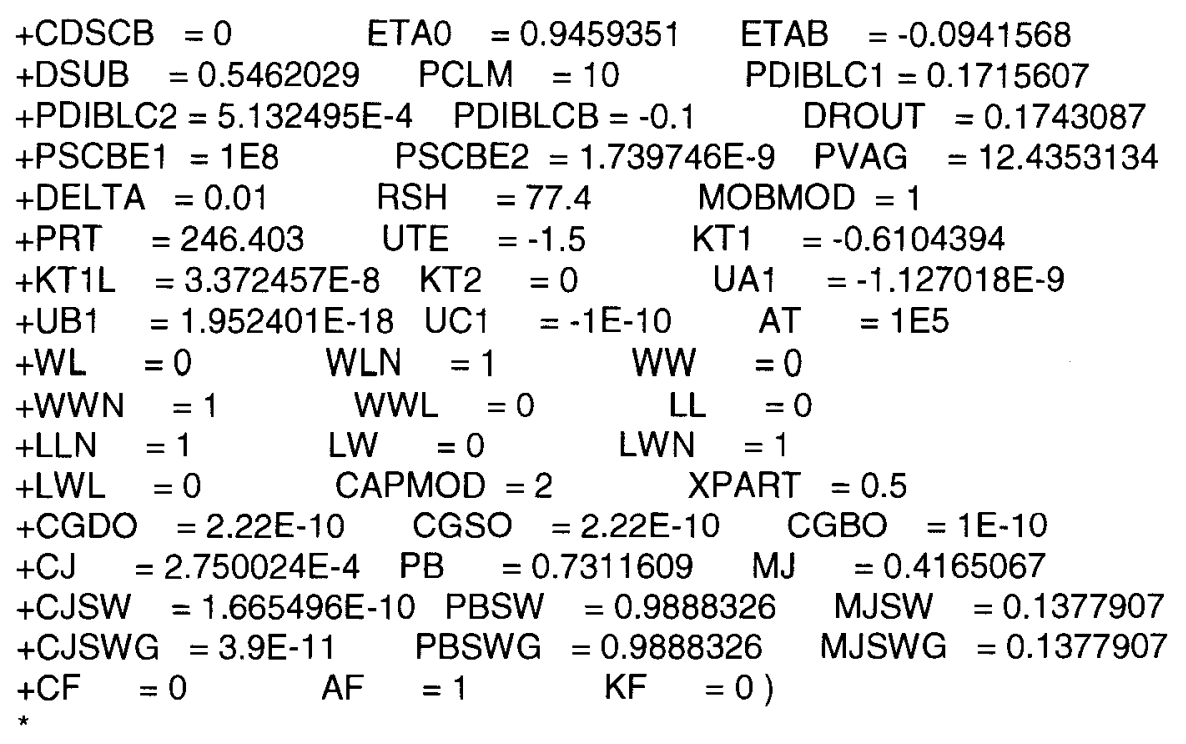

* DATE: Jun $14 / 02$

* Tech: AMI_ABN

* LOT: T22X_FS (fast-slow) WAF: 6606

*Temperature_parameters=Optimized MODEL CMOSN NMOS (

+ VERSION $=3.1 \quad$ TNOM $=27 \quad$ TOX $=3.1 \mathrm{E}-8$

$+\mathrm{XJ}=1.5 \mathrm{E}-7 \quad \mathrm{NCH}=1.7 \mathrm{E} 17 \quad \mathrm{VTHO}=0.3552941$

$+\mathrm{K} 1=1 \quad \mathrm{~K} 2=-0.0902551 \quad \mathrm{~K} 3=80.4408341$

$+\mathrm{K} 3 \mathrm{~B}=-2.0401761 \quad \mathrm{WO}=5.986863 \mathrm{E}-6 \quad \mathrm{NLX}=2.004975 \mathrm{E}-7$

+DVTOW $=0 \quad$ DVT1W $=0 \quad$ DVT2W $=0$

+ DVTO $=1.1516023 \quad$ DVT1 $=0.3035573 \quad$ DVT2 $=-0.2699118$

$+\mathrm{UO}=525.7080358 \quad \mathrm{UA}=1 \mathrm{E}-13 \quad \mathrm{UB}=2.178146 \mathrm{E}-20$

$+\mathrm{UC}=-4.24067 \mathrm{E}-11$ VSAT $=1.330286 \mathrm{E} 5 \quad \mathrm{AO}=0.6608039$

+ AGS $=0.0739246 \quad$ BO $=1.234506 \mathrm{E}-6 \quad \mathrm{~B} 1=5 \mathrm{E}-6$

+ KETA $=6.152135 \mathrm{E}-4 \quad \mathrm{~A} 1=0.0319649 \quad \mathrm{~A} 2=0.3555416$

$+\mathrm{RDSW}=2.776237 \mathrm{E} 3$ PRWG $=0.0434954$ PRWB $=0.0513048$

$+W R=1 \quad W I N T=3.615794 \mathrm{E}-7 \quad$ LINT $=2.824851 \mathrm{E}-7$

$+\mathrm{XL}=0 \quad \mathrm{XW}=0 \quad \mathrm{DWG}=7.804304 \mathrm{E}-8$

$+\mathrm{DWB}=1 \mathrm{E}-7 \quad$ VOFF $=0 \quad$ NFACTOR $=0$

$+\mathrm{CIT}=0 \quad \mathrm{CDSC}=2.4 \mathrm{E}-4 \quad \mathrm{CDSCD}=0$

$+\mathrm{CDSCB}=0 \quad \mathrm{ETAO}=3.988663 \mathrm{E}-3 \quad \mathrm{ETAB}=-1.860237 \mathrm{E}-3$

+ DSUB $=0.0717376 \quad \mathrm{PCLM}=2.9673455 \quad \mathrm{PDIBLC} 1=1.7324734$

+ PDIBLC2 $=2.44682 \mathrm{E}-3 \quad \mathrm{PDIBLCB}=-0.0311057 \quad$ DROUT $=1.3514359$

+ PSCBE1 $=1.980083 \mathrm{E} 8 \quad \mathrm{PSCBE} 2=5.517543 \mathrm{E}-7 \quad \mathrm{PVAG}=0$

+ DELTA $=0.01 \quad \mathrm{RSH}=54.7 \quad$ MOBMOD $=1$

$+\mathrm{PRT}=182.01$ UTE $=-1.5 \quad \mathrm{KT} 1=-0.282143$

$+\mathrm{KT} 1 \mathrm{~L}=3.296 \mathrm{E}-9 \quad \mathrm{KT} 2=0 \quad \mathrm{UA} 1=1.206664 \mathrm{E}-9$

$+\mathrm{UB} 1=-5.06439 \mathrm{E}-18 \quad \mathrm{UC} 1=-1 \mathrm{E}-10 \quad$ AT $=1 \mathrm{E} 5$

$+W L=0 \quad W L N=1 \quad W W=0$

$+W W N=1 \quad W W L=0 \quad L L=0$

$+\mathrm{LLN}=1 \quad \mathrm{LW}=0 \quad \mathrm{LWN}=1$

$+\mathrm{LWL}=0 \quad \mathrm{CAPMOD}=2 \quad \mathrm{XPART}=0.5$

$+\mathrm{CGDO}=1.79 \mathrm{E}-10 \quad \mathrm{CGSO}=1.79 \mathrm{E}-10 \quad \mathrm{CGBO}=1 \mathrm{E}-10$

$+\mathrm{CJ}=2.819905 \mathrm{E}-4 \quad \mathrm{~PB}=0.9892687 \mathrm{MJ}=0.5330165$

$+\mathrm{CJSW}=1.608294 \mathrm{E}-10$ PBSW $=0.2096834 \quad \mathrm{MJSW}=0.1$

$+\mathrm{CJSWG}=6.4 \mathrm{E}-11 \quad \mathrm{PBSWG}=0.2096834 \quad \mathrm{MJSWG}=0.1$

$+\mathrm{CF}=0 \quad \mathrm{AF}=1 \quad \mathrm{KF}=0)^{*}$ 


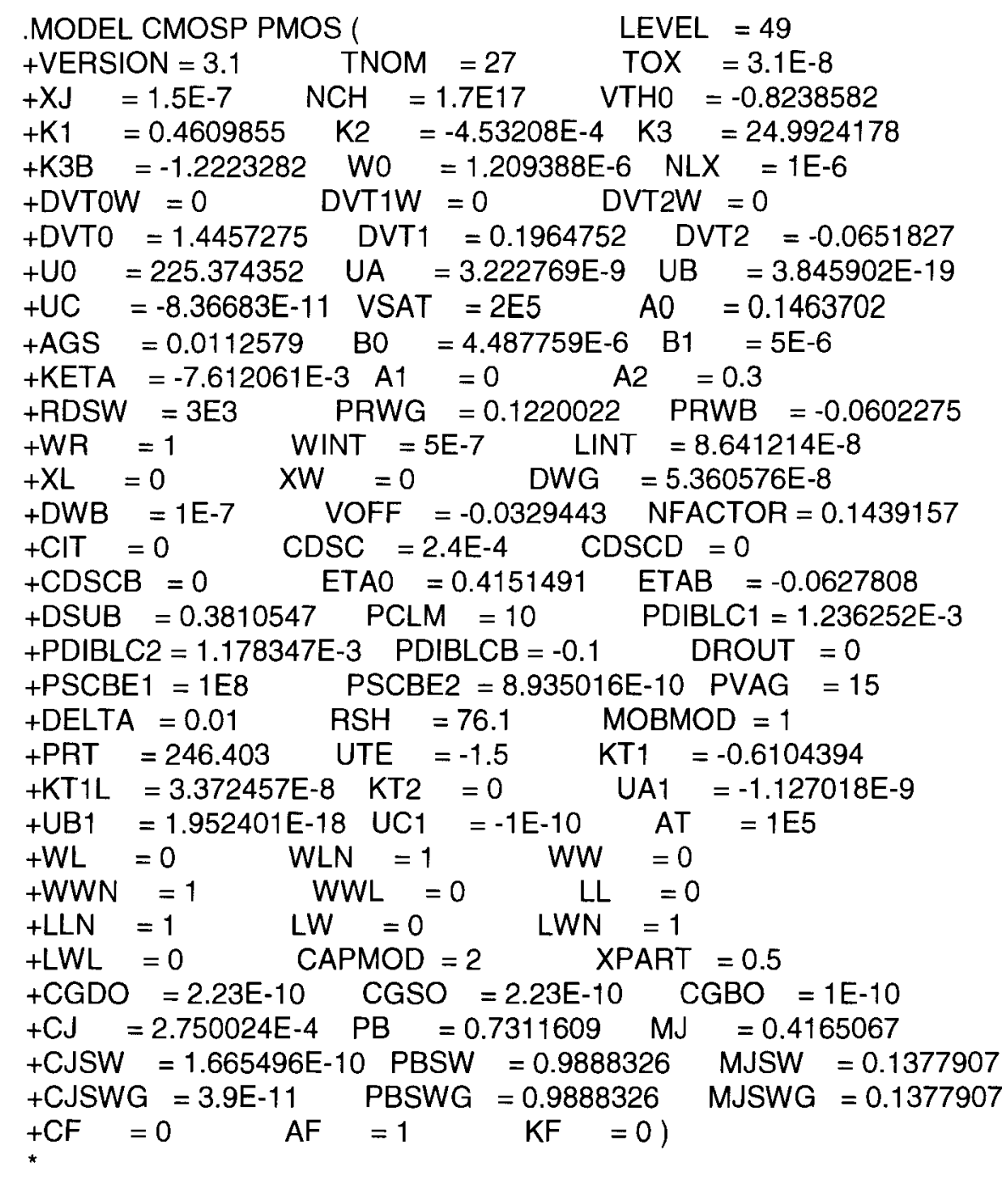




\section{Appendix (D)}

\section{MOSFET Results}

UnOptimized and Optimized data using Percentage Error method for 2.4x1.6 um NMOS FETs.

\begin{tabular}{|c|c|c|c|c|c|c|c|}
\hline \multicolumn{2}{|c|}{$\begin{array}{l}W=2.4 u m \& \\
L=1.6 \text { um }\end{array}$} & \multicolumn{3}{|c|}{$\begin{array}{l}\text { Using the optimized values of } \\
\qquad t=0.48 V \text { and } M=1.05\end{array}$} & \multicolumn{3}{|c|}{$\begin{array}{l}\text { Using the default values of } \mathrm{Vt} \\
=0.48 \mathrm{~V} \text { and } \mathrm{M}=1\end{array}$} \\
\hline \multirow[t]{3}{*}{$\begin{array}{l}\text { Vgs } \\
\text { (V) }\end{array}$} & $\begin{array}{l}\text { Vds } \\
\text { (V) }\end{array}$ & $\begin{array}{c}\text { Ids } \\
\text { Measured } \\
\text { with dual } \\
\text { SMUs }\end{array}$ & $\begin{array}{c}\text { Ids } \\
\text { Simulated } \\
w / \\
\text { Vt=0.48V } \\
\text { and } M= \\
1.05\end{array}$ & $\begin{array}{l}\text { Error } \\
\text { Factor } \\
\text { Meas. } \\
\text { Vs } \\
\text { Sim. } \\
\text { (SMU/ } \\
\text { Sim) }\end{array}$ & $\begin{array}{c}\text { Ids } \\
\text { Measured } \\
\text { with dual } \\
\text { SMUs }\end{array}$ & $\begin{array}{c}\text { Ids } \\
\text { Simulated } \\
w / \\
V t=0.48 \mathrm{~V} \\
\text { and } M=1\end{array}$ & $\begin{array}{c}\text { Error } \\
\text { Factor } \\
\text { Meas. } \\
\text { Vs } \\
\text { Sim. } \\
\text { (SMU/ } \\
\text { Sim) }\end{array}$ \\
\hline & & Die \#3 & & & Die \#3 & & \\
\hline & & (A) & (A) & & (A) & (A) & \\
\hline 0 & 1.0 & 9.26E-09 & $1.59 \mathrm{E}-12$ & 5812.75 & $9.26 \mathrm{E}-09$ & 1.57E-12 & 5917.84 \\
\hline 0 & 3.0 & 1.06E-08 & $3.83 \mathrm{E}-12$ & 2768.50 & $1.06 \mathrm{E}-08$ & $3.79 \mathrm{E}-12$ & 2797.41 \\
\hline 0 & 5.0 & 1.12E-08 & $6.07 \mathrm{E}-12$ & 1839.03 & 1.12E-08 & $6.02 E-12$ & 1854.58 \\
\hline 1.0 & 1.0 & $1.54 \mathrm{E}-06$ & $6.40 \mathrm{E}-06$ & 0.24 & $1.54 \mathrm{E}-06$ & $6.10 \mathrm{E}-06$ & 0.25 \\
\hline 1.0 & 3.0 & $1.96 \mathrm{E}-06$ & 7.23E-06 & 0.27 & 1.96E-06 & $6.88 E-06$ & 0.29 \\
\hline 1.0 & 5.0 & $2.29 E-06$ & 7.90E-06 & 0.29 & $2.29 \mathrm{E}-06$ & 7.52E-06 & 0.30 \\
\hline 2.0 & 1.0 & $1.37 \mathrm{E}-05$ & 3.57E-05 & 0.39 & 1.37E-05 & $3.40 E-05$ & 0.40 \\
\hline 2.0 & 3.0 & $1.78 \mathrm{E}-05$ & 4.05E-05 & 0.44 & $1.78 \mathrm{E}-05$ & $3.86 E-05$ & 0.46 \\
\hline 2.0 & 5.0 & $2.01 \mathrm{E}-05$ & $4.24 \mathrm{E}-05$ & 0.47 & $2.01 \mathrm{E}-05$ & 4.04E-05 & 0.50 \\
\hline 3.0 & 1.0 & 3.67E-05 & 6.82E-05 & 0.54 & 3.67E-05 & $6.49 \mathrm{E}-05$ & 0.56 \\
\hline 3.0 & 3.0 & $5.12 E-05$ & 8.93E-05 & 0.57 & $5.12 E-05$ & $8.50 \mathrm{E}-05$ & 0.60 \\
\hline 3.0 & 5.0 & $5.63 E-05$ & $9.25 E-05$ & 0.61 & 5.63E-05 & 8.81E-05 & 0.64 \\
\hline 4.0 & 1.0 & $6.29 \mathrm{E}-05$ & 9.63E-05 & 0.65 & $6.29 \mathrm{E}-05$ & $9.17 \mathrm{E}-05$ & 0.69 \\
\hline 4.0 & 3.0 & $9.71 \mathrm{E}-05$ & $1.47 \mathrm{E}-04$ & 0.66 & $9.71 \mathrm{E}-05$ & 1.40E-04 & 0.69 \\
\hline 4.0 & 5.0 & $1.06 \mathrm{E}-04$ & $1.52 E-04$ & 0.70 & $1.06 \mathrm{E}-04$ & 1.45E-04 & 0.73 \\
\hline 5.0 & 1.0 & 8.93E-05 & $1.21 \mathrm{E}-04$ & 0.74 & 8.93E-05 & 1.15E-04 & 0.78 \\
\hline 5.0 & 3.0 & $1.51 \mathrm{E}-04$ & $2.12 \mathrm{E}-04$ & 0.71 & $1.51 \mathrm{E}-04$ & 2.02E-04 & 0.75 \\
\hline 5.0 & 5.0 & $1.65 \mathrm{E}-04$ & $2.20 \mathrm{E}-04$ & 0.75 & $1.65 \mathrm{E}-04$ & $2.10 \mathrm{E}-04$ & 0.79 \\
\hline & & & AVG Error & $46.44 \%$ & & AVG Error & $43.76 \%$ \\
\hline & & & SD Error & 0.18 & & SD Error & 0.18 \\
\hline
\end{tabular}


FET.

\begin{tabular}{|c|c|c|c|c|c|c|c|}
\hline \multicolumn{2}{|c|}{$\begin{array}{l}W=38.4 u m \\
\& L=1.6 \text { um }\end{array}$} & \multicolumn{3}{|c|}{$\begin{array}{l}\text { Using the optimized values of } \\
\qquad t=0.48 \mathrm{~V} \text { and } M=1.05\end{array}$} & \multicolumn{3}{|c|}{$\begin{array}{c}\text { Using the default values of } \mathrm{Vt} \\
\quad=0.48 \mathrm{~V} \text { and } \mathrm{M}=1\end{array}$} \\
\hline \multirow[t]{3}{*}{$\begin{array}{l}\text { Vgs } \\
\text { (V) }\end{array}$} & \multirow[t]{3}{*}{$\begin{array}{l}\text { Vds } \\
\text { (V) }\end{array}$} & $\begin{array}{c}\text { Ids } \\
\text { Measured } \\
\text { with dual } \\
\text { SMUs } \\
\end{array}$ & $\begin{array}{c}\text { Ids } \\
\text { Simulated } \\
\text { w/ } \\
\mathrm{Vt}=0.48 \mathrm{~V} \\
\text { and } M= \\
1.05 \\
\end{array}$ & $\begin{array}{l}\text { Error } \\
\text { Factor } \\
\text { Meas. } \\
\text { Vs } \\
\text { Sim. } \\
\text { (SMU/ } \\
\text { Sim) } \\
\end{array}$ & $\begin{array}{c}\text { Ids } \\
\text { Measured } \\
\text { with dual } \\
\text { SMUs } \\
\end{array}$ & $\begin{array}{c}\text { Ids } \\
\text { Simulated } \\
w / \\
V t=0.48 \mathrm{~V} \\
\text { and } M=1\end{array}$ & $\begin{array}{c}\text { Error } \\
\text { Factor } \\
\text { Meas. } \\
\text { Vs } \\
\text { Sim. } \\
\text { (SMU/ } \\
\text { Sim) } \\
\end{array}$ \\
\hline & & Die \#3 & & & Die \#3 & & \\
\hline & & (A) & (A) & & (A) & (A) & \\
\hline 0 & 1.0 & $6.01 \mathrm{E}-11$ & $4.22 \mathrm{E}-11$ & 1.42 & $6.01 E-11$ & $4.02 \mathrm{E}-11$ & 1.49 \\
\hline 0 & 3.0 & $7.74 \mathrm{E}-11$ & $6.04 \mathrm{E}-11$ & 1.28 & $7.74 \mathrm{E}-11$ & $5.77 \mathrm{E}-11$ & 1.34 \\
\hline 0 & 5.0 & $3.93 \mathrm{E}-11$ & $7.86 \mathrm{E}-11$ & 0.50 & $3.93 \mathrm{E}-11$ & $7.51 \mathrm{E}-11$ & 0.52 \\
\hline 1.0 & 1.0 & $2.82 E-04$ & 3.02E-04 & 0.93 & $2.82 E-04$ & $2.87 \mathrm{E}-04$ & 0.98 \\
\hline 1.0 & 3.0 & $3.31 \mathrm{E}-04$ & $3.41 E-04$ & 0.97 & $3.31 E-04$ & $3.24 \mathrm{E}-04$ & 1.02 \\
\hline 1.0 & 5.0 & 3.69E-04 & 3.71E-04 & 0.99 & $3.69 E-04$ & 3.54E-04 & 1.04 \\
\hline 2.0 & 1.0 & -03 & $151 \mathrm{~F}-03$ & 1.02 & 1. & -03 & 1.07 \\
\hline 2.0 & 3.0 & 1.79E-03 & $1.76 \mathrm{E}-03$ & 1.02 & 1.79E-03 & 1.67E-03 & 1.07 \\
\hline 2.0 & 5.0 & $1.90 \mathrm{E}-03$ & $1.84 \mathrm{E}-03$ & 1.03 & $1.90 \mathrm{E}-03$ & $1.75 \mathrm{E}-03$ & 1.09 \\
\hline 3.0 & 1.0 & $2.78 \mathrm{E}-03$ & $2.69 \mathrm{E}-03$ & 1.03 & $2.78 \mathrm{E}-03$ & $2.56 \mathrm{E}-03$ & 1.08 \\
\hline 3.0 & 3.0 & $3.65 \mathrm{E}-03$ & $3.69 \mathrm{E}-03$ & 0.99 & $3.65 \mathrm{E}-03$ & $3.52 \mathrm{E}-03$ & 1.04 \\
\hline 3.0 & 5.0 & $3.81 \mathrm{E}-03$ & $3.83 E-03$ & 1.00 & $3.81 \mathrm{E}-03$ & $3.65 \mathrm{E}-03$ & 1.05 \\
\hline & & & & 3 & & & \\
\hline 4.0 & 1.0 & $3.75 \mathrm{E}-03$ & $3.66 \mathrm{E}-03$ & 1.02 & $3.75 \mathrm{E}-03$ & $3.49 \mathrm{E}-03$ & 1.07 \\
\hline 4.0 & 3.0 & $5.66 \mathrm{E}-03$ & 5.87E-03 & 0.96 & $5.66 \mathrm{E}-03$ & $5.59 \mathrm{E}-03$ & 1.01 \\
\hline 4.0 & 5.0 & $5.86 \mathrm{E}-03$ & $6.08 \mathrm{E}-03$ & 0.96 & $5.86 \mathrm{E}-03$ & $5.79 \mathrm{E}-03$ & 1.01 \\
\hline & & & & & & & + \\
\hline 5.0 & 1.0 & $4.54 \mathrm{E}-03$ & $4.46 \mathrm{E}-03$ & 1.02 & $4.54 \mathrm{E}-03$ & $4.25 \mathrm{E}-03$ & 1.07 \\
\hline 5.0 & 3.0 & 7.67E-03 & $8.15 \mathrm{E}-03$ & 0.94 & 7.67E-03 & 7.76E-03 & 0.99 \\
\hline 5.0 & 5.0 & $7.96 \mathrm{E}-03$ & $8.54 \mathrm{E}-03$ & 0.93 & $7.96 \mathrm{E}-03$ & 8.13E-03 & 0.98 \\
\hline & & & & & & & \\
\hline & & & AVG Error & $-0.22 \%$ & & AVG Error & $-5.20 \%$ \\
\hline & & & SD Error & 0.18 & & SD Error & 0.18 \\
\hline & & & & & & & \\
\hline
\end{tabular}




\begin{tabular}{|c|c|c|c|c|c|c|c|}
\hline \multicolumn{2}{|c|}{$\begin{array}{l}W=57.6 u m \\
\& L=1.6 \mathrm{um}\end{array}$} & \multicolumn{3}{|c|}{$\begin{array}{l}\text { Using the optimized values of } \\
V t=0.48 \mathrm{~V} \text { and } M=1.05\end{array}$} & \multicolumn{3}{|c|}{$\begin{array}{l}\text { Using the default values of } \mathrm{Vt} \\
=0.48 \mathrm{~V} \text { and } \mathrm{M}=1\end{array}$} \\
\hline \multirow[t]{3}{*}{$\begin{array}{l}\text { Vgs } \\
\text { (V) }\end{array}$} & $\begin{array}{l}\text { Vds } \\
\text { (V) }\end{array}$ & $\begin{array}{c}\text { Ids } \\
\text { Measured } \\
\text { with dual } \\
\text { SMUs } \\
\end{array}$ & $\begin{array}{c}\text { Ids } \\
\text { Simulate } \\
d w / \\
V t=0.48 V \\
\text { and } M= \\
1.05\end{array}$ & $\begin{array}{c}\text { Error } \\
\text { Factor } \\
\text { Meas. } \\
\text { Vs Sim. } \\
\text { (SMU/Si } \\
\text { m) }\end{array}$ & $\begin{array}{c}\text { Ids } \\
\text { Measured } \\
\text { with dual } \\
\text { SMUs }\end{array}$ & \begin{tabular}{|c|} 
Ids \\
Simulated \\
$w /$ \\
Vt=0.48V \\
and $M=1$
\end{tabular} & $\begin{array}{c}\text { Error } \\
\text { Factor } \\
\text { Meas. } \\
\text { Vs Sim. } \\
\text { (SMU/Si } \\
\text { m) }\end{array}$ \\
\hline & & Die \#3 & & & Die \#3 & & \\
\hline & & (A) & (A) & & (A) & (A) & \\
\hline 0 & 1.0 & $4.86 \mathrm{E}-08$ & $6.49 \mathrm{E}-11$ & 747.75 & $4.86 \mathrm{E}-08$ & $6.19 \mathrm{E}-11$ & 784.54 \\
\hline 0 & 3.0 & 8.34E-08 & $9.21 \mathrm{E}-11$ & 905.38 & 8.34E-08 & $8.78 \mathrm{E}-11$ & 949.11 \\
\hline 0 & 5.0 & 1.36E-07 & $1.19 \mathrm{E}-10$ & 1140.84 & 1.36E-07 & $1.14 \mathrm{E}-10$ & 1195.43 \\
\hline 1.0 & 1.0 & $6.83 E-04$ & $4.62 E-04$ & 1.48 & $6.83 E-04$ & $4.40 \mathrm{E}-04$ & 1.55 \\
\hline 1.0 & 3.0 & 7.97E-04 & 5.22E-04 & 1.53 & 7.97E-04 & 4.97E-04 & 1.60 \\
\hline 1.0 & 5.0 & 8.80E-04 & $5.69 \mathrm{E}-04$ & 1.55 & $8.80 \mathrm{E}-04$ & $5.42 \mathrm{E}-04$ & 1.63 \\
\hline 2.0 & 1.0 & $2.57 \mathrm{E}-03$ & $2.31 \mathrm{E}-03$ & 1.11 & $2.57 \mathrm{E}-03$ & $2.20 \mathrm{E}-03$ & 1.17 \\
\hline 2.0 & 3.0 & $3.09 \mathrm{E}-03$ & $2.69 \mathrm{E}-03$ & 1.15 & $3.09 \mathrm{E}-03$ & $2.56 \mathrm{E}-03$ & 1.21 \\
\hline 2.0 & 5.0 & 3.27E-03 & 2.81E-03 & 1.16 & $3.27 \mathrm{E}-03$ & $2.68 \mathrm{E}-03$ & 1.22 \\
\hline 3.0 & 1.0 & $4.22 E-03$ & $4.10 \mathrm{E}-03$ & 1.03 & $4.22 \mathrm{E}-03$ & $3.90 \mathrm{E}-03$ & 1.08 \\
\hline 3.0 & 3.0 & $5.85 E-03$ & $5.64 \mathrm{E}-03$ & 1.04 & $5.85 \mathrm{E}-03$ & $5.37 \mathrm{E}-03$ & 1.09 \\
\hline 3.0 & 5.0 & 6.11E-03 & $5.85 \mathrm{E}-03$ & 1.05 & $6.11 \mathrm{E}-03$ & $5.57 \mathrm{E}-03$ & 1.10 \\
\hline 4.0 & 1.0 & 5.52E-03 & 5.57E-03 & 0.99 & $5.52 \mathrm{E}-03$ & $5.31 \mathrm{E}-03$ & 1.04 \\
\hline 4.0 & 3.0 & 8.78E-03 & $8.95 \mathrm{E}-03$ & 0.98 & $8.78 \mathrm{E}-03$ & $8.52 E-03$ & 1.03 \\
\hline 4.0 & 5.0 & $9.12 E-03$ & $9.28 \mathrm{E}-03$ & 0.98 & $9.12 \mathrm{E}-03$ & $8.83 \mathrm{E}-03$ & 1.03 \\
\hline 5.0 & 1.0 & $6.58 \mathrm{E}-03$ & $6.78 \mathrm{E}-03$ & 0.97 & $6.58 \mathrm{E}-03$ & $6.46 \mathrm{E}-03$ & 1.02 \\
\hline 5.0 & 3.0 & 1.17E-02 & $1.24 \mathrm{E}-02$ & 0.94 & $1.17 \mathrm{E}-02$ & $1.18 \mathrm{E}-02$ & 0.99 \\
\hline 5.0 & 5.0 & 1.22E-02 & $1.30 \mathrm{E}-02$ & 0.94 & $1.22 \mathrm{E}-02$ & 1.24E-02 & 0.98 \\
\hline & & & & & & & \\
\hline & & & AVG Error & $-12.64 \%$ & & AVG Error & $-18.27 \%$ \\
\hline & & & SD Error & 0.21 & & SD Error & 0.23 \\
\hline
\end{tabular}


UnOptimized and Optimized data using Percentage Error method for $76.8 \times 1.6$ um NMOS FET

\begin{tabular}{|c|c|c|c|c|c|c|c|}
\hline \multicolumn{2}{|c|}{$\begin{array}{l}W=76.8 \mathrm{um} \& \\
L=1.6 \mathrm{um}\end{array}$} & \multicolumn{3}{|c|}{$\begin{array}{l}\text { Using the optimized values of } \\
\mathrm{Vt}=0.48 \mathrm{~V} \text { and } \mathrm{M}=1.05\end{array}$} & \multicolumn{3}{|c|}{$\begin{array}{l}\text { Using the default values of } \mathrm{Vt} \\
\quad=0.48 \mathrm{~V} \text { and } \mathrm{M}=1\end{array}$} \\
\hline $\begin{array}{l}\text { Vgs } \\
\text { (V) }\end{array}$ & $\begin{array}{l}\text { Vds } \\
\text { (V) }\end{array}$ & $\begin{array}{l}\text { Ids } \\
\text { Measured } \\
\text { with dual } \\
\text { SMUs }\end{array}$ & $\begin{array}{l}\text { Ids } \\
\text { Simulated } \\
w / V t=0.48 \mathrm{~V} \\
\text { and } \\
M=1.05\end{array}$ & $\begin{array}{l}\text { Error } \\
\text { Factor } \\
\text { Meas. } \\
\text { Vs } \\
\text { Sim. } \\
\text { (SMU/ } \\
\text { Sim) }\end{array}$ & $\begin{array}{l}\text { Ids } \\
\text { Measured } \\
\text { with dual } \\
\text { SMUs }\end{array}$ & $\begin{array}{l}\text { Ids } \\
\text { Simulated } \\
w / \\
V t=0.48 V \\
\text { and } M=1\end{array}$ & $\begin{array}{l}\text { Error } \\
\text { Factor } \\
\text { Meas. } \\
\text { Vs } \\
\text { Sim. } \\
\text { (SMU/ } \\
\text { Sim) }\end{array}$ \\
\hline & & Die \#3 & & & Die \#3 & & \\
\hline & & (A) & (A) & & (A) & (A) & \\
\hline 0 & 1.0 & $7.71 \mathrm{E}-11$ & $8.77 \mathrm{E}-11$ & 0.88 & $7.71 E-11$ & $8.36 \mathrm{E}-11$ & 0.92 \\
\hline 0 & 3.0 & $9.27 \mathrm{E}-11$ & $1.24 \mathrm{E}-10$ & 0.75 & $9.27 \mathrm{E}-11$ & $1.18 \mathrm{E}-10$ & 0.79 \\
\hline 0 & 5.0 & $1.12 \mathrm{E}-10$ & $1.60 \mathrm{E}-10$ & 0.70 & $1.12 \mathrm{E}-10$ & $1.52 \mathrm{E}-10$ & 0.73 \\
\hline 1.0 & 1.0 & $5.69 \mathrm{E}-04$ & $6.22 E-04$ & 0.91 & $5.69 \mathrm{E}-04$ & $5.93 E-04$ & 0.96 \\
\hline 1.0 & 3.0 & $6.66 \mathrm{E}-04$ & 7.03E-04 & 0.95 & $6.66 \mathrm{E}-04$ & $6.69 \mathrm{E}-04$ & 1.00 \\
\hline 1.0 & 5.0 & $7.43 \mathrm{E}-04$ & $7.66 \mathrm{E}-04$ & 0.97 & $7.43 \mathrm{E}-04$ & $7.30 \mathrm{E}-04$ & 1.02 \\
\hline 2.0 & 1.0 & 3.07E-03 & $3.11 E-03$ & 0.99 & 3.07E-03 & $2.96 \mathrm{E}-03$ & 1.04 \\
\hline 2.0 & 3.0 & 3.56E-03 & $3.62 \mathrm{E}-03$ & 0.98 & $3.56 \mathrm{E}-03$ & $3.44 \mathrm{E}-03$ & 1.03 \\
\hline 2.0 & 5.0 & 3.77E-03 & 3.78E-03 & 1.00 & 3.77E-03 & $3.60 \mathrm{E}-03$ & 1.05 \\
\hline 3.0 & 1.0 & $5.44 \mathrm{E}-03$ & $5.50 \mathrm{E}-03$ & 0.99 & $5.44 \mathrm{E}-03$ & $5.24 \mathrm{E}-03$ & 1.04 \\
\hline 3.0 & 3.0 & $7.22 \mathrm{E}-03$ & $7.59 \mathrm{E}-03$ & 0.95 & $7.22 \mathrm{E}-03$ & $7.22 \mathrm{E}-03$ & 1.00 \\
\hline 3.0 & 5.0 & $7.52 \mathrm{E}-03$ & $7.86 \mathrm{E}-03$ & 0.96 & $7.52 \mathrm{E}-03$ & $7.49 \mathrm{E}-03$ & 1.00 \\
\hline 4.0 & 1.0 & $7.28 \mathrm{E}-03$ & $7.48 \mathrm{E}-03$ & 0.97 & $7.28 \mathrm{E}-03$ & $7.12 \mathrm{E}-03$ & 1.02 \\
\hline 4.0 & 3.0 & $1.12 \mathrm{E}-02$ & $1.20 \mathrm{E}-02$ & 0.93 & $1.12 \mathrm{E}-02$ & $1.15 \mathrm{E}-02$ & 0.97 \\
\hline 4.0 & 5.0 & 1.15E-02 & 1.25E-02 & 0.93 & $1.15 \mathrm{E}-02$ & $1.19 \mathrm{E}-02$ & 0.97 \\
\hline 5.0 & 1.0 & $8.76 \mathrm{E}-03$ & $9.10 \mathrm{E}-03$ & 0.96 & $8.76 \mathrm{E}-03$ & $8.66 \mathrm{E}-03$ & 1.01 \\
\hline 5.0 & 3.0 & $1.51 \mathrm{E}-02$ & $1.67 \mathrm{E}-02$ & 0.90 & $1.51 \mathrm{E}-02$ & $1.59 \mathrm{E}-02$ & 0.95 \\
\hline 5.0 & 5.0 & 1.56E-02 & $1.75 \mathrm{E}-02$ & 0.89 & $1.56 \mathrm{E}-02$ & 1.67E-02 & 0.94 \\
\hline & & & & & & & \\
\hline & & & AVG Error & $772 \%$ & & AVG Error & $3.12 \%$ \\
\hline & & & SD Error & 0.08 & & SD Error & 0.08 \\
\hline
\end{tabular}


UnOptimized and Optimized data using Average Error Current method for 2.4 x1.6um NMOS FET

\begin{tabular}{|c|c|c|c|c|c|c|c|}
\hline \multicolumn{2}{|c|}{$\begin{array}{l}W=2.4 \text { um } 8 \\
L=1.6 \text { um }\end{array}$} & \multicolumn{3}{|c|}{$\begin{array}{l}\text { Using the optimized values of } \mathrm{Vt} \\
=0.48 \mathrm{~V} \text { and } \mathrm{M}=1.05\end{array}$} & \multicolumn{3}{|c|}{$\begin{array}{c}\text { Using the default values of } \mathrm{Vt}= \\
0.48 \mathrm{~V} \text { and } \mathrm{M}=1\end{array}$} \\
\hline \multirow[t]{3}{*}{$\begin{array}{l}\text { Vgs } \\
\text { (V) }\end{array}$} & $\begin{array}{l}\text { Vds } \\
\text { (V) }\end{array}$ & $\begin{array}{l}\text { Ids } \\
\text { Measured } \\
\text { with dual } \\
\text { SMUs }\end{array}$ & $\begin{array}{l}\text { Ids } \\
\text { Simulated } \\
w / \\
\mathrm{Vt}=0.48 \mathrm{~V} \\
\text { and } \\
\mathrm{M}=1.05\end{array}$ & $\begin{array}{l}\text { Error } \\
\text { Factor } \\
\text { Meas. Vs } \\
\text { Sim. } \\
\text { (SMU- } \\
\text { Sim) }\end{array}$ & $\begin{array}{l}\text { Ids } \\
\text { Measured } \\
\text { with dual } \\
\text { SMUs }\end{array}$ & \begin{tabular}{|l|} 
Ids \\
Simulated \\
$w /$ \\
$V t=0.48 \mathrm{~V}$ \\
and \\
$M=1.0$
\end{tabular} & $\begin{array}{l}\text { Error } \\
\text { Factor } \\
\text { Meas. } \\
\text { Vs Sim. } \\
\text { (SMU- } \\
\text { Sim) }\end{array}$ \\
\hline & & Die \#3 & & & Die \#3 & & \\
\hline & & (A) & (A) & & (A) & (A) & \\
\hline & & & & & & & \\
\hline 0 & 1.0 & $9.26 \mathrm{E}-09$ & $1.59 \mathrm{E}-12$ & 9.26E-09 & $9.26 \mathrm{E}-09$ & 1.57E-12 & $9.26 \mathrm{E}-09$ \\
\hline 0 & 3.0 & 1.06E-08 & $3.83 \mathrm{E}-12$ & 1.06E-08 & $1.06 \mathrm{E}-08$ & $3.79 \mathrm{E}-12$ & 1.06E-08 \\
\hline 0 & 5.0 & 1.12E-08 & $6.07 \mathrm{E}-12$ & $1.12 \mathrm{E}-08$ & 1.12E-08 & $6.02 \mathrm{E}-12$ & $1.12 \mathrm{E}-08$ \\
\hline 1.0 & 1.0 & $1.54 \mathrm{E}-06$ & $6.40 \mathrm{E}-06$ & $4.86 E-06$ & $1.54 \mathrm{E}-06$ & $6.10 \mathrm{E}-06$ & $4.56 \mathrm{E}-06$ \\
\hline 1.0 & 3.0 & $1.96 \mathrm{E}-06$ & $7.23 \mathrm{E}-06$ & $5.26 E-06$ & $1.96 \mathrm{E}-06$ & $6.88 \mathrm{E}-06$ & $4.92 E-06$ \\
\hline 1.0 & 5.0 & $2.29 E-06$ & $7.90 \mathrm{E}-06$ & $5.61 \mathrm{E}-06$ & 2.29E-06 & $7.52 E-06$ & $5.23 E-06$ \\
\hline 2.0 & 1.0 & 1.37E-05 & $3.57 \mathrm{E}-05$ & 2.19E-05 & 1.37E-05 & $3.40 \mathrm{E}-05$ & $2.02 E-05$ \\
\hline 2.0 & 3.0 & $1.78 \mathrm{E}-05$ & $4.05 \mathrm{E}-05$ & 2.27E-05 & $1.78 \mathrm{E}-05$ & 3.86E-05 & $2.08 E-05$ \\
\hline 2.0 & 5.0 & $2.01 \mathrm{E}-05$ & 4.24E-05 & 2.23E-05 & 2.01E-05 & 4.04E-05 & $2.02 E-05$ \\
\hline 3.0 & 1.0 & 3.67E-05 & $6.82 \mathrm{E}-05$ & 3.15E-05 & 3.67E-05 & 6.49E-05 & $2.82 E-05$ \\
\hline 3.0 & 3.0 & $5.12 E-05$ & $8.93 \mathrm{E}-05$ & 3.81E-05 & $5.12 E-05$ & $8.50 \mathrm{E}-05$ & $3.39 \mathrm{E}-05$ \\
\hline 3.0 & 5.0 & 5.63E-05 & $9.25 \mathrm{E}-05$ & 3.61E-05 & 5.63E-05 & $8.81 E-05$ & 3.17E-05 \\
\hline 4.0 & 1.0 & $6.29 \mathrm{E}-05$ & $9.63 \mathrm{E}-05$ & 3.35E-05 & $6.29 E-05$ & 9.17E-05 & $2.89 E-05$ \\
\hline 4.0 & 3.0 & $9.71 \mathrm{E}-05$ & $1.47 \mathrm{E}-04$ & $5.00 E-05$ & 9.71E-05 & $1.40 \mathrm{E}-04$ & $4.30 E-05$ \\
\hline 4.0 & 5.0 & $1.06 \mathrm{E}-04$ & $1.52 \mathrm{E}-04$ & $4.62 E-05$ & 1.06E-04 & $1.45 E-04$ & $3.89 E-05$ \\
\hline 5.0 & 1.0 & 8.93E-05 & $1.21 \mathrm{E}-04$ & $3.15 E-05$ & 8.93E-05 & $1.15 E-04$ & $2.58 \mathrm{E}-05$ \\
\hline 5.0 & 3.0 & $1.51 \mathrm{E}-04$ & $2.12 \mathrm{E}-04$ & $6.05 E-05$ & $1.51 \mathrm{E}-04$ & $2.02 E-04$ & 5.04E-05 \\
\hline 5.0 & 5.0 & 1.65E-04 & $2.20 \mathrm{E}-04$ & $5.53 E-05$ & 1.65E-04 & $2.10 \mathrm{E}-04$ & $4.49 \mathrm{E}-05$ \\
\hline & & & & & & & \\
\hline & & & AVG Error & $3.10 E-05$ & & AVG Error & $2,68 E-05$ \\
\hline & & & SD Error & $1.76 E-05$ & & SD Error & $1.45 \mathrm{E}-05$ \\
\hline
\end{tabular}




\begin{tabular}{|c|c|c|c|c|c|c|c|}
\hline \multicolumn{2}{|c|}{$\begin{array}{l}W=38.4 u m \\
\& L=1.6 \\
\text { um }\end{array}$} & \multicolumn{3}{|c|}{$\begin{array}{l}\text { Using the optimized values of } \mathrm{Vt} \\
=0.48 \mathrm{~V} \text { and } \mathrm{M}=1.05\end{array}$} & \multicolumn{3}{|c|}{$\begin{array}{c}\text { Using the default values of } \mathrm{Vt}= \\
0.48 \mathrm{~V} \text { and } M=1\end{array}$} \\
\hline \multirow[t]{3}{*}{$\begin{array}{l}\text { Vgs } \\
\text { (V) }\end{array}$} & $\begin{array}{l}\text { Vds } \\
\text { (V) }\end{array}$ & $\begin{array}{c}\text { Ids } \\
\text { Measured } \\
\text { with dual } \\
\text { SMUs } \\
\end{array}$ & $\begin{array}{c}\text { Ids } \\
\text { Simulated } \\
w / \\
V t=0.48 \mathrm{~V} \\
\text { and } M= \\
1.05 \\
\end{array}$ & $\begin{array}{l}\text { Error } \\
\text { Factor } \\
\text { Meas. Vs } \\
\text { Sim. } \\
\text { (SMU- } \\
\text { Sim) } \\
\end{array}$ & $\begin{array}{c}\text { Ids } \\
\text { Measured } \\
\text { with dual } \\
\text { SMUs } \\
\end{array}$ & $\begin{array}{c}\text { Ids } \\
\text { Simulated } \\
w / \\
V t=0.48 V \\
\text { and } M=1.0\end{array}$ & $\begin{array}{l}\text { Error } \\
\text { Factor } \\
\text { Meas. } \\
\text { Vs Sim. } \\
\text { (SMU- } \\
\text { Sim) } \\
\end{array}$ \\
\hline & & Die \#3 & & & Die \#3 & & \\
\hline & & (A) & (A) & & (A) & (A) & \\
\hline & & & & & & & \\
\hline 0 & 1.0 & $6.01 \mathrm{E}-11$ & $4.22 \mathrm{E}-11$ & $1.79 \mathrm{E}-11$ & $6.01 \mathrm{E}-11$ & $4.02 \mathrm{E}-11$ & $1.98 E-11$ \\
\hline 0 & 3.0 & $7.74 \mathrm{E}-11$ & $6.04 \mathrm{E}-11$ & $1.70 E-11$ & $7.74 \mathrm{E}-11$ & $5.77 \mathrm{E}-11$ & $1.97 \mathrm{E}-11$ \\
\hline 0 & 5.0 & $3.93 \mathrm{E}-11$ & $7.86 \mathrm{E}-11$ & $3.92 \mathrm{E}-11$ & $3.93 \mathrm{E}-11$ & $7.51 \mathrm{E}-11$ & $3.57 \mathrm{E}-11$ \\
\hline & & & & & & & \\
\hline 1.0 & 1.0 & $2.82 \mathrm{E}-04$ & $3.02 E-04$ & 1.97E-05 & $2.82 E-04$ & 2.87E-04 & $5.34 \mathrm{E}-06$ \\
\hline 1.0 & 3.0 & $3.31 \mathrm{E}-04$ & $3.41 \mathrm{E}-04$ & 9.87E-06 & $3.31 E-04$ & 3.24E-04 & $6.35 E-06$ \\
\hline 1.0 & 5.0 & $3.69 \mathrm{E}-04$ & $3.71 \mathrm{E}-04$ & $2.06 \mathrm{E}-06$ & 3.69E-04 & $3.54 \mathrm{E}-04$ & $1.56 \mathrm{E}-05$ \\
\hline 2.0 & 1.0 & $1.55 \mathrm{E}-03$ & $1.51 \mathrm{E}-03$ & 3.59E-05 & $1.55 \mathrm{E}-03$ & 1.44E-03 & $1.08 \mathrm{E}-04$ \\
\hline 2.0 & 3.0 & $1.79 \mathrm{E}-03$ & $1.76 \mathrm{E}-03$ & 3.41E-05 & $1.79 \mathrm{E}-03$ & 1.67E-03 & $1,18 E-04$ \\
\hline 2.0 & 5.0 & $1.90 \mathrm{E}-03$ & $1.84 \mathrm{E}-03$ & $6.31 E-05$ & $1.90 \mathrm{E}-03$ & $1.75 \mathrm{E}-03$ & $1.51 \mathrm{E}-04$ \\
\hline 3.0 & 1.0 & $2.78 \mathrm{E}-03$ & $2.69 \mathrm{E}-03$ & $8.35 E-05$ & $2.78 \mathrm{E}-03$ & 2.56E-03 & $212 E-04$ \\
\hline 3.0 & 3.0 & $3.65 \mathrm{E}-03$ & $3.69 \mathrm{E}-03$ & $3.98 \mathrm{E}-05$ & $3.65 \mathrm{E}-03$ & $3.52 E-03$ & $1.36 \mathrm{E}-04$ \\
\hline 3.0 & 5.0 & $3.81 \mathrm{E}-03$ & $3.83 \mathrm{E}-03$ & $1.49 E-05$ & $3.81 \mathrm{E}-03$ & $3.65 E-03$ & $1.67 \mathrm{E}-04$ \\
\hline 4.0 & 1.0 & $3.75 \mathrm{E}-03$ & $3.66 \mathrm{E}-03$ & 8.11E-05 & $3.75 \mathrm{E}-03$ & $3.49 \mathrm{E}-03$ & $2.56 \mathrm{E}-04$ \\
\hline 4.0 & 3.0 & $5.66 \mathrm{E}-03$ & 5.87E-03 & 2.11E-04 & $5.66 \mathrm{E}-03$ & $5.59 \mathrm{E}-03$ & $6.87 \mathrm{E}-05$ \\
\hline 4.0 & 5.0 & $5.86 \mathrm{E}-03$ & $6.08 \mathrm{E}-03$ & $2.16 \mathrm{E}-04$ & $5.86 \mathrm{E}-03$ & $5.79 \mathrm{E}-03$ & $7.34 \mathrm{E}-05$ \\
\hline 5.0 & 1.0 & $4.54 \mathrm{E}-03$ & $4.46 \mathrm{E}-03$ & $8.15 E-05$ & $4.54 \mathrm{E}-03$ & $4.25 \mathrm{E}-03$ & $2.94 \mathrm{E}-04$ \\
\hline 5.0 & 3.0 & 7.67E-03 & $8.15 \mathrm{E}-03$ & $4.80 \mathrm{E}-04$ & 7.67E-03 & 7.76E-03 & $9.22 E-05$ \\
\hline 5.0 & 5.0 & 7.96E-03 & $8.54 \mathrm{E}-03$ & $5.82 E-04$ & 7.96E-03 & 8.13E-03 & $1.75 E-04$ \\
\hline & & & & & & & \\
\hline & & & AVG Error & $1.09 E-04$ & & AVG Error & $1.04 \mathrm{E}-04$ \\
\hline & & & SD Error & $1.68 \mathrm{E}-04$ & & SD Error & $9.23 E-05$ \\
\hline
\end{tabular}


UnOptimized and Optimized data using Average Error Current method for 57.6x1.6um NMOS FET

\begin{tabular}{|c|c|c|c|c|c|c|c|}
\hline \multicolumn{2}{|c|}{$\begin{array}{l}W=57.6 u m \\
\& L=1.6 \\
u m\end{array}$} & \multicolumn{3}{|c|}{$\begin{array}{l}\text { Using the optimized values of } \mathrm{Vt} \\
\quad=0.48 \mathrm{~V} \text { and } M=1.05\end{array}$} & \multicolumn{3}{|c|}{$\begin{array}{c}\text { Using the default values of } V t= \\
0.48 \mathrm{~V} \text { and } M=1\end{array}$} \\
\hline \multirow[t]{3}{*}{$\begin{array}{l}\text { Vgs } \\
\text { (V) }\end{array}$} & \multirow[t]{2}{*}{$\begin{array}{c}\text { Vds } \\
\text { (V) }\end{array}$} & $\begin{array}{c}\text { Ids } \\
\text { Measured } \\
\text { with dual } \\
\text { SMUs } \\
\end{array}$ & $\begin{array}{c}\text { Ids } \\
\text { Simulated } \\
\text { with } \\
V t=0.48 V \\
\text { and } \\
M=1.05\end{array}$ & $\begin{array}{c}\text { Error } \\
\text { Factor } \\
\text { Meas. Vs } \\
\text { Sim. } \\
\text { (SMU- } \\
\text { Sim) }\end{array}$ & $\begin{array}{c}\text { Ids } \\
\text { Measured } \\
\text { with dual } \\
\text { SMUs } \\
\end{array}$ & $\begin{array}{c}\text { Ids } \\
\text { Simulated } \\
\text { with } \\
\mathrm{Vt}=0.48 \mathrm{~V} \\
\text { and } \\
\mathrm{M}=1 \\
\end{array}$ & $\begin{array}{c}\text { Error } \\
\text { Factor } \\
\text { Meas. Vs } \\
\text { Sim. } \\
\text { (SMU- } \\
\text { Sim) }\end{array}$ \\
\hline & & Die \#3 & & & Die \#3 & & \\
\hline & & (A) & (A) & & (A) & (A) & \\
\hline & & & & & & & \\
\hline 0 & 1.0 & $4.86 \mathrm{E}-08$ & $6.49 \mathrm{E}-11$ & $4.85 E-08$ & $4.86 \mathrm{E}-08$ & $6.19 \mathrm{E}-11$ & $4.85 \mathrm{E}-08$ \\
\hline 0 & 3.0 & $8.34 \mathrm{E}-08$ & $9.21 \mathrm{E}-11$ & $8.33 E-08$ & $8.34 \mathrm{E}-08$ & $8.78 \mathrm{E}-11$ & 8.33E-08 \\
\hline 0 & 5.0 & $1.36 \mathrm{E}-07$ & $1.19 \mathrm{E}-10$ & 1.36E-07 & $1.36 \mathrm{E}-07$ & $1.14 \mathrm{E}-10$ & 1.36E-07 \\
\hline 10 & 10 & $683 F-04$ & & 4 & $683 F-04$ & 4 & 4 \\
\hline 1.0 & 3.0 & 7.97E-04 & $5.22 E-04$ & $2.76 E-04$ & $\begin{array}{l}0.00 \mathrm{E}-\mathrm{U} 4 \\
7.97 \mathrm{E}-04\end{array}$ & $4.97 E-04$ & 3.00 E-04 \\
\hline 1.0 & 5.0 & $8.80 E-04$ & 5.69E-04 & $3.12 E-04$ & $8.80 \mathrm{E}-04$ & 5.42E-04 & 3.39E-04 \\
\hline & & & & & & & \\
\hline 2.0 & 1.0 & $2.57 \mathrm{E}-03$ & $2.31 \mathrm{E}-03$ & 2.62E-04 & 2.57E-03 & $2.20 \mathrm{E}-03$ & 3.72E-04 \\
\hline 2.0 & 3.0 & $3.09 \mathrm{E}-03$ & $2.69 \mathrm{E}-03$ & 3.98E-04 & 3.09E-03 & 2.56E-03 & 5.26E-04 \\
\hline 2.0 & 5.0 & $3.27 \mathrm{E}-03$ & $2.81 E-03$ & $4.60 \mathrm{E}-04$ & $3.27 \mathrm{E}-03$ & $2.68 \mathrm{E}-03$ & $5.93 \mathrm{E}-04$ \\
\hline 3.0 & 1.0 & $4.22 \mathrm{E}-03$ & $4.10 \mathrm{E}-03$ & $1.23 E-04$ & $4.22 \mathrm{E}-03$ & $3.90 \mathrm{E}-03$ & $3.19 \mathrm{E}-04$ \\
\hline 3.0 & 3.0 & $5.85 E-03$ & $5.64 \mathrm{E}-03$ & $2,16 E-04$ & $5.85 \mathrm{E}-03$ & $5.37 E-03$ & $4.85 \mathrm{E}-04$ \\
\hline 3.0 & 5.0 & $6.11 \mathrm{E}-03$ & $5.85 \mathrm{E}-03$ & $2.67 \mathrm{E}-04$ & $6.11 \mathrm{E}-03$ & $5.57 \mathrm{E}-03$ & $5.45 \mathrm{E}-04$ \\
\hline 4.0 & 1.0 & $5.52 \mathrm{E}-03$ & $5.57 \mathrm{E}-03$ & $5.03 \mathrm{E}-05$ & $5.52 \mathrm{E}-03$ & 5.31E-03 & $2.15 \mathrm{E}-04$ \\
\hline 4.0 & 3.0 & $8.78 \mathrm{E}-03$ & $8.95 \mathrm{E}-03$ & $1,67 E-04$ & $8.78 \mathrm{E}-03$ & $8.52 E-03$ & 2.59E-04 \\
\hline 4.0 & 5.0 & $9.12 \mathrm{E}-03$ & $9.28 \mathrm{E}-03$ & $1.58 E-04$ & $9.12 \mathrm{E}-03$ & $8.83 E-03$ & 2.84E-04 \\
\hline 5.0 & 1.0 & $6.58 \mathrm{E}-03$ & $6.78 \mathrm{E}-03$ & $1.99 \mathrm{E}-04$ & $6.58 \mathrm{E}-03$ & $6.46 \mathrm{E}-03$ & $1.24 E-04$ \\
\hline 5.0 & 3.0 & $1.17 \mathrm{E}-02$ & $1.24 \mathrm{E}-02$ & 7.39E-04 & $1.17 \mathrm{E}-02$ & $1.18 \mathrm{E}-02$ & $1.48 \mathrm{E}-04$ \\
\hline 5.0 & 5.0 & $1.22 \mathrm{E}-02$ & $1.30 \mathrm{E}-02$ & $8.43 \mathrm{E}-04$ & $1.22 \mathrm{E}-02$ & $1.24 \mathrm{E}-02$ & 2.23E-04 \\
\hline & & & & & & & \\
\hline & & & AVG Error & 2.61E-04 & & AVG Error & 2.76E-04 \\
\hline & & & SD Error & $2.33 E-04$ & & SD Error & $1.83 E-04$ \\
\hline
\end{tabular}


UnOptimized and Optimized data using Average Error Current method for 76.8x1.6um NMOS FET

\begin{tabular}{|c|c|c|c|c|c|c|c|}
\hline \multicolumn{2}{|c|}{$\begin{array}{l}W=76.8 u m \\
\& L= \\
1.6 u m\end{array}$} & \multicolumn{3}{|c|}{$\begin{array}{l}\text { Using the optimized values of } \\
V t=0.48 \mathrm{~V} \text { and } M=1.05\end{array}$} & \multicolumn{3}{|c|}{$\begin{array}{c}\text { Using the default values of } \mathrm{Vt}= \\
0.48 \mathrm{~V} \text { and } M=1\end{array}$} \\
\hline \multirow[t]{3}{*}{$\begin{array}{c}\text { Vgs } \\
\text { (V) }\end{array}$} & $\begin{array}{c}\text { Vds } \\
\text { (V) }\end{array}$ & $\begin{array}{l}\text { Ids } \\
\text { Measured } \\
\text { with dual } \\
\text { SMUs }\end{array}$ & $\begin{array}{l}\text { Ids } \\
\text { Simulated } \\
\mathrm{w} / \\
\mathrm{Vt}=0.48 \mathrm{~V} \\
\text { and } \\
\mathrm{M}=1.05\end{array}$ & $\begin{array}{l}\text { Error } \\
\text { Factor } \\
\text { Meas. } \\
\text { Vs Sim. } \\
\text { (SMU- } \\
\text { Sim) }\end{array}$ & $\begin{array}{l}\text { Ids } \\
\text { Measured } \\
\text { with dual } \\
\text { SMUs }\end{array}$ & $\begin{array}{l}\text { Ids } \\
\text { Simulated } \\
w / \\
V t=0.48 \mathrm{~V} \\
\text { and } \\
M=1.0\end{array}$ & $\begin{array}{l}\text { Error } \\
\text { Factor } \\
\text { Meas. Vs } \\
\text { Sim. } \\
\text { (SMU- } \\
\text { Sim) }\end{array}$ \\
\hline & & Die \#3 & & & Die \#3 & & \\
\hline & & (A) & (A) & & (A) & (A) & \\
\hline 0 & 1.0 & 1 & 11 & 1.06 & $\gamma$ & .J & \\
\hline 0 & 3.0 & $9.27 \mathrm{E}-11$ & $1.24 \mathrm{E}-10$ & $3.11 \mathrm{E}-11$ & $9.27 \mathrm{E}-11$ & $1.18 \mathrm{E}-10$ & $2.53 \mathrm{E}-11$ \\
\hline 0 & 5.0 & $1.12 \mathrm{E}-10$ & $1.60 \mathrm{E}-10$ & $4.78 E-11$ & $1.12 \mathrm{E}-10$ & $1.52 E-10$ & $4.04 \mathrm{E}-11$ \\
\hline 1.0 & 1.0 & 5.69E-04 & $6.22 E-04$ & $5.38 E-05$ & 5.69E-04 & 5.93E-04 & $2,42 E-05$ \\
\hline 1.0 & 3.0 & $6.66 \mathrm{E}-04$ & 7.03E-04 & $3.66 \mathrm{E}-05$ & 6.66E-04 & $6.69 \mathrm{E}-04$ & 3.13E-06 \\
\hline 1.0 & 5.0 & $7.43 \mathrm{E}-04$ & $7.66 \mathrm{E}-04$ & $2.32 E-05$ & 7.43E-04 & 7.30E-04 & $1,33 E-05$ \\
\hline 2.0 & 1.0 & $3.07 \mathrm{E}-03$ & $3.11 \mathrm{E}-03$ & $3.50 E-05$ & $3.07 \mathrm{E}-03$ & $2.96 \mathrm{E}-03$ & $1.13 E-04$ \\
\hline 2.0 & 3.0 & $3.56 \mathrm{E}-03$ & $3.62 E-03$ & $6.06 E-05$ & $3.56 \mathrm{E}-03$ & $3.44 \mathrm{E}-03$ & $1.12 E-04$ \\
\hline 2.0 & 5.0 & $3.77 \mathrm{E}-03$ & $3.78 E-03$ & 1.07E-05 & 3.77E-03 & $3.60 \mathrm{E}-03$ & $1.69 E-04$ \\
\hline 3.0 & 1.0 & $5.44 E-03$ & $5.50 \mathrm{E}-03$ & $6.77 \mathrm{E}-05$ & $5.44 \mathrm{E}-03$ & $5.24 \mathrm{E}-03$ & $=-04$ \\
\hline 3.0 & 3.0 & $7.22 \mathrm{E}-03$ & 7.59E-03 & 3.66E 04 & $7.22 \mathrm{E}-03$ & $7.22 \mathrm{E}-03$ & $4.60 \mathrm{E}-06$ \\
\hline 3.0 & 5.0 & $7.52 \mathrm{E}-03$ & 7.86E-03 & $3.40 \mathrm{E}=04$ & $7.52 E-03$ & 7.49E-03 & $3.44 \mathrm{E}-05$ \\
\hline 4.0 & 1.0 & $7.28 \mathrm{E}-03$ & $7.48 E-03$ & $2.05 E-04$ & $7.28 \mathrm{E}-03$ & 7.12E-03 & 1.51E-04 \\
\hline 4.0 & 3.0 & $1.12 \mathrm{E}-02$ & 1.20E-02 & $8.73 E-04$ & $1.12 \mathrm{E}-02$ & 1.15E-02 & $3.00 \mathrm{E}-04$ \\
\hline 4.0 & 5.0 & $1.15 \mathrm{E}-02$ & $1.25 \mathrm{E}-02$ & $9.34 \mathrm{E}-04$ & $1.15 \mathrm{E}-02$ & 1.19E-02 & $3,40 \mathrm{E}-04$ \\
\hline 5.0 & 1.0 & $8.76 \mathrm{E}-03$ & $9.10 \mathrm{E}-03$ & $3.38 E-04$ & $8.76 \mathrm{E}-03$ & $8.66 \mathrm{E}-03$ & $9.53 E-05$ \\
\hline 5.0 & 3.0 & $1.51 \mathrm{E}-02$ & 1.67E-02 & $1.60 \mathrm{E}-03$ & $1.51 \mathrm{E}-02$ & 1.59E-02 & $8.07 E-04$ \\
\hline 5.0 & 5.0 & $1.56 \mathrm{E}-02$ & 1.75E-02 & $1.88 \mathrm{E}-03$ & 1.56E-02 & 1.67E-02 & 1.05E-03 \\
\hline & & & & & & & \\
\hline & & & AVG Error & & & AVG Error & $1.89 \mathrm{E}-04$ \\
\hline & & & SD Error & $5.72 E-04$ & & SD Error & $2.90 \mathrm{E}-04$ \\
\hline
\end{tabular}


FET.

\begin{tabular}{|c|c|c|c|c|c|c|c|}
\hline \multicolumn{2}{|c|}{$\begin{array}{l}W=2.4 \text { um\& } \\
L=1.6 \text { um }\end{array}$} & \multicolumn{3}{|c|}{$\begin{array}{l}\text { Using the optimized values of } \\
\qquad t=-0.84 V \text { and } M=0.9\end{array}$} & \multicolumn{3}{|c|}{$\begin{array}{l}\text { Using the default values of } \mathrm{Vt} \\
=-0.84 \mathrm{~V} \text { and } \mathrm{M}=1\end{array}$} \\
\hline $\begin{array}{l}\text { Vgs } \\
\text { (V) }\end{array}$ & $\begin{array}{l}\text { Vds } \\
\text { (V) }\end{array}$ & $\begin{array}{c}\text { Ids } \\
\text { Measure } \\
\text { d with } \\
\text { dual } \\
\text { SMUs }\end{array}$ & $\begin{array}{c}\text { Ids } \\
\text { Simulate } \\
\mathrm{d} w / \mathrm{Vt}=- \\
0.84 \mathrm{~V} \text { and } \\
\mathrm{M}=0.9\end{array}$ & $\begin{array}{c}\text { Error } \\
\text { Factor } \\
\text { Meas. } \\
\text { Vs } \\
\text { Sim. } \\
\text { (SMU/ } \\
\text { Sim) } \\
\end{array}$ & $\begin{array}{c}\text { Ids } \\
\text { Measure } \\
\text { d with } \\
\text { dual } \\
\text { SMUs }\end{array}$ & $\begin{array}{c}\text { Ids } \\
\text { Simulate } \\
d w / V t=- \\
0.84 V \\
\text { and } M= \\
1\end{array}$ & $\begin{array}{c}\text { Error } \\
\text { Factor } \\
\text { Meas. } \\
\text { Vs } \\
\text { Sim. } \\
\text { (SMU/ } \\
\text { Sim) }\end{array}$ \\
\hline & & Die \#3 & & & Die \#3 & & \\
\hline & & (A) & (A) & & (A) & (A) & \\
\hline 0.0 & -1.0 & $\mathrm{E}-11$ & $5 E-12$ & 1 & $-1.80 \mathrm{t}$ & $-1.63 \mathrm{E}-12$ & \\
\hline 0.0 & -3.0 & $-4.752 E-11$ & $-4.525 E-12$ & 10.502 & $-4.75 E-11$ & $-4.63 \mathrm{E}-12$ & 10.275 \\
\hline 0.0 & -5.0 & $-7.794 \mathrm{E}-11$ & $-7.143 \mathrm{E}-12$ & 10.911 & $-7.79 \mathrm{E}-11$ & $-7.14 \mathrm{E}-12$ & 10.911 \\
\hline-1.0 & -1.0 & $-2.081 E-09$ & $-4.498 E-08$ & 0.046 & $-2.08 E-09$ & $-5.68 E-08$ & 0.037 \\
\hline-1.0 & -3.0 & $-3.160 \mathrm{E}-09$ & $-5.055 E-07$ & 0.006 & $-3.16 \mathrm{E}-09$ & $-5.86 \mathrm{E}-07$ & 0.005 \\
\hline-1.0 & -5.0 & $-4.273 E-09$ & $-1.421 \mathrm{E}-06$ & 0.003 & $-4.27 \mathrm{E}-09$ & $-1.58 \mathrm{E}-06$ & 0.003 \\
\hline-2.0 & -1.0 & $-4.568 E-06$ & $-3.945 E-06$ & 1.16 & $-4.57 E-06$ & $-4.45 E-06$ & 1.03 \\
\hline-2.0 & -3.0 & $-5.626 \mathrm{E}-06$ & $-6.252 E-06$ & 0.90 & $-5.63 E-06$ & $-7.02 E-06$ & 0.80 \\
\hline-2.0 & -5.0 & $-6.322 \mathrm{E}-06$ & $-8.751 \mathrm{E}-06$ & 0.72 & $-6.32 E-06$ & $-9.72 E-06$ & 0.65 \\
\hline & & & & & & & \\
\hline-3.0 & -1.0 & $-1.547 \mathrm{E}-05$ & $-1.247 \mathrm{E}-05$ & 1.24 & $-1.55 E-05$ & $-1.39 E-05$ & 1.11 \\
\hline-3.0 & -3.0 & $-2.124 \mathrm{E}-05$ & $-1.689 \mathrm{E}-05$ & 1.26 & $-2.12 E-05$ & $-1.88 \mathrm{E}-05$ & 1.13 \\
\hline-3.0 & -5.0 & $-2.346 \mathrm{E}-05$ & $-2.031 \mathrm{E}-05$ & 1.16 & $-2.35 E-05$ & $-2.26 \mathrm{E}-05$ & 1.04 \\
\hline & & & & & & & \\
\hline-4.0 & -1.0 & \begin{tabular}{|l|}
$-2.579 E-05$ \\
\end{tabular} & $-2.094 \mathrm{E}-05$ & 1.23 & $-2.58 E-05$ & $-2.33 E-05$ & 1.11 \\
\hline-4.0 & -3.0 & \begin{tabular}{|l|}
$-4.230 E-05$ \\
\end{tabular} & $-3.157 \mathrm{E}-05$ & 1.34 & $-4.23 E-05$ & $-3.51 E-05$ & 1.21 \\
\hline-4.0 & -5.0 & \begin{tabular}{|l|}
$-4.685 E-05$ \\
\end{tabular} & $-3.513 E-05$ & 1.33 & $-4.69 \mathrm{E}-05$ & $-3.90 E-05$ & 1.20 \\
\hline & & & & & & & \\
\hline-5.0 & -1.0 & $-3.489 E-05$ & $-2.852 \mathrm{E}-05$ & 1.22 & $-3.49 E-05$ & $-3.17 E-05$ & 1.10 \\
\hline-5.0 & -3.0 & \begin{tabular}{|l|}
$-6.612 \mathrm{E}-05$ \\
\end{tabular} & $-4.982 E-05$ & 1.33 & $-6.61 \mathrm{E}-05$ & $-5.54 \mathrm{E}-05$ & 1.19 \\
\hline-5.0 & -5.0 & \begin{tabular}{|l}
$-7.424 \mathrm{E}-05$ \\
\end{tabular} & $-5.264 E-05$ & 1.41 & $-7.42 E-05$ & $-5.85 E-05$ & 1.27 \\
\hline & & & & & & & \\
\hline & & & AVG Error & $4.3 \%$ & & AVG Error & $14.1 \%$ \\
\hline & & & SD Error & 0.52 & & SD Error & 0.46 \\
\hline
\end{tabular}




\begin{tabular}{|c|c|c|c|c|c|c|c|}
\hline \multicolumn{2}{|c|}{$\begin{array}{l}W=38.4 \mathrm{um} \\
\& \\
L=1.6 \mathrm{um}\end{array}$} & \multicolumn{3}{|c|}{$\begin{array}{l}\text { Using the optimized values of } \\
\qquad t=-0.84 V \text { and } M=0.9\end{array}$} & \multicolumn{3}{|c|}{$\begin{array}{l}\text { Using the default values of } \mathrm{Vt} \\
\qquad=-0.84 \mathrm{~V} \text { and } M=1\end{array}$} \\
\hline \multirow[t]{3}{*}{$\begin{array}{l}\text { Vgs } \\
\text { (V) }\end{array}$} & \multirow[t]{3}{*}{$\begin{array}{l}\text { Vds } \\
\text { (V) }\end{array}$} & $\begin{array}{c}\text { Ids } \\
\text { Measured } \\
\text { with dual } \\
\text { SMUs }\end{array}$ & $\begin{array}{c}\text { Ids } \\
\text { Simulated } \\
w / V t=- \\
0.84 V \text { and } \\
M=0.9\end{array}$ & $\begin{array}{c}\text { Error } \\
\text { Factor } \\
\text { Meas. } \\
\text { Vs } \\
\text { Sim. } \\
\text { (SMU/ } \\
\text { Sim) } \\
\end{array}$ & $\begin{array}{c}\text { Ids } \\
\text { Measured } \\
\text { with dual } \\
\text { SMUs }\end{array}$ & $\begin{array}{c}\text { Ids } \\
\text { Simulated } \\
w / V t=- \\
0.84 V \text { and } \\
M=1\end{array}$ & $\begin{array}{c}\text { Error } \\
\text { Factor } \\
\text { Meas. } \\
\text { Vs } \\
\text { Sim. } \\
\text { (SMU/ } \\
\text { Sim) } \\
\end{array}$ \\
\hline & & Die \#3 & & & Die \#3 & & \\
\hline & & (A) & (A) & & (A) & (A) & \\
\hline 0.0 & -1.0 & $-2.352 E-11$ & $-1.525 \mathrm{E}-12$ & 15.423 & $-2.35 \mathrm{E}-11$ & $-1.63 \mathrm{E}-12$ & 14.474 \\
\hline 0.0 & -3.0 & $-5.100 \mathrm{E}-11$ & $-4.536 E-12$ & 11.244 & $-5.10 \mathrm{E}-11$ & $-4.64 \mathrm{E}-12$ & 10.997 \\
\hline 0.0 & -5.0 & $-3.044 E-11$ & $-9.623 E-12$ & 3.163 & $-3.04 \mathrm{E}-11$ & $-9.90 E-12$ & 3.075 \\
\hline-1.0 & -1.0 & $-4.813 E-07$ & $-1.227 \mathrm{E}-05$ & 0.039 & $-4.81 E-07$ & $-1.48 \mathrm{E}-05$ & 0.032 \\
\hline-1.0 & -3.0 & $-9.243 E-07$ & $-5.614 \mathrm{E}-05$ & 0.016 & $-9.24 \mathrm{E}-07$ & $-6.45 E-05$ & 0.014 \\
\hline-1.0 & -5.0 & $-1.499 \mathrm{E}-06$ & $-1.216 \mathrm{E}-04$ & 0.012 & $-1.50 \mathrm{E}-06$ & $-1.35 \mathrm{E}-04$ & 0.011 \\
\hline-2.0 & -1.0 & $-2.193 \mathrm{E}-04$ & $-2.667 \mathrm{E}-04$ & 0.82 & $-2.19 \mathrm{E}-04$ & $-3.00 E-04$ & 0.73 \\
\hline-2.0 & -3.0 & $-2.792 E-04$ & $-4.235 E-04$ & 0.66 & $-2.79 \mathrm{E}-04$ & $-4.75 E-04$ & 0.59 \\
\hline-2.0 & -5.0 & $-3.192 E-04$ & $-5.883 E-04$ & 0.54 & $-3.19 E-04$ & $-6.54 E-04$ & 0.49 \\
\hline-3.0 & -1.0 & $-5.838 E-04$ & $-5.982 E-04$ & 0.98 & $-5.84 E-04$ & $-6.68 E-04$ & 0.87 \\
\hline-3.0 & -3.0 & $-8.573 E-04$ & $-1.033 \mathrm{E}-03$ & 0.83 & $-8.57 \mathrm{E}-04$ & $-1.15 \mathrm{E}-03$ & 0.74 \\
\hline-3.0 & -5.0 & $-9.607 E-04$ & $-1.286 E-03$ & 0.75 & $-9.61 \mathrm{E}-04$ & $-1.43 E-03$ & 0.67 \\
\hline-4.0 & -1.0 & $-8.772 \mathrm{E}-04$ & $-8.767 E-04$ & 1.00 & $-8.77 \mathrm{E}-04$ & $-9.76 \mathrm{E}-04$ & 0.90 \\
\hline-4.0 & -3.0 & $-1.553 \mathrm{E}-03$ & $-1.786 E-03$ & 0.87 & $-1.55 \mathrm{E}-03$ & $-1.99 E-03$ & 0.78 \\
\hline-4.0 & -5.0 & $-1.742 \mathrm{E}-03$ & $-2.127 \mathrm{E}-03$ & 0.82 & $-1.74 \mathrm{E}-03$ & $-2.36 E-03$ & 0.74 \\
\hline & & & & & & & \\
\hline-5.0 & -1.0 & $-1.122 E-03$ & $-1.099 E-03$ & 1.02 & $-1.12 \mathrm{E}-03$ & $-1.22 E-03$ & 0.92 \\
\hline-5.0 & -3.0 & $-2.283 E-03$ & $-2.543 E-03$ & 0.90 & $-2.28 \mathrm{E}-03$ & $-2.83 E-03$ & 0.81 \\
\hline-5.0 & -5.0 & $-2.620 \mathrm{E}-03$ & $-3.097 \mathrm{E}-03$ & 0.85 & $-2.62 \mathrm{E}-03$ & $-3.44 E-03$ & 0.76 \\
\hline & & & & & & & \\
\hline & & & AVG Error & $32.67 \%$ & & AVG Error & $39.59 \%$ \\
\hline & & & SD Error & 0.36 & & SD Error & 0.32 \\
\hline
\end{tabular}


UnOptimized and Optimized data using Percentage Error method for 57.6x1.6 um PMOS

FET

\begin{tabular}{|c|c|c|c|c|c|c|c|}
\hline \multicolumn{2}{|c|}{$\begin{array}{l}W=57.6 \mathrm{um} \mathrm{L} \\
=1.6 \mathrm{um}\end{array}$} & \multicolumn{3}{|c|}{$\begin{array}{l}\text { Using the optimized values of } \\
\qquad t=-0.84 \mathrm{~V} \text { and } M=0.9\end{array}$} & \multicolumn{3}{|c|}{$\begin{array}{l}\text { Using the default values of } \mathrm{Vt} \\
\quad=-0.84 \mathrm{~V} \text { and } \mathrm{M}=1\end{array}$} \\
\hline $\begin{array}{l}\text { Vgs } \\
\text { (V) }\end{array}$ & $\begin{array}{l}\text { Vds } \\
\text { (V) }\end{array}$ & $\begin{array}{c}\text { Ids } \\
\text { Measured } \\
\text { with dual } \\
\text { SMUs }\end{array}$ & $\begin{array}{c}\text { Ids } \\
\text { Simulated } \\
w / V t=- \\
0.84 V \text { and } \\
M=0.9\end{array}$ & $\begin{array}{c}\text { Error } \\
\text { Factor } \\
\text { Meas. } \\
\text { Vs } \\
\text { Sim. } \\
\text { (SMU/ } \\
\text { Sim) }\end{array}$ & $\begin{array}{c}\text { Ids } \\
\text { Measured } \\
\text { with dual } \\
\text { SMUs }\end{array}$ & $\begin{array}{c}\text { Ids } \\
\text { Simulated } \\
w / V t=- \\
0.84 V \text { and } \\
M=1\end{array}$ & $\begin{array}{c}\text { Error } \\
\text { Factor } \\
\text { Meas. } \\
\text { Vs } \\
\text { Sim. } \\
\text { (SMU/ } \\
\text { Sim) }\end{array}$ \\
\hline & & Die \#3 & & & Die \#3 & & \\
\hline & & (A) & (A) & & (A) & (A) & \\
\hline 0.0 & -1.0 & $9.820 \mathrm{E}-12$ & $-1.525 \mathrm{E}-12$ & 6.439 & $9.82 E-12$ & $-1.63 E-12$ & 6.043 \\
\hline 0.0 & -3.0 & $-1.684 \mathrm{E}-11$ & $-4.543 \mathrm{E}-12$ & 3.707 & $-1.68 \mathrm{E}-11$ & $-4.65 \mathrm{E}-12$ & 3.624 \\
\hline 0.0 & -5.0 & $-1.616 \mathrm{E}-11$ & $-1.132 \mathrm{E}-11$ & 1.428 & $-1.62 \mathrm{E}-11$ & $-1.18 \mathrm{E}-11$ & 1.371 \\
\hline-1.0 & -1.0 & $-6.732 E-07$ & $-1.942 \mathrm{E}-05$ & 0.035 & -6.73E-07 & $-2.35 E-05$ & 0.029 \\
\hline-1.0 & -3.0 & $-1.245 \mathrm{E}-06$ & $-8.822 E-05$ & 0.014 & $-1.25 \mathrm{E}-06$ & $-1.01 E-04$ & 0.012 \\
\hline-1.0 & -5.0 & $-2.004 E-06$ & $-1.910 \mathrm{E}-04$ & 0.010 & $-2.00 \mathrm{E}-06$ & $-2.12 E-04$ & 0.009 \\
\hline-2.0 & -1.0 & $-3.298 E-04$ & $-4.132 \mathrm{E}-04$ & 0.80 & $-3.30 \mathrm{E}-04$ & $-4.65 E-04$ & 0.71 \\
\hline-2.0 & -3.0 & $-4.179 \mathrm{E}-04$ & $-6.624 \mathrm{E}-04$ & 0.63 & $-4.18 E-04$ & $-7.44 \mathrm{E}-04$ & 0.56 \\
\hline-2.0 & -5.0 & $-4.769 \mathrm{E}-04$ & $-9.237 E-04$ & 0.52 & $-4.77 \mathrm{E}-04$ & $-1.03 E-03$ & 0.46 \\
\hline-3.0 & -1.0 & $-8.951 E-04$ & $-9.162 E-04$ & 0.98 & $-8.95 \mathrm{E}-04$ & $-1.02 E-03$ & 0.88 \\
\hline-3.0 & -3.0 & $-1.303 E-03$ & $-1.613 \mathrm{E}-03$ & 0.81 & $-1.30 \mathrm{E}-03$ & $-1.80 \mathrm{E}-03$ & 0.72 \\
\hline-3.0 & -5.0 & $-1.454 \mathrm{E}-03$ & $-2.019 E-03$ & 0.72 & $-1.45 \mathrm{E}-03$ & $-2.24 E-03$ & 0.65 \\
\hline-4.0 & -1.0 & $-1.358 E-03$ & $-1.338 E-03$ & 1.01 & $-1.36 \mathrm{E}-03$ & $-1.49 \mathrm{E}-03$ & 0.91 \\
\hline-4.0 & -3.0 & $-2.385 E-03$ & $-2.782 E-03$ & 0.86 & $-2.38 \mathrm{E}-03$ & $-3.10 \mathrm{E}-03$ & 0.77 \\
\hline-4.0 & -5.0 & $-2.660 \mathrm{E}-03$ & $-3.342 E-03$ & 0.80 & $-2.66 \mathrm{E}-03$ & $-3.71 E-03$ & 0.72 \\
\hline-5.0 & -1.0 & $-1.741 \mathrm{E}-03$ & $-1.674 \mathrm{E}-03$ & 1.04 & $-1.74 \mathrm{E}-03$ & $-1.86 \mathrm{E}-03$ & 0.94 \\
\hline-5.0 & -3.0 & $-3.511 E-03$ & $-3.929 \mathrm{E}-03$ & 0.89 & $-3.51 E-03$ & $-4.37 E-03$ & 0.80 \\
\hline-5.0 & -5.0 & $-3.992 E-03$ & $-4.864 \mathrm{E}-03$ & 0.82 & $-3.99 \mathrm{E}-03$ & $-5.40 \mathrm{E}-03$ & 0.74 \\
\hline & & & & & & & \\
\hline & & & AVG Error & $33.79 \%$ & & AVG Error & $40.60 \%$ \\
\hline & & & SD Error & 0.36 & & SD Error & 0.32 \\
\hline
\end{tabular}




\begin{tabular}{|c|c|c|c|c|c|c|c|}
\hline \multicolumn{2}{|c|}{$\begin{array}{l}W=76.8 \text { um } \& \\
L=1.6 \text { um }\end{array}$} & \multicolumn{3}{|c|}{$\begin{array}{l}\text { Using the optimized values of } \\
\qquad \mathrm{Vt}=-0.84 \mathrm{~V} \text { and } M=0.9\end{array}$} & \multicolumn{3}{|c|}{$\begin{array}{l}\text { Using the default values of } \mathrm{Vt} \\
\quad=-0.84 \mathrm{~V} \text { and } \mathrm{M}=1\end{array}$} \\
\hline $\begin{array}{l}\text { Vgs } \\
\text { (V) }\end{array}$ & $\begin{array}{l}\text { Vds } \\
\text { (V) }\end{array}$ & $\begin{array}{c}\text { Ids } \\
\text { Measured } \\
\text { with dual } \\
\text { SMUs }\end{array}$ & $\begin{array}{c}\text { Ids } \\
\text { Simulated } \\
w / V t=- \\
0.84 V \text { and } \\
M=0.9\end{array}$ & $\begin{array}{c}\text { Error } \\
\text { Factor } \\
\text { Meas. } \\
\text { Vs } \\
\text { Sim. } \\
\text { (SMU/ } \\
\text { Sim) }\end{array}$ & $\begin{array}{c}\text { Ids } \\
\text { Measured } \\
\text { with dual } \\
\text { SMUs }\end{array}$ & $\begin{array}{c}\text { Ids } \\
\text { Simulate } \\
d w / V t=- \\
0.84 V \text { and } \\
M=1\end{array}$ & $\begin{array}{c}\text { Error } \\
\text { Factor } \\
\text { Meas. } \\
\text { Vs } \\
\text { Sim. } \\
\text { (SMU/ } \\
\text { Sim) }\end{array}$ \\
\hline & & Die \#3 & & & Die \#3 & & \\
\hline & & (A) & (A) & & (A) & (A) & \\
\hline 0.0 & -1.0 & $-2.866 \mathrm{E}-11$ & $-1.525 \mathrm{E}-12$ & 18.792 & $-2.87 \mathrm{E}-11$ & $-1.63 \mathrm{E}-12$ & 17.636 \\
\hline 0.0 & -3.0 & $-1.383 E-10$ & $-4.550 \mathrm{E}-12$ & 30.402 & $-1.38 E-10$ & $-4.66 \mathrm{E}-12$ & 29.718 \\
\hline 0.0 & -5.0 & $-3.167 \mathrm{E}-10$ & $-1.305 \mathrm{E}-11$ & 24.271 & $-3.17 E-10$ & $-1.37 \mathrm{E}-11$ & 23.110 \\
\hline-1.0 & -1.0 & $-6.930 \mathrm{E}-07$ & $-2.661 \mathrm{E}-05$ & 0.026 & $-6.93 E-07$ & $-3.22 \mathrm{E}-05$ & 0.022 \\
\hline-1.0 & -3.0 & $-1.333 E-06$ & $-1.205 E-04$ & 0.011 & $-1.33 E-06$ & $-1.38 \mathrm{E}-04$ & 0.010 \\
\hline-1.0 & -5.0 & $-2.186 \mathrm{E}-06$ & $-2.607 E-04$ & 0.008 & $-2.19 \mathrm{E}-06$ & $-2.90 \mathrm{E}-04$ & 0.008 \\
\hline-2.0 & -1.0 & $-4.252 E-04$ & $-5.608 E-04$ & 0.76 & $-4.25 \mathrm{E}-04$ & $-6.32 E-04$ & 0.67 \\
\hline-2.0 & -3.0 & $-5.403 E-04$ & $-9.053 E-04$ & 0.60 & $-5.40 \mathrm{E}-04$ & $-1.02 E-03$ & 0.53 \\
\hline-2.0 & -5.0 & $-6.181 E-04$ & $-1.264 \mathrm{E}-03$ & 0.49 & $-6.18 \mathrm{E}-04$ & $-1.40 \mathrm{E}-03$ & 0.44 \\
\hline-3.0 & -1.0 & $-1.147 \mathrm{E}-03$ & $-1.235 \mathrm{E}-03$ & 0.93 & $-1.15 \mathrm{E}-03$ & $-1.38 \mathrm{E}-03$ & 0.83 \\
\hline-3.0 & -3.0 & $-1.687 \mathrm{E}-03$ & $-2.195 \mathrm{E}-03$ & 0.77 & $-1.69 \mathrm{E}-03$ & $-2.45 \mathrm{E}-03$ & 0.69 \\
\hline-3.0 & -5.0 & $-1.885 \mathrm{E}-03$ & $-2.757 \mathrm{E}-03$ & 0.68 & $-1.89 \mathrm{E}-03$ & $-3.06 \mathrm{E}-03$ & 0.62 \\
\hline & & & & & & & \\
\hline-4.0 & -1.0 & $-1.691 \mathrm{E}-03$ & $-1.800 \mathrm{E}-03$ & 0.94 & $-1.69 \mathrm{E}-03$ & $-2.00 \mathrm{E}-03$ & 0.84 \\
\hline-4.0 & -3.0 & \begin{tabular}{|l|}
$-3.080 E-03$ \\
\end{tabular} & $-3.783 \mathrm{E}-03$ & 0.81 & $-3.08 E-03$ & $-4.21 \mathrm{E}-03$ & 0.73 \\
\hline-4.0 & -5.0 & $-3.444 \mathrm{E}-03$ & $-4.564 \mathrm{E}-03$ & 0.75 & $-3.44 E-03$ & $-5.07 E-03$ & 0.68 \\
\hline-5.0 & -1.0 & $-2.107 E-03$ & $-2.249 \mathrm{E}-03$ & 0.94 & $-2.11 E-03$ & $-2.50 \mathrm{E}-03$ & 0.84 \\
\hline-5.0 & -3.0 & $-4.516 \mathrm{E}-03$ & $-5.317 \mathrm{E}-03$ & 0.85 & $-4.52 E-03$ & $-5.91 E-03$ & 0.76 \\
\hline-5.0 & -5.0 & \begin{tabular}{|l|}
$-5.152 E-03$ \\
\end{tabular} & $-6.643 \mathrm{E}-03$ & 0.78 & $-5.15 \mathrm{E}-03$ & $-7.38 \mathrm{E}-03$ & 0.70 \\
\hline & & & & & & & \\
\hline & & & AVG Error & $37.72 \%$ & & AVG Error & $44.12 \%$ \\
\hline & & & SD Error & 0.34 & & SD Error & 0.30 \\
\hline
\end{tabular}


UnOptimized and Optimized data using Average Error Current method for 2.4x1.6 um

PMOS FET.

\begin{tabular}{|c|c|c|c|c|c|c|c|}
\hline \multicolumn{2}{|c|}{$\begin{array}{l}W=2.4 \mathrm{um} \\
\& L=1.6 \mathrm{um}\end{array}$} & \multicolumn{3}{|c|}{$\begin{array}{c}\text { Using the optimized values of } \mathrm{Vt}=- \\
0.84 \mathrm{~V} \text { and } \mathrm{M}=0.9\end{array}$} & \multicolumn{3}{|c|}{$\begin{array}{l}\text { Using the default values of } \mathrm{Vt} \\
\quad=-0.84 \mathrm{~V} \text { and } \mathrm{M}=1\end{array}$} \\
\hline $\begin{array}{l}\text { Vgs } \\
\text { (V) }\end{array}$ & $\begin{array}{l}\text { Vds } \\
(V)\end{array}$ & $\begin{array}{c}\text { Ids } \\
\text { Measured } \\
\text { with dual } \\
\text { SMUs }\end{array}$ & $\begin{array}{c}\text { Ids } \\
\text { Simulated } \\
w / V t=-0.84 V \\
\text { and } M=0.9\end{array}$ & $\begin{array}{c}\text { Error } \\
\text { Factor } \\
\text { Meas. } \\
\text { Vs Sim. } \\
\text { (SMU- } \\
\text { Sim) }\end{array}$ & $\begin{array}{c}\text { Ids } \\
\text { Measured } \\
\text { with dual } \\
\text { SMUs }\end{array}$ & $\begin{array}{c}\text { Ids } \\
\text { Simulated } \\
w / V t=- \\
0.84 V \text { and } \\
M=1\end{array}$ & $\begin{array}{l}\text { Error } \\
\text { Factor } \\
\text { Meas. } \\
\text { Vs } \\
\text { Sim. } \\
\text { (SMU- } \\
\text { Sim) }\end{array}$ \\
\hline & & Die \#3 & & & Die \#3 & & \\
\hline & & (A) & (A) & & (A) & (A) & \\
\hline 0.0 & -1.0 & $-1.800 \mathrm{E}-11$ & $-1.525 E-12$ & $1.65 \mathrm{E}-11$ & $-1.80 \mathrm{E}-11$ & $-1.63 E-12$ & $1.64 \mathrm{E}-11$ \\
\hline 0.0 & -3.0 & $-4.752 E-11$ & $-4.525 E-12$ & $4.30 \mathrm{E}-11$ & $-4.75 E-11$ & $-4.63 E-12$ & $4.29 \mathrm{E}-11$ \\
\hline 0.0 & -5.0 & $-7.794 E-11$ & $-7.143 E-12$ & $7.08 \mathrm{E}-11$ & $-7.79 \mathrm{E}-11$ & $-7.14 \mathrm{E}-12$ & $7.08 \mathrm{E}-11$ \\
\hline-1.0 & -1.0 & $-2.081 E-09$ & $-4.498 \mathrm{E}-08$ & $4.29 \mathrm{E} 08$ & $-2.08 \mathrm{E}-09$ & $-5.68 E-08$ & 5.47E-08 \\
\hline-1.0 & -3.0 & -3.160 E-09 & $-5.055 E-07$ & $5.02 E-07$ & $-3.16 \mathrm{E}-09$ & $-5.86 E-07$ & 5.83E-07 \\
\hline-1.0 & -5.0 & $-4.273 E-09$ & $-1.421 \mathrm{E}-06$ & $1.42 E-06$ & $-4.27 \mathrm{E}-09$ & $-1.58 E-06$ & $1.57 \mathrm{E}-06$ \\
\hline-2.0 & -1.0 & $-4.568 E-06$ & $-3.945 \mathrm{E}-06$ & $6.22 E-07$ & $-4.57 \mathrm{E}-06$ & $-4.45 E-06$ & 1.21E-07 \\
\hline-2.0 & -3.0 & $-5.626 E-06$ & $-6.252 E-06$ & $6.26 \mathrm{E}-07$ & $-5.63 \mathrm{E}-06$ & $-7.02 \mathrm{E}-06$ & 1.39E-06 \\
\hline-2.0 & -5.0 & $-6.322 \mathrm{E}-06$ & $-8.751 \mathrm{E}-06$ & 2.43E-06 & $-6.32 \mathrm{E}-06$ & $-9.72 E-06$ & 3.40E-06 \\
\hline-3.0 & -1.0 & $-1.547 \mathrm{E}-05$ & $-1.247 \mathrm{E}-05$ & $3.00 \mathrm{E}-06$ & $-1.55 E-05$ & $-1.39 E-05$ & $1.55 \mathrm{E}-06$ \\
\hline-3.0 & -3.0 & $-2.124 \mathrm{E}-05$ & $-1.689 \mathrm{E}-05$ & $4.36 \mathrm{E}-06$ & $-2.12 E-05$ & $-1.88 \mathrm{E}-05$ & 2.43E-06 \\
\hline-3.0 & -5.0 & $-2.346 \mathrm{E}-05$ & $-2.031 \mathrm{E}-05$ & $3.16 E-06$ & $-2.35 \mathrm{E}-05$ & $-2.26 \mathrm{E}-05$ & 9.02E-07 \\
\hline-4.0 & -1.0 & $-2.579 E-05$ & $-2.094 E-05$ & $4.86 E-06$ & $-2.58 E-05$ & $-2.33 E-05$ & 2.49E-06 \\
\hline-4.0 & -3.0 & $-4.230 \mathrm{E}-05$ & $-3.157 E-05$ & $1.07 E-05$ & $-4.23 E-05$ & $-3.51 \mathrm{E}-05$ & $7.21 \mathrm{E}-06$ \\
\hline-4.0 & -5.0 & $-4.685 E-05$ & $-3.513 \mathrm{E}-05$ & 1.17E-05 & $-4.69 E-05$ & $-3.90 \mathrm{E}-05$ & 7.82E-06 \\
\hline-5.0 & -1.0 & $-3.489 E-05$ & $-2.852 E-05$ & $6.37 E-06$ & $-3.49 \mathrm{E}-05$ & $-3.17 E-05$ & $3.20 \mathrm{E}-06$ \\
\hline-5.0 & -3.0 & $-6.612 E-05$ & $-4.982 E-05$ & $1.63 \mathrm{E}-05$ & $-6.61 E-05$ & $-5.54 \mathrm{E}-05$ & $1.08 \mathrm{E}-05$ \\
\hline-5.0 & -5.0 & $-7.424 \mathrm{E}-05$ & $-5.264 \mathrm{E}-05$ & $216 \mathrm{E}-05$ & $-7.42 \mathrm{E}-05$ & $-5.85 E-05$ & $1.58 \mathrm{E}-05$ \\
\hline & & & AV & 5.8 & & AVG Error & E-06 \\
\hline & & & SD Error & $6.45 \mathrm{E}-06$ & & SD Error & $4.51 E-06$ \\
\hline
\end{tabular}



PMOS FET.

\begin{tabular}{|c|c|c|c|c|c|c|c|}
\hline \multicolumn{2}{|c|}{$\begin{array}{l}W=38.4 u m \\
\& L=1.6 \text { um }\end{array}$} & \multicolumn{3}{|c|}{$\begin{array}{l}\text { Using the optimized values of } \\
\qquad t=-0.84 V \text { and } M=0.9\end{array}$} & \multicolumn{3}{|c|}{$\begin{array}{l}\text { Using the default values of } \mathrm{Vt} \\
=-0.84 \mathrm{~V} \text { and } \mathrm{M}=1\end{array}$} \\
\hline $\begin{array}{l}\text { Vgs } \\
\text { (V) }\end{array}$ & $\begin{array}{l}\text { Vds } \\
\text { (V) }\end{array}$ & $\begin{array}{c}\text { Ids } \\
\text { Measured } \\
\text { with dual } \\
\text { SMUs }\end{array}$ & $\begin{array}{c}\text { Ids } \\
\text { Simulated } \\
w / V t=- \\
0.84 V \text { and } \\
M=0.9\end{array}$ & $\begin{array}{c}\text { Error } \\
\text { Factor } \\
\text { Meas. Vs } \\
\text { Sim. } \\
\text { (SMU- } \\
\text { Sim) }\end{array}$ & $\begin{array}{l}\text { Ids } \\
\text { Measured } \\
\text { with dual } \\
\text { SMUs }\end{array}$ & $\begin{array}{l}\text { Ids } \\
\text { Simulated } \\
w / V t=- \\
0.84 V \text { and } \\
M=1\end{array}$ & \begin{tabular}{|c|} 
Error \\
Factor \\
Meas. Vs \\
Sim. \\
(SMU- \\
Sim)
\end{tabular} \\
\hline & & Die \#3 & & & Die \#3 & & \\
\hline & & (A) & (A) & & (A) & (A) & \\
\hline 0.0 & -1.0 & $-2.352 E-11$ & $-1.525 \mathrm{E}-12$ & $2.20 \mathrm{E}-11$ & $-2.35 E-11$ & $-1.63 E-12$ & $2.19 \mathrm{E}-11$ \\
\hline 0.0 & -3.0 & $-5.100 \mathrm{E}-11$ & $-4.536 \mathrm{E}-12$ & $4.65 \mathrm{E}-11$ & $-5.10 E-11$ & $-4.64 \mathrm{E}-12$ & $4.64 \mathrm{E}-11$ \\
\hline 0.0 & -5.0 & \begin{tabular}{|l|}
$-3.044 \mathrm{E}-11$ \\
\end{tabular} & $-9.623 \mathrm{E}-12$ & $2.08 \mathrm{E}-11$ & $-3.04 E-11$ & $-9.90 \mathrm{E}-12$ & 2.05E-11 \\
\hline-1.0 & -1.0 & \begin{tabular}{|l|}
$-4.813 \mathrm{E}-07$ \\
\end{tabular} & $-1.227 \mathrm{E}-05$ & $1.18 \mathrm{E}-05$ & $-4.81 E-07$ & $-1.48 \mathrm{E}-05$ & $1.44 E-05$ \\
\hline-1.0 & -3.0 & \begin{tabular}{|l|}
$-9.243 E-07$ \\
\end{tabular} & $-5.614 \mathrm{E}-05$ & 5.52E-05 & $-9.24 E-07$ & $-6.45 \mathrm{E}-05$ & $6.36 \mathrm{E}-05$ \\
\hline-1.0 & -5.0 & \begin{tabular}{|l|}
$-1.499 E-06$ \\
\end{tabular} & $-1.216 \mathrm{E}-04$ & $1.20 \mathrm{E}-04$ & $-1.50 \mathrm{E}-06$ & $-1.35 \mathrm{E}-04$ & 1.34E-04 \\
\hline-2.0 & -1.0 & $-2.193 E-04$ & $-2.667 E-04$ & $4.74 \mathrm{E}-05$ & $-2.19 E-04$ & $-3.00 \mathrm{E}-04$ & $8.11 \mathrm{E}=05$ \\
\hline-2.0 & -3.0 & $-2.792 \mathrm{E}-04$ & $-4.235 E-04$ & $1.44 \mathrm{E}-04$ & $-2.79 E-04$ & $-4.75 E-04$ & 1.96E-04 \\
\hline-2.0 & -5.0 & -3.192E-04 & $-5.883 E-04$ & 2.69E-04 & $-3.19 \mathrm{E}-04$ & $-6.54 \mathrm{E}-04$ & $3.34 \mathrm{E}-04$ \\
\hline-3.0 & -1.0 & $-5.838 E-04$ & $-5.982 E-04$ & $1.45 \mathrm{E}-05$ & $-5.84 E-04$ & $-6.68 \mathrm{E}-04$ & 8.38E-05 \\
\hline-3.0 & -3.0 & -8.573E-04 & $-1.033 \mathrm{E}-03$ & $1.75 \mathrm{E}-04$ & $-8.57 \mathrm{E}-04$ & $-1.15 \mathrm{E}-03$ & 2.95E-04 \\
\hline-3.0 & -5.0 & -9.607E-04 & $-1.286 \mathrm{E}-03$ & $3.25 \mathrm{E}-04$ & $-9.61 E-04$ & $-1.43 \mathrm{E}-03$ & $4.68 \mathrm{E}-04$ \\
\hline-4.0 & -1.0 & -8.772E-04 & $-8.767 E-04$ & 4.90E-07 & $-8.77 \mathrm{E}-04$ & $-9.76 \mathrm{E}-04$ & $9.84 E-05$ \\
\hline-4.0 & -3.0 & $-1.553 \mathrm{E}-03$ & $-1.786 E-03$ & $2.33 E-04$ & $-1.55 \mathrm{E}-03$ & $-1.99 \mathrm{E}-03$ & $4.34 \mathrm{E}-04$ \\
\hline-4.0 & -5.0 & $-1.742 E-03$ & $-2.127 \mathrm{E}-03$ & 3.86E-04 & $-1.74 \mathrm{E}-03$ & $-2.36 E-03$ & 6.22E-04 \\
\hline-5.0 & -1.0 & \begin{tabular}{|l|}
$-1.122 \mathrm{E}-03$ \\
\end{tabular} & $-1.099 \mathrm{E}-03$ & $2.37 \mathrm{E}-05$ & $-1.12 \mathrm{E}-03$ & $-1.22 E-03$ & 9.83E-05 \\
\hline-5.0 & -3.0 & $-2.283 \mathrm{E}-03$ & $-2.543 E-03$ & 2.61E-04 & $-2.28 \mathrm{E}-03$ & $-2.83 E-03$ & $5.43 \mathrm{E}-04$ \\
\hline-5.0 & -5.0 & $-2.620 \mathrm{E}-03$ & $-3.097 \mathrm{E}-03$ & $4.77 \mathrm{E}-04$ & $-2.62 E-03$ & $-3.44 \mathrm{E}-03$ & $8.21 \mathrm{E}-04$ \\
\hline & & & & & & & \\
\hline & & & AVG Error & $1.70 \mathrm{E}-04$ & & AVG Error & $2.86 \mathrm{E}-04$ \\
\hline & & & SD Error & $1.51 \mathrm{E}-04$ & & SD Error & 2.44E-04 \\
\hline
\end{tabular}


UnOptimized and Optimized data using Average Error Current method for $57.6 \times 1.6 \mathrm{um}$ PMOS FET.

\begin{tabular}{|c|c|c|c|c|c|c|c|}
\hline \multicolumn{2}{|c|}{$\begin{array}{l}W=57.6 u m \\
\& L=1.6 \text { um }\end{array}$} & \multicolumn{3}{|c|}{$\begin{array}{c}\text { Using the optimized values of } \\
\qquad t=-0.84 \mathrm{~V} \text { and } M=0.9\end{array}$} & \multicolumn{3}{|c|}{$\begin{array}{c}\text { Using the default values of } \mathrm{Vt} \\
=-0.84 \mathrm{~V} \text { and } M=1\end{array}$} \\
\hline \multirow[t]{3}{*}{$\begin{array}{l}\text { Vgs } \\
\text { (V) }\end{array}$} & \multirow[t]{3}{*}{$\begin{array}{l}\text { Vds } \\
\text { (V) }\end{array}$} & $\begin{array}{c}\text { Ids } \\
\text { Measured } \\
\text { with dual } \\
\text { SMUs }\end{array}$ & \multirow[t]{2}{*}{$\begin{array}{c}\text { Ids } \\
\text { Simulated } w \\
V t=-0.84 V \\
\text { and } M=0.9\end{array}$} & $9 \begin{array}{c}\text { Error } \\
\text { Factor } \\
\text { wMeas. Vs } \\
\text { Sim. } \\
(\text { SMU- } \\
\text { Sim) }\end{array}$ & $\begin{array}{l}\text { Ids } \\
\text { Measured } \\
\text { with dual } \\
\text { SMUs }\end{array}$ & \multirow[t]{2}{*}{$\begin{array}{l}\text { Ids } \\
\text { Simulated } \\
w / V t=- \\
0.84 V \text { and } \\
M=1\end{array}$} & \begin{tabular}{|l} 
Error \\
Factor \\
Meas. Vs \\
Sim. \\
(SMU- \\
Sim)
\end{tabular} \\
\hline & & Die \#3 & & & Die \#3 & & \\
\hline & & (A) & (A) & & (A) & (A) & \\
\hline 0.0 & -1.0 & $9.820 \mathrm{E}-12$ & $-1.525 E-12$ & $1.13 \mathrm{E}-11$ & $9.82 \mathrm{E}-12$ & $-1.63 E-12$ & $1.14 \mathrm{E}-11$ \\
\hline 0.0 & -3.0 & $-1.684 \mathrm{E}-11$ & $-4.543 E-12$ & $1.23 \mathrm{E}-11$ & $-1.68 \mathrm{E}-11$ & $-4.65 E-12$ & $1.22 \mathrm{E}-11$ \\
\hline 0.0 & -5.0 & $-1.616 \mathrm{E}-11$ & $-1.132 \mathrm{E}-11$ & $4.84 \mathrm{E}-12$ & $-1.62 \mathrm{E}-11$ & $-1.18 \mathrm{E}-11$ & $4.38 \mathrm{E}-12$ \\
\hline-1.0 & -1.0 & $-6.732 E-07$ & $-1.942 E-05$ & $1.87 E-05$ & 3E-07 & $-2.35 E-05$ & $2.28 \mathrm{E}-05$ \\
\hline-1.0 & -3.0 & $-1.245 \mathrm{E}-06$ & $-8.822 E-05$ & $8.70 \mathrm{E}-05$ & E-06 & $-1.01 E-04$ & $1.00 \mathrm{E}-04$ \\
\hline-1.0 & -5.0 & $-2.004 \mathrm{E}-06$ & -1.910 E-04 & 1.89E-04 & $-2.00 \mathrm{E}-06$ & $-2.12 E-04$ & $2.10 \mathrm{E}-04$ \\
\hline & & & & & & & \\
\hline-2.0 & -1.0 & $-3.298 \mathrm{E}-04$ & $-4.132 E-04$ & 8.33E-05 & $-3.30 \mathrm{E}-04$ & $-4.65 E-04$ & $1.36 \mathrm{E}-04$ \\
\hline-2.0 & -3.0 & $-4.179 E-04$ & $-6.624 \mathrm{E}-04$ & $2.44 E-04$ & $-4.18 \mathrm{E}-04$ & $-7.44 \mathrm{E}-04$ & $3.26 \mathrm{E}-04$ \\
\hline-2.0 & -5.0 & $-4.769 \mathrm{E}-04$ & $-9.237 E-04$ & 4.47E-04 & $-4.77 \mathrm{E}-04$ & $-1.03 E-03$ & $5.49 \mathrm{E}-04$ \\
\hline-3.0 & -1.0 & $-8.951 E-04$ & $-9.162 E-04$ & 2.11E-05 & $-8.95 E-04$ & $2 E-03$ & 1.27E-04 \\
\hline-3.0 & -3.0 & $-1.303 E-03$ & $-1.613 \mathrm{E}-03$ & $3.10 E_{04}$ & $-1.30 \mathrm{E}-03$ & $-1.80 E-03$ & $4.97 \mathrm{E}-04$ \\
\hline-3.0 & -5.0 & $-1.454 \mathrm{E}-03$ & $-2.019 \mathrm{E}-03$ & 5.65E-04 & $-1.45 \mathrm{E}-03$ & $-2.24 \mathrm{E}-03$ & $7,90 \mathrm{E}-04$ \\
\hline-4.0 & -1.0 & $-1.358 E-03$ & $-1.338 E-03$ & $1.97 \mathrm{E}-05$ & $-1.36 \mathrm{E}-03$ & $-1.49 \mathrm{E}-03$ & $1.31 \mathrm{E}-04$ \\
\hline-4.0 & -3.0 & $-2.385 E-03$ & $-2.782 \mathrm{E}-03$ & $3.98 \mathrm{E}-04$ & $-2.38 \mathrm{E}-03$ & $-3.10 \mathrm{E}-03$ & $7.12 E-04$ \\
\hline-4.0 & -5.0 & $-2.660 \mathrm{E}-03$ & $-3.342 \mathrm{E}-03$ & $6.82 E-04$ & $-2.66 \mathrm{E}-03$ & $-3.71 \mathrm{E}-03$ & $1.05 E-03$ \\
\hline-5.0 & -1.0 & $-1.741 \mathrm{E}-03$ & $-1.674 \mathrm{E}-03$ & $6.74 \mathrm{E}-05$ & $-1.74 \mathrm{E}-03$ & $-1.86 \mathrm{E}-03$ & $1.19 \mathrm{E}-04$ \\
\hline-5.0 & -3.0 & $-3.511 E-03$ & $-3.929 E-03$ & $4.18 E-04$ & $-3.51 E-03$ & $-4.37 E-03$ & $8.54 E-04$ \\
\hline-5.0 & -5.0 & $-3.992 E-03$ & $-4.864 \mathrm{E}-03$ & $8.73 \mathrm{E}-04$ & $-3.99 \mathrm{E}-03$ & $-5.40 E-03$ & $1.41 \mathrm{E}-03$ \\
\hline & & & & & & & \\
\hline & & & AVG Error & $2.95 E-04$ & & AVG Error & $4.69 E-04$ \\
\hline & & & SD Error & 2.65E-04 & & SD Error & $4.17 \mathrm{E}-04$ \\
\hline
\end{tabular}




\begin{tabular}{|c|c|c|c|c|c|c|c|}
\hline \multicolumn{2}{|c|}{$\begin{array}{l}W=76.8 \mathrm{um} \\
\& L=1.6 \mathrm{um}\end{array}$} & \multicolumn{3}{|c|}{$\begin{array}{l}\text { Using the optimized values of } \\
V t=-0.84 V \text { and } M=0.9\end{array}$} & \multicolumn{3}{|c|}{$\begin{array}{l}\text { Using the default values of } \mathrm{Vt} \\
\quad=-0.84 \mathrm{~V} \text { and } M=1\end{array}$} \\
\hline \multirow[t]{3}{*}{$\begin{array}{l}\text { Vgs } \\
\text { (V) }\end{array}$} & \multirow[t]{3}{*}{$\begin{array}{l}\text { Vds } \\
\text { (V) }\end{array}$} & $\begin{array}{c}\text { Ids } \\
\text { Measured } \\
\text { with dual } \\
\text { SMUs }\end{array}$ & $\begin{array}{c}\text { Ids } \\
\text { Simulated } \\
w / V t=- \\
0.84 V \text { and } \\
M=0.9\end{array}$ & \begin{tabular}{|c|} 
Error \\
Factor \\
Meas. \\
Vs \\
Sim. \\
(SMU- \\
Sim) \\
\end{tabular} & $\begin{array}{l}\text { Ids } \\
\text { Measured } \\
\text { with dual } \\
\text { SMUs }\end{array}$ & $\begin{array}{l}\text { Ids } \\
\text { Simulated } \\
w / V t=- \\
0.84 V \text { and } \\
M=1\end{array}$ & \begin{tabular}{|c} 
Error \\
Factor \\
Meas. \\
Vs \\
Sim. \\
(SMU- \\
Sim)
\end{tabular} \\
\hline & & Die \#3 & & & Die \#3 & & \\
\hline & & (A) & (A) & & (A) & (A) & \\
\hline 0.0 & -1.0 & $-2.866 \mathrm{E}-11$ & $-1.525 \mathrm{E}-12$ & $2.71 \mathrm{E}-11$ & $-2.87 \mathrm{E}-11$ & $-1.63 \mathrm{E}-12$ & $2.70 \mathrm{E}-11$ \\
\hline 0.0 & -3.0 & $-1.383 E-10$ & $-4.550 \mathrm{E}-12$ & $1.34 \mathrm{E}-10$ & $-1.38 \mathrm{E}-10$ & $-4.66 \mathrm{E}-12$ & $1.34 \mathrm{E}-10$ \\
\hline 0.0 & -5.0 & $-3.167 \mathrm{E}-10$ & $-1.305 \mathrm{E}-11$ & $3.04 \mathrm{E}-10$ & $-3.17 \mathrm{E}-10$ & $-1.37 \mathrm{E}-11$ & $3.03 E-10$ \\
\hline-1.0 & -1.0 & -07 & -05 & E-05 & 7 & 05 & 05 \\
\hline-1.0 & -3.0 & $-1.333 \mathrm{E}-06$ & $-1.205 E-04$ & $1.19 \mathrm{E}-04$ & $3 \mathrm{E}-06$ & $-1.38 \mathrm{E}-04$ & 1.37E-04 \\
\hline-1.0 & -5.0 & \begin{tabular}{|l|}
$-2.186 E-06$ \\
\end{tabular} & $-2.607 \mathrm{E}-04$ & $2.58 E-04$ & $-2.19 \mathrm{E}-06$ & $-2.90 E-04$ & $2.87 \mathrm{E}-04$ \\
\hline & & & & & & & \\
\hline-2.0 & -1.0 & $2 \mathrm{E}-04$ & E-04 & E-04 & & 2E-04 & -04 \\
\hline-2.0 & -3.0 & $-5.403 E-04$ & $-9.053 E-04$ & $3.65 \mathrm{E}-04$ & 10E-04 & $-1.02 E-03$ & $4.76 \mathrm{E}-04$ \\
\hline-2.0 & -5.0 & \begin{tabular}{|c|}
$-6.181 E-04$ \\
\end{tabular} & $-1.264 \mathrm{E}-03$ & $6.46 E-04$ & $-6.18 E-04$ & $-1.40 \mathrm{E}-03$ & 7.86E-04 \\
\hline & & & & & & & \\
\hline-3.0 & -1.0 & $-1.147 \mathrm{E}-03$ & $-1.235 E-03$ & $8.71 E-05$ & $-1.15 \mathrm{E}-03$ & $8 \mathrm{E}-03$ & 2.30E-04 \\
\hline-3.0 & -3.0 & \begin{tabular}{|c|}
$-1.687 E-03$ \\
\end{tabular} & $-2.195 E-03$ & $5.08 \mathrm{E}-04$ & $-1.69 \mathrm{E}-03$ & E-03 & $7.63 E-04$ \\
\hline-3.0 & -5.0 & $-1.885 \mathrm{E}-03$ & $-2.757 E-03$ & $8.72 E-04$ & $-1.89 \mathrm{E}-03$ & $-3.06 \mathrm{E}-03$ & $1.18 \mathrm{E}-03$ \\
\hline & & & & & & & \\
\hline-4.0 & -1.0 & $-1.691 \mathrm{E}-03$ & $-1.800 \mathrm{E}-03$ & $1.08 \mathrm{E}-04$ & $-1.69 \mathrm{E}-03$ & $-2.00 E-03$ & 3.11E-04 \\
\hline-4.0 & -3.0 & \begin{tabular}{|l|}
$-3.080 E-03$ \\
\end{tabular} & $-3.783 E-03$ & $7.03 E-04$ & $-3.08 \mathrm{E}-03$ & $-4.21 \mathrm{E}-03$ & $1.13 E-03$ \\
\hline-4.0 & -5.0 & $-3.444 \mathrm{E}-03$ & $-4.564 \mathrm{E}-03$ & $1,12 E-03$ & $-3.44 \mathrm{E}-03$ & $-5.07 \mathrm{E}-03$ & $1.63 \mathrm{E}-03$ \\
\hline & & & & & & & \\
\hline-5.0 & -1.0 & $-2.107 \mathrm{E}-03$ & $-2.249 \mathrm{E}-03$ & $1.42 E-04$ & $-2.11 \mathrm{E}-03$ & $-2.50 \mathrm{E}-03$ & $3.92 E-04$ \\
\hline-5.0 & -3.0 & $-4.516 \mathrm{E}-03$ & $-5.317 \mathrm{E}-03$ & $8.01 \mathrm{E}-04$ & $-4.52 \mathrm{E}-03$ & $-5.91 E-03$ & $1.39 \mathrm{E}-03$ \\
\hline-5.0 & -5.0 & $-5.152 E-03$ & $-6.643 E-03$ & $1.49 \mathrm{E}-03$ & $-5.15 E-03$ & $-7.38 \mathrm{E}-03$ & 2.23E-03 \\
\hline & & & & & & & \\
\hline & & & AVG Error & $4.92 \mathrm{E}-04$ & & AVG Error & $745 \mathrm{E}-04$ \\
\hline & & & SD Error & $4.38 \mathrm{E}-04$ & & SD Error & $6.42 \mathrm{E}-04$ \\
\hline
\end{tabular}


Repeatability Data for $38.4 \times 1.6$ um NMOS FET

\begin{tabular}{|c|c|c|c|c|c|c|c|}
\hline \multicolumn{6}{|c|}{$W=38.4 \mathrm{um} \& L=1.6 \mathrm{um}$} & \multirow{2}{*}{\begin{tabular}{|c|}
$\begin{array}{c}\text { Worst } \\
\text { case }\end{array}$ \\
$\begin{array}{c}\text { Variation } \\
\text { (A) }\end{array}$ \\
\end{tabular}} & \multirow{2}{*}{\begin{tabular}{|c|}
$\begin{array}{c}\% \text { Worst } \\
\text { case }\end{array}$ \\
$\begin{array}{c}\text { Variation I I } \\
\text { Avg I }\end{array}$ \\
\end{tabular}} \\
\hline & & $6 / 17 / 2004$ & $6 / 17 / 2004$ & $6 / 18 / 2004$ & $6 / 18 / 2004$ & & \\
\hline & & Day 1 & Day 1 & Day 2 & Day 2 & & \\
\hline \multirow[t]{3}{*}{$\begin{array}{c}\text { Vgs } \\
\text { (V) }\end{array}$} & $\begin{array}{l}\text { Vds } \\
\text { (V) }\end{array}$ & Test 1 & Test 2 & Test 1 & Test 2 & & \\
\hline & & Die \#3 & Die \#3 & Die \#3 & Die \#3 & & \\
\hline & & (A) & (A) & (A) & (A) & & \\
\hline 0 & 1.0 & $8.660 \mathrm{E}-11$ & $4.438 \mathrm{E}-11$ & $1.356 \mathrm{E}-11$ & $3.436 \mathrm{E}-11$ & $7.304 \mathrm{E}-11$ & $163.309 \%$ \\
\hline 0 & 3.0 & $2.960 \mathrm{E}-11$ & $3.296 \mathrm{E}-11$ & $3.494 \mathrm{E}-11$ & $5.258 \mathrm{E}-11$ & $2.298 \mathrm{E}-11$ & $61.247 \%$ \\
\hline 0 & 5.0 & $9.990 \mathrm{E}-11$ & $3.604 \mathrm{E}-11$ & $6.702 \mathrm{E}-11$ & $9.120 \mathrm{E}-11$ & $6.386 \mathrm{E}-11$ & $86.837 \%$ \\
\hline 1.0 & 1.0 & 2.715E-04 & 2.715E-04 & $2.715 \mathrm{E}-04$ & $2.715 \mathrm{E}-04$ & $4 \mathrm{E}-08$ & $0.015 \%$ \\
\hline 1.0 & 3.0 & $3.178 \mathrm{E}-04$ & 3.176E-04 & $3.176 \mathrm{E}-04$ & 3.180E-04 & $4.4 \mathrm{E}-07$ & $0.138 \%$ \\
\hline 1.0 & 5.0 & 3.548E-04 & 3.547E-04 & 3.547E-04 & $3.548 \mathrm{E}-04$ & 1.6E-07 & $0.045 \%$ \\
\hline 2.0 & 1.0 & $1.526 \mathrm{E}-03$ & 1.527E-03 & $1.527 \mathrm{E}-03$ & $1.528 \mathrm{E}-03$ & $1.8 E-06$ & $0.118 \%$ \\
\hline 2.0 & 3.0 & $1.763 \mathrm{E}-03$ & 1.764E-03 & $1.765 \mathrm{E}-03$ & $1.765 \mathrm{E}-03$ & $2 \mathrm{E}-06$ & $0.113 \%$ \\
\hline 2.0 & 5.0 & $1.872 \mathrm{E}-03$ & $1.873 \mathrm{E}-03$ & 1.874E-03 & $1.875 \mathrm{E}-03$ & $2.4 \mathrm{E}-06$ & $0.128 \%$ \\
\hline 3.0 & 1.0 & $2.742 \mathrm{E}-03$ & $2.742 \mathrm{E}-03$ & 2.744E-03 & $2.746 \mathrm{E}-03$ & $4.60 \mathrm{E}-06$ & $0.168 \%$ \\
\hline 3.0 & 3.0 & $3.608 \mathrm{E}-03$ & $3.608 \mathrm{E}-03$ & 3.612E-03 & $3.614 \mathrm{E}-03$ & 6.6E-06 & $0.183 \%$ \\
\hline 3.0 & 5.0 & $3.766 \mathrm{E}-03$ & 3.766E-03 & $3.771 \mathrm{E}-03$ & $3.773 \mathrm{E}-03$ & $7 \mathrm{E}-06$ & $0.186 \%$ \\
\hline 4.0 & 1.0 & 3.706E-03 & 3.705E-03 & $3.708 \mathrm{E}-03$ & $3.711 \mathrm{E}-03$ & $6 \mathrm{E}-06$ & $0.162 \%$ \\
\hline 4.0 & 3.0 & $5.595 \mathrm{E}-03$ & 5.597E-03 & $5.598 \mathrm{E}-03$ & $5.602 \mathrm{E}-03$ & $7 E-06$ & $0.125 \%$ \\
\hline 4.0 & 5.0 & $5.803 \mathrm{E}-03$ & 5.802E-03 & 5.804E-03 & $5.807 \mathrm{E}-03$ & $4.8 \mathrm{E}-06$ & $0.083 \%$ \\
\hline & & & & & & & \\
\hline 5.0 & 1.0 & 4.497E-03 & 4.497E-03 & 4.502E-03 & $4.505 \mathrm{E}-03$ & $7.8 \mathrm{E}-06$ & $0.173 \%$ \\
\hline 5.0 & 3.0 & $7.603 \mathrm{E}-03$ & 7.602E-03 & $7.609 \mathrm{E}-03$ & $7.612 \mathrm{E}-03$ & $1.06 \mathrm{E}-05$ & $0.139 \%$ \\
\hline 5.0 & 5.0 & 7.892E-03 & 7.892E-03 & $7.898 \mathrm{E}-03$ & $7.903 \mathrm{E}-03$ & $1.08 \mathrm{E}-05$ & $0.137 \%$ \\
\hline & & & & & & & 5 \\
\hline & & & & & & Avg error & $0.128 \%$ \\
\hline
\end{tabular}


Repeatability Data for $76.8 \times 1.6$ um NMOS FET

\begin{tabular}{|c|c|c|c|c|c|c|c|}
\hline \multicolumn{6}{|c|}{$W=76.8 \mathrm{um} \quad \& L=1.6 \mathrm{um}$} & \multirow{2}{*}{\begin{tabular}{|c|}
$\begin{array}{c}\text { Worst } \\
\text { case }\end{array}$ \\
$\begin{array}{c}\text { Variation } \\
\text { (A) }\end{array}$ \\
\end{tabular}} & \multirow{2}{*}{\begin{tabular}{|c|}
$\begin{array}{c}\% \text { Worst } \\
\text { case }\end{array}$ \\
$\begin{array}{c}\text { Variation } \\
\text { / Avg I }\end{array}$ \\
\end{tabular}} \\
\hline & & $6 / 17 / 2004$ & $6 / 17 / 2004$ & $6 / 18 / 2004$ & $6 / 18 / 2004$ & & \\
\hline & & Day 1 & Day 1 & Day 2 & Day 2 & & \\
\hline \multirow[t]{3}{*}{$\begin{array}{l}\text { Vgs } \\
\text { (V) }\end{array}$} & Vds (V) & Test 1 & Test 2 & Test 1 & Test 2 & & \\
\hline & & Die \#3 & Die \#3 & Die \#3 & Die \#3 & & \\
\hline & & (A) & (A) & (A) & (A) & & \\
\hline 0 & & $E-04$ & 2 & 227 & 4 & 6 & $14 \%$ \\
\hline 0 & 3.0 & $2.852 \mathrm{E}-04$ & $2.858 \mathrm{E}-04$ & $2.800 \mathrm{E}-04$ & $2.870 \mathrm{E}-04$ & $6.96 \mathrm{E}-06$ & $2.446 \%$ \\
\hline 0 & 5.0 & 3.296E-04 & 3.304E-04 & $3.239 \mathrm{E}-04$ & 3.314E-04 & $7.56 \mathrm{E}-06$ & $2.299 \%$ \\
\hline & & & & & & & \\
\hline 1.0 & 1.0 & $2.222 \mathrm{E}-03$ & $2.223 \mathrm{E}-03$ & $2.222 \mathrm{E}-03$ & $2.230 \mathrm{E}-03$ & $8.8 \mathrm{E}-06$ & $0.396 \%$ \\
\hline 1.0 & 3.0 & $2.636 \mathrm{E}-03$ & $2.637 \mathrm{E}-03$ & $2.635 \mathrm{E}-03$ & $2.646 \mathrm{E}-03$ & 1.04E-05 & $0.394 \%$ \\
\hline 1.0 & 5.0 & 2.835E-03 & $2.836 \mathrm{E}-03$ & $2.834 \mathrm{E}-03$ & $2.846 \mathrm{E}-03$ & $1.2 \mathrm{E}-05$ & $0.423 \%$ \\
\hline & & & & & & & \\
\hline 2.0 & 1.0 & $4.530 \mathrm{E}-03$ & $4.530 \mathrm{E}-03$ & $4.538 \mathrm{E}-03$ & $4.546 \mathrm{E}-03$ & $1.66 \mathrm{E}-05$ & $0.366 \%$ \\
\hline 2.0 & 3.0 & $6.061 \mathrm{E}-03$ & $6.061 \mathrm{E}-03$ & $6.068 \mathrm{E}-03$ & $6.080 E-03$ & $1.84 \mathrm{E}-05$ & $0.303 \%$ \\
\hline 2.0 & 5.0 & $6.379 \mathrm{E}-03$ & $6.379 \mathrm{E}-03$ & $6.386 \mathrm{E}-03$ & 6.399E-03 & $2.04 \mathrm{E}-05$ & $0.319 \%$ \\
\hline 3.0 & 1.0 & $6.399 \mathrm{E}-03$ & $6.399 \mathrm{E}-03$ & $6.416 \mathrm{E}-03$ & $6.426 \mathrm{E}-03$ & $2.76 E-05$ & $0.431 \%$ \\
\hline 3.0 & 3.0 & $9.840 \mathrm{E}-03$ & $9.840 \mathrm{E}-03$ & $9.860 \mathrm{E}-03$ & $9.876 \mathrm{E}-03$ & 3.54E-05 & $0.359 \%$ \\
\hline 3.0 & 5.0 & $1.028 \mathrm{E}-02$ & 1.027E-02 & $1.029 \mathrm{E}-02$ & 1.030E-02 & $3 E-05$ & $0.292 \%$ \\
\hline & & & & & & & \\
\hline 4.0 & 1.0 & $7.928 \mathrm{E}-03$ & $7.927 \mathrm{E}-03$ & $7.950 \mathrm{E}-03$ & $7.959 E-03$ & $3.16 \mathrm{E}-05$ & $0.398 \%$ \\
\hline 4.0 & 3.0 & $1.368 \mathrm{E}-02$ & 1.368E-02 & $1.370 \mathrm{E}-02$ & 1.372E-02 & $3.6 \mathrm{E}-05$ & $0.263 \%$ \\
\hline 4.0 & 5.0 & 1.429E-02 & $1.428 \mathrm{E}-02$ & $1.430 \mathrm{E}-02$ & 1.433E-02 & $4.2 \mathrm{E}-05$ & $0.294 \%$ \\
\hline 5.0 & 1.0 & $9.206 \mathrm{E}-03$ & $9.204 \mathrm{E}-03$ & $9.232 \mathrm{E}-03$ & $9.243 E-03$ & $3.9 E-05$ & $0.423 \%$ \\
\hline 5.0 & 3.0 & $1.732 \mathrm{E}-02$ & 1.732E-02 & $1.735 \mathrm{E}-02$ & 1.737E-02 & $5.20 \mathrm{E}-05$ & $0.300 \%$ \\
\hline 5.0 & 5.0 & $1.831 \mathrm{E}-02$ & $1.830 \mathrm{E}-02$ & $1.834 \mathrm{E}-02$ & $1.836 \mathrm{E}-02$ & $5.8 \mathrm{E}-05$ & $0.316 \%$ \\
\hline & & & & & & Avg error & $0.352 \%$ \\
\hline
\end{tabular}


Repeatability Data for 38.4x1.6um PMOS FET

\begin{tabular}{|c|c|c|c|c|c|c|c|}
\hline \multicolumn{6}{|c|}{$W=38.4 u m \& L=1.6 u m$} & \multirow{2}{*}{\begin{tabular}{|c|}
$\begin{array}{c}\text { Worst } \\
\text { case }\end{array}$ \\
$\begin{array}{c}\text { Variation } \\
(\mathrm{A})\end{array}$ \\
\end{tabular}} & \multirow{2}{*}{\begin{tabular}{|c|}
$\begin{array}{c}\% \text { Worst } \\
\text { case }\end{array}$ \\
$\begin{array}{c}\text { Variation I } \\
\text { Avg I }\end{array}$ \\
\end{tabular}} \\
\hline & & $6 / 17 / 2004$ & $6 / 17 / 2004$ & $6 / 18 / 2004$ & $6 / 18 / 2004$ & & \\
\hline & & Day 1 & Day 1 & Day 2 & Day 2 & & \\
\hline \multirow[t]{3}{*}{ Vgs (V) } & Vds (V) & Test 1 & Test 2 & Test 1 & Test 2 & & \\
\hline & & Die \#3 & Die \#3 & Die \#3 & Die \#3 & & \\
\hline & & (A) & (A) & (A) & (A) & & \\
\hline 0.0 & -1.0 & $\mid-1.542 \mathrm{E}-11$ & $-3.840 \mathrm{E}-11$ & $-5.03 E-11$ & $-3.134 \mathrm{E}-11$ & $3.488 \mathrm{E}-11$ & $-87.021 \%$ \\
\hline 0.0 & -3.0 & $-1.768 \mathrm{E}-11$ & $-3.484 \mathrm{E}-11$ & $1.940 \mathrm{E}-12$ & $-8.040 \mathrm{E}-12$ & $3.29 \mathrm{E}-11$ & $-187.253 \%$ \\
\hline 0.0 & -5.0 & $-3.204 \mathrm{E}-11$ & \begin{tabular}{|l|}
$-1.906 \mathrm{E}-11$ \\
\end{tabular} & $-3.948 \mathrm{E}-11$ & $-5.862 E-11$ & 3.956E-11 & $-106.059 \%$ \\
\hline-1.0 & -1.0 & $-4.972 \mathrm{E}-07$ & \begin{tabular}{|l|}
$-496 E-07$ \\
\end{tabular} & $-4.925 E-07$ & $-4.924 \mathrm{E}-07$ & $7.28 \mathrm{E}-09$ & $1.469 \%$ \\
\hline-1.0 & -3.0 & $-9.509 E-07$ & \begin{tabular}{|l|}
$-9.520 \mathrm{E}-07$ \\
\end{tabular} & $-9.456 E-07$ & $-9.442 E-07$ & $7.86 \mathrm{E}-09$ & $0.829 \%$ \\
\hline-1.0 & -5.0 & $-1.536 \mathrm{E}-06$ & $-1.542 \mathrm{E}-06$ & $-1.528 \mathrm{E}-06$ & $-1.529 \mathrm{E}-06$ & 1.34E-08 & $-0.874 \%$ \\
\hline-2.0 & -1.0 & $|-2.170 E-04|$ & $\mid-2.169 E-04$ & $-2.172 E-04$ & $-2.171 \mathrm{E}-04$ & $3.4 \mathrm{E}-07$ & $0.157 \%$ \\
\hline-2.0 & -3.0 & $-2.770 E-04$ & $-2.768 \mathrm{E}-04$ & $-2.774 \mathrm{E}-04$ & $-2.775 \mathrm{E}-04$ & $6.8 \mathrm{E}-07$ & $0.245 \%$ \\
\hline-2.0 & -5.0 & $-3.171 \mathrm{E}-04$ & $-3.169 \mathrm{E}-04$ & $-3.177 \mathrm{E}-04$ & $-3.177 \mathrm{E}-04$ & $8 \mathrm{E}-07$ & $-0.252 \%$ \\
\hline & & & & & & & \\
\hline-3.0 & -1.0 & $-5.740 \mathrm{E}-04$ & $-5.722 E-04$ & $-5.734 \mathrm{E}-04$ & $-5.736 \mathrm{E}-04$ & $1.78 \mathrm{E}-06$ & $0.310 \%$ \\
\hline-3.0 & -3.0 & $-8.448 E-04$ & $-8.429 E-04$ & $-8.463 E-04$ & $-8.457 E-04$ & 3.38E-06 & $0.400 \%$ \\
\hline-3.0 & -5.0 & $-9.483 E-04$ & $-9.462 E-04$ & $-9.496 \mathrm{E}-04$ & $-9.492 E-04$ & 3.34E-06 & $0.352 \%$ \\
\hline & & | o cn15 & 1 & 0055001 & & & \\
\hline-4.0 & -1.0 & & -8.632E-04 & $-8.655 \mathrm{E}-04$ & & & \\
\hline-4.0 & -3.0 & $-1.517 \mathrm{E}-03$ & $-1.514 \mathrm{E}-03$ & $-1.512 \mathrm{E}-03$ & $-1.510 \mathrm{E}-03$ & $6.6 \mathrm{E}-06$ & $-0.436 \%$ \\
\hline-4.0 & -5.0 & $-1.703 \mathrm{E}-03$ & $-1.700 \mathrm{E}-03$ & $-1.694 \mathrm{E}-03$ & $-1.695 \mathrm{E}-03$ & 8.6E-06 & $-0.506 \%$ \\
\hline & & & & & & & \\
\hline-5.0 & -1.0 & $-1.111 \mathrm{E}-03$ & $-1.109 \mathrm{E}-03$ & $-1.114 \mathrm{E}-03$ & $-1.113 E-03$ & $4.8 \mathrm{E}-06$ & $-0.432 \%$ \\
\hline-5.0 & -3.0 & \begin{tabular}{|l|} 
\\
\end{tabular} & $-2.200 \mathrm{E}-03$ & $-2.210 \mathrm{E}-03$ & $-2.203 E-03$ & $9.8 \mathrm{E}-06$ & $-0.444 \%$ \\
\hline-5.0 & -5.0 & $-2.513 \mathrm{E}-03$ & $-2.509 \mathrm{E}-03$ & $-2.513 E-03$ & $-2.511 E-03$ & $4.8 \mathrm{E}-06$ & $0.191 \%$ \\
\hline & & & & & & & \\
\hline & & & & & & Avg error & 0.478 \\
\hline
\end{tabular}


Repeatability Data for $76.8 \times 1.6 u m$ PMOS FET

\begin{tabular}{|c|c|c|c|c|c|c|c|}
\hline \multicolumn{6}{|c|}{$W=76.8$ um $\& L=1.62$ um } & \multirow{2}{*}{$\begin{array}{c}\begin{array}{c}\text { Worst } \\
\text { case }\end{array} \\
\begin{array}{c}\text { Variation } \\
\text { (A) }\end{array}\end{array}$} & \multirow{2}{*}{\begin{tabular}{|c|}
$\begin{array}{c}\% \text { Worst } \\
\text { case }\end{array}$ \\
$\begin{array}{c}\text { Variation I } \\
\text { Avg I }\end{array}$ \\
\end{tabular}} \\
\hline & & $6 / 17 / 2004$ & $6 / 17 / 2004$ & $6 / 18 / 2004$ & $6 / 18 / 2004$ & & \\
\hline & & Day 1 & Day 1 & Day 2 & Day 2 & & \\
\hline $\operatorname{Vgs}(V)$ & Vds (V) & Test 1 & Test 2 & Test 1 & Test 2 & & \\
\hline & & Die \#3 & Die \#3 & Die \#3 & Die \#3 & & \\
\hline & & (A) & (A) & (A) & (A) & & \\
\hline & & & & & & & \\
\hline 0.0 & -1.0 & $-5.846 \mathrm{E}-11$ & $-4.190 \mathrm{E}-11$ & $-1.080 \mathrm{E}-11$ & $-8.018 \mathrm{E}-11$ & $6.938 \mathrm{E}-11$ & $-145.040 \%$ \\
\hline 0.0 & -3.0 & $-1.595 \mathrm{E}-10$ & $-1.813 E-10$ & $-1.228 \mathrm{E}-10$ & $-1.640 \mathrm{E}-10$ & $5.848 \mathrm{E}-11$ & $-37.273 \%$ \\
\hline 0.0 & -5.0 & $-3.101 \mathrm{E}-10$ & $-3.714 \mathrm{E}-10$ & $-3.090 \mathrm{E}-10$ & $-3.300 \mathrm{E}-10$ & $6.238 \mathrm{E}-11$ & $-18.895 \%$ \\
\hline-1.0 & -1.0 & $-7.027 \mathrm{E}-07$ & $-7.052 E-07$ & $-7.077 \mathrm{E}-07$ & $-7.357 \mathrm{E}-07$ & 3.302E-08 & $-4.632 \%$ \\
\hline-1.0 & -3.0 & $-1.360 \mathrm{E}-06$ & $-1.366 \mathrm{E}-06$ & $-1.372 \mathrm{E}-06$ & $-1.367 \mathrm{E}-06$ & $1.22 \mathrm{E}-08$ & $-0.893 \%$ \\
\hline-1.0 & -5.0 & $-2.229 \mathrm{E}-06$ & $-2.235 \mathrm{E}-06$ & $-2.245 \mathrm{E}-06$ & $-2.234 \mathrm{E}-06$ & 1.6E-08 & $0.716 \%$ \\
\hline & & & & & & & \\
\hline-2.0 & -1.0 & $-4.207 \mathrm{E}-04$ & $-4.209 E-04$ & $-4.226 \mathrm{E}-04$ & $-4.225 \mathrm{E}-04$ & $1.88 \mathrm{E}-06$ & $0.446 \%$ \\
\hline-2.0 & -3.0 & $-5.371 \mathrm{E}-04$ & $-5.368 E-04$ & $-5.389 E-04$ & $-5.390 \mathrm{E}-04$ & $2.2 \mathrm{E}-06$ & $-0.409 \%$ \\
\hline-2.0 & -5.0 & $-6.154 E-04$ & $-6.154 E-04$ & $-6.171 E-04$ & $-6.174 \mathrm{E}-04$ & $2.02 E-06$ & $-0.328 \%$ \\
\hline-3.0 & -1.0 & $-1.116 \mathrm{E}-03$ & $-1.118 \mathrm{E}-03$ & $-1.125 \mathrm{E}-03$ & $-1.129 \mathrm{E}-03$ & 1.3E-05 & $-1.158 \%$ \\
\hline-3.0 & -3.0 & $-1.671 \mathrm{E}-03$ & $-1.671 \mathrm{E}-03$ & $-1.682 \mathrm{E}-03$ & $-1.683 \mathrm{E}-03$ & $1.2 \mathrm{E}-05$ & $-0.716 \%$ \\
\hline-3.0 & -5.0 & $-1.873 \mathrm{E}-03$ & $-1.871 \mathrm{E}-03$ & $-1.883 \mathrm{E}-03$ & $-1.882 E-03$ & 1.18E-05 & $-0.629 \%$ \\
\hline-4.0 & -1.0 & $-1.615 E-03$ & $\mid-1.616 \mathrm{E}-03$ & $-1.622 \mathrm{E}-03$ & $-1.634 \mathrm{E}-03$ & $1.88 \mathrm{E}-05$ & $-1.159 \%$ \\
\hline-4.0 & -3.0 & $-3.048 \mathrm{E}-03$ & $-3.047 \mathrm{E}-03$ & $-3.064 \mathrm{E}-03$ & $-3.066 \mathrm{E}-03$ & $1.9 \mathrm{E}-05$ & $-0.622 \%$ \\
\hline-4.0 & -5.0 & $-3.414 \mathrm{E}-03$ & $-3.415 E-03$ & $-3.432 E-03$ & $-3.435 E-03$ & $2.06 \mathrm{E}-05$ & $-0.602 \%$ \\
\hline-5.0 & -1.0 & $-2.033 E-03$ & $-2.027 \mathrm{E}-03$ & $-2.035 \mathrm{E}-03$ & $-2.039 \mathrm{E}-03$ & $1.26 \mathrm{E}-05$ & $0.620 \%$ \\
\hline-5.0 & -3.0 & $-4.443 \mathrm{E}-03$ & $-4.441 \mathrm{E}-03$ & $-4.461 \mathrm{E}-03$ & $-4.472 \mathrm{E}-03$ & $3.12 \mathrm{E}-05$ & $0.700 \%$ \\
\hline-5.0 & -5.0 & $-5.091 E-03$ & $-5.089 E-03$ & $-5.113 \mathrm{E}-03$ & $-5.121 E-03$ & $3.24 E-05$ & $-0.635 \%$ \\
\hline & & & & & & & \\
\hline & & & & & & Avg error & $-0.951 \%$ \\
\hline
\end{tabular}


Alpha0 calculation.

\begin{tabular}{|c|c|c|c|c|c|}
\hline \multirow[t]{3}{*}{$\begin{array}{l}\text { Vin } \\
\text { (V) }\end{array}$} & \multicolumn{3}{|c|}{$\begin{array}{l}\text { Vout } \\
\text { (V) }\end{array}$} & \multicolumn{2}{|c|}{ Error Calculation } \\
\hline & \multirow{2}{*}{\begin{tabular}{|c|}
$\begin{array}{l}\text { Measured } \\
\text { Data }\end{array}$ \\
Die\#1 \\
\end{tabular}} & \multicolumn{2}{|c|}{ Simulated Data } & \multirow{2}{*}{\begin{tabular}{|c|} 
A0 \\
$\begin{array}{c}\text { Abs (meas- } \\
\text { sim) } / \mathrm{sim}\end{array}$
\end{tabular}} & \multirow{2}{*}{$\begin{array}{c}\text { alpha0) } \\
\begin{array}{c}\text { Abs (meas- } \\
\text { sim)/sim }\end{array}\end{array}$} \\
\hline & & AO & alpha0 & & \\
\hline 0 & 0.030 & 1.152 & 1.128 & 0.974 & 0.973 \\
\hline 0.5 & 0.481 & 1.165 & 1.140 & 0.587 & 0.578 \\
\hline 1 & 0.993 & 1.275 & 1.260 & 0.221 & 0.212 \\
\hline 1.5 & 1.489 & 1.595 & 1.590 & 0.066 & 0.064 \\
\hline 2 & 2.000 & 2.058 & 2.056 & 0.028 & 0.027 \\
\hline 2.5 & 2.498 & 2.530 & 2.529 & 0.013 & 0.012 \\
\hline 3 & 2.987 & 3.000 & 3.000 & 0.004 & 0.004 \\
\hline 3.5 & 3.465 & 3.468 & 3.468 & 0.001 & 0.001 \\
\hline 4 & 3.969 & 3.927 & 3.928 & 0.011 & 0.010 \\
\hline 4.5 & 4.465 & 4.336 & 4.342 & 0.030 & 0.028 \\
\hline \multirow[t]{2}{*}{5} & 4.961 & 4.605 & 4.619 & 0.077 & 0.074 \\
\hline & & \multicolumn{2}{|c|}{ Average Error } & $18.29 \%$ & $18.04 \%$ \\
\hline
\end{tabular}

Beta0 calculation.

\begin{tabular}{|c|c|c|c|c|c|}
\hline \multirow[t]{3}{*}{$\begin{array}{l}\text { Vin } \\
\text { (V) }\end{array}$} & \multicolumn{3}{|c|}{$\begin{array}{l}\text { Vout } \\
\text { (V) }\end{array}$} & \multicolumn{2}{|c|}{ Error Calculation } \\
\hline & \multirow{2}{*}{$\begin{array}{c}\begin{array}{c}\text { Measured } \\
\text { Data }\end{array} \\
\text { Die\#1 } \\
\end{array}$} & \multicolumn{2}{|c|}{ Simulated Data } & \multirow{2}{*}{\begin{tabular}{|c|}
$\mathbf{B 0}=\mathbf{3 0})$ \\
$\begin{array}{c}\text { abs }(\text { meas- } \\
\text { sim) } / \mathrm{sim}\end{array}$ \\
\end{tabular}} & \multirow{2}{*}{$\begin{array}{c}\mathbf{B 0}=\mathbf{3 0 0}) \\
\text { abs }(\text { meas- } \\
\text { sim) } / \text { sim } \\
\end{array}$} \\
\hline & & $(\tilde{\square}=30)$ & $(\tilde{\square}=300)$ & & \\
\hline 0 & 0.030 & 1.152 & 1.152 & 0.974 & 0.974 \\
\hline 0.5 & 0.481 & 1.165 & 1.165 & 0.587 & 0.587 \\
\hline 1 & 0.993 & 1.275 & 1.275 & 0.221 & 0.221 \\
\hline 1.5 & 1.489 & 1.595 & 1.595 & 0.066 & 0.066 \\
\hline 2 & 2.000 & 2.058 & 2.058 & 0.028 & 0.028 \\
\hline 2.5 & 2.498 & 2.530 & 2.530 & 0.013 & 0.013 \\
\hline 3 & 2.987 & 3.000 & 3.000 & 0.004 & 0.004 \\
\hline 3.5 & 3.465 & 3.468 & 3.468 & 0.001 & 0.001 \\
\hline 4 & 3.969 & 3.927 & 3.927 & 0.011 & 0.011 \\
\hline 4.5 & 4.465 & 4.336 & 4.336 & 0.030 & 0.030 \\
\hline \multirow[t]{2}{*}{5} & 4.961 & 4.605 & 4.605 & 0.077 & 0.077 \\
\hline & & \multicolumn{2}{|c|}{ Average Error } & $18.29 \%$ & $18.29 \%$ \\
\hline
\end{tabular}


Delta calculation.

\begin{tabular}{|c|c|c|c|c|c|}
\hline \multirow[t]{3}{*}{$\begin{array}{l}\text { Vin } \\
\text { (V) }\end{array}$} & \multicolumn{3}{|c|}{$\begin{array}{c}\text { Vout } \\
\text { (V) }\end{array}$} & \multicolumn{2}{|c|}{ Error Calculation } \\
\hline & \multirow{2}{*}{\begin{tabular}{|c|}
$\begin{array}{c}\text { Measured } \\
\text { Data }\end{array}$ \\
Die\#1
\end{tabular}} & \multicolumn{2}{|c|}{ Simulated Data } & \multirow{2}{*}{$\begin{array}{c}\text { delta }=0.01 \\
\begin{array}{c}\text { Abs (meas- } \\
\text { sim) } / \mathrm{sim}\end{array}\end{array}$} & \multirow{2}{*}{$\begin{array}{c}\text { delta }=0.001 \\
\text { Abs (meas- } \\
\text { sim) } / \text { sim }\end{array}$} \\
\hline & & delta $=0.01$ & delta $=0.001$ & & \\
\hline 0 & 0.030 & 1.387 & 1.385 & 0.978 & 0.978 \\
\hline 0.5 & 0.481 & 1.393 & 1.391 & 0.655 & 0.654 \\
\hline 1 & 0.993 & 1.420 & 1.418 & 0.301 & 0.300 \\
\hline 1.5 & 1.489 & 1.633 & 1.630 & 0.088 & 0.086 \\
\hline 2 & 2.000 & 2.074 & 2.073 & 0.035 & 0.035 \\
\hline 2.5 & 2.498 & 2.538 & 2.538 & 0.016 & 0.016 \\
\hline 3 & 2.987 & 3.002 & 3.002 & 0.005 & 0.005 \\
\hline 3.5 & 3.465 & 3.462 & 3.463 & 0.001 & 0.001 \\
\hline 4 & 3.969 & 3.928 & 3.929 & 0.010 & 0.010 \\
\hline 4.5 & 4.465 & 4.338 & 4.339 & 0.029 & 0.029 \\
\hline \multirow[t]{2}{*}{5} & 4.961 & 4.703 & 4.712 & 0.055 & 0.053 \\
\hline & & \multicolumn{2}{|c|}{ Average Error } & $19.76 \%$ & $19.70 \%$ \\
\hline
\end{tabular}

Drout calculation.

\begin{tabular}{|c||c|c|c|c||c|c|c|}
\hline \multicolumn{1}{|c|}{$\begin{array}{c}\text { Vin } \\
\text { (V) }\end{array}$} & \multicolumn{4}{c||}{ Vout (V) } & \multicolumn{3}{c|}{ Error Calculation } \\
\hline & $\begin{array}{l}\text { Measured } \\
\text { Data }\end{array}$ & \multicolumn{2}{c|}{ Simulated Data } & Drout=0 & Drout=0.5 & Drout=1 \\
\hline & Die\#1 & Drout = 0 & $\begin{array}{l}\text { Drout }= \\
\mathbf{0 . 5}\end{array}$ & $\begin{array}{l}\text { Drout }= \\
\mathbf{1}\end{array}$ & $\begin{array}{c}\text { Abs } \\
\text { (meas- } \\
\text { sim)/sim }\end{array}$ & $\begin{array}{c}\text { Abs (meas- } \\
\text { sim)/sim }\end{array}$ & $\begin{array}{c}\text { Abs } \\
\text { (meas- } \\
\text { sim)/sim }\end{array}$ \\
\hline 0 & 0.030 & 1.387 & 1.382 & 0.405 & 0.978 & 0.978 & 0.926 \\
\hline 0.5 & 0.481 & 1.393 & 1.388 & 0.569 & 0.655 & 0.654 & 0.154 \\
\hline 1 & 0.993 & 1.420 & 1.416 & 1.029 & 0.301 & 0.299 & 0.035 \\
\hline 1.5 & 1.489 & 1.633 & 1.631 & 1.519 & 0.088 & 0.087 & 0.020 \\
\hline 2 & 2.000 & 2.074 & 2.073 & 2.011 & 0.035 & 0.035 & 0.005 \\
\hline 2.5 & 2.498 & 2.538 & 2.538 & 2.502 & 0.016 & 0.016 & 0.001 \\
\hline 3 & 2.987 & 3.002 & 3.002 & 2.992 & 0.005 & 0.005 & 0.002 \\
\hline 3.5 & 3.465 & 3.462 & 3.463 & 3.484 & 0.001 & 0.001 & 0.006 \\
\hline 4 & 3.969 & 3.928 & 3.929 & 3.968 & 0.010 & 0.010 & 0.000 \\
\hline 4.5 & 4.465 & 4.338 & 4.338 & 4.429 & 0.029 & 0.029 & 0.008 \\
\hline 5 & 4.961 & 4.703 & 4.704 & 4.831 & 0.055 & 0.055 & 0.027 \\
\hline & & Average Error & & $19.76 \%$ & $\mathbf{1 9 . 7 1 \%}$ & $\mathbf{1 0 . 7 6 \%}$ \\
\hline
\end{tabular}


Due to the large discrepancy between the least percentage error value and the default value, this parameter was left unchanged. The Dsub value for the NMOS FET was unchanged, which is 1 . Figure below shows the change in the output with respect to the input with different Dsub values. Table shows the Dsub calculations. Since the Dsub value at Dsub $=0.4373$ lowers the curve without affecting the output much at the higher voltage values, this value is chosen for the modeling of the PMOS FETs for the 2-18-03 mask set.

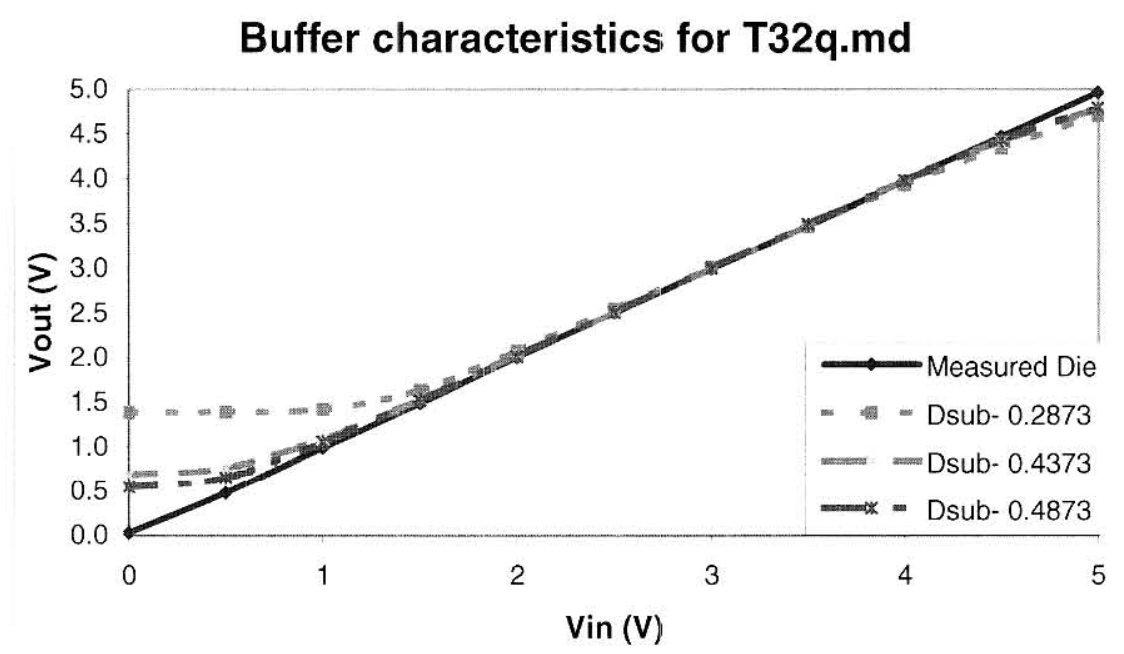

Output curve with different Dsub values 
Dsub calculation for PMOS FETs.

\begin{tabular}{|c|c|c|c|c|c|c|c|}
\hline \multirow{3}{*}{\begin{tabular}{|l||} 
Vin \\
(V)
\end{tabular}} & \multicolumn{4}{|c|}{ Vout (V) } & \multicolumn{3}{|c|}{ Error Calculation } \\
\hline & \multirow[t]{2}{*}{ Measured Data } & \multicolumn{3}{|c|}{ Simulated Data } & \multirow{2}{*}{\begin{tabular}{|c|}
$\begin{array}{c}\text { Dsub - } \\
0.2873\end{array}$ \\
Abs (meas- \\
sim)/sim
\end{tabular}} & \multirow{2}{*}{\begin{tabular}{|c|c}
$\begin{array}{c}\text { Dsub - } \\
0.4373\end{array}$ \\
$\begin{array}{c}\text { Abs (meas- } \\
\text { sim) } / \mathrm{sim}\end{array}$ \\
\end{tabular}} & \multirow{2}{*}{\begin{tabular}{|c|}
$\begin{array}{c}\text { Dsub - } \\
\mathbf{0 . 4 8 7 3}\end{array}$ \\
Abs (meas \\
sim)/sim
\end{tabular}} \\
\hline & & $\begin{array}{l}\text { Dsub - } \\
0.2873\end{array}$ & \begin{tabular}{|l|} 
Dsub - \\
0.4373
\end{tabular} & $\begin{array}{l}\text { Dsub - } \\
0.4873\end{array}$ & & & \\
\hline 0 & 0.030 & 1.387 & 0.687 & 0.548 & 0.978 & 0.956 & 0.945 \\
\hline 0.5 & 0.481 & 1.393 & 0.763 & 0.651 & 0.655 & 0.369 & 0.261 \\
\hline 1 & 0.993 & 1.420 & 1.090 & 1.054 & 0.301 & 0.089 & 0.058 \\
\hline 1.5 & 1.489 & 1.633 & 1.530 & 1.521 & 0.088 & 0.027 & 0.021 \\
\hline 2 & 2.000 & 2.074 & 2.019 & 2.013 & 0.035 & 0.009 & 0.006 \\
\hline 2.5 & 2.498 & 2.538 & 2.507 & 2.504 & 0.016 & 0.004 & 0.002 \\
\hline 3 & 2.987 & 3.002 & 2.996 & 2.996 & 0.005 & 0.003 & 0.003 \\
\hline 3.5 & 3.465 & 3.462 & 3.482 & 3.485 & 0.001 & 0.005 & 0.006 \\
\hline 4 & 3.969 & 3.928 & 3.969 & 3.974 & 0.010 & 0.000 & 0.001 \\
\hline 4.5 & 4.465 & 4.338 & 4.415 & 4.432 & 0.029 & 0.011 & 0.008 \\
\hline \multirow[t]{2}{*}{5} & 4.961 & 4.703 & 4.777 & 4.788 & 0.055 & 0.039 & 0.036 \\
\hline & & & \multicolumn{2}{|c|}{ Average Error } & $19.76 \%$ & $13.75 \%$ & $12.24 \%$ \\
\hline
\end{tabular}

Nfactor calculation.

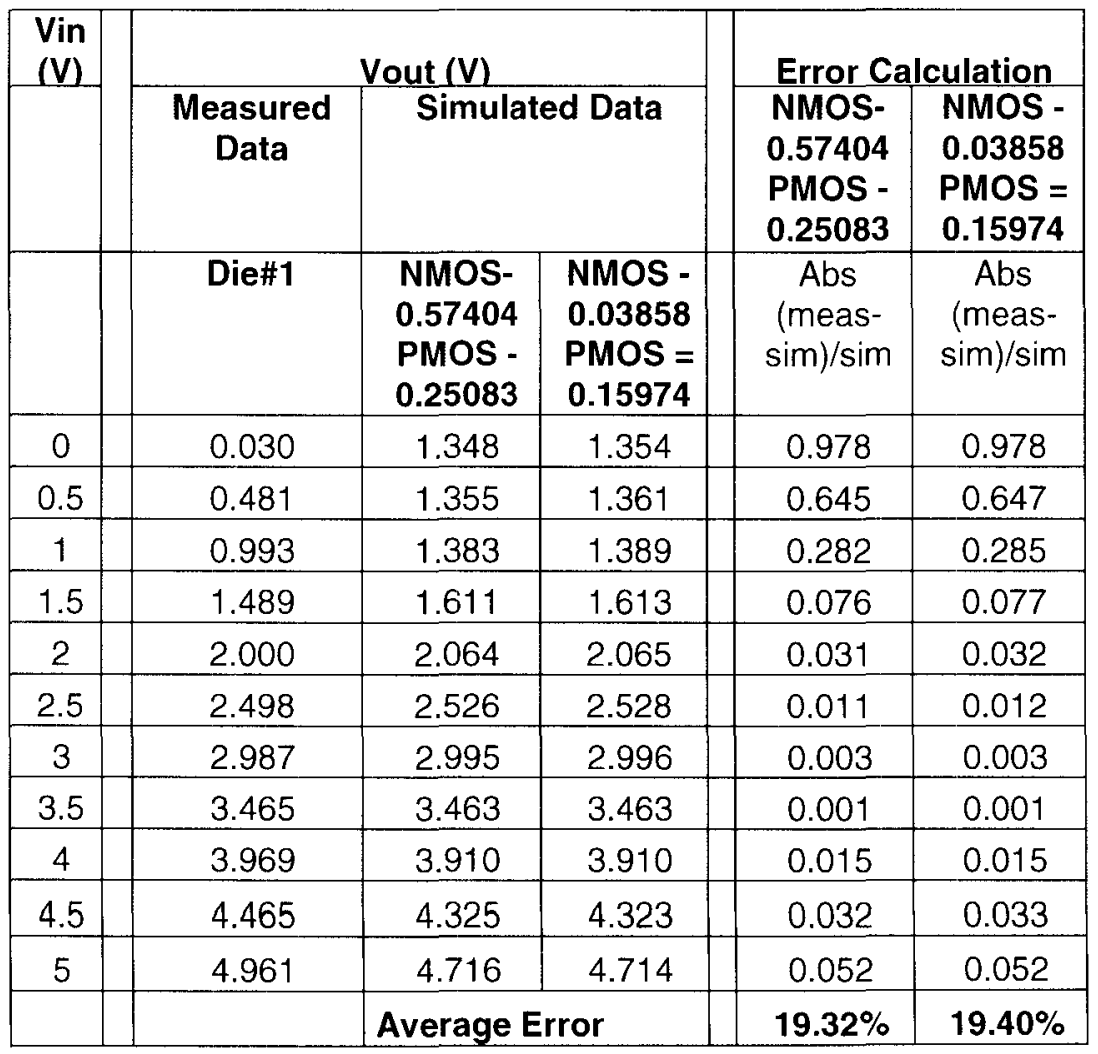


PCLM calculation.

\begin{tabular}{|c|c|c|c|c|c|c|c|}
\hline \multirow{3}{*}{$\begin{array}{l}\text { Vin } \\
\text { (V) }\end{array}$} & \multirow{3}{*}{$\begin{array}{c}\begin{array}{c}\text { Measured } \\
\text { Data }\end{array} \\
\text { Die\#1 }\end{array}$} & \multicolumn{3}{|c|}{ Vout (V) } & \multicolumn{3}{|c|}{ Error Calculation } \\
\hline & & \multicolumn{3}{|c|}{ Simulated Data } & \multirow{2}{*}{$\begin{array}{c}\begin{array}{c}\text { PCLM }= \\
1 \mathrm{e}-9\end{array} \\
\text { abs(meas- } \\
\operatorname{sim}) / \mathrm{sim}\end{array}$} & \multirow{2}{*}{$\begin{array}{c}\begin{array}{c}\text { PCLM = } \\
1 \mathrm{e}-10\end{array} \\
\begin{array}{c}\text { abs (meas- } \\
\text { sim) } / \mathrm{sim}\end{array}\end{array}$} & \multirow{2}{*}{$\begin{array}{c}\begin{array}{c}\text { PCLM }= \\
1 \mathrm{e}-11\end{array} \\
\begin{array}{c}\text { abs(meas } \\
\text { sim)/sim }\end{array}\end{array}$} \\
\hline & & $\begin{array}{c}\text { PCLM= } \\
1 \mathrm{e}-9\end{array}$ & $\begin{array}{c}\text { PCLM }= \\
1 \mathrm{e}-10\end{array}$ & $\begin{array}{l}\mathrm{PCLM}= \\
1 \mathrm{e}-11\end{array}$ & & & \\
\hline 0 & 0.030 & 1.387 & 1.387 & 1.387 & 0.978 & 0.978 & 0.978 \\
\hline 0.5 & 0.481 & 1.393 & 1.393 & 1.393 & 0.655 & 0.655 & 0.655 \\
\hline 1 & 0.993 & 1.420 & 1.420 & 1.420 & 0.301 & 0.301 & 0.301 \\
\hline 1.5 & 1.489 & 1.633 & 1.633 & 1.633 & 0.088 & 0.088 & 0.088 \\
\hline 2 & 2.000 & 2.074 & 2.074 & 2.074 & 0.035 & 0.035 & 0.035 \\
\hline 2.5 & 2.498 & 2.538 & 2.538 & 2.538 & 0.016 & 0.016 & 0.016 \\
\hline 3 & 2.987 & 3.002 & 3.002 & 3.002 & 0.005 & 0.005 & 0.005 \\
\hline 3.5 & 3.465 & 3.462 & 3.462 & 3.462 & 0.001 & 0.001 & 0.001 \\
\hline 4 & 3.969 & 3.928 & 3.928 & 3.928 & 0.010 & 0.010 & 0.010 \\
\hline 4.5 & 4.465 & 4.338 & 4.338 & 4.338 & 0.029 & 0.029 & 0.029 \\
\hline 5 & 4.961 & 4.703 & 4.703 & 4.703 & 0.055 & 0.055 & 0.055 \\
\hline & & & & & $19.76 \%$ & $19.76 \%$ & $19.76 \%$ \\
\hline
\end{tabular}


PSCBE1 and PSCBE2 calculation.

\begin{tabular}{|c|c|c|c|c|c|}
\hline \multirow[t]{3}{*}{$\operatorname{Vin}(V)$} & \multicolumn{3}{|c|}{ Vout (V) } & \multicolumn{2}{|c|}{ Error Calculation } \\
\hline & Measured & & Iulated Data & Default & PSCBE1 \\
\hline & Die\#1 & Default & $\begin{array}{c}\text { PSCBE1 } \\
\text { (NMOS/PMOS)- } \\
1 E 30 \\
\text { PSCBE2 } \\
\text { (NMOS/PMOS)- } 0\end{array}$ & $\begin{array}{c}\text { Abs (meas- } \\
\mathrm{sim}) / \mathrm{sim}\end{array}$ & $\begin{array}{l}\text { Abs (meas- } \\
\text { sim)/sim }\end{array}$ \\
\hline 0 & 0.030 & 1.152 & 1.152 & 0.974 & 0.974 \\
\hline 0.5 & 0.481 & 1.165 & 1.165 & 0.587 & 0.587 \\
\hline 1 & 0.993 & 1.275 & 1.275 & 0.221 & 0.221 \\
\hline 1.5 & 1.489 & 1.595 & 1.595 & 0.066 & 0.066 \\
\hline 2 & 2.000 & 2.058 & 2.058 & 0.028 & 0.028 \\
\hline 2.5 & 2.498 & 2.530 & 2.530 & 0.013 & 0.013 \\
\hline 3 & 2.987 & 3.000 & 3.000 & 0.004 & 0.004 \\
\hline 3.5 & 3.465 & 3.468 & 3.468 & 0.001 & 0.001 \\
\hline 4 & 3.969 & 3.927 & 3.927 & 0.011 & 0.011 \\
\hline 4.5 & 4.465 & 4.336 & 4.336 & 0.030 & 0.030 \\
\hline 5 & 4.961 & 4.605 & 4.605 & 0.077 & 0.077 \\
\hline & & & & $18.29 \%$ & $18.29 \%$ \\
\hline
\end{tabular}


u0 (NMOS)calculation.

\begin{tabular}{|c|c|c|c|c|c|c|c|c|c|}
\hline \multirow[t]{3}{*}{$\begin{array}{l}\text { Vin } \\
\text { (V) }\end{array}$} & \multicolumn{5}{|c|}{ Vout (V) } & \multicolumn{4}{|c|}{ Error Calculation } \\
\hline & \multirow{2}{*}{$\begin{array}{c}\begin{array}{c}\text { Meas } \\
\text { Data }\end{array} \\
\text { Die\#1 }\end{array}$} & \multicolumn{4}{|c|}{$\begin{array}{c}\text { Dsub (PMOS - 0.4373) } \\
\text { Simulated Data }\end{array}$} & \multirow{2}{*}{\begin{tabular}{|c|}
$\mathbf{u} 0=620$ \\
Default \\
abs $($ meas \\
$-\operatorname{sim}) /$ \\
sim
\end{tabular}} & \multirow{2}{*}{\begin{tabular}{|l|}
$\mathbf{u} 0-\mathbf{1 0 0 0}$ \\
abs(meas \\
$-\operatorname{sim}) /$ \\
sim \\
\end{tabular}} & \multirow{2}{*}{\begin{tabular}{|l|}
$\mathbf{u 0 - 5 0 0 0}$ \\
$\begin{array}{l}\text { abs (meas } \\
-\operatorname{sim}) / \\
\operatorname{sim}\end{array}$ \\
\end{tabular}} & \multirow{2}{*}{\begin{tabular}{|l}
$\mathbf{u 0 - 1 0 0 0 0}$ \\
$a b s($ meas \\
$-\operatorname{sim}) /$ \\
sim
\end{tabular}} \\
\hline & & $\begin{array}{l}\text { u0 }=620 \\
\text { Default }\end{array}$ & $\begin{array}{l}40- \\
1000\end{array}$ & u0-5000 & $\begin{array}{l}\text { u0- } \\
10000\end{array}$ & & & & \\
\hline 0 & 0.030 & 0.687 & 0.537 & 0.373 & 0.352 & 0.956 & 0.944 & 0.920 & 0.915 \\
\hline 0.5 & 0.481 & 0.763 & 0.651 & 0.583 & 0.570 & 0.369 & 0.262 & 0.175 & 0.156 \\
\hline 1 & 0.993 & 1.090 & 1.054 & 1.021 & 1.016 & 0.089 & 0.058 & 0.027 & 0.022 \\
\hline 1.5 & 1.489 & 1.530 & 1.525 & 1.513 & 1.505 & 0.027 & 0.023 & 0.016 & 0.010 \\
\hline 2 & 2.000 & 2.019 & 2.014 & 2.002 & 1.997 & 0.009 & 0.007 & 0.001 & 0.002 \\
\hline 2.5 & 2.498 & 2.507 & 2.505 & 2.495 & 2.490 & 0.004 & 0.003 & 0.001 & 0.003 \\
\hline 3 & 2.987 & 2.996 & 2.995 & 2.987 & 2.983 & 0.003 & 0.003 & 0.000 & 0.001 \\
\hline 3.5 & 3.465 & 3.482 & 3.483 & 3.474 & 3.472 & 0.005 & 0.005 & 0.003 & 0.002 \\
\hline 4 & 3.969 & 3.969 & 3.970 & 3.965 & 3.950 & 0.000 & 0.000 & 0.001 & 0.005 \\
\hline 4.5 & 4.465 & 4.415 & 4.425 & 4.336 & 4.263 & 0.011 & 0.009 & 0.030 & 0.047 \\
\hline \multirow[t]{2}{*}{5} & 4.961 & 4.777 & 4.737 & 4.452 & 4.340 & 0.039 & 0.047 & 0.114 & 0.143 \\
\hline & & & & \multicolumn{2}{|c|}{ Average Error } & $13.75 \%$ & $12.37 \%$ & $11.71 \%$ & $11.88 \%$ \\
\hline
\end{tabular}

u0 (PMOS) calculation.

\begin{tabular}{|c|c|c|c|c|c|c|c|c|c|}
\hline \multirow[t]{3}{*}{$\begin{array}{l}\text { Vin } \\
\text { (V) }\end{array}$} & \multicolumn{5}{|c|}{ Vout (V) } & \multicolumn{4}{|c|}{ Error Calculation } \\
\hline & \multirow{2}{*}{$\begin{array}{c}\begin{array}{c}\text { Meas } \\
\text { Data }\end{array} \\
\text { Die\#1 }\end{array}$} & \multicolumn{4}{|c|}{$\begin{array}{c}\text { Dsub (PMOS - 0.4373) } \\
\text { Simulated Data }\end{array}$} & \multirow{2}{*}{\begin{tabular}{|c|}
$\mathbf{u 0 - 5 0}$ \\
Abs \\
(Meas- \\
Sim)/ \\
Sim
\end{tabular}} & \multirow{2}{*}{\begin{tabular}{|c}
$\mathbf{u 0 - 1 0 0}$ \\
Abs \\
(Meas- \\
sim)/ \\
sim
\end{tabular}} & \multirow{2}{*}{\begin{tabular}{|c|}
$\begin{array}{c}\mathbf{u} 0-236 \\
\text { Default }\end{array}$ \\
$\begin{array}{c}\text { Abs } \\
(\text { Meas- } \\
\text { sim)/sim }\end{array}$ \\
\end{tabular}} & \multirow{2}{*}{$\begin{array}{c}\text { u0-500 } \\
\text { Abs } \\
\text { (Meas- } \\
\text { sim)/ } \\
\text { Sim }\end{array}$} \\
\hline & & u0-50 & $u 0-100$ & $\begin{array}{l}\text { u0-236 } \\
\text { (default) }\end{array}$ & u0-500 & & & & \\
\hline 0 & 0.030 & 0.396 & 0.468 & 0.687 & 1.133 & 0.924 & 0.936 & 0.956 & 0.974 \\
\hline 0.5 & 0.481 & 0.589 & 0.619 & 0.763 & 1.141 & 0.184 & 0.223 & 0.369 & 0.578 \\
\hline 1 & 0.993 & 1.026 & 1.040 & 1.090 & 1.232 & 0.032 & 0.045 & 0.089 & 0.194 \\
\hline 1.5 & 1.489 & 1.512 & 1.519 & 1.530 & 1.546 & 0.015 & 0.020 & 0.027 & 0.037 \\
\hline 2 & 2.000 & 2.004 & 2.010 & 2.019 & 2.030 & 0.002 & 0.005 & 0.009 & 0.015 \\
\hline 2.5 & 2.498 & 2.496 & 2.501 & 2.507 & 2.516 & 0.001 & 0.001 & 0.004 & 0.007 \\
\hline 3 & 2.987 & 2.989 & 2.992 & 2.996 & 3.000 & 0.001 & 0.002 & 0.003 & 0.004 \\
\hline 3.5 & 3.465 & 3.478 & 3.480 & 3.482 & 3.483 & 0.004 & 0.004 & 0.005 & 0.005 \\
\hline 4 & 3.969 & 3.968 & 3.969 & 3.969 & 3.967 & 0.000 & 0.000 & 0.0001 & 0.001 \\
\hline 4.5 & 4.465 & 4.344 & 4.422 & 4.415 & 4.394 & 0.028 & 0.010 & 0.011 & 0.016 \\
\hline \multirow[t]{2}{*}{5} & 4.961 & 4.437 & 4.657 & 4.777 & 4.808 & 0.118 & 0.065 & 0.039 & 0.032 \\
\hline & & & & \multicolumn{2}{|c|}{ Average Error } & $11.89 \%$ & $11.92 \%$ & $13.75 \%$ & $16.93 \%$ \\
\hline
\end{tabular}


Saturation Current (IS) calculation.

\begin{tabular}{|c|c|c|c||c|c|}
\hline \multirow{2}{*}{ Vin (V) } & \multicolumn{3}{|c|}{ Vout (V) } & \multicolumn{2}{c|}{ Error Calculation } \\
\hline & $\begin{array}{c}\text { Measured } \\
\text { Data }\end{array}$ & \multicolumn{2}{c|}{ Simulated Data } & IS=0 & IS= 1E-14 \\
& Die\#1 & IS=0 & IS= 1E-14 & $\begin{array}{c}\text { abs(meas } \\
\text {-sim)/sim }\end{array}$ & $\begin{array}{c}\text { abs(meas- } \\
\text { sim)/sim }\end{array}$ \\
\hline & & & & & \\
\hline 0 & 0.030 & 1.152 & 1.152 & 0.974 & 0.974 \\
\hline 0.5 & 0.481 & 1.165 & 1.165 & 0.587 & 0.587 \\
\hline 1 & 0.993 & 1.275 & 1.275 & 0.221 & 0.221 \\
\hline 1.5 & 1.489 & 1.595 & 1.595 & 0.066 & 0.066 \\
\hline 2 & 2.000 & 2.058 & 2.058 & 0.028 & 0.028 \\
\hline 2.5 & 2.498 & 2.530 & 2.530 & 0.013 & 0.013 \\
\hline 3 & 2.987 & 3.000 & 3.000 & 0.004 & 0.004 \\
\hline 3.5 & 3.465 & 3.468 & 3.468 & 0.001 & 0.001 \\
\hline 4 & 3.969 & 3.927 & 3.927 & 0.011 & 0.011 \\
\hline 4.5 & 4.465 & 4.336 & 4.336 & 0.030 & 0.030 \\
\hline 5 & 4.961 & 4.605 & 4.605 & 0.077 & 0.077 \\
\hline & & & & & \\
\hline & & Average Error & $\mathbf{1 8 . 2 9 \%}$ & $\mathbf{1 8 . 2 9 \%}$ \\
\hline
\end{tabular}


CURRICULUM VITAE

NAME: $\quad$ Mallika Gopinath

ADDRESS: $\quad 5527$, Bent Fork

Evansville, IN -47712

DOB:

Bangalore, India, 12-09-1977

Education: B.E., Electronics and Communication, Manipal Institute of Technology, Karnataka, India 1995-99

159 